\title{
Alerta Alcohol
}

Citation for published version (APA):

Martínez Montilla, J. M. (2020). Alerta Alcohol: Design and evaluation of a web-based computer-tailored intervention for prevention of alcohol consumption and binge drinking in Spanish adolescents. [Doctoral Thesis, Maastricht University, University of Seville]. Maastricht University. https://doi.org/10.26481/dis.20201012jm

\section{Document status and date:}

Published: 01/01/2020

DOI:

10.26481/dis.20201012jm

Document Version:

Publisher's PDF, also known as Version of record

\section{Please check the document version of this publication:}

- A submitted manuscript is the version of the article upon submission and before peer-review. There can be important differences between the submitted version and the official published version of record.

People interested in the research are advised to contact the author for the final version of the publication, or visit the DOI to the publisher's website.

- The final author version and the galley proof are versions of the publication after peer review.

- The final published version features the final layout of the paper including the volume, issue and page numbers.

Link to publication

\footnotetext{
General rights rights.

- You may freely distribute the URL identifying the publication in the public portal. please follow below link for the End User Agreement:

www.umlib.nl/taverne-license

Take down policy

If you believe that this document breaches copyright please contact us at:

repository@maastrichtuniversity.nl

providing details and we will investigate your claim.
}

Copyright and moral rights for the publications made accessible in the public portal are retained by the authors and/or other copyright owners and it is a condition of accessing publications that users recognise and abide by the legal requirements associated with these

- Users may download and print one copy of any publication from the public portal for the purpose of private study or research.

- You may not further distribute the material or use it for any profit-making activity or commercial gain

If the publication is distributed under the terms of Article $25 \mathrm{fa}$ of the Dutch Copyright Act, indicated by the "Taverne" license above, 


\section{ALERTA ALCOHOL}

Design and evaluation of a web-based computer-tailored intervention for prevention of alcohol consumption and binge drinking in Spanish adolescents. 



\begin{abstract}
ALERTA ALCOHOL
Design and evaluation of a web-based computer-tailored intervention for prevention of alcohol consumption and binge drinking in Spanish adolescents.
\end{abstract}

\title{
Dissertation
}

to obtain the degree of doctor at Maastricht University and University of Seville on the authority of the Rector Magnificus

Prof. Dr. Rianne Letschert, in accordance with the decision of the Board of Deans, to defend in public on Monday, October 12, 2020 at 16:00 p.m. in Maastricht

José Manuel Martínez Montilla

He was born on March 23, 1988 in Seville (Spain). 


\section{Supervisors}

Prof. Dr. Hein de Vries (Maastricht University)

Dr. Marta Lima Serrano (University of Seville)

\section{Co-supervisors}

Dr. Liesbeth Mercken (Maastricht University)

Dr. Joaquín Salvador Lima Rodríguez (University of Seville)

\section{Assessment Committee}

Prof. Dr. Stef Kremers, Maastricht University (Chairman)

Prof. Dr. Catherine Bolman, Open University Heerlen

Dr. Eline Smit, Amsterdam University

Prof. Dr. José Rafael González López, University of Seville

The research presented in this thesis was conducted at CAPHRI Care and Public Health Research Institute, Department Health Promotion, of Maastricht University. CAPHRI participates in the Netherlands School of Public Health and Care Research CaRe.

Department of Nursing. Faculty of Nursing, Physiotherapy, and Podiatry. University of Seville. 


\section{Contents}

Chapter 1: General Introduction and outline of the thesis

Part I: Formative research: process of the cultural adaptation of the Alerta Alcohol program

Chapter 2: Design, implementation, and evaluation of a web-based computer-tailored intervention to prevent binge drinking in adolescents: study protocol.

Chapter 3: Why are Spanish adolescents binge drinkers? Focus group with adolescents and parents.

Chapter 4: Cultural adaptation and feasibility assessment of a web-based-computer-tailoring programme for alcohol use and binge drinking prevention in Spanish adolescents: Delphi panel and pilot study.

Part II: Effect study: development, implementation and evaluation of the effectiveness of the Alerta Alcohol programme.

Chapter 5: Effectiveness of a Web-based computer-tailored intervention to reduce alcohol consumption and binge drinking among Spanish adolescents: a cluster randomized

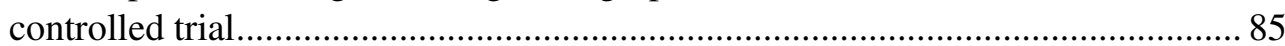

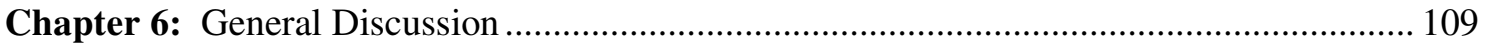

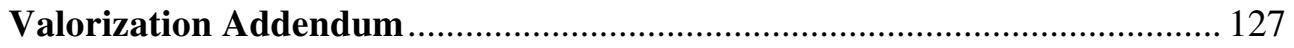

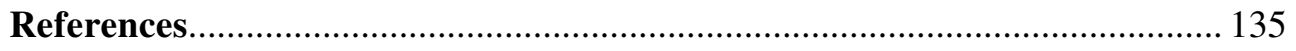

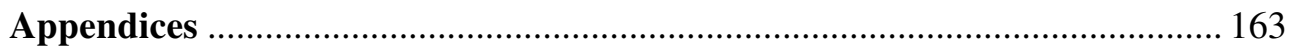

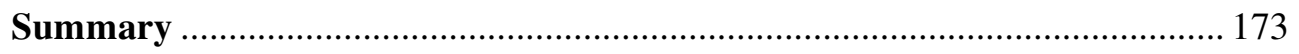

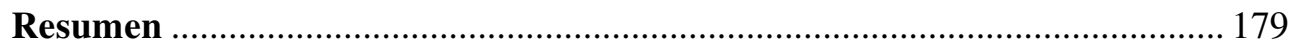

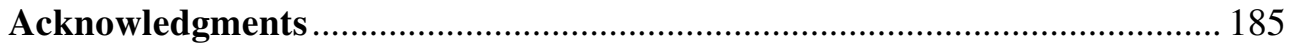

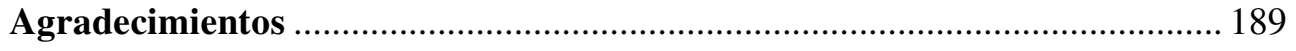

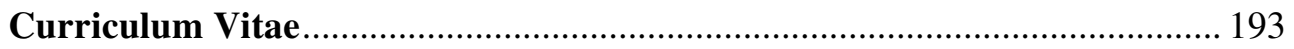

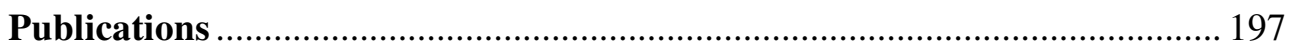




\section{Chapter 1}

General Introduction 
Alcohol consumption is a public health problem worldwide, with important social, health and economic consequences (Falcón et al., 2018), as well as the leading risk factor globally for both deaths and disability-adjusted life years (DALYs) (GBD, 2018). It has been estimated that alcohol consumption causes 3.3 million deaths every year $(5.3 \%$ of all deaths) (WHO, 2011; Chestnov, 2014) and led also to a total of 132.6 million DALYs, representing 5.1\% of the global burden of disease and injury in 2016 (GBD, 2018; WHO, 2018; Mravčík, Chomynová, Nechanská, Černíková \& Csémy, 2019). Moreover, alcohol use continues to be one of the major health risk behaviours of adolescents (Palfai, Winter, Lu, Rosenbloom \& Saitz, 2014), and 10\% of adolescent deaths (those aged 15 to 19 years) are attributable to alcohol (WHO, 2014; Drost et al., 2016). Alcohol consumption is associated with detrimental long- and short-term consequences, since it affects neurocognitive development and leads to physical, psychological, and social disorders. In addition, it has been associated with traffic accidents, violence, homicide, suicide, early sexual contact, school failure, mental illnesses, and delinquency, among other issues (Howell et al., 2013; Hunter \& Francescutti 2013; Falcón et al., 2018).

\section{Alcohol consumption, binge drinking, and heavy episodic drinking}

Alcohol consumption is part of many cultural, religious, and social practices worldwide. The European region has the highest record of per capita alcohol use worldwide (9.8 litres) and an increased global burden of disease attributable to alcohol (WHO, 2018). Nationwide, per capita alcohol consumption identified in Spain was 9.2 litres (14.6 in males and 3.8 in females), which is slightly below the European average. In Spain, the last Survey on Alcohol and Drugs among the population aged 15 to 64 revealed that alcohol represents the most commonly consumed legal drug in the country (75.2\%), followed by tobacco (40.9\%) and hypnosedatives (11.1\%) (EDADES, 2018). In Europe, $48 \%$ of adolescents aged 15-16 had consumed alcohol during the past 30 days, and an average of $13 \%$ of students reported having been intoxicated during the last 30 days (ESPAD, 2016). US studies showed further that 33\% of 15 -year-old adolescents had drunk alcohol at least once during their lifetime, increasing to $60 \%$ at 18 years old (NIAAA, 2020). When focusing on Spain, research reports $75.8 \%$ of adolescents between 14-18 years of age to have consumed alcohol in the last twelve months (ESTUDES, 2019).

In addition, a risky phenomenon among adolescents is binge drinking (BD), which is characterised by consuming large quantities of alcohol in sessions of a few hours, intermittently, mainly on weekend nights and in groups of peers (Parada et al., 2011; Golpe, Isorna, Barreiro, Braña \& Rial, 2017). The World Health Organisation defined this behaviour as young adults (over 15 years old) drinking at least 60 grams or more of pure alcohol at least once a week (WHO, 2011), being approximately equivalent to six Standard Drinks Unit (SDU) of alcohol in a single episode. However, the vagueness in the time period considered a "single episode" has led several authors to take into account blood alcohol concentration levels. In this sense, The National Institute of Alcohol and Alcoholism of the United States (NIAAA) defines concentrated alcohol consumption as a pattern of drinking that brings Blood Alcohol Concentration (BAC) to 0.8 grs./1. or more within a period of 2 hours (Golpe et al., 2017; NIAAA, 2020). This would typically occur in men after consuming five or more drinks in about 2 hours, and, in women, after consuming four or more drinks (Donovan, 2009; Chung, Creswell, Bachrach, Clark \& Martin, 2018; NIAAA 2020), due to the differences in weight between men and women resulting in different alcohol intoxication levels (Dawson \& Archer, 1992). 
It is challenging to provide one clear BD definition, since there is a lack of consensus as to what is considered an SDU (Parada et al., 2011; Katainen \& Rolando, 2015; Mongan \& Long, 2015; Golpe et al., 2017), as well as a lack of consensus on the estimated average BAC for the adolescent population (Donovan, 2009). The World Health Organisation defined the standard drink unit as that which contains approximately $14 \mathrm{~g}$. of alcohol based on the percentage of alcohol for different kinds of drinks (Babor \& Higgins-Biddle, 2001; Anderson, Gual \& Colon, 2008) (Figure 1.1). Therefore, in the present study, BD has been defined as the consumption of five or more and four or more SDUs of alcohol by men and women, respectively, in a short space of time or on a single occasion (Gmel, Rehm \& Kuntsche, 2003; Jander, Mercken, Crutzen \& de Vries, 2013; Golpe et al., 2017; Chung et al., 2018; ESTUDES 2019; NIAAA, 2020). This definition is consistent with the Spanish epidemiological data from the Survey on Drug Use in Secondary School Students (ESTUDES) (ESTUDES, 2019).

Figure 1.1: Standard drinking.

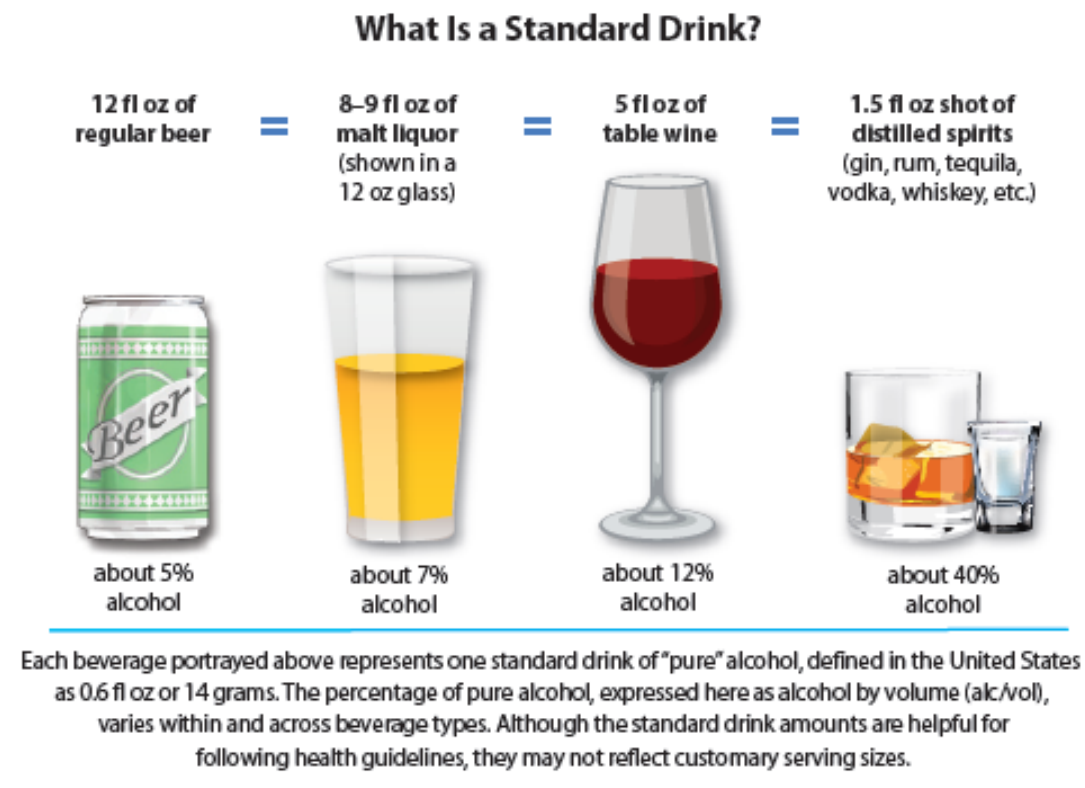

Source: Alcohol Research: Current Reviews Editorial Staff (2018).

Binge drinking is a great problem worldwide due to its high prevalence in adolescents (Golpe et al., 2017; WHO, 2018; Mravčík et al., 2019). In Europe, 35\% of 15-16-year-old adolescents reported having engaged in BD (ESPAD 2016), while in Spain, the percentage stood slightly lower, at 32.3\% of students between 14 and 18 years of age (ESTUDES 2019). In addition, other drinking variations are observed among adolescents. Measham (2009) argued that many young people intentionally consume alcohol for a maximal intoxicating effect, referred to as a "big bang". In this line, the consumption of 10 or more SDU on at least one occasion in the previous week was named by others studies as heavy episodic drinking (HED) (Best, Manning Gossop Gross \& Strang, 2006; Cox, Fadardi, Hosier \& Pothos, 2015; WHO, 2018) or excessive drinking (Jander, Crutzen, Mercken, Candel \& de Vries, 2016). Research showed that $10.5 \%$ of Upper Sixth Form students reported having consumed 10 or more drinks in a row, and $5.6 \%$ reported having consumed 15 or more drinks in a row in the past 2 weeks (Patrick et al. 2013). Therefore, this dissertation also focuses on HED, understood as drinking at a level of consumption that could be expected to produce intoxication with significant impairment of thinking, judgement and behaviour, which was operationally defined as consumption of more than 10 standard units of alcohol in the previous week. 
In Spain, both these behaviours have been associated with a phenomenon called Botellón, a more prevalent drinking event amongst the adolescent population, consisting of drinking alcohol excessively in public places during weekend nights (Donath et al., 2011; Parada et al., 2011; Romo-Avilés, Marcos-Marcos, Marquina-Márquez, Tarragona-Camacho \& Gil-García, 2016a), using it as a synonym for intoxicationoriented drinking (Guise \& Gill, 2007). Around 51.3\% of adolescents between 14 and 18 years old engaged in a Botellón in the last 12 months (ESTUDES, 2019). Moreover, alcohol intoxication (subjectively perceived) in the last 30 days was reported by $15 \%$ of European 16-year olds (18\% of boys and 12\% of girls) in 2015 (ESPAD, 2016), while in Spain the percentage remained slightly higher and $24.3 \%(23.7 \%$ of boys and $25 \%$ of girls) reported having engaged in alcohol intoxication in the last month (ESTUDES, 2019).

\section{Consequences of alcohol consumption, binge drinking and heavy episodic drinking}

Alcohol consumption is related to a wide range of physical, mental and social health effects, affecting practically every organ in the body (WHO, 2018). Several studies relate it to more than 60 different diseases (Gmel et al., 2003; Golpe et al., 2017; WHO, 2018).

Regarding BD, some studies have confirmed a close relationship between it and long-term organic damage, such liver cirrhosis, hypertension and coronary diseases (Golpe et al., 2017; WHO, 2018), as well as different forms of cancer (e.g., liver cancer, female breast cancer, stomach cancer) (Farke \& Anderson, 2007; Howell et al., 2013). Furthermore, BD is associated with disorders at the cerebral level in adolescents, causing possible neurocognitive and neurobehavioral repercussions, such as impaired learning or cognitive deficits (Howell et al., 2013; López-Caneda et al., 2013; Dormal et al., 2018). In addition, various short-term health consequences have been described for both BD and HED (Best et al., 2006; Cox et al., 2015; Jander et al., 2016), including accidents, violence, fights and crimes, among others (Gmel et al., 2003; Farke et al., 2007; Howell et al., 2013; Golpe et al., 2017), which are associated with significant social and personal costs per year, leading to high financial and social burdens (Best et al., 2006; Farke et al., 2007; Rehm et al., 2009; Cox et al., 2015; Falcón et al., 2018). Other authors highlight a lower academic performance associated with BD (Miller, Naimi, Brewer \& Jones, 2007), or truancy from school associated with HED (Best et al., 2006). Besides, both BD and HED have been linked to other several problematic behaviours, such as increased risk of unplanned sexual activity, unintended pregnancies (Wechsler, Kuo, Lee \& Dowdall, 2000; WHO, 2018), and later alcohol abuse and dependence in adulthood or illegal drug use (Calafat 2007; Parada et al., 2011; Golpe et al., 2017).

\section{Adolescents as a target group}

This dissertation focuses on adolescents. The WHO establishes that adolescence is the stage of life between 10 and 19 years old. It considers two phases, which are early adolescence (10 to 14 years) and late adolescence (15 to 19 years) (Pineda \& Aliño, 2002; WHO, 2019). The research presented in this dissertation will focus on late adolescence. At this stage of life, there are multiple physical and psychological changes, as it marks the acquisition of new social, cognitive and emotional skills (Gil, González \& Meneses, 2010; Pasqualini \& Llorens, 2010), and it is a phase in which large steps towards greater psychological and social independence are made (Pineda \& Aliño, 2002).

Adolescence occurs in the context of a shift from parents and family to peers as a primary source of support and guidance. Factors related to family, school or peer group 
can influence the tendency of adolescents to take risks (Espada, Pereira \& GarcíaFernández, 2008; Donath et al., 2011). In general, adolescence is considered as a stage perceived as problematic, since it increases emotional instability, conflicts with parents, and favours the development of certain risk behaviours (Gil et al., 2010) such as alcohol consumption, BD, among others (Meneses et al., 2009; Jander et al., 2013; Romo-Avilés, Marcos-Marcos, Marquina-Márquez, \& Gil-García, 2016b).

\section{The Theoretical framework}

Currently, there are different theories and models that try to explain health behaviour acquisition and its determinants, translating science into practice, as is the case of the I-Change Model (de Vries, 2017). The I-Change Model is derived from its predecessor, the Attitude-Social influence-self-Efficacy (ASE) model (De Vries \& Mudde, 1998), which was based on the Theory of Reasoned Action (TRA) (Fishbein, 1979) and Social Cognitive Theory (Bandura, 1986). Moreover, for the creation of the IChange Model, the ASE model integrated several ideas, such as Ajzen's Theory of Planned Behaviour (TPB) (Ajzen, 1991; de Vries et al., 1998), the Health Belief Model (HBM) (Janz \& Becker, 1984), the Precaution Adoption Process Model (PAPM) (Weinstein, 1988), and the Transtheoretical Model (TTM) (Prochaska \& DiClemente, 1983; Prochaska \& Velicer, 1997).

The I-Change Model has been used as an integrative model to explain motivational and behavioural change (de Vries et al., 2003), establishing that a person's behaviour is the result of intentions and abilities. Currently, the I-Change Model states that behaviours are determined by the intention that a person has to carry out a certain type of behaviour (de Vries et al., 2012; Jander, Crutzen, Mercken \& de Vries, 2014) as well as action plans and abilities. However, there are some barriers that can reduce the likelihood of intentions being translated into action (de Vries, Mesters, Van de Steeg, Honing, 2005a; Cremers, Mercken, Oenema \& de Vries, 2012), also known as the intention-behaviour gap (Figure 1.2).

Figure 1.2: I-Change Model

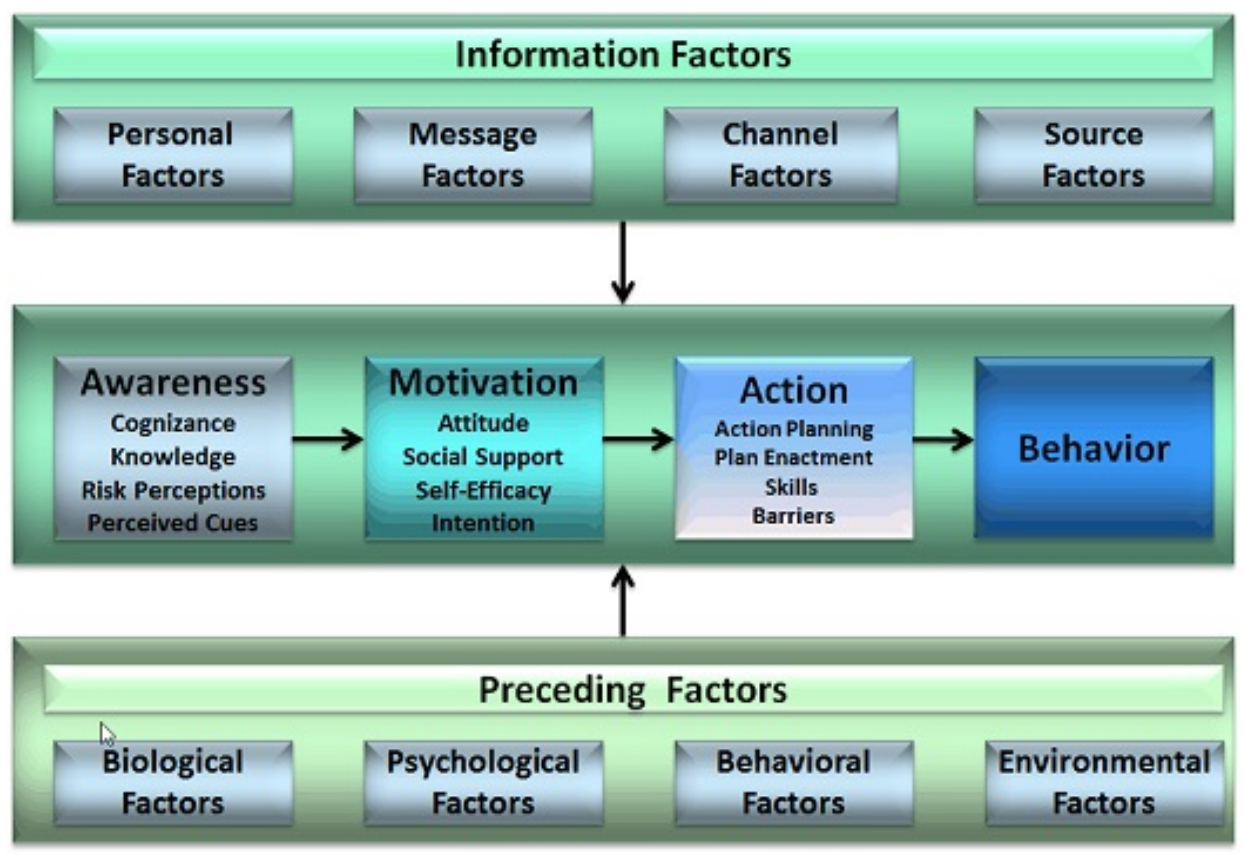

Source: Figure obtained from de Vries (2017). 
Behavioural change is a process that occurs in three stages: the pre-motivational, motivational, and post-motivational phases, with each of these stages having different factors that play an important role. In the pre-motivational stage, we find the predisposing factors (i.e., behavioural factors, psychological factors, biological factors, social and cultural factors), awareness factors (i.e., knowledge, cues to action, risk perception), and information factors (i.e., message, channel, source), which will influence the next stage, that is, the motivational stage (Cremers et al., 2012; de Vries et al., 2012; Jander et al., 2014; Walthouwer, Oenema, Candel, Lechner \& de Vries, 2015). The motivational stage is the central axis of the model and is characterised by different factors, such as the person's attitude towards a certain behaviour, the social influence experienced (modelling, norms and pressure), and self-efficacy expectations, which influences the intention of a person to develop a specific behaviour (de Vries et al., 2003; de Vries, Lezwijn, Hol \& Honing, 2005b; Jander et al., 2013; de Vries, 2017). Firstly, the person's attitude consists of the advantages and disadvantages of perceived cognitive and emotional behaviour (pros and cons) (Cremers et al., 2012; de Vries et al., 2012; Jander et al., 2014). Then, social influences consist of the perception of others carrying out this type of behaviour (social modelling), the norms that people have with respect to these behaviours (social norms) and the support that they encounter from others in carrying out a certain behaviour, as well as the pressure that may be exercised by the people closest to adolescents (social pressure), such as parents, siblings, friends, etc. (de Vries et al., 2005a; Martínez-Hernáez, Marí-Klose, Julià, Escapa \& Marí-Klose, 2012; Jander et al., 2013; Patrick et al., 2013). Finally, self-efficacy refers to the ability to carry out the type of behaviour, that is, how easy or difficult it is for the adolescent to say "NO" to a certain risk behaviour (Bandura, Cioffi, Taylor \& Brouillard, 1988; de Vries, Dijkstra \& Kuhlman, 1988; de Vries et al., 2005a). In addition, the behaviour is the result of the intentions and abilities of a person. The intention state can go from not contemplating the change of behaviour (pre-contemplation) to contemplation, and then to preparing (preparation) to change the behaviour very quickly, for example, within a month, based on the Transtheoretical Model (TTM) (Prochaska et al., 1997). A person's skills, such as being able to prepare and execute specific plans to achieve objective behaviour (i.e., action plans), as well as actual behavioural skills, will increase the likelihood that intentions will be transferred into action (Cremers et al., 2012; de Vries et al., 2012). Finally, in the post-motivational stage, the behaviour change has taken place, and coping plans are often necessary to maintain the new behaviour.

Different studies have previously used the I-Change Model to study the motivational determinants of risk behaviours, such as physical activity and nutrition (Smeets, Brug, \& de Vries, 2008; Van Keulen et al., 2011), smoking prevention (de Vries et al., 2003; Smit, Vries, \& Hoving, 2012; Schulz et al., 2014a), as well as alcohol consumption (Schulz et al., 2013; Schulz et al., 2014a) and binge drinking (Jander et al., 2013; Walthouwer et al., 2015), among others (de Vries et al., 2005b; de Vries, Kremers, Smeets, Brug, \& Eijmael, 2008). This dissertation also used the I-Change Model as the main theoretical framework for developing the intervention and structuring the questionnaires.

\section{Predisposing and information factors of drinking behaviour}

According to the I-Change Model, a person's motivation and behaviour can be influenced by predisposing factors and information factors (de Vries et al., 2003; de Vries, 2017). Predisposing factors are, for instance, the socio-cultural environment where alcohol consumption is regarded as acceptable or is encouraged (Anderson, Møller, \& 
Galea, 2012; Romo-Avilés et al., 2016a). Alcohol consumption has become endemic and part of people's social and cultural life, resulting in a great social permissiveness and low perception of its risks, with easy access and insufficiently restrictive legislation (Espada, Griffin, Pereira, Orgilés \& García-Fernández, 2012; Jander et al., 2013; Romo-Avilés et al., 2016a; ESTUDES, 2018). In Spain, over the last few decades, important changes have occurred regarding the amount of ingested alcohol and the drinking patterns, particularly in the adolescent and the young adult population (de la Villa, Rodríguez \& Ovejero, 2010; Parada et al., 2011). For example, recent studies show that many young Spaniards consume alcohol in public places, this phenomenon being known as a Botellón, with a general trend towards BD and even intoxication (Donath et al., 2011; Anderson et al., 2012; Romo-Avilés et al., 2016a). In Spain, the legal age to consume alcohol is 18 years old (Anderson et al., 2012; Romo-Avilés et al., 2016a), but the Botellón is a clear example of the limitations of health policies, as well as the ease of access to alcohol by underage youth (Espada et al., 2012; Romo-Avilés et al., 2016a; ESTUDES, 2018). A broader discussion can be found in the discussion section of this thesis.

In addition, BD and other types of alcohol use are also influenced by sociodemographic factors such as age, with higher rates associated with being older adolescents (Elisaus et al., 2018, ESTUDES, 2019); gender (Henkel \& Zemlin, 2016; Romo-Avilés et al., 2016a), or socio-economic status (SES) (French \& Cooke, 2012; Henkel et al., 2016; Elisaus et al, 2018), among others. The Spanish State Survey on the use of Drugs in Secondary Schools established that the average age of onset of alcohol consumption is 14 years, with the prevalence at age 16 being $37 \%$, more than double that at age $14(13.2 \%)$, and increasing to $47.5 \%$ at 17 years old (ESTUDES 2018). This implies that regulations concerning alcohol purchases in this underage group are absent and that it is the responsibility of parents and adolescents to regulate their alcohol consumption (Jander et al., 2013). Regarding gender, during recent years, alcohol consumption and BD have now also become common among Spanish girls as a standard feature of their social life; moreover, the prevalence of alcohol intoxication in girls was greater than in boys (Romo-Avilés et al., 2016b; ESTUDES 2018). These trends result in a disappearing gender gap in the prevalence of drinking and BD between boys and girls (Keyes, Li \& Hasin, 2011; Romo-Avilés et al., 2016b; Jang, Patrick, Keyes, Hamilton \& Schulenberg, 2017; ESTUDES 2018). However, predictors of consumption may still differ between boys and girls, as one study showed that sensation-seeking was a noticeably stronger predictor in males than in the female sample. These differences did not exist regarding the reason for drinking to avoid experiencing negative emotions (coping reason) (Lac \& Donaldson, 2016). Furthermore, socio-economic status can also be an important predictor, since those adolescents with greater access to money, as well as a high family affluence, could be more likely to have experiences with alcohol (Bosque-Prous et al., 2017; Elisaus et al., 2018). In addition, some studies found that boys with a high socio-economic status are significantly more likely to have experienced BD compared to boys with a low socio-economic status (Henkel et al., 2016; Elisaus et al., 2018). However, Henkel et al. (2016) did not find an association between girls who engaged in BD and socio-economic status, although the relationship between socioeconomic status and BD could vary between countries (Bosque-Prous et al., 2017).

In addition, certain psychological characteristics can also be important and may influence beliefs about alcohol. One example is self-esteem. Several authors highlighted low self-esteem as an important predisposing factor in alcohol consumption and BD (Bartsch, King, Vidourek \& Merianos, 2017; Lee, Seo, Torabi, Lohrmann \& Song, 2018). Self-esteem refers to the degree to which individuals value, like, respect, and accept 
themselves, and is widely considered to be one of the critical elements that affect future behavioural choice and action (Leary \& Baumeister, 2000; Lee et al., 2018). Most adolescents use alcohol to socialise, to try to "fit in", as well as to lose fear and shame. In this context, Hamilton \& DeHart (2017) concluded that students with low self-esteem were drinking because they lacked the self-resources to deal with unmet needs of belongingness to a group.

Finally, some studies demonstrate the importance of information factors such as media influences that promote attitudes and standards that lead to alcohol consumption and engaging in BD, such as TV or advertising (Suárez, del Moral, Musitu \& VillarrealGonzález, 2013; Zimmermann, Kohlmann, Monter \& Ameis, 2017). A meta-analysis of 132 econometric studies found a small but significant positive association between alcohol advertising and alcohol consumption, although only for spirits advertising (Gallet, 2007). Saffer \& Dave (2006) estimated that a $28 \%$ reduction in alcohol advertising would reduce the monthly share of adolescent drinkers from $25 \%$ to $24-21 \%$, and BD would be reduced from $12 \%$ to $11-8 \%$. Regarding preventive activities, different types of health communication campaigns can be developed with different ranges of effectiveness (Anderson et al., 2012). In this thesis, the focus is to assess the impact of a computertailored intervention to prevent BD and heavy episodic drinking. The role of health communication interventions and computer tailoring will be discussed in more detail at the end of this chapter. The role and importance of different types of factors within such interventions will be discussed below, following the outline of the I-Change Model.

\section{Pre-motivational determinants of drinking behaviour}

In the I-Change Model, development of awareness of the problem and one's own health behaviour is central in the pre-motivational phase, and it is determined by factors such as knowledge, risk perceptions and cognizance (i.e. an accurate perception) of one's own behaviour (Eggers et al., 2016; de Vries, 2017). Behavioural cognizance concerns the level of a person's awareness about his or her own health behaviour (Kasten, van Osch, Candel, \& de Vries, 2019). If a person is aware of the problem, the associated health risks and their (lack of) health behaviour (e.g. not engaging in BD), a person will be more motivated to process information about motivational factors (Eggers et al., 2016). Therefore, adolescents need to know the effects of alcohol in order to become aware of the negative effects and the role of their own drinking behaviour (Jander et al., 2013; Kasten et al., 2019). Furthermore, some studies suggest that levels of adolescents' knowledge about what BD is and causes may be suboptimal (Botvin, Griffin, Diaz, \& Ifill-Williams, 2001; Jander et al. 2013). Studies also show that adolescents and young adults may be underestimating their own and others' level of BD (Wechsler et al., 2000). In addition, perceiving the risks of BD and alcohol consumption may influence the extent to which people engage in BD and alcohol drinking (Graham, Ward, Munro, Snow \& Ellis, 2006; Espada et al., 2008; Patrick et al., 2013). Lower risk perceptions have been found to be associated to an increased willingness to participate in alcohol-related activities (Hampson, Severson, Burns, Slovic \& Fishere, 2001). In addition, males generally report higher levels of knowledge and lower levels of risk perception and protective behaviour than females (Hampson et al., 2001). In Spain, some studies revealed quite alarming low-risk perceptions concerning alcohol in both adolescents and parents (Graham et al., 2006; Espada et al., 2008). Espada et al. (2008) claimed that the risk perception of adolescents is 0.54 times lower among those whose parents drink, 0.61 times lower among those whose siblings drink, and 0.58 times lower among those whose best friend is a drinker. Cues refer to hints or signals that a person perceives within his or 
her environment (external) or himself or herself (internal) that trigger an action linked to the health behaviour (Kasten et al., 2019). According to Jander et al. (2013), environmental cues such as the weekend itself, going out during the weekend, being at a party and being with friends (at a party or at home), would most likely lead to a BD event in Dutch adolescents. Lastly, previous research shows that pre-motivational factors can be seen as a prerequisite for behavioural change, this factor being relatively easy to manipulate and change (de Vries et al., 2003; de Vries et al., 2008; Jander et al., 2016).

\section{Motivational determinants of drinking behaviour}

In the I-Change Model, attitudes, social influence, beliefs about what others do and think, and self-efficacy are the key factors influencing a person's intention (de Vries et al., 2003). These factors are also key in Ajzen's Theory of Planned Behaviour (Ajzen, 1991). For instance, a study by Norman \& Conner (2006) showed that attitude, selfefficacy, and perceived control were predictive for BD intentions, accounting for $66 \%$ of the variance in intention.

Alcohol consumption of adolescents responds both to attempts to satisfy hedonic motivations, such as exploratory, ritualised practices, experimentation desires, socioaffective imbalances and perceived needs for integration in the peer group, as well as their youth leisure styles, typical of a recreational culture (de la Villa et al., 2010; EDADES, 2018; ESTUDES, 2019). In this vein, Kuntsche, Knibbe, Gmel \& Engels (2005) also identified four factors as the main reasons for adolescents to consume alcohol, which are social motives, coping motives, conformity motives, and enhancement motives. Therefore, in adolescents, an important incentive to drink is to gain social rewards and affiliation (Kuntsche et al., 2005; Lac et al., 2016). In this sense, some authors suggest that much of human behaviour is motivated by a desire to satisfy belongingness needs, to feel accepted and fit in with those around them (Baumeister \& Leary, 1995; Hamilton et al., 2017). Furthermore, although less frequently, young people reported having drunk alcohol to avoid the experience of negative emotions (coping motive), as well as to avoid social rejection (conformity motive) (Kuntsche et al., 2005; Lac et al., 2016). Regarding the enhancement motive, alcohol consumption increases their feeling of well-being (Kuntsche et al., 2005). In this sense, Gómez, Luque, Cortés, Espejo \& Giménez (2012) established that binge drinkers had characterised BD as positive (pros) (i.e. as fun, satisfying, enjoyable, desirable, good, and healthy), associating it with greater sociability. In addition, it is known that attitude is perceived to be an important determinant of intention. In this sense, one study developed by Boers, Zebregs, Hendriks, \& Van Den Putte (2018) showed that both cognitive attitude (related to the disadvantages) and affective attitude (related to the advantages) positively influenced students' intentions to engage in BD. The authors concluded that affective attitude was a significantly stronger predictor of students' intention to engage in BD than cognitive attitude. Thus, an individual is more likely to engage in a risky behaviour such as BD when expectations of positive consequences (e.g. benefits) outweigh expectations of negative outcomes (e.g. associated with risks) (Fromme, Katz \& Rivet, 1997; Johnson, Albery, Frings \& Moss, 2018).

With regard to social influence beliefs, several studies identified the impact of peer influence on alcohol consumption and BD in adolescents (Jander et al.,2013; RomoAvilés et al., 2016a), such as best-friend norms and friend norms (Lac et al., 2016), and social pressure from friends (Donath et al., 2011; Mercken, Steglich, Knibbe \& de Vries, 2012; Jander et al., 2013; Romo-Avilés et al., 2016a). Regarding the social influence of peers, several studies have shown peer influence as a predictor of substance abuse such 
as alcohol consumption or BD, especially during late adolescence (Donath et al., 2011; Mercken et al., 2012; Patrick et al., 2013; Pedersen \& von Soest, 2013; Romo-Avilés et al., 2016b). According to Clapp \& Shillington (2001), the presence of friends in a meeting increased 2.4 times the likelihood of engaging in BD at a certain event, and if there are many drunk people at the event, the likelihood increases 12.8 times. Moreover, friends' norms, as well as their behaviour regarding alcohol, were found to be strong predictors of BD. The norms of closest friends and those of other friends could be differentiated, being the norms of closest friends those that most influence personal decisions (Lac et al., 2016). Other researchers also indicated that romantic relationships influence the motivation to give up engaging in BD (Gómez et al., 2012). On the other hand, several authors highlight the positive relationship between the size of the peer group and increased alcohol consumption (Hunter et al., 2013; Jander et al., 2013; Golpe et al., 2017). In this sense, Hunter \& Francescutti (2013) stated that due to peer pressure, students will consume 6.2 drinks per night in a large group versus 1.8 drinks per night when alone.

Other studies also looked at the importance of parents and parental modelling (Jander et al., 2013; Pedersen et al., 2013), highlighting family influence to explain the participation of adolescents in alcohol consumption, BD and other types of alcohol use. For instance, high parental consumption levels (Espada et al., 2008; Martínez-Hernáez et al., 2012; Pedersen et al., 2013; Gersh et al., 2017), low parental supervision, availability of alcohol to the child, approval of adolescent drinking (Ryan, Jorm, \& Lubman, 2010), unstructured household (Patrick et al., 2013; Golpe et al., 2017), as well as less strict alcohol rules (Clark, Shamblen, Ringwalt \& Hanley, 2012; Mejia et al., 2016), the low quality of the relationship between parents and children, and lack of parental support or general communication (Ryan et al., 2010) increased the onset of BD. In Spain, parents' permissiveness regarding their children's alcohol consumption is high, since the parents of $48.3 \%$ of adolescents allow them to drink alcohol (20 points higher than tobacco) (ESTUDES, 2018). In this line, although many attributes of the family environment have been investigated as risk and protective factors for adolescent substance use, parent-child communication has received limited research attention (Ennett, Bauman, Foshee, Pemberton \& Hicks, 2001). Communication between parents and children about drinking has shown beneficial effects, limiting the availability of alcohol for the adolescent, and reducing levels of consumption (Ryan et al., 2010). For this reason, some researchers highlight the need to increase family communication related to alcohol consumption in adolescents (Jander et al., 2013).

Adolescents with lower self-efficacy are at higher risk of engaging in BD (Johnson et al., 2018; Ehret, Ghaidarov \& LaBrie, 2013). Some studies clearly showed the importance of drinking-related self-efficacy, since adolescents' ability to resist drinking (challenging situations) and initiate behavioural change relies upon that individual's perceived self-efficacy to do so (Ehret et al., 2013). McKay, Sumnall, Cole \& Percy (2012) showed a domain-specific association between alcohol involvement and selfefficacy, with more problematic alcohol use associated with lower emotional selfefficacy. Guilles, Turk \& Fresco (2006) showed that high levels of self-efficacy for avoiding $\mathrm{BD}$ in social situations and positive expectations for social facilitation were consistently related to all indices of drinking. Self-efficacy for not drinking alcohol may be increased by changes in the environment that make BD less acceptable, as well as the legal age to consume alcohol (Anderson et al., 2012) or easy accessibility for underage youth (Anderson et al., 2012; Montes, 2012; Romo-Avilés et al., 2016a), but also provides students with specific examples of strategies to refuse having drinks (Norman, 2011). 
However, more effective alcohol prevention programmes are needed, and these programmes should include components that specifically focus on building self-efficacy to resist drinking and BD (Ehret et al., 2013).

\section{Post-motivational determinants of drinking behaviour}

The translation of intentions to behaviour has been an important topic of study, as intentions do not automatically translate into behaviour and it does not explain all behaviour (de Vries et al., 2003; Eggers et al., 2016; de Vries, 2017). For instance, a review showed that intentions explain $28 \%$ of the variance, on average, in future behaviour (Sheeran, 2002). The intention to carry out a certain behaviour is influenced by previously mentioned motivational factors (Jander, Crutzen, Mercken, \& de Vries, 2015). For instance, intention only predicted various alcohol outcomes with an explained variance ranging from $26-38 \%$ in undergraduates, although $76 \%$ of the variance in intention was explained by attitudes, social influences and self-efficacy (Marcoux \& Shope, 1997). Previous studies show that BD is also determined by an individual's intention to engage in BD (Jander et al., 2013; Boers et al., 2018).

The importance of action planning as a determinant as well as a behavioural change strategy to translate intentions into behaviour has been assessed in several publications (Hagger \& Luszczynska, 2014; de Vries, 2017). Action planning refers to the process of planning and executing specific actions that may help to adopt successfully and maintain a new health behaviour (e.g., "not to drink too much alcohol or not to binge drink") (Kulick \& Rosenberg, 2000; de Vries et al., 2003: de Vries et al., 2008). Furthermore, coping plans help reduce relapse after a successful behavioural change by providing specific plans for how to act in a predefined difficult situation (Araújo-Soares, McIntyre \& Sniehotta, 2009; de Vries, 2017). Consequently, there has been a rapid increase in research on the effects of action planning interventions to promote healthrelated behaviour (Abraham, Kok, Schaalma, \& Luszczynska, 2011; Hagger et al., 2014), being considered the most promising intervention by several authors (Green \& Kreuter, 2005; Bartholomew, Parcel, Kok, Gottlieb, \& Fernández, 2011). Intention and action planning interventions have been shown to be effective in changing various behaviours (Hagger et al., 2014). An intervention carried out by de Vries, Eggers \& Bolman (2013) to decrease tobacco use revealed that $29 \%$ of the smokers who completed fewer plans than the median had quit successfully after six months versus $59 \%$ of the smokers who completed more than the median. In addition, some studies claimed that implementation intentions and action planning have successfully reduced alcohol consumption (Armitage, 2009; Hagger et al., 2012). A study developed by Armitage (2009) showed that there were clinically and statistically significant decreases in alcohol consumption through action planning intervention. In addition, some researchers claimed that encouraging skills and action plans helps adolescents to reject alcohol consumption and BD (Arden \& Armitage, 2012; Hagger et al., 2012; Jander et al., 2016). Furthermore, Arden \& Armitage (2012) also showed a significant effect indicating that participants in the experimental condition (provided action planning) reported having drunk significantly fewer units at the followup stage, and they indicated that participants in the condition reported significantly fewer occasions of engaging in BD than control conditions. However, not many studies currently evaluate the effectiveness of action planning to prevent $\mathrm{BD}$ in adolescents (Arden et al., 2012). 


\section{The role of health communication programmes}

Even though several interventions have been carried out for the prevention of alcohol consumption and BD in adolescents (Sussman, Arriaza \& Grigsby, 2014; Jander et al., 2016; Onrust, Otten, Lammers \& Smit, 2016; Sá, Rocha, Machado \& Precioso, 2018; Vázquez, Muñoz, Juárez \& Ariza, 2018), the findings regarding the efficacy of primary prevention interventions are contradictory (Onrust et al., 2016; Vázquez et al., 2018), especially in approaches based on the attention to prohibitive measures (Gómez et al., 2002). In this sense, authors such as McKay, Summall, McBride \& Harvey (2014) and Amezcua, Hernández-Zambrano, Rodriguez-Rodriguez, \& Quesada-García (2015), suggested focusing educational action on the control of limits or education on moderate consumption, instead of setting ideal models in the social world of the young person, such as the prescription of abstinence, although the definition of limits is controversial (Amezcua et al., 2015).

Some interventions focused on environmental prevention strategies that seek to modify the social, cultural, physical, and economic environment that influences individual decision-making (Burkhart, 2011). However, several authors considered more promising those programmes focusing on life skills training and multi-component programmes (Faggiano et al., 2008; West et al., 2008; Onrust et al., 2016), since programmes that emphasise the promotion of attitudes, behaviours and life skills are more effective in reducing substance use than those that focus only on affective goals, such as self-esteem (Sambrano, Springer, Sale, Kasim \& Hermann, 2005; Vázquez et al., 2018). A meta-analysis examined the effectiveness of health programmes to prevent the consumption of illicit drugs in adolescents (Faggiano et al., 2008). The results revealed that affect-centred (self-esteem, self-efficacy or motivational aspects of substance use) or knowledge-based (knowledge about the effects or consequences of drug use) programmes were generally ineffective in changing behaviour. However, it was found that skill-based (interpersonal or intrapersonal skills) interventions significantly reduce illicit drug use, as well as improve decision-making and resistance skills among peers, proving to be a key and effective component of prevention programmes.

In Spain, Espada et al. (2012) evaluated the effects of the primary prevention programme Saluda, to prevent alcohol consumption and the use of other substances among Spanish secondary school students. They focused their intervention on social skills and problem-solving training, being both conditions significantly more effective than the control condition. This finding is consistent with other research such as that of Sussman et al. (2014), who showed that in order for prevention programmes to be effective, they must include explicit reinforcement of motivation, training in social skills, decisionmaking, and a critical attitude towards social influences that encourage consumption. Currently, most of the studies evaluating the effectiveness of prevention and risk reduction interventions associated with alcohol consumption have been carried out in the educational environment, given that the compulsory schooling of minors in certain countries makes children and adolescents stay for a significant time at schools (Espada et al., 2012; Lima-Serrano \& Lima-Rodríguez, 2014; Pearson et al., 2015; Onrust et al., 2016). A meta-analysis on the effectiveness of alcohol and drug abuse prevention programmes in Spanish schools found that the programmes were generally effective (Espada et al., 2002), with moderate intervention effect sizes $(d=.65)$, with informative content, training in social skills and training in problem solving being the most common components of prevention, and the inclusion of these latter elements substantially increases the effectiveness of interventions. 


\section{Web-Based Computer-Tailored Programmes}

In the prevention area, web-based computer-tailored (CT) programmes are increasingly used as platforms for health promotion, including interventions aimed at reducing alcohol consumption (Krebs, Prochaska \& Rossi, 2010; Velicer et al., 2013; Jander et al., 2016; Brick, Redding, Paiva \& Velicer, 2017; Newton et al., 2017), being one of the fastest growing type of interventions in Europe (Cremers et al., 2012; Jander et al., 2016). This kind of intervention offers the possibility of obtaining highly tailored advice to the participants, helping to effectively change various health risk behaviours and their determinants (Dijkstra, 2005; Krebs et al., 2010; Kohl, Crutzen, \& de Vries, 2013; Lustria et al., 2013; Schulz et al., 2013), as well as showing to be more costeffective than face-to-face interventions (de Bourdeaudhuij et al., 2010; Schulz et al., 2014a; Drost et al., 2016; Tebb et al., 2016). In addition, recent technology innovations enable web-based CT programmes to be interactive, provide individually tailored messages and simulate experiences where adolescents can learn and practice skills in convenient and private settings (Elfeddali, Bolman, Candel, Wiers \& de Vries, 2012; Schulz et al., 2013; Jander et al., 2016; Tebb et al., 2016). Moreover, some previous metaanalysis has shown that computer tailoring (CT) is effective in supporting health-related changes for a number of different behaviours (Krebs et al., 2010; Tebb et al., 2016). These tailored advices are based on the individual characteristics of each participant. To be able to provide tailored feedback, an online questionnaire should be previously completed; this questionnaire consists of questions about demographic and socio-cognitive (premotivational or motivational) variables (Walthouwer et al., 2015). These behaviours and opinions are previously assessed on the basis of their answers in a questionnaire, using data-driven decision rules that produce personalised feedback automatically from a database (de Vries \& Brug, 1999). In this way, people will receive advice that is personally relevant to them. Therefore, it will be more likely to attract their attention and be read, and it will be better remembered than a non-tailored general message (Krebs et al., 2010).

In addition, CT interventions have shown great advantages, such as accessibility, ease in filling out the questionnaires, and cost effectiveness (de Bourdeaudhuij et al., 2010). In addition, CT interventions have the potential to reach a large number of people, as access to the Internet is growing worldwide (Bewick et al., 2008). Additionally, computers have become widely accessible and are especially popular among adolescents and young adults (Tebb et al., 2016). Besides, CT interventions can be used anonymously, with the participant being able to determine the time and place to complete the intervention, becoming a motivational and attractive tool for working with adolescents (Lustria, Cortese, Noar, \& Glueckauf, 2009; Jander et al., 2014).

Similar previous studies aiming to evaluate web-based healthcare programmes used by adults have been conducted (Elfeddali et al., 2012; Schulz et al., 2013; Schulz et al., 2014a; Boudreau et al., 2015), as well as those aiming to promote healthy eating and physical activity among adolescents (de Bourdeaudhuij et al., 2010) and the prevention of drug dependence, such as smoking (de Josselin de Jong, Candel, Segaar, Cremers \& de Vries, 2014) or alcohol drinking (Walton et al., 2010; Bannink et al., 2014; Jander et al., 2014). Thus, the reduction of alcohol use and BD in adolescents could be achieved with the help of web-based computer-tailored (CT) interventions (Schulz et al., 2013; Jander et al., 2016), which provide highly personalised feedback to individuals (de Vries et al., 1999). 


\section{Current limitations of health prevention programmes}

Despite the great advantages of the CT programmes, their effect sizes are generally small to medium (Krebs et al., 2010; Schuckit et al., 2015). Moreover, the low adherence and high attrition rates is an important problem in a web-based CT intervention, even over 50\% (Elfeddali et al., 2012; Schulz et al., 2013; Jander et al., 2016), causing significant negative consequences such as a reduced ability to reveal intervention effects (Eysenbach, 2005). A previous CT programme that focused on reducing $\mathrm{BD}$ in Dutch adolescents obtained extremely low adherence rates in the programme $(\mathrm{N}$ total $=824 ; 31.1 \%)$, so optimal achievements could not be obtained upon the completion of the intervention. Nonetheless, the intervention was effective in reducing $\mathrm{BD}$ in adolescents between 15 and 16 years old who completed at least two sessions (Jander et al., 2016).

In addition, a review carried out by Vázquez et al. (2018) identified various limitations to take into account in the intervention or evaluation of health programmes, such as the design of the evaluation and the effects on consumption, since $50 \%$ of the studies did not explain the exclusion and inclusion criteria sufficiently, which suggests some selection errors. In addition, a third of the studies did not properly define the indicators or outcome variables. Another limitation was an inadequate and scarce provision of information in the process evaluation of the study, outcome variables, attrition, adherence and follow-up rate of the participants throughout the study, despite it being one of the basic evaluative standards (Nation et al., 2003; Dusenbury, Brannigan, Hansen, Walsh \& Falco, 2005). Finally, beyond the quality of the studies, the most expected aspect of health programmes is the effectiveness and impact they have on the main addictive behaviour. In this sense, Vázquez et al. (2018) indicated that $43 \%$ of the studies showed effectiveness with statistical significance. This percentage is similar to that found in the review by Sussman et al. (2014), who claimed that almost all interventions had some impact on any indicator, but only half of them showed significant changes in the main variables.

\section{Cultural adaptation of a health communication programmes.}

In spite of the fact that health programmes are required to be easily adopted by the educational system and be effective for the target group (Escobar-Chaves et al., 2011), the development, implementation and evaluation of such programmes from scratch are a costly and time-consuming endeavour (Villarruel, Jemmott \& Jemmott, 2005; Zometa et al., 2007). Therefore, the cultural adaptation of an empirically validated evidence-based programme could provide a more cost-effective and immediate solution (Escobar-Chaves et al., 2011). In addition, Cuijpers, de Graaf \& Bohlmeijer (2005) stated that the adaptation and dissemination of effective interventions for international use require that programmes address an acknowledged public health problem, are potentially effective, and have sufficient evaluation trials and positive results, so that they can be generalised and implemented in other contexts. Currently, several web-based international healthcare programmes that focus on BD and alcohol consumption in adolescents or young adults have been carried out (Walton et al., 2010; Schulz et al., 2013; Bannink et al., 2014), but few use web-based CT programmes aimed at Spanish adolescents in the school environment (Lima-Serrano, Martínez-Montilla, Lima-Rodríguez, Mercken \& de Vries, 2018). A potential candidate for such an existing evidence-based programme targeting BD is Alcohol Alert, which has been shown to be effective in reducing BD in Dutch adolescents aged 15 and 16 who started consuming alcohol (Jander et al., 2016). The programme, as well as being cost-effective (Drost et al., 2016), has great potential for the 
dissemination and replication of the intervention in other European adolescents. Therefore, it was proposed to replicate the Alcohol Alert programme in the Spanish context (Lima-Serrano et al., 2018).

Cultural adaptation of an intervention is defined as "the process of altering a programme to reduce the mismatches between its characteristics and those of the new context in which it is going to be implemented" (Card, Solomon \& Cunningham, 2011). Cultural adaptation of a programme may include adding or omitting components, changing or adjusting content to match a cultural context (McKleroy, Galbraith, Cummings, \& Jones, 2006; Holtrop \& Holcomb, 2018). However, the challenge of cultural adaptation of a successful intervention is to maintain the essential elements of the original programme that made it effective, while adapting delivery methods and materials to the target population (Tortolero et al., 2005; Escobar-Chaves et al., 2011). Therefore, when these essential elements of a programme are known, efforts to replicate or adapt an intervention will be more successful, since these key characteristics can be kept intact (Espada et al., 2012).

For optimal cultural adaptation, attention to the surface and deep structure must be taken into account (Escobar-Chaves et al., 2011; McNaughton, Cowell \& Fogg, 2014). The surface structure would involve designing messages with observable and "superficial" characteristics of a target population (e.g., people, clothes, places, language and youthful jargon, etc.). To attend to the deep structure would imply the incorporation of cultural norms, and social, historical, environmental and psychological behavioural influences (Escobar-Chaves et al., 2011). These strategies require first-hand knowledge, understanding, and communication with community members to incorporate their priorities, problems, and preferred methods of participation (McNaughton et al., 2014). Furthermore, ideally, for the implementation of a programme, its viability should be previously evaluated, as well as its possible effectiveness, thus optimising operational reliability (Escobar-Chaves et al., 2011). In this sense, authors such as Cameron et al. (2017) stated that a multi-stage approach, as well as mixed methods (qualitative and quantitative) to test its acceptability, would be a promising way of carrying out formative research to adapt health communications into another language or for different cultural communities.

\section{Aim of the dissertation}

The main aim of this dissertation is to describe the design, cultural adaptation, development, implementation and evaluation of the Alerta Alcohol programme, which was the first web-based computer-tailored intervention to reduce alcohol consumption and binge drinking in Spanish adolescents.

\section{Outline of the dissertation}

The dissertation is divided into two parts, and both consist of several studies and research questions. The first part of this dissertation (Chapters 2-4) describes the formative research, i.e., process of cultural adaptation of the programme. Initially, Chapter 2 describes the study protocol for the design, cultural adaptation, implementation and evaluation of the Alerta Alcohol programme. Subsequently, due to the need to develop some changes for Alerta Alcohol in the Spanish context, Chapter 3 focuses on the qualitative research through focus groups of adolescents and parents, with special attention to the knowledge about the determinants of alcohol consumption and BD in Spanish adolescents based on the I-Change Model. Then, Chapter 4 describes the critical analysis of the cultural adaptation, which was developed through a Delphi panel, as well 
as the feasibility assessment of the Alerta Alcohol programme, which was developed through a pilot study. Both studies took place before the development of the intervention, and the results of these studies were taken as a base for the design and adaptation of the Alerta Alcohol programme.

The second part of this dissertation (Chapter 5) describes the effect study, i.e., the development, implementation and evaluation of the effectiveness of the Alerta Alcohol programme, based on a two-arm Cluster Randomised Controlled Trial (CRCT), showing the predictors of adherence as well as the process evaluation of the programme. Finally, Chapter 6 provides a general discussion of the main findings and conclusions of all the studies presented in this dissertation (Chapters 2-5), as well as a discussion of the main methodological considerations encountered during the study evaluation, and recommendations for practice and future research, ending with the general conclusion of the dissertation. 


\section{Part I}

Formative research: process of the cultural adaptation of the Alerta Alcohol program 


\section{Chapter 2}

Design, implementation, and evaluation of a web-based computer-tailored intervention to prevent binge drinking in adolescents: study protocol.

Based on:

Lima-Serrano, M., Martínez-Montilla, J.M., Lima-Rodríguez, J.S., Mercken, L., de Vries, H. (2018). Design, implementation and evaluation of a web-based computertailored intervention to prevent binge drinking in adolescents: study protocol. $B M C$ Public Health, 18(449). https://doi.org/10.1186/s12889-018-5346-4 


\begin{abstract}
Background: Binge-drinking in adolescents is a highly prevalent healthcare problem that associates physical and mental health complications with community implications. This paper describes the design, implementation and evaluation of the first web-based computer tailored intervention aimed at the prevention of binge drinking in Spanish adolescents.
\end{abstract}

Methods: The Alerta Alcohol program is based on the I-Change Model. First, feedback from focus and Delphi groups are used for cultural adaptation and to obtain further information on the items to be included on the program. A pilot study is then conducted to assess feasibility and to identify strengths and weaknesses. Second, a Cluster Randomized Controlled Trial is conducted to test the effectiveness of Alerta Alcohol in students aged 16 to 18 years. The study is performed in 16 high schools from Andalusia (southern Spain), which are randomized either to the experimental or the control condition (EC and CC). The EC receives the Alerta Alcohol intervention, which consists of four sessions at school (baseline questionnaire, two sessions in three scenarios: at home, celebrations, and public places, and a final evaluation). The adolescents are provided with answers related to their views of each scenario; this information is used to provide highly specific feedback regarding their knowledge, risk perception, self-esteem, attitude, social influence, and self-efficacy. In addition, two booster sessions are given at home to reinforce the previous messages. The $\mathrm{CC}$ just completes the baseline and the final evaluation questionnaires and then they are allowed to receive the intervention as well (as a waiting list). Evaluation takes place after four months. The primary endpoint is binge drinking within 30 days prior to the evaluation and alcohol use in the previous week. It is expected that Alerta Alcohol reduce the prevalence of binge drinking by $10 \%$. Follow up analyses are carried out to determine the differences in effectiveness according to the compliance of the program (quality of the implementation).

Discussion: The results are expected to be applicable and may incorporate improvements in the practice of the Healthcare and Education Systems. If the program proves to be effective, regional and eventual national implementation should be considered.

Trial registration: Trial registration number (ClinicalTrials.gov): NCT03288896. This study was retrospectively registered on 19/09/2017.

Keywords: Adolescence, Alcohol drinking, Binge drinking, I-change model, Web-based interventions, Computertailoring 


\section{Background}

The consumption of alcoholic beverages is a public healthcare problem worldwide, causing 3.3 million deaths every year (WHO, 2011; Chestnov, 2014). The toxicity associated with excessive alcohol ingestion and its enormous addictive power makes alcohol one of the most consumed and dangerous drugs (WHO, 2011). Moreover, alcohol is linked to several conditions like brain damage, cardiovascular lesions, cancer, suicide, sexually transmitted diseases, alcohol dependence and premature death. Alcohol consumption also affects society, leading to high financial and social burden, as in cases of violence, crime, accidents, etc. (Farke et al., 2007).

Alcohol drinking has become endemic, and part of the social and cultural life, resulting in a great social permissiveness and a low perception of its risks. It is widely available, easy accessible and lacks restrictive legislation (Espada et al., 2012). In Spain, traditional drinking patterns are classically associated to the adult population, characterized by daily drinking, usually during meals, although hardly ever leading to acute intoxication. However, in the recent years, important changes have occurred concerning the amount of ingested alcohol and the drinking patterns, particularly in the adolescent and the young adult population (Parada et al., 2011). Binge drinking, defined as consuming five or more drinks by men, or four or more by women, within a short period of time (Calafat, 2007; NIAAA, 2016), is increasingly prevalent among youngsters aged 15 to 24 , in whom it is becoming the usual pattern of consumption.

Regarding Spanish adolescents, the national survey ESTUDES (2016) showed that the prevalence of binge drinking at the age of 16 was $37.1 \%$, which doubled that of 14-year-olds (14.2\%), and reached 44.2\% at the age of 17 (ESTUDES, 2016). These figures highlight the importance of preventing binge drinking.

For predicting healthy behavior acquisition, several theoretic models, borrowed from health and social psychology, have been used (de Vries et al., 1998). The present study is based on the I-Change Model that integrates elements of various social cognition and self-regulation models, as well as principles from socio-ecological models (de Vries et al., 2005ab; de Vries, 2017). It has been used before to study alcohol dependency and seems to influence alcohol consumption (Figure 2.1) (Jander et al., 2013; Schulz et al., 2013; Van der Wulp et al., 2014; Van Lettow, de Vries, Burdorf, Boon, \& van Empelen, 2015; Drost et al., 2016). The I-Change Model states that a behavior is the result of an individual's intentions, action plans and abilities. The intention of an individual can range from no intention at all for change (pre-contemplation) to a real intention of changing a certain behavior (preparation). The individual's abilities and environmental constraints determine whether the intentions will be accomplished (de Vries et al., 2003; Walthouwer et al., 2015). In addition, the rejection of consumption seems to be influenced by different individual skills (Espada et al., 2012), like the ability to carry out action plans that may increase the chances of going from intention to action.

Specifically, the I-Change Model focuses on three motivational factors: the person's attitude (pros and cons) towards a certain behavior, the social influence experienced (modelling, norms and pressure), and his or her selfefficacy expectations, which influences the intention of a person to develop a specific behaviour (de Vries et al., 2003; de Vries et al., 2005ab; Richter Leppin \& Gabhainn, 2006; Donath et al., 2011; Cremers et al., 2012; de Vries, 2017). 
Figure 2.1: I-Change Model.

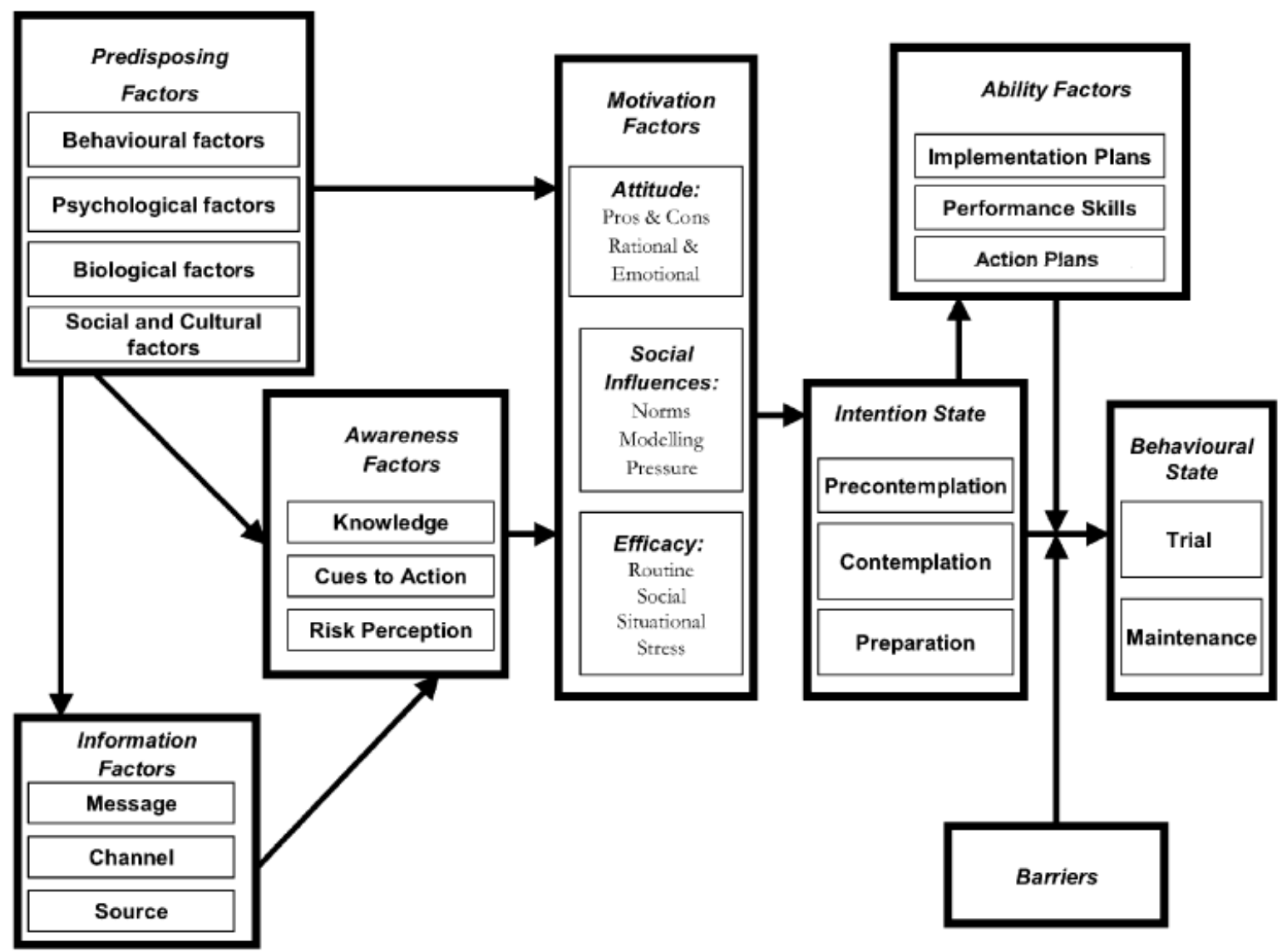

Source: Figure obtained from de Vries et al. (2005b).

Regarding alcohol abuse prevention among adolescents, most of the programs are carried out at schools, for they are considered the most suitable places for learning interventions and where children and adolescents stay for significant amounts of time (NIDA, 2004; Lima-Serrano et al., 2014; Pearson et al., 2015). In Spain, previous national preventive programs of alcohol abuse in adolescents have been conducted in the school environment (de la Villa, Rodriguez, Ovejero \& Sirvent, 2009; Espada et al., 2012). The use of Internet based programs at schools is growing, specifically those concerning the prevention of alcohol abuse (Cremers et al., 2012; Jander et al., 2014; Jander et al., 2016). Of particular interest is the utilization of computer tailored technology (CTT), which provides highly personalized behavioral and motivational feedback to the individual. On one hand, the Internet has become a worldwide available and promising tool, accessible to large populations (Stanczyk et al., 2014). On the other hand, a previous meta-analysis has shown that computer tailoring (CT) is effective in supporting health-related changes for a number of different behaviors (Krebs et al., 2010). Moreover, for the adolescent population, Internet based programs may also be a motivational and attractive tool to work with (Lustria et al., 2009; Jander et al., 2014).

CTT is a method of assessing individuals' behaviors and opinions and selecting communication content on the basis of their answers, using data-driven decision rules that produce personalized feedback automatically from a database of content elements (Krebs et al., 2010). CT has shown advantages, such as accessibility, ease in filling out the questionnaires in the appropriate time, the possibility of obtaining tailored advice at the 
participant's request, and it has shown to be cost-effective (de Bourdeaudhuij et al., 2010). In addition, CT consists of dynamically tailored interventions (assessing intervention variables prior to each feedback), opposed to static tailoring (providing one baseline assessment on which to base all successive feedbacks), that has shown to increase efficacy over time (Krebs et al., 2010).

Similar previous studies, aiming to evaluate web-based healthcare programs in adults have been conducted (Elfeddali et al., 2012; Schulz et al., 2013; Schulz et al., 2014b; Boudreau et al., 2015). Computer tailoring has been used to promote healthy food and physical activity in adolescents (de Bourdeaudhuij et al., 2010) and in the prevention of drug dependence, such as smoking (de Josselin de Jong, Candel, Segaar, Cremers \& de Vries, 2014) or excessive alcohol drinking (Walton et al., 2010; Jander et al., 2014; Bannink et al., 2014). In this regard, Jander et al. (2014; 2016) developed a dynamically tailored internet based intervention in the context of a tailored game, for the prevention of excessive alcohol drinking in Dutch adolescents, aiming to change the motivational factors and the actual occurrence of binge drinking. In this intervention, also based on the I-Change Model, the adolescents received personalized information on their consumption behavior, as well as messages aimed at its prevention. It resulted effective in binge drinking prevention among 15 and 16-year-old participants beginning to consume alcohol, although efficacy was not confirmed in older groups.

The goal of this paper is to describe the design, implementation and evaluation of the first web-based computer tailored intervention aimed at the prevention of binge drinking in Spanish adolescents (Alerta Alcohol). This program is a dynamically webbased computertailored intervention, which is delivered at schools and is an adaptation of the Dutch program (Jander et al., 2014). First, we designed a web-based computertailored intervention, given that certain cultural differences may exist between the Dutch and the Spanish adolescent population. In this regard, feedback from focus groups with adolescents and parents were analyzed to consider their viewpoints regarding the risk and protective factors of binge drinking. The information obtained from these interviews was used for the development of the CT intervention, which was later assessed by a Delphi Panel and by a pilot study. Second, a two-arm Cluster Randomized Controlled Trial (CRCT) aimed at testing the effectiveness of the Alerta Alcohol program is then performed.

\section{Methods}

\section{Intervention design}

A CRTC was designed, with one experimental and one waiting-list control condition randomized at the school level (EC and CC), with an initial (pre-test) evaluation and a final (post-test) evaluation, performed four months after the intervention (Figure 2.2). To design the program, we followed the study by Jander et al. (2014; 2016), which was carried out in the Netherlands with an equivalent objective. The CONSORT guidelines were followed (Moher, Schulz \& Altman, 2001). The independent variable was the participation versus nonparticipation of the student in the Alerta Alcohol program. 
Figure 2.2: Flowchart of the intervention.

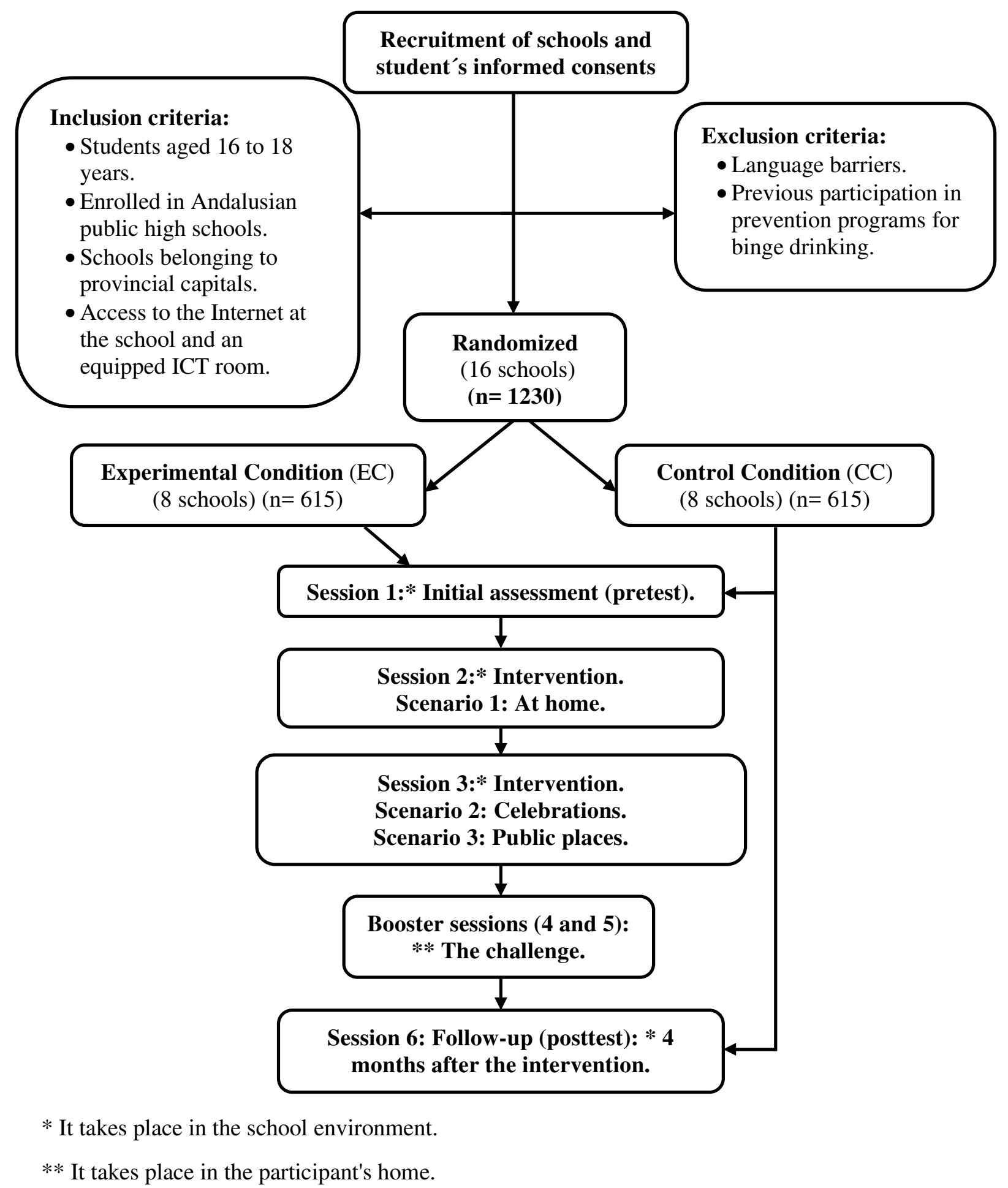

Source: Own elaboration

\section{Participants}

The study was conducted with students aged 16 to 18 years belonging to the public-school system. In order to calculate the sample size, the online GRANMO tool was used (http://www.imim.cat/ofertadeserveis/software-public/granmo/). According to the ESTUDES 2016 study, in Spain, the prevalence of adolescent binge drinking within the previous 30 days is $32,2 \%$ (ESTUDES, 2016). It is estimated that the intervention 
reduces the consumption by $10 \%$. Accepting a significant $P$ value $<.05$, a statistical power of .80, for a two-sided test, 615 subjects were required for the $\mathrm{CC}$ and 615 for the EC (1230 participants) to find a statistically significant proportion difference, expected to be of .32 for CC and. 22 for EC. Following the study by Jander et al., it has been anticipated a drop out rate of about 50\%. The ARCSINE approximation was used (Jander et al., 2014).

\section{Selection of the sample}

Collaboration was requested from the Educational Plans and Programs Service of the Department of Education, Culture and Sports of the Government of Andalusia. A total of 16 high school centers, two from each province of Andalusia (southern Spain) were contacted and randomly assigned to either the EC or the CC. The participating students in the $\mathrm{CC}$ were considered to be on a waiting list and were allowed to receive the intervention voluntarily once the study was finalized. For the selection of centers, the criteria were: 1. Public secondary education schools from Andalusia; 2. Belonging to provincial capitals; 3 . Access to the Internet at school and an equipped ICT room available for the student. From the list of centers that met these criteria, a random selection was made.

Participation in the study was confirmed by e-mail, telephone or, when necessary, by visit. A formal letter and an informative folder were sent to each center. If they accepted the collaboration, the inclusion criteria were checked.

All students enrolled gave consent to participate and had an Internet access point in their homes. Those with language difficulties or those who had previously participated in prevention programs of binge drinking were excluded.

The selected schools were not blinded, since the EC needs to schedule a total of four sessions during school hours. In the first session, the reference questionnaire (pretest) is filled out throughout January/February. For the second and third sessions, computerized interventions were carried out. There was a 1-2-week period between sessions. Then, in a fourth session at school, the follow-up questionnaire (post-test) was carried out throughout May/June. Each session takes approximately one hour.

The CC only gets two sessions: baseline data in January/February 2017, and the follow-up questionnaire (posttest) four months later, in May/June 2017.

\section{Intervention}

\section{Design of the web-based computer-tailored intervention}

The design is developed using several strategies (Figure 2.3):

1. Because this study is based on the Dutch program, it is reasonable that certain cultural differences may exist. Consequently, the first phase of the project consists of gathering 10 to 14 focus groups, each with 6-8 adolescents 16 to 18 years old, as well as, focus groups with fathers/mothers (Jander et al., 2013). The goal of these studies is to identify in detail the patterns of alcohol consumption, binge-drinking, binge drinking intention and the cognitive and motivational variables determining factors such as attitudes and self-efficacy. The group interviews are recorded and analyzed by members of the research team, resulting in a list of the most important items to be addressed in the Spanish computer tailoring intervention. 
Figure 2.3: ALERTA ALCOHOL: study timeline.

\section{Preparation Phase:}

- Review of studies about prevention of binge drinking and web-based computer-tailored interventions.

- Updating the study protocol, permissions, and contacts with schools via telephone, e-mail or through visits.

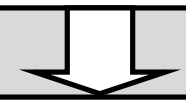

\section{Exploratory phase:}

- Cross-sectional surveys about risk and protective factors of binge drinking.

- Focus group and interviews with students and parents.

- Design of health "tailored-messages" and assessment of these by experts.

- Design of web, stories, and other activities, including questionnaires and messages.

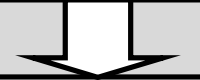

Development phase:

- Pilot study for assessing the adequacy and viability of the intervention.

- Diffusion of preliminary results.

\section{Intervention phase:}

- Recruitment of schools and students (Experimental and Control Condition)

- Implementation of the web-based tailored intervention. Pretest.

- Posttest at 4 months after intervention.

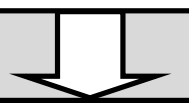

Evaluation and diffusion of results:

- Data entry, tabulation, and analysis.

- Diffusion and publication of final results.

\section{Source: Own elaboration}

2. In a second phase, the feedback from these interviews is used for the development of the computer tailored intervention Alerta Alcohol. We designed tailored health messages about the needs of adolescents, which were assessed by Delphi expert groups. To make the program more attractive, we designed stories with avatars (based on the focus group interviews). The group of experts also reviewed and consulted the content of these stories.

3. The third phase consists of piloting the Program with a sample of 100 students. The appropriateness and the feasibility were analyzed. Using scales like the Likert five-point scale, we assessed: the name of the program, joint evaluation of the web-based computer-tailored activities, extension, perceived interest, credibility, acceptability, understanding, ease of use and perceived impact. 
Feedback from the participants in the pilot study was used for the final design of the program used in the CRCT, which was carried out subsequently (Cortese \& Lustria, 2012).

\section{Program content}

The Alerta Alcohol program consists of preventive messages and information about the benefits of not consuming alcohol, reducing the positive attitudes and encouraging the negative attitudes towards alcohol drinking and binge drinking, as well as social influence and self-efficacy, as personalized feedback. Skills and action plans are encouraged to help the student to reject binge drinking. This information is presented as different tailored messages, personalized using the student's first name and gender. Moreover, taking into account the results from the focus groups, we designed the program using terminology adapted to the age and gender of the participant. Finally, we designed four avatars or characters (two males and two females) that can be chosen by the participant as part of the story development.

The Alerta Alcohol program consists of a short story in which the main character wakes up after an evening in which he/she consumed alcohol excessively and does not remember what happened. There are two different stories based on the participant gender: one for boys and one for girls (however, very similar). The stories take place in three different scenarios (at home, at celebrations and in public places). Under these scenarios, the story is presented, and questions and tailored messages are offered. We used strategies to reinforce certain behaviors. For example, we developed different messages customized with the names of the participants to provide personalization and using elements like repetition of the answer, showing respect and empathy, counter persuasion, introducing social modeling and new beliefs, and reinforcing the positive behaviors and motivational feedback (Bandura, 1986; de Vries et al., 1999).

The questions and tailored messages are related to alcohol drinking and binge drinking and based on the Ichange model and its central concepts (attitude, social influences, self-efficacy and action planning) (Figure 2.4). For all scenarios, self-efficacy is reinforced, and specific action plans are offered to the adolescent in order to reject alcohol and binge drinking in situations that incite to such behaviors. In addition, we developed questions and tailored messages aiming to increase self-esteem and awareness of factors such as the acknowledgement of risk perception of alcohol drinking and binge drinking.

To start the intervention, students are provided with access to a website. This website has a section in which they can create an account to get access to the intervention. In this account, they select their school, which determines their control or experimental status.

The intervention consists of six sessions. A baseline questionnaire followed by three different scenarios (sessions 1-3), a fourth session in which adolescents may accept the challenge of not consuming alcohol in excess in an upcoming event, a session to evaluate the challenge (session 5), and session 6 which is the evaluation of the intervention or post-test evaluation. The control condition only receives the pre-test and post-test (sessions 1 and 6), whereas the experimental condition performs all the sessions.

Session 1 or baseline. Participants begin responding a baseline questionnaire (with a series of measurement variables), including demographics, alcohol use behaviors, 
and mediator variables such us risk perception, motivational determinants (attitude, modeling, social influences, selfefficacy) and intention to decrease alcohol consumption.

Figure 2.4: Description of the intervention routings.

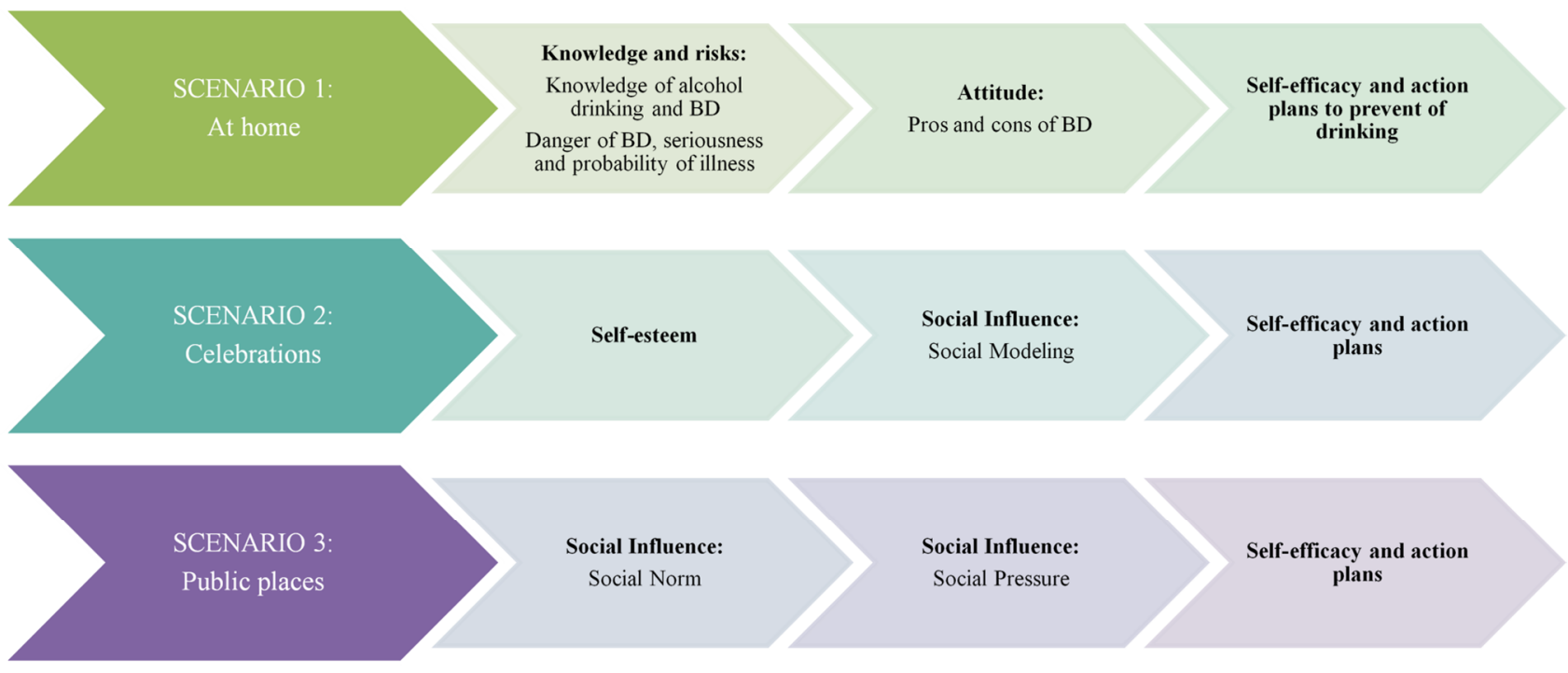

Booster Sessions: THE CHALLENGE

Source: Own elaboration

Session 2. In this session, participants are confronted with the first scenario (at home), in which the knowledge and risk of alcohol drinking and binge drinking are addressed, as well as the degree of danger and seriousness of binge-drinking, probability of a medical complication, and pros and cons of binge drinking. The feedback is focused on providing information on the general and individual consequences of alcohol drinking and binge drinking, as well as making the adolescent aware of the negative aspects of binge drinking and reinforcing the negative beliefs about it with the aim of changing to an attitude against alcohol abuse.

Session 3. In this session, participants continue with the second and third scenarios. In the second scenario (celebrations such as Christmas, wedding parties or festivals), healthy messages include how to manage self-esteem, providing information on its importance. In addition, the scenario addresses issues related to social models, helping the adolescents to choose models considered most appropriate, encouraging them to seek support from friends and family members who do not drink alcohol in excess.

The third scenario (a public place) addresses issues related to social norms regarding binge drinking, like the opinion of others. It helps adolescents to deal with the perceived approval of drinking among family and friends, and to choose true relationships that may help them to avoid alcohol drinking and binge drinking. In addition, questions and messages also address how to resist the social pressure to drink alcohol, coming from friends or family members.

In all the scenarios, a last step is included, in which self-efficacy towards handling these situations is assessed. The answers are used to develop specific suggestions on how to cope with these situations, and specific action plans are offered to adolescents to handle alcohol and binge drinking under these scenarios. Adolescents are provided with a list of 
action plans for each scenario and are invited to indicate which specific action plans they are likely to undertake.

Session 4. One week after the last scenario, an additional session is offered at home. At this point, "The Challenge" is proposed: not to consume alcohol in excess in an upcoming drinking event. Adolescents receive an email inviting them to respond to a question on their alcohol drinking during the previous week. Then, they receive feedback on their drinking behavior in comparison to baseline, in order to create awareness of their own consumption (Jander et al., 2014). Afterwards, they are questioned whether they have an event in the next 30 days where they might consume alcohol excessively. If so, adolescents are dared to accept the challenge ("I challenge you NOT to drink alcohol in this event, or at least, not to drink four or more glasses if you are a girl or five glasses or more if you are a boy"). If they accept the challenge, the date of the event is registered, as well as the type of event (at home, celebration, public place). Then, they are invited to build their own action plan with the aim of supporting their attempt not to drink. If they are not willing to make their own plan, they are provided with a list of plans that they previously suggested (in sessions 2 and 3 ) that they would likely follow for the specific scenario of the drinking event, since action plans are important for behavior changing in adolescents (de Vries et al., 2003; Jander et al., 2014). Besides, participants receive feedback from sessions 2 and 3 to booster their motivation (attitude, social norms, modeling, and pressure). Finally, one day before the drinking event takes place, an email is sent as a reminder of the acceptance of the challenge. This mail is meant to self-monitor their behavior at the drinking event.

Session 5. On the day after the drinking event, the adolescent is invited to respond to a brief questionnaire about it, and whether he achieved the goal of not consuming four/five glasses of alcohol. If the adolescent manages to achieve this goal, a congratulatory message is given to reinforce the positive behavior; if he did not manage to achieve it, he is asked about the reasons, so that he/she can receive feedback and information about external and internal reasons for that behavior and what to do about it. In this feedback, adolescents are encouraged to continue avoiding/reducing alcohol consumption by using a cue reminder (an object that helps them remember not to consume four/five glasses of alcohol) at the next social event (Kleinjan, Strick, Lemmers \& Engels, 2012; Jander et al., 2014). Finally, adolescents are asked to repeat the challenge if they wish to.

Session 6 or evaluation. Four months after the first session, all participants complete the evaluation questionnaire which includes the same measurement variables as the baseline questionnaire.

Invitations and reminders. The first session is performed in the presence of a member of the research team. When participants create the account, they have to provide their e-mail. This e-mail is used to send invitations and reminders to participate. The first invitation is sent to the participants of the experimental condition who have not completed sessions 2 or 3 . On week after completing session 3, participants receive an invitation to "The Challenge" (session 4). They receive a reminder two days before the drinking event. Then, two days after the drinking event a new message is sent to the participants who accepted the challenge in order to evaluate it (session 5). One and two weeks after session 6 , students who have not completed it receive a reminder to complete the post-test.

In addition, schools receive reminders (emails and phone calls) to complete sessions 2, 3 and 6 (which are supposed to be implemented at schools). 


\section{Measurement instruments}

We use a Spanish version of the self-administered online questionnaire that was designed for the Dutch youth population, which has been previously validated (Jander et al., 2014; Lima-Serrano et al., 2017).

\section{Social-demographic variables}

Gender (male/female), age, parents' educational level (none, primary, compulsory high school, higher secondary/vocational, university). Social status is measured by the social affluence scale (Does your family have own car or van? Do you have your own room at home? During the last twelve months, how many times have you gone on holiday with your family? How many computers does your family have?). We also ask about whether they have a tablet or a smart-phone (Currie et al., 2008).

The family functional status is evaluated with the Family Apgar Test, broadly used to evaluate the functioning of families with an adolescent child. It consists of five questions answered by a Likert three-point scale, assessing the adaptability or resource mobilization (Are you satisfied with the help you received from your family when you have problems?), participation or cooperation (Do you talk at home about the problems that you have?), development or growth (Are important family decisions discussed together at home?), resolution or capacity of spending time with a family member (Are you satisfied with the time that you spend together with your family?), and affection (Do you feel that your family loves you?) (Lima-Serrano, Martínez-Montilla, Guerra-Martín, Vargas-Martínez \& Lima-Rodríguez, 2016).

\section{Drinking behavior}

We assess two drinking patterns: weekly drinking and binge-drinking in the previous 30 days.

To assess weekly drinking behavior, adolescents indicate whether they have been drinking alcohol within the previous 7 days and if they did, how many glasses of alcohol they drunk. Based on this information we calculate the total amount of alcohol taken in the previous week (Jander et al., 2014).

To assess binge drinking (e.g. having $4 / 5$ or more glasses of alcohol in one occasion for a girl/boy), we asked adolescents how many binge-drinking occasions they had in the previous 30 days.

\section{Risk perception}

We explore the perception of danger related to binge drinking, as well as the seriousness of health problems related to binge-drinking (such as liver problems, alcoholism or traffic accidents), and the probability of acquiring these problems. We use Likert scales with five answer options (from never to almost always).

\section{Attitude towards binge drinking}

We explore four items measuring pros (e.g. "Drinking 4/ 5 or more glasses of alcohol helps to have fun with my friends"); and four items measuring cons (e.g. "I don't like myself when I drink 4/5 or more glasses of alcohol"). We use Likert scales with five answer options ( $1=$ absolutely disagree; $5=$ absolutely agree $)$. 


\section{Social influence. Model, norms and social pressure}

Social modeling is assessed by asking participants how often people in their environment (i. e. parents, siblings, (best) friend(s), girlfriend/boyfriend) drink alcohol and engage in binge drinking $(1=$ never; $4=$ very often). Social norm is measured for each person in their direct environment (i. e. parents, siblings, (best) friend(s), girlfriend/ boyfriend) by one item "My (e.g. mother) thinks that" $\ldots 1=$ "I am certainly not allowed to drink $4 / 5$ glasses or more of alcohol" to $5=$ "I am certainly allowed to drink 4/5 glasses or more of alcohol". Social pressure is assessed by "Have you ever felt pressure from (i. e. parents, siblings, (best) friend(s), girlfriend/boyfriend) to drink 4/5 or more glasses of alcohol?" We use a five-point scale ( $1=$ never; 5 = always $)$.

\section{Self-efficacy}

Self-efficacy is measured by ten items. Each item assesses whether participants feel able not to drink in a certain difficult situation (situations that would usually trigger binge drinking, e.g. "How difficult or easy is it for you not to drink more than 3 (if you are female) or 4 (if you are male) glasses of alcohol if others around you drink $4 / 5$ glasses or more of alcohol?"). We use a fivepoint scale ( 1 = very difficult; $5=$ very easy).

\section{Intention}

We used two questions about the intention of alcohol use and binge drinking with a five-point scale ( 1 = absolutely will not; $5=$ absolutely will), "Are you intending to generally reduce your drinking in one occasion (e.g. in a bar, at a party etc.)" and "Are you intending to drink less than $4 / 5$ glasses of alcohol in one occasion (e.g. in a bar, at a party etc.)".

\section{Process evaluation}

To assess the implementation compliance, the number or sessions performed by the participants are registered. After completing each session and in the posttest, we ask respondents whether the intervention was useful, realistic, interesting, and personally relevant on a fivepoint Likert scale (e.g., $1=$ Totally disagree; $5=$ Totally agree). In the final evaluation, we also assessed the general satisfaction (e.g., $1=$ Very unsatisfied; $5=$ Very satisfied) and, by using a five-point Likert scale, the opportunity of learning, and the probability of using the counselling (e.g., $1=$ Totally disagree; $5=$ Totally agree) (Bannink et al., 2014).

\section{Procedures and ethics approval}

The implementation of the intervention is carried out in a school context and the students are who fill out the questionnaires. The first session in the different centers is guided by a member of the project, who also provides access to the website and register on the Alerta Alcohol platform. Then, sessions 2 and 3 are conducted by the teacher at school, and sessions 4 and 5 are selfadministered by adolescents at home. The final evaluation or session 6 is again conducted by the teacher at school. Before initiating the participation in the study, parental and individual informed consent must be obtained.

The interventions are carried out according to bioethical guidelines: the students need to answer the questionnaires themselves and confidentiality is guaranteed. Informed consent and an online form to collect data are used. The study has the approval of the Bioethical Committee of Andalusia. The registration number for clinical trial is: PI0031-2014. Registration date: 04 August 2015. 


\section{Data analyses}

Descriptive analyses are performed to describe the characteristics of the participants. Subsequently, multivariate analyses by multiple linear regression are conducted to analyze the effect of the program on the weekly consumption of alcohol, and the intention of reducing alcohol drinking. A binary logistic regression aiming to assess the effect on binge drinking within the last 30 days is performed. The independent variable was participating vs. not participating in the program, and co-variables were the outcome at baseline, socio-demographic variables and explored risk factors, which showed significance after a previous bivariate analysis. Analyses are conducted to explore the differential effects of the sociodemographic characteristics like age, gender or social status. Cases of linearity, homoscedasticity, normality of the quantitative variables, independence of errors, and non-co-linearity are taken into account. Also, analyses are carried out to determine the differential effect, according to the program compliance (i.e., number of performed sessions by participant), on the program outcomes. This may eventually provide information about the influence of the quality of the implementation on the program outcomes and of a possible implementation threshold effect.

The analysis of the data is supported by the $\mathrm{R}$ statistical program. A level of significance of $P<.05$ is used, and the size of the effect is calculated (r coefficient and Odds Ratio), with $95 \%$ confidence intervals.

\section{Discussion}

Alcohol drinking in adolescents is a socio-health problem of crucial importance, because of its high prevalence and the physical and mental health risks affecting the adolescent consumers, in addition to the psychosocial and community implications derived from alcohol abuse (Calafat, 2007; Farke et al., 2007; de la Villa et al., 2010; Parada et al., 2011; Espada et al., 2012). This paper describes the design, implementation, and evaluation of the first CT tailored intervention aimed to prevent alcohol drinking and specifically binge drinking in Spanish adolescents aged 16 to 18.

An important issue regarding program implementation at schools is compliance according to the original scheme, since implementing school programs often requires cooperation from teachers, who may find it difficult to provide the intervention as it was originally conceived. Thus, delivering an online intervention, i.e. a web-based computertailored intervention, may improve the program implementation, specifically regarding its compliance, integrity, and replicability, so that objectives can be achieved (Durlak \& DuPre, 2008).

The high drop out rate is an important problem in a web-based computer-tailored intervention (de Vries et al., 2012; Elfeddali et al., 2012; Jander et al., 2014; Jander et al., 2016). Jander et al. (2016) obtained a very low adherence to the complete program ( $\mathrm{N}$ total $=824 ; 31.1 \%$ ), so that optimal achievements could not be obtained at the finalization of the intervention. According to that study, they could not confirm a global effect of the intervention over binge drinking behavior in Dutch adolescents. Nonetheless, the intervention was effective in reducing binge drinking in adolescents between 15 and 16 years that completed at least two sessions. Additionally, they showed that a longer use of this intervention was associated with stronger effects for binge drinking.

In order to minimize the drop out rate, we followed different strategies to improve the characteristics of the program. First, we designed the intervention considering the feedbacks from focus groups with adolescents and parents. Second, we developed a 
dynamic intervention, with different interactions and stories adapted to gender and age (Krebs et al., 2010). Third, a Delphi expert group gathered to assess the program questionnaire and the tailored messages. Fourth, we carried out most of the interventions at schools as part of the health promotion curriculum. Fifth, reminders on participation were also sent via emails when participants had not finished the intervention procedures, so they could complete them out of school. Finally, concise, direct and personalized relevant messages were sent to promote the adhesion to the intervention (Pearson et al., 2015; Jander et al., 2014; Jander et al., 2016).

In the adaptation of the intervention, we think that some changes were needed for the Alerta Alcohol program. There are different cultural issues related to alcohol drinking among different countries. For instance, drinking behavior can be associated with certain cultural or seasonal events, such us "Spring Break" in the United States or certain folk festivals like the Oktoberfest in Germany. In Spain, there is an alcohol drinking phenomenon called "Botellón", which is the most prevalent event for alcohol drinking in adolescent population and consists in drinking alcohol in public places (Donath et al., 2011). In Spain, around 70\% of adolescents between 16 and 18 years old have participated in "Botellón" in the last 12 months (ESTUDES, 2016). This may be partially attributed to the prohibition of selling alcohol in bars and pubs to individuals younger than 18 years of age. Therefore, we decided to replace the bar scenario by public places.

Furthermore, since previous studies have found that a large proportion of adolescents may be in a premotivational phase, we believe it is reasonable to focus on prior aspects, relatively easier to modify, like factors of awareness (knowledge, action clues and risk perception) (Jander, 2016). In this regard, along with the motivational factors (attitude, social influences, self-efficacy and action plans), which are necessary to initiate and maintain a healthy behavior (de Vries et al., 2005a; Richter et al., 2006; Donath et al., 2011; Cremers et al., 2012), in our intervention we emphasize awareness factors, like knowledge about alcohol drinking or binge-drinking and risk perception. According to Prochaska, Redding \& Evers (2008) becoming aware is the first step to promote a change in health behavior.

In addition, we believe that it is necessary to provide with messages aiming to improve self-esteem, since low self-esteem is considered a determinant for risky behaviors in adolescents, such as alcohol drinking or binge-drinking. This is particularly relevant in the adolescence period, because self-esteem is a critical factor affecting the psychological and social fitting (Rodríguez \& Caño, 2012; Richardson, Kwon \& Ratner, 2013).

In summary, this study tests the effectiveness of an intervention focused on reducing alcohol drinking and specifically binge drinking in Spanish adolescents between 16 and 18 years of age. If the program proves to be effective, the ultimate goal would be regional and eventual national implementation. 


\section{Chapter 3}

\section{Why are Spanish adolescents binge drinkers? Focus group with adolescents and parents.}

Based on:

Martínez-Montilla, J.M., Mercken, L., Lima-Serrano, M., de Vries, H., Lima-Rodríguez, J.S. (2020). Why are Spanish adolescents binge drinkers? Focus group with adolescents and parents.

International Journal Environmental Research and Public Health. 17(10), 3551; https://doi.org/10.3390/ijerph17103551. 


\begin{abstract}
Binge drinking in adolescents is a worldwide public healthcare problem. The aim of this study was to explore the perceptions about determinants of binge drinking in Spanish adolescents from the perspective of adolescents and parents. A qualitative study using fourteen semi-structured focus groups of adolescents was conducted during the $2014 / 2015$ school year $(n=94)$, and four with parents $(n=19)$, based on the I-Change Model for health behaviour acquisition. Students had a low level of knowledge and risk perception and limited self-efficacy. Girls reported more parental control, and when they get drunk, society perceives them worse. Adolescents suggested focus preventive actions to improve self-efficacy and self-esteem. Parents were permissive about alcohol drinking but rejected binge drinking. They offered alcohol to their children, mainly during celebrations. A permissive family environment, lack of control by parents, adolescents' low-risk perception, low self-esteem and self-efficacy, as well as the increase of binge drinking in girls as part of the reduction of the gender gap, emerge as risk factors for binge drinking. Future health programmes aimed at reducing binge drinking should focus on enhancing motivational factors, self-esteem, and self-efficacy in adolescents; supervision and parental control; as well as pre-motivational factors by increasing knowledge and risk awareness, considering gender differences.
\end{abstract}

Keywords: adolescents; parents; binge drinking; risk factors; I-Change Model; focus group interviews; nursing 


\section{Introduction}

Binge drinking (BD) is the most common risky drinking behaviour among adolescents, which has raised concern in many European countries (Katainen et al., 2015; Golpe et al., 2017; NIAAA, 2020). BD consists of alcohol consumption that results in a blood alcohol concentration (BAC) of $0.08 \mathrm{~g} / \mathrm{dL}$ or more within a period of $2 \mathrm{~h}$ (Golpe et al., 2017; NIAAA, 2020). In men, blood alcohol concentrations of more than $0.08 \mathrm{~g} / \mathrm{dL}$ typically occur after consuming five or more standard drink units (SDUs), or standard glasses of alcohol, in about $2 \mathrm{~h}$; in women, this occurs after consuming four or more SDUs in about $2 \mathrm{~h}$ (Donovan, 2009; Chung et al., 2018; NIAAA, 2020). There is a lack of consensus as to what is considered an SDU, which could be the result of the cross-country variability of criteria regarding the amount of alcohol consumption per episode (Parada et al., 2011; Katainen et al., 2015; Mongan et al., 2015; Golpe et al., 2017), as well as a lack of consensus on the estimated average BAC in the adolescent population (Donovan, 2009). In this study, BD is considered the consumption of five or more and four or more SDUs of alcohol by men and women, respectively, in a short space of time, or on a single occasion (Gmel et al., 2003; Golpe et al., 2017; Chung et al., 2018; ESTUDES, 2018; NIAAA, 2020), this definition being consistent with Spanish epidemiological data from the survey Encuesta Sobre Uso de Drogas en Estudiantes de Enseñanzas Secundarias (ESTUDES) (ESTUDES, 2018). BD has serious consequences such as brain damage, suicide, sexually transmitted diseases, violence or road traffic accidents (Hingson \& Zha, 2018).

In Europe, according to the 2015 European School Survey Project on Alcohol and Other Drugs (ESPAD), 35\% of 15 to 16-year-old adolescents reported BD (ESPAD, 2016), while in Spain, the percentage stood slightly lower, at $32.2 \%$ of students between 14 and 18 years of age (ESTUDES, 2018). However, previous research has suggested a convergent trend in youth drinking cultures, since BD has increased in southern Europe and decreased in the north (Rolando \& Katainen, 2014a; Pape, Rossow \& Brunborg, 2018). Despite these global trends of current adolescent cultures, the ways in which young people are socialised regarding drinking customs are still very different among the countries of Europe (Katainen et al., 2015). A study carried out by Rolando and Katainen (Rolando et al., 2014a), where they compare Italian and Finnish adolescents, established that both have very different expectations about the consequences of drinking, as well as the kinds of drinks, quantities or with whom they drink alcohol. In Spain, BD is associated with the "Botellon", consisting of drinking alcohol excessively in public places with friends during weekend nights (Romo-Avilés et al., 2016ab), using it as a synonym for intoxication-oriented drinking (Guise et al., 2007).

In order to prevent $\mathrm{BD}$ in adolescents, it is important to know the factors associated with this behaviour. Based on the I-Change Model (de Vries, 2017), a behaviour is the result of a person's intentions, action plans and abilities. It also highlights the influence of motivational factors (attitude, social influence and self-efficacy) as determinants of behaviour acquisition. The person's attitude consists of the perceived advantages and disadvantages of the behaviour. Social influences consist of the perception of others carrying out this type of behaviour (social modelling), the norms that people have with respect to these behaviours (social norms) and the perceived pressure from the environment (social pressure). Self-efficacy refers to a person's perception of their capability to carry out the type of behaviour (de Vries et al., 2003; Lima-Serrano et al., 2018). Motivational factors are determined by various awareness factors (knowledge, 
risk perceptions and cues to action), predisposing factors (behavioural, psychological, biological, social and cultural factors) and information factors (de Vries, 2017).

Most of the evidence regarding the determinants of BD emerged from different methodological approaches, due to the lack of qualitative studies that delved deeper into this topic. Some qualitative studies have explored the social meanings and functions of alcohol use among young people, while also considering cultural differences (Østergaard, 2009; Rolando et al., 2014a; Rolando, Beccaria, Petrilli \& Prina, 2014b; Romo-Avilés et al., 2016a). Despite this, only two qualitative studies, one about pregnant women and their alcohol consumption in pregnancy (Van der Wulp, Hoving \& de Vries, 2013), and the study conducted by Jander et al. (2013) in the Netherlands, with the same target group, used an approach based on a behavioural change from the I-Change Model. For instance, previous studies, with different methodological approaches, show that BD is determined by an individual's intention to engage in BD (Jander et al., 2013; Boers et al., 2018), their attitude and self-efficacy (Boers et al., 2018; Johnson et al., 2018), as well as by social influences of people around them (Van der Wulp et al., 2013), such as best-friend norms and friend norms (Lac et al., 2016), social pressure (Donath et al., 2011; Jander et al., 2013) and friend (Mercken et al., 2012; Romo-Avilés et al., 2016b) and parent modelling (Jander et al., 2013; Pedersen et al., 2013; Rolando et al., 2014a). Finally, BD can also be influenced by socio-demographic factors such as age (Elisaus et al., 2018), gender (Henkel et al., 2016; Romo-Avilés et al., 2016a) and socio-economic status (SES) (Espada et al., 2008; Elisaus et al., 2018), among others. Likewise, the Spanish context, with its own characteristics, such as the "Botellón", can lead to differences with respect to other countries (Rolando et al., 2014a).

Furthermore, previous research demonstrated the importance of parental influence on BD in adolescents. Currently, attitudes toward traditional alcohol-raising practices appear to be ambiguous and they are being called into question (Rolando et al., 2014b). On the one hand, some qualitative research established that letting children drink at home with them can be protective against BD (Østergaard, 2009; Rolando et al., 2014b). In this sense, a focus group study with parents conducted in Italy stated that allowing children to taste alcohol for the first time at home and under the parents' supervision can be an effective way to establish a clear dialogue between parents and children, with the aim of improving shared rules and parental control (Rolando et al., 2014b). Similarly, another qualitative study conducted with Danish parents established that instead of trying to ban adolescents drinking, they try to minimise the risk by helping them learn to "master intoxication" by controlling the amount and type of alcohol that they consume (Østergaard, 2009). Instead, other studies established that high parental alcohol consumption levels (Espada et al., 2008; Jander et al., 2013; Pedersen et al., 2013), low parental supervision, non-rejection of BD and unstructured households (Patrick et al., 2013; Golpe et al., 2017), as well as less strict alcohol-related rules (Clark et al., 2012; Mejia et al., 2016), were directly related to the alcohol consumption and BD of adolescents. In Spain, parental permissiveness regarding their children's alcohol consumption is high: $48.3 \%$ of adolescents are allowed to drink alcohol by their parents (ESTUDES, 2018). As we found contradictory findings in the different studies, we highlight the importance of continuing with the research on parental views of alcohol consumption and $\mathrm{BD}$ in their children, which could guide the development of effective health programmes to address BD (Lima-Serrano et al., 2018).

Regarding gender, Spanish girls increasingly report BD as a standard feature of their social life, and at younger ages with respect to boys (Romo-Avilés et al., 2016a; 
ESTUDES, 2018), showing a diminishing gender gap in the prevalence of drinking, with equal levels between boys and girls (Keyes et al., 2011; Romo-Avilés et al., 2016a; Jang et al., 2017; ESTUDES, 2018). A previous study showed that sensation-seeking was a noticeably stronger predictor in males, although it did not find significant differences by gender regarding coping motives (Lac et al., 2016). Another study found that boys with high socio-economic status are significantly more likely to have BD experience, whereas girls' BD was not found to be associated with socio-economic status (Henkel et al., 2016). Although the way of drinking between boys and girls may be different, there has been little research on the differences between girls and boys regarding the different determinants that influence both genders to engage in BD, suggesting the need for genderspecific analyses of factors associated with $\mathrm{BD}$.

The objective of this paper is to explore the perceptions about determinants of BD in Spanish adolescents from the perspective of adolescents and parents, considering gender differences and whether they are engaging in BD.

\section{Method}

\section{Design}

A qualitative study based on Focus Groups (FG) was carried out, which took place during the 2014/2015 school year in Andalusia (South of Spain), following the COREQ guide (Tong, Sainsbury \& Craig, 2007).

\section{Sample/Participants}

Fourteen FGs with students between 16-18 years of age $(n=94)$ enrolled in the 4th year of Compulsory Secondary Education (CSE) and the 1st year of Baccalaureate (equivalent to 10th and 11th grades in the USA) were created. In addition, four FGs with parents $(n=19)$ of students of the same age groups were composed.

A purposive sample was used. After contacting the head of the schools, adolescents were recruited by teachers and were told beforehand about the purpose of the study. FGs were organised based on academic year, gender and drinking behaviour. We conducted eight FG interviews with students from the 4th year of CSE, and six with students from the 1st year of Baccalaureate. Regarding gender, four FGs consisted of males, three consisted of females and seven were mixed. In three FGs, students met the criteria for BD (in the previous 30 days); in three other FGs, the students had not participated in $\mathrm{BD}$; and eight were mixed.

In addition, the parents were recruited through the parents' association. Parent FGs were composed of mothers, except for one including one father. Therefore, in general, we talk about groups of mothers. The four groups of mothers belong to four different secondary schools (Table 3.1). 
Table 3.1: Characteristics of adolescent participants in the focus group interviews.

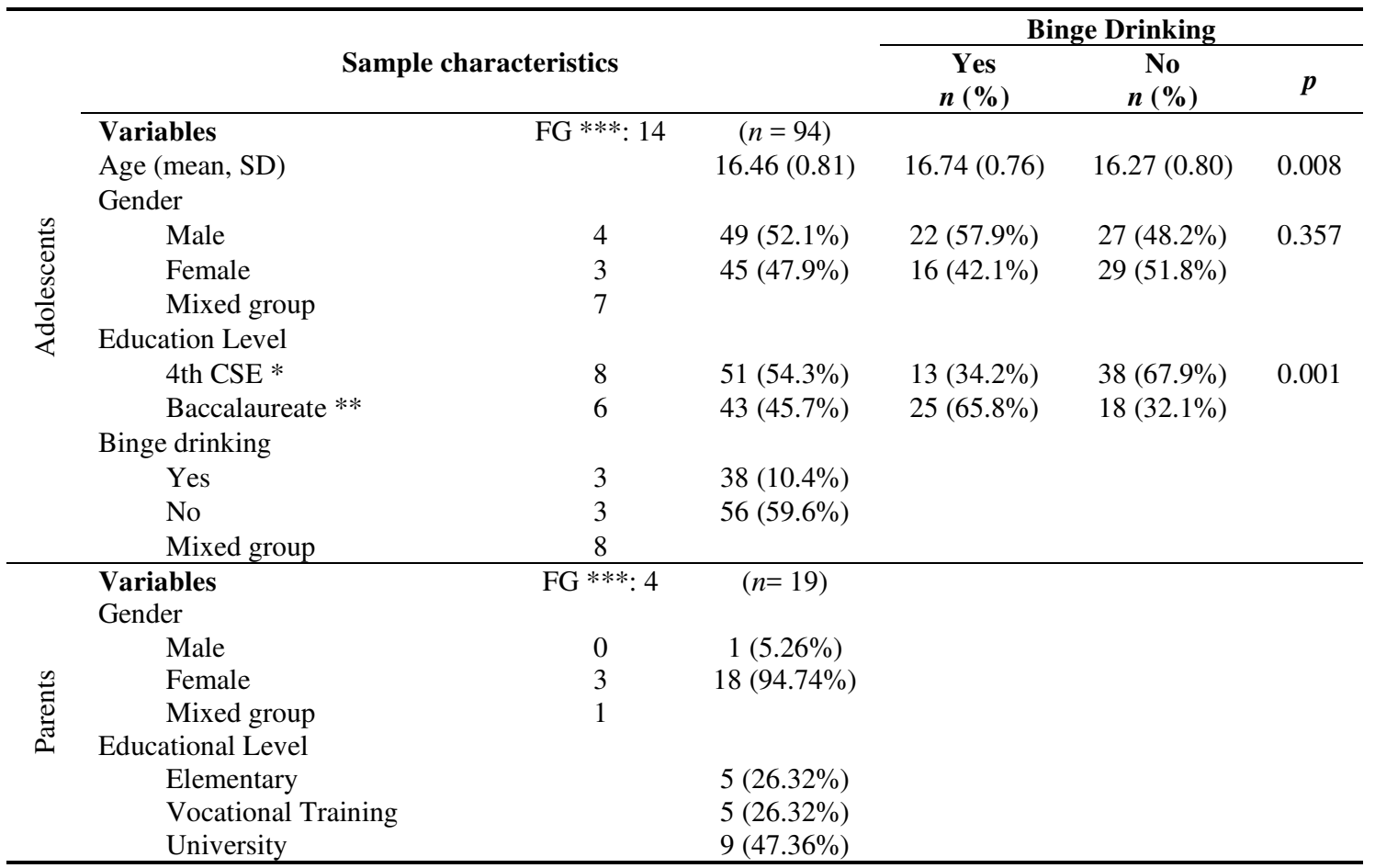

* 4th CSE = acronym Compulsory Secondary Education (equivalent to 10th grade in the United States of America). ** 1st Baccalaureate: (equivalent to 11th grade in the United States of America). *** FG: number of focus group. SD, standard deviation.

\section{Recruitment Process}

The researcher was introduced and explained the objective of the FG. Teachers were present only during the selection of the children. First, the adolescents filled out a short questionnaire to assess demographic variables. Afterwards, we asked them if they had participated in BD in the past 30 days ("How often did you have 4/5 or more glasses of alcohol on a single occasion in the previous 30 days? Answer with a number"). Depending on the response, groups were assigned.

Regarding the parent group, only the researchers were present during the interviews. Initially, parents filled out a demographic questionnaire. The average duration of both adolescent and parent groups was $1 \mathrm{~h}$.

Two researchers were present in all FGs. One guided the discussion until all questions were exhaustively answered. The second took notes and checked whether all question topics were covered. Both had previous experience in the subject matter and performed the subsequent analysis.

\section{Data Collection}

A semi-structured script, based on the I-Change Model (Jander et al., 2013), was provided. The script asked open-ended questions that allowed participants to get involved and discuss the information received and ensured the natural flow of the discussion. In addition, it allowed us to centre the discussion on what we really wanted to know. Tables 3.2 and 3.3 show the themes, subcategories, frequency of words and concepts and sample questions for adolescent and parent FGs. Saturation criteria were considered, in order to conclude data collection. 
Table 3.2: Themes, subcategories, frequency of words and concepts, and sample questions for the adolescent FG interview.

\begin{tabular}{|c|c|c|c|}
\hline Theme & Sample Questions & Subcategories & Frequency of Words and Concepts $(n)$ \\
\hline \multirow{5}{*}{$\begin{array}{l}\text { Binge drinking } \\
\text { patterns/ first } \\
\text { binge drinking } \\
\text { experience }\end{array}$} & \multirow{5}{*}{$\begin{array}{l}\text { Do you drink alcohol? How many glasses? } \\
\text { In which situations do you drink/binge drink? } \\
\text { With whom do you usually drink/binge drink? } \\
\text { When was the first time you drank/binge drank and } \\
\text { why? } \\
\text { What consequences did you experience? }\end{array}$} & $\begin{array}{l}\text { - First drinking/binge drinking } \\
\text { episode. }\end{array}$ & $\begin{array}{l}\text { Testing/experimentation (8); get drunk (10); Psychosomatic alterations } \\
\text { (18); disinhibition (5). }\end{array}$ \\
\hline & & - Age of onset. & $14-15$ years old $(20)$. \\
\hline & & $\begin{array}{l}\text { - Occasions, places and days when } \\
\text { drinking/binge drinking. }\end{array}$ & $\begin{array}{l}\text { Weekend nights (12); "botellón" (12); celebration (40); birthdays (11); } \\
\text { fairs (17). }\end{array}$ \\
\hline & & - Type of drinks, quantity. & $\begin{array}{l}\text { 4-5 glasses (15); bottles (15); rum (9); vodka (12); whisky (11); beer } \\
\text { (13); spirits (30); wine with soda (8). }\end{array}$ \\
\hline & & $\begin{array}{l}\text { - People with whom you usually } \\
\text { drink. }\end{array}$ & Friends (13); Siblings (6); Parents (3); Consumer environment (4). \\
\hline $\begin{array}{l}\text { Predisposing } \\
\text { factors }\end{array}$ & $\begin{array}{l}\text { Do you think that the drinking/binge drinking } \\
\text { behaviour in boys and girls is similar or different? }\end{array}$ & - Gender: stigmatisation of girl. & $\begin{array}{l}\text { Parental control (4); socially stigmatised (9); more vulnerable (4); } \\
\text { sexual assault (5); aggressive boys (5); boys' tolerance (3). }\end{array}$ \\
\hline Awareness & $\begin{array}{l}\text { What do you know about binge drinking? } \\
\text { What kind of dangers do you perceive of binge } \\
\text { drinking? }\end{array}$ & $\begin{array}{l}\text { - Knowledge about binge drinking. } \\
\text { - Risk perception. }\end{array}$ & $\begin{array}{l}\text { It is bad (23); long-term consequences (7); short-term consequences } \\
\text { (27); disinhibition (6); damaging the liver (3); BD depends on several } \\
\text { factors (18); BD is normal consumption (17); reduce shame (3); } \\
\text { tolerance (9); memory loss (8). }\end{array}$ \\
\hline \multirow{5}{*}{$\begin{array}{l}\text { Motivational } \\
\text { factors: } \\
\text { - Attitude } \\
\text { - Social influence } \\
\text { - Self-efficacy }\end{array}$} & \multirow{5}{*}{$\begin{array}{l}\text { What are the advantages or disadvantages of binge } \\
\text { drinking? } \\
\text { Which people around you usually drink/binge drink } \\
\text { (friends, boyfriend/girlfriend, siblings, family, etc.)? } \\
\text { Which people approve/disapprove of you } \\
\text { drinking/binge drinking? } \\
\text { Have you ever felt pressured to drink/binge drink? } \\
\text { In what situations do you think it is difficult to say NO } \\
\text { to binge drinking (at a party, at a bar, at a friend's } \\
\text { house, in a public place, etc.)? How difficult is saying } \\
\text { NO in such situations? }\end{array}$} & - Attitudes: Pros. & $\begin{array}{l}\text { Reduce shame (28); disinhibition (9); flirt (6); having fun/laughing } \\
\text { (28); socialise (6). }\end{array}$ \\
\hline & & - Attitudes: Cons. & $\begin{array}{l}\text { Disinhibition (7); lose consciousness (7); damaging the liver (8); } \\
\text { hangovers (5); memory loss (10); vomiting/headache (5); addiction (2); } \\
\text { ethylic coma (7); traffic accident (3); affects social life (5). }\end{array}$ \\
\hline & & - Social modelling. & $\begin{array}{l}\text { Drank alcohol: friends (30); parents (15); siblings (5); uncles (5); } \\
\text { cousins (4); beer (17). }\end{array}$ \\
\hline & & - Social norms. & $\begin{array}{l}\text { Disapprove: parents (15); grandparents (13); best friend (9). Approve: } \\
\text { friends (15); cousins (4); siblings (10); permissiveness in society (2). }\end{array}$ \\
\hline & & - Social pressure. & $\begin{array}{l}\text { Pressure of friends (12); Group size pressure (12); no pressure (20); } \\
\text { "botellón" (5). }\end{array}$ \\
\hline
\end{tabular}


- Self-efficacy.

- Parental influence in alcohol drinking/binge drinking: Do your parents know where and with whom you are when you go out? drink?

Family factors

Are you allowed to drink alcohol at home?

Do your parents drink alcohol at home? Have your

parents ever offered alcohol to you? In which

situation?

Have you ever talked with your parents about drinking or how much you can drink?

- Parental influence in alcohol drinking/binge drinking: Behaviour and rules.

- Parental influence in alcohol drinking/binge drinking:
What do your parents think about you drinking/binge

Ability to say no (16); difficulty saying no (9); never considered (3);

"botellón" (25); celebration (25); group (7); at home (3).

Supervision and control. Communication.

\begin{tabular}{|c|c|c|c|}
\hline Ability & $\begin{array}{l}\text { What do you do when you do not want to binge drink? } \\
\text { How do you handle the situation? } \\
\text { Which alternatives are there to prevent binge drinking? }\end{array}$ & $\begin{array}{l}\text { - Action plans. } \\
\text { - Abilities. } \\
\text { - Alternatives. } \\
\text { - Low self-esteem. }\end{array}$ & $\begin{array}{l}\text { Resistance capacity (14); low resistance (3); leisure activities (14); } \\
\text { self-esteem (6); self-confidence (3); social support (3); self-security } \\
\text { (2); sport (17). }\end{array}$ \\
\hline Intention & $\begin{array}{l}\text { Do you have any plans for this weekend (party, } \\
\text { birthday, "botellón", etc.)? If so, are you going to } \\
\text { drink/binge drink? } \\
\text { Are you planning to quit or reduce drinking/binge } \\
\text { drinking? }\end{array}$ & $\begin{array}{l}\text { - Precontemplation. } \\
\text { - Contemplation. } \\
\text { - Preparation. }\end{array}$ & Drink in the future (17); not drink in the future (15). \\
\hline
\end{tabular}

Reprimands (7); supervision (6); permissiveness (18); control (7); strict (7); punishments (3).

Beer (8); wine (9); parental consumption (15); BD is not approved (4);

permissiveness (19); alcohol offered by the family (35).

Alcohol (12); tobacco (3); other drugs (8); consequences (5). 
Table 3.3: Themes, subcategories, frequency of words and concepts, and sample questions for the parent FG interview.

\begin{tabular}{|c|c|c|c|}
\hline Theme & Sample Questions & Subcategories & Frequency of Words and Concepts $(n)$ \\
\hline \multirow[t]{2}{*}{ Awareness } & \multirow{2}{*}{$\begin{array}{l}\text { What do you know about drinking/binge drinking and its short- and } \\
\text { long-term consequences? } \\
\text { What dangers do you perceive of binge drinking in adolescents? }\end{array}$} & $\begin{array}{l}\text { - Knowledge about alcohol } \\
\text { drinking and binge drinking. }\end{array}$ & $\begin{array}{l}\text { It is bad (8); disinhibition (5); addiction (2); } \\
\text { permissiveness in society (8); short-term consequences } \\
\text { (4). }\end{array}$ \\
\hline & & - Risk perception. & $\begin{array}{l}\text { Low risk perception of adolescents (3); economic interests } \\
\text { (3); group of friends (7); think their children do not drink } \\
\text { (17). }\end{array}$ \\
\hline \multirow{4}{*}{ Motivation } & \multirow[b]{2}{*}{$\begin{array}{l}\text { What is your opinion about drinking/binge drinking in adolescents? } \\
\text { Which are the advantages or disadvantages? }\end{array}$} & - Attitudes: Pros. & Socialise (4). \\
\hline & & - Attitudes: Cons. & $\begin{array}{l}\text { Disinhibition (3); addiction (2); chronic problems (2); } \\
\text { ethylic coma (7). }\end{array}$ \\
\hline & $\begin{array}{l}\text { What are the rules at home with respect to your children's arrivals and } \\
\text { departures (arrival time, with whom they go out, what they are doing)? } \\
\text { What rules do you have at home about drinking? Are your children } \\
\text { allowed to drink at home? } \\
\text { What do you do when your child drinks/binge drinks? Are there any } \\
\text { consequences for him/her? }\end{array}$ & $\begin{array}{l}\text { - Rules and norms. } \\
\text { - Parental supervision and } \\
\text { control. } \\
\text { - Consequences of alcohol } \\
\text { consumption of their children. } \\
\text { - Parental behaviour. }\end{array}$ & $\begin{array}{l}\text { Permissiveness (33); offers alcohol (3); no clear rules (5); } \\
\text { supervision (6); control (4); strict (6); parental control of } \\
\text { girls (3); no prohibition (6); punishments (3); few } \\
\text { reprimands (9). }\end{array}$ \\
\hline & $\begin{array}{l}\text { In what way do you think that parent' alcohol consumption influences } \\
\text { on kids? }\end{array}$ & $\begin{array}{l}\text { - Beliefs about parental } \\
\text { influence. }\end{array}$ & $\begin{array}{l}\text { Permissiveness (3); normalised (10); does not allow } \\
\text { consumption (3); permissiveness in society (23); drink at } \\
\text { home (7); beer (6); wine (8); family responsibility (10); } \\
\text { does not influence (5). }\end{array}$ \\
\hline Action planning & $\begin{array}{l}\text { Which actions could help to prevent drinking/binge drinking in } \\
\text { adolescents? What are the alternatives to drinking/binge drinking? } \\
\text { How could the prevention of drinking/binge drinking in adolescents be } \\
\text { improved? }\end{array}$ & $\begin{array}{l}\text { - Action plans. } \\
\text { - Alternatives to consumption. } \\
\text { Beliefs about prevention of } \\
\text { drinking/binge drinking. }\end{array}$ & $\begin{array}{l}\text { No alternatives (8); training to say no (7); prevention (10); } \\
\text { prohibit the sale of alcohol to minors (3); leisure activities } \\
\text { (4); house party as an alternative (4). }\end{array}$ \\
\hline Communication & $\begin{array}{l}\text { Have you ever talked with your children about drinking/binge drinking } \\
\text { and its consequences? }\end{array}$ & $\begin{array}{l}\text { - Communication between } \\
\text { parents and children. }\end{array}$ & $\begin{array}{l}\text { Communication (9); trust (6); no communication (5); tell } \\
\text { the truth (9). }\end{array}$ \\
\hline
\end{tabular}




\section{Data Analysis}

Recordings were transcribed literally for content analysis using QSR NVivo 10 software (Melbourne, Victoria, Australia). First, all material was revised in its original form. These transcriptions were completed by comparing the interviewer and observer's field notes. For the analysis and interpretation, the responses and conversations of each adolescent were summarised and categorised in different sections, according to the analysis categories of the I-Change Model. More than one conversation or verbatim can appear in different categories of the model, since these are not airtight compartments. In addition, adolescents' comments were categorised according to gender, and according to whether they had participated in BD in the previous 30 days. Verbatim were classified in each of the following groups: General Verbatim (VG); Verbatim Gender Male (VGM); Verbatim Gender Female (VGF); Verbatim Binge drinking Yes (VBDY); Verbatim Binge drinking No (VBDN); and Verbatim Parents (VP).

Descriptive analyses of all participants were performed. Regarding adolescents, we researched the differences between BD and non-BD through the chi-square test for categorical variables (gender and educational level) and the Mann-Whitney test for continuous variables (age), as well as a Pearson $\mathrm{R}$ for the number of BD occasions and age. For the sample of the parents, only a descriptive analysis was carried out.

\section{Validity and Reliability/Rigour}

The semi-structured script was previously used by Dutch adolescents, ensuring validity (Jander et al., 2013). Information analysis was carried out by two members of the research team, who coded the information according to themes, in order to check the analysis process and give it a greater degree of reliability (Tong et al., 2007).

\section{Ethical Considerations}

The ethical considerations of the Declaration of Helsinki adopted at the 18th Assembly of the World Medical Association in Helsinki (Finland) in June 1964 were respected.

In addition, the participants were informed that the FG would be recorded on tape, only be accessible to the research team and that the processing of the answers would be confidential. Informed consent was obtained actively from parents and adolescents. The study was approved by the Bioethics Committee of Andalusia, contract PI-0031-2014.

\section{Results}

\section{Adolescents' Focus Group Interviews}

\section{Questionnaire: Characteristics of Adolescents}

Forty-nine (52.1\%) participants were male, the average age was 16.46 (standard deviation $(\mathrm{SD})=0.81) ; 51(54.3 \%)$ participants were in the fourth year of CSE and 43 $(45.7 \%)$ in the first year of Baccalaureate. In addition, $38(40.4 \%)$ adolescents had engaged in BD in the last 30 days, being $22(57.9 \%)$ males and $16(42.1 \%)$ females. The average number of $\mathrm{BD}$ episodes in the last 30 days was 1.22 times $(\mathrm{SD}=2.75)$. Age $(P=$ $.008)$ and educational level $(P=.001)$ were significantly associated with $\mathrm{BD}$, with older adolescents associated with engaging more in $\mathrm{BD}$. In addition, educational level was also associated with the number of BD episodes $(P=.008)$. 


\section{Binge-Drinking Patterns}

The common BD age of onset was 14-15 years old, without gender differences. They related this moment to "testing", alcohol-drinking experimentation in an environment where others were also drinking (VG):

"(alcohol drinking) My first time was at 14..", "There were a lot of friends there in the group and they started to drink, and they seemed quite happy and I wanted to feel like them...then, they said 'come on, nothing happens...drink a little', and then you start to do silly things and end up drinking".

Binge drinkers stated that they usually participate in BD with friends on weekend nights at parties, at "Botellón" events, celebrations and birthdays (VBDY): "I do not usually drink if it's not a party...just parties...", "at the fair, at parties, birthdays...", and they used to drink more than 4/5 standard glasses of spirits, i.e., rum, whisky, etc. (VBDY):

"In the past, when you drank 4 glasses you were (drunk)...and now you drink 4, 5 or 6 and you're still not drunk", "Maybe I've drunk 4 or $5 \ldots$ or half of a bottle", "Rum, for example, I drink Barceló® (a brand)", "Whiskey", "I, Beefeater ${ }^{\circledR}(a$ brand of Gin)".

However, non-binge drinkers reported to have consumed alcohol, but they did not usually drink more than one glass. There is a very similar pattern of BD between girls and boys. Although, boys reported that during the week they usually drink beers, whereas girls usually drink red wine with soda.

\section{Predisposing Factors}

For many binge drinkers, the main way to have fun was to go out to drink with friends, instead of other healthy leisure activities. Furthermore, they said that different psychological aspects, such as shyness, low self-esteem and fear of starting relationships, directly affect BD (VBDY):

"Not for me, but for people who are very shy, they let themselves go more when they are drunk, they do other kinds of things, it takes away your fears...", "you lose shame, that's an advantage for shy people", "if you do not have self-esteem, you're going bad", "shame is more removed and you are going to talk to people, even if you do not know them".

Girls reported more parental control than boys and they are more socially stigmatised. Moreover, girls reported that boys engage more in BD because of their higher alcohol tolerance. Additionally, when boys had participated in BD, they tended to become aggressive and look for fights, which was less frequent among girls. Non-BD girls said that they usually feel more vulnerable to non-consensual sex or sexual assault if they get drunk (VGF):

"A drunk man looks less ugly than a drunk woman... that is what society thinks...", "...you're not going to rape a guy in the street, but a girl who is "too" drunk...a guy can rape her...", "If you are drunk, 2 or 3 guys throw something into your drink and they can do whatever they want with you...", "In addition, parents think that it is more dangerous for their daughter as she is more at risk...". 


\section{Awareness Factors}

Binge drinkers mentioned alcohol's disinhibiting effects, which help reduce shame; however, they did acknowledge that BD can also affect your health, for instance, damaging the liver. They also mentioned that BD consequences would probably depend on people and alcohol tolerance (VBDY): "and that inhibits you... you lose your shame...", "If it's excessive... it can lead you to suffer diseases and things in your body", "Of course it's bad... because over time it damages your liver".

In the mixed group, there was no consensus on the consequences of BD. They mentioned ambivalent short-term consequences, such as fun during parties but having hangovers the next day, memory loss (from the previous day) and parental reprimands (VG): "Then the next day it was bad", "I felt awful", "I felt very good, because I laughed at everything, but later when I arrived at home all the laughter was taken away...", "...When I arrived, I was punished".

Both genders associated the concept of BD with daily consumption, going over the limit or losing consciousness. Yet, as none of the adolescents were familiar with the definition of BD: the concept was explained to clarify it for the remaining part of the interview. Almost all adolescents thought that that amount of glasses of alcohol was small. Some girls believed that BD depended on many factors, such as the type of drink, personal tolerance or having previously eaten (VGF): "That consumption is normal...", "it depends on the person's tolerance and also the volume of alcohol you have or what you drink", "it depends on the person and the day, whether you have eaten or have not eaten...", "Losing consciousness, when you lose control".

The boys did not perceive any dangers in BD (VGM): “...Nothing bad happened to me with the alcohol", "If it is under control, nothing happens", just like the bingedrinker group. Instead, the girls referred to dangers such as an alcohol-induced coma, family damage, fights, traffic accidents, injuries, etc. as short-term consequences of BD (VGF): "You are not aware of what happens around you, they can give you a push...and you only realise when you are already "thrown" to the ground", "Because you can do things unconsciously...", "The hangover", "The headache", "The vomit", "Dizziness", "can give you an alcohol-induced coma...", just like the non-BD groups (VBDN): "You get more aggressive", "fights, a lot of fights over alcohol", "that hooks you, it can affect your life in many ways, your health, your friends", as well as addiction and liver diseases in the long-term (VBDN): "That destroys you in the long term...", "you have a good time, but then in the long run you have to pay...", "... you become addicted...".

\section{Motivational Factors}

Regarding the attitude, as advantages, binge drinkers stated that BD could help to socialise, flirt or dance (VBDY): "I do not dance like this, I'm incapable... I drink until I'm tipsy and then I dance", "well, to socialise, if I use it...". They also highlighted emotional factors such as having fun, laughing, feeling adrenaline, etc. (VBDY): "It gives you an adrenaline rush...", "having fun with friends... being silly, and we laugh a lot".

As disadvantages, they highlighted fights, aggressiveness, memory loss, losing keys or wallets, falling to the floor, or doing things that they later regret (VBDY): "Things are done without thinking", "and then you regret it, because you don't know what you're doing. Imagine you're in that state and you decide to drive the car".

However, non-binge drinkers saw no benefits to $\mathrm{BD}$ (VBDN): "It really does not help you at all", "The truth is that there are no advantages", "They are inconveniences 
more than anything...". As disadvantages, they mentioned dizziness, vomiting, disorientation, memory loss, addiction or even death. They also mentioned that sometimes they are involved in problems, such as fighting when their friends get drunk. In addition, they pointed out that being drunk does not help them flirt (VBDN): "It brings very bad diseases, I have an uncle who has a liver disease and is dying", "The hangover", "The headache...", "The vomit", "Because if they get into a fight and you are not drunk, they can involve you in the fight, they get you into trouble". No differences in these beliefs were found regarding gender.

Concerning social modelling, some non-BD mentioned that their families (parents and siblings) do not usually drink alcohol, although some friends have engaged in BD, whereas binge drinkers indicated that their friends and family (parents, siblings, uncles/aunts and cousins) often drank alcohol (VBDY): "I drink with my sister", "oh well, and with my cousin too", "My parents and friend", "My sister, but she drinks like me". There is no difference regarding gender.

In relation to social norms, in general, students emphasised that people who would not approve of their drinking were those who love them and older people, for instance, grandparents (VG): "all the people who love you, they will not want you to drink", "my grandparents would tell me not to drink". Moreover, they said their best friends think they should not drink, while other friends think that they should, differentiating between their most intimate and other friends (VG): "It depends on the type of friends you have. If it's a friend who really loves you, when you're bad with alcohol they will tell you to stop", "my closest friends think I should not drink".

In addition, students thought that there was a certain alcohol-related permissiveness in society (VG): "It is something that is widely accepted nowadays", "... it is very "legalised" today". Many students from the mixed group said that parents, siblings, cousins and friends think that they should drink, but they do not approve of BD (VG): "he always tells me... do not drink too much...", "they let me drink as long as I do not return to my house completely out of my head". No difference was found regarding $\mathrm{BD}$ and gender.

Binge drinkers did not perceive any pressure from their peers regardless of the situation. However, non-BD perceived pressure from peers, mostly when they were with a large group, at a party, "Botellón", etc. (VBDN): "If pressured, I would say yes, for friends", "When I am at a 'botellón' and I do not feel like drinking, they say "well, then why do you come to the 'botellón'?” and then I drink", "...they say let's go, and call me boring or dull".

Furthermore, the group also affected the amount of alcohol consumed, the type of drinks and the higher probability of $\mathrm{BD}(\mathrm{VBDN})$ : "I think that what people do is also very influential. If everyone drinks, I have to drink, because I will not be left behind".

The pressure to drink is greater in younger students, being a significant trigger for the onset of drinking (VBDN): "The youngest ones feel more forced to start to drink. They see the older ones, and they want to grow up fast", "the first time it is normal to be told to drink".

Binge drinkers mentioned having been offered alcohol by a family member or their parents when they were at a family celebration, such as a wedding, fair, birthday or in a bar, etc. (VBDY): "Yes, when my mother takes us from time to time to a bar and she 
says, do you want some red wine? And she offers it to me", "maybe beer with my father too, if he has a beer, he gets one for me". No difference was found regarding gender.

Concerning self-efficacy, all adolescents found it more difficult to say "no" when they are at drinking places, events such as a "Botellón", celebrations, parties or at a disco (VG): "When you go to the disco, or to the 'botellon'... you know that what you do there is drink", "at a 'botellón' it is more difficult...". Some binge drinkers said they had never considered it difficult to say "no" to drinking. However, non-BD found more difficulty with a larger group of friends, and it was easier when they were at home or at a friend's home (VBDN): "I think it is more difficult when you are with more people. When you are alone you say: "Why, if I do not want to" but with people you say: "Go on then"”, "Why am I going to drink at home alone... to look in a mirror and imagine people are there?", "it is easier not to drink at a friend's house...". No difference was found regarding gender.

\section{Family Factors}

Most students outlined not experiencing much strictness from parents regarding drinking, and mothers are even less strict (VBDN): "My mother perhaps does not punish me too much for arriving an hour late", although parents know at all times with whom their children go out, and even know that they and their friends drink alcohol. Non-BD claimed their parents to be stricter with them (VBDN): "my father is stricter", "They like to know where I am and who I am with...to control what I'm doing and what I'm not doing". Binge drinkers revealed that they had permissive parents. They can easily disobey the rules, such as being home late and/or drunk with scarce reprimands or punishments (VBDY): "They tell me today half an hour less, but then, I arrive at the same time", "they scold me, they tell me "next time", but then nothing happens". In contrast, girls and non$\mathrm{BD}$ reported that if they arrived home drunk, their parents would get angry, punish them, lose faith in them and not allow them to go out again (VGF): "my mother is like that...she gives me a slap that leaves me like..." (VBDN): "Man...my mother sees me coming through the doors and if I fall on the floor...my mother does not let me out anymore or give me more money...". Yet, these consequences would be unlikely for boys when arriving home drunk.

Binge drinkers reported that their parents know that they drink alcohol and allow it, although they do not approve of BD (VBDY): "My parents, when I am going to a party...they say...do not drink too much", "They know I drink".

In general, students said that their parents usually drink alcohol at home but not excessively (a glass of wine or a beer, usually accompanied by food), their father being the one who drinks more beverages with a higher alcohol content (VG): "My father drinks beer on weekends, when we go out to eat", "my mother drinks beer without alcohol and my father regular beer", "they drink beer...my father 'cubata' (spirits), but my mother does not".

The boys reported on the permissiveness of their parents. They stated that they have consumed alcohol in front of their parents and that parents allowed this. Parents tell them not to drink too much. The boys also revealed that, during celebrations, parents and family members offered them alcohol, and parents allowed them to drink. This was also reported in the conversations of binge-drinker groups (VGM): "Maybe they'll have a beer and they'll grab one for me", "in a bar, they ask me: what do you want?" (VBDY): "My father gives me a beer". However, the girls reported that they had never been offered alcohol by their family (VGF): "My mother has never offered me (alcohol) but has never told me not to drink either". 
In general, parents do tell them about the consequences of alcohol, but they allow them to make their own decisions (VBDY): "My father has never forbidden me to drink, he has taught me that it will not bring me anything good, you know what you have to do and what not". Adolescents reported that parents have spoken to them about alcohol and its consequences. Some of the non-BD boys said that their fathers alluded to doing sports to prevent drinking, smoking or using drugs (VG): "My father has always told me about alcohol, what can happen" (VBDN): "I love sports, because my father always tells me that athletes do not drink, or smoke, or anything, they can be role models, that helps me a lot".

\section{Ability Factors}

Some binge drinkers said they only drink if they want to, so they proposed some alternatives to avoid BD. Instead, non-BD proposed doing alcohol-free activities and avoiding situations where they could be pressured into drinking (VBDN):

“if it's a 'botellón' I do not go...but if it's a party or a birthday I go...why do I have to drink?", "I am by the river with my friends and we spend the day playing football, cards, etc.", "Being with your friends, but not going to a party, for example, being at home with your friends and ordering a pizza, watching a movie...", "bowling...", "or say that you do not drink".

Some said they do not usually drink because they practice sports and it would affect their performance, and their teammates did not usually drink. They also proposed elaborate strategies, such as improving self-esteem and self-confidence, losing one's shyness to be able to relate to people without drinking and counting on the support of non-drinking friends and family (VBDN):

"An alternative is to be sure of yourself, that you do not need alcohol to do what you want to do", "Loving yourself", "be in an environment of trust... feel good in the place where you are... you do not need anything more", "look for people who think the same as you...", "be sure of yourself and of what you want".

Furthermore, some girls said they drink less when they go out with their boyfriends, as well as when they have an exam the following day.

\section{Intention Stage}

Most adolescents had no intention of changing their behaviour. We found a negative precontemplation among binge drinkers (VBDY): "Saturday we will go out to drink", "this weekend we have a party", "I have a barbecue tomorrow and some beer will be had", whereas we found a positive precontemplation among non-BD (VBDN): "I have a party to attend but I do not think I'll drink...", "we have tests, I do not usually go to parties to drink", "we prefer drinking juice or eating sweets and playing cards in the park, more than drinking alcohol...". No difference was found regarding gender.

\section{Mothers Focus Group Interviews}

\section{Characteristics of Parents}

Eighteen parents (94.7\%) were female and the average age was $46.5(\mathrm{SD}=2.5)$. Regarding educational level, nine $(47.4 \%)$ had university degrees, five $(26.3 \%)$ had vocational training and five $(26.3 \%)$ were secondary school graduates. 


\section{Awareness Factors}

Mothers did not know the definition of BD, believing that it is prolonged and chronic consumption that causes long-term health problems (addiction and developmental impairment). In addition, some of them mentioned short-term consequences, such as disinhibition, needing emergency care or entering an alcoholinduced coma (VP): “...it causes addiction", "delays certain levels of physical and mental development", "there are many who drink excessively at a 'botellón', and in an ethylic coma you can be done for (die)". Some of them thought that girls are more vulnerable than boys (VP): "my daughter told me that someone put something in a girl's drink, and the girl was totally uninhibited and started to flirt with the boys".

Moreover, some mothers considered the social influence of the consumer society and the major economic interests associated with $\mathrm{BD}$, which pressure adolescents to drink alcohol (VP):

"The consumption of alcohol is very normalised", "consumer society pushes young people", "because that brings a lot of money and it's a market of interest...".

In fact, in some towns there are places designated for drinking. Other mothers highlight the influences of the group of friends on drinking/BD (VP):

"The group pressures you and it depends on your level of maturity to say yes or no", "the opinion of a friend weighs more than that of a father".

Finally, some mothers believed that their children had not started drinking or never would, so they are not at risk, although many classmates and even younger adolescents had started (VP):

"my kids, as far as I know, have not yet tried alcohol, but the kids around them... it's crazy, I have seen children with 'litronas' (big bottles of beer) and tobacco, the same age as my kids...".

They consider it normal that their children do not recognise the consequences of alcohol consumption, due to the nature of adolescence (VP):

"I have been a teenager, and I was not aware of dangers... I am aware now that I have children".

\section{Attitude Towards Adolescents' Drinking and Binge Drinking}

Most mothers do not allow their children to binge-drink; they prefer their children to have a healthy life (VP): "them being athletes is the best". They thought that drinking is not necessary to have fun (VP): "... you do not have to drink to have a good time". Others did not consider it bad that their children drink alcohol moderately, considering that giving access to alcohol at home could prevent them from going to the "Botellón" (VP):

"But normally he gets drunk when he goes out", "You can do it with control", "excess is what makes it bad", "They met in my house and they had a little party. Their father and I went out and we left them at home, there were 6 or 7 of them and the rest of the class went to the "botellón". 


\section{Rules and Norms}

More than half of the mothers did not have clear rules, and said they cannot control their children's drinking, departure or arrival times, the group of friends with whom they spend time, etc. (VP):

"I give him the freedom that my mother gave me, with moderation", "She is the one that establishes the curfew", "there are times I exercise more control and times when I am less strict", "in high school you lose a little (control), because you do not know the kids or their parents as you did at school".

Others said they are stricter regarding their children's schedules, and try to know with whom they spend time (VP): "I do not think that my 15-year-old daughter has to go out until 12", "when she goes out I want to know where she is". In addition, one mother said that they did not treat sons and daughters equally, showing gender bias, being more protective and stricter with the daughters, even having the son take the sisters home (VP): "My son comes home later because he is a boy... and he picks up his sister".

Most mothers showed permissiveness, allowing their children to drink at home, and even offering them alcohol (VP): "my son can drink at home if he wants...and out", "I've told him 'of course', and he's taken a sip and tasted it". Some mothers thought that forbidding their children from going to the "Botellón" or from drinking alcohol could be worse because it could encourage them to do so (VP): "I think that everything that is prohibited is what makes you want to do it".

They reported few reprimands when their children disobeyed a parent's rules, such as if they came home drunk (VP): "I would not scold him either, because in those situations there is no point in scolding them".

\section{Beliefs about Parental Influence}

Some mothers thought that it is a family's responsibility to educate and inform their children about the dangers of drinking and BD (VP): "They have to be informed, with the basic work done in the family, that they have other activities and other alternatives to the "botellon"'. However, others stated that it was not only family who influences adolescent behaviour, but also the consumer society, as was previously indicated.

\section{Action Planning: Abilities and Alternatives}

More than half of the mothers highlighted that adolescents had no alternatives, since society and groups of friends imposed the "Botellón" as a socialisation mechanism. Moreover, some mothers stated that drinking does not interfere with adolescents' studies, leisure or life, provided that they drink with "control" (VP): "There does not have to be an alternative, they can do it with control". However, many mothers would prefer that adolescents substitute the "Botellón" with other leisure activities.

There should be greater awareness about alcohol, with more emphasis on training adolescents to say "no" (VP): "...having other enriching activities, other alternatives to the 'botellón' when they go out with friends", "Learning to say "NO", that must be taught...". They said that talks about alcohol at school were ineffective, so they proposed to present real cases in order to shock adolescents (VP): "Even if there are talks, there should be other things", "I would show them more in real life...". 


\section{Parent-Child Communication}

Almost all mothers stated that they have good communication with their children, and that they talked about alcohol. They thought that if their children had any problems, they trusted them, although they stated that their children are reluctant to talk about certain topics (VP): "We trust each other", "I talk to her about the 'botellón'...". Others claimed their children may not tell them the truth about their drinking behaviour: "What happens is that you can talk to them, but you never know if they're telling you the truth or not".

\section{Discussion}

The main purpose was to explore the perceptions about determinants of BD in Spanish adolescents from the perspective of adolescents and parents, taking into account gender differences and whether they are engaging in BD. To our knowledge, this is the first in-depth study on the determinants of BD in Spanish adolescents from the perspective of adolescents and parents, based on the I-Change Model.

Regarding BD patterns, this study is in line with other works carried out in Spain and Europe, where BD shows positive representation among adolescents (Luquiens, Falissard \& Aubin, 2016; Golpe et al., 2017). In addition, some factors, such as intensity and frequency of BD, seem to determine its consequences (Luquiens et al., 2016). Currently, the ways in which young people are socialised in terms of consumer habits are very different among European countries, although there may be certain global trends and cultures (Katainen et al., 2015). Culture plays the main role in shaping the way people learn to drink and establish their alcohol consumption patterns, as well as their problematic alcohol-related behaviours (Rolando et al., 2014b). Despite this, BD is no longer associated with certain cultural events, being a regular activity for many adolescents (Donath et al., 2011). In our study, many students are often involved in BD at public places, mostly on weekends, drinking mostly spirits with their friends ("Botellón”). Therefore, accessibility to alcohol, and planning of spaces and leisure time, can affect BD (Romo-Avilés et al., 2016ab).

A previous study with parents claimed that adults' opinions regarding to the alcohol consumption of adolescents seem to some extent to be affected by an excessive alarm spread by media messages (Rolando et al., 2014b). In our study, mothers claimed that BD is institutionalised, with economic interests that pressure adolescents to drink alcohol (ESTUDES, 2018). In Spain, although only legally purchased and consumed from the age of 18, alcohol is provided to adolescents, and the "Botellón" phenomenon shows the limitations of the law (Montes, 2012). Consequently, not only legislation, but sociopolitical and environmental factors should be addressed, as well as the development of alternatives for leisure activities and free time for adolescents (Romo-Avilés et al., 2016ab).

Gender can be considered a predisposing factor for BD; girls have more gender stereotypes and a stigmatised negative social image regarding drinking, with a higher risk of being exposed to non-consensual sex. In this line, in a previous study with focus groups, authors claimed that both girls and boys are reluctant to associate women with a variety of alcohol-related activities, including being intoxicated. Besides, this sexual stereotyping appears present at a relatively young age, and continues through adolescent experimentation with alcohol (Østergaard, 2009). In our study, girls reported more parental control than boys, as well as more punishments if they got drunk (Romo-Avilés et al., 2016ab). Different studies show that boys tend to drink alcohol more heavily (Montes, 2012; Golpe et al., 2017). However, recent evidence suggests a diminishing 
gender gap, with equal levels of consumption between both genders (Romo-Avilés et al., 2016ab; ESTUDES, 2018), as indicated in our study. Furthermore, an increase in female alcohol drinking, together with the vulnerability to which they are exposed, requires greater efforts to address drinking problems according to gender (Bartsch et al., 2017).

Adolescents highlighted low self-esteem as an important factor in BD, using alcohol to socialise, to try to "fit in", as well as to lose fear and shame. In this sense, some authors suggest that the needs to belong to a group and develop self-esteem may both be related to student drinking (Hamilton et al., 2017). Much of human behaviour is motivated by a desire to satisfy needs of belonging, as feeling accepted and fitting in with those around them is a fundamental need (Baumeister et al., 1995; Hamilton et al., 2017). Furthermore, self-esteem may influence how individuals satisfy their connectedness goals within specific relationships (Murray, Derrick, Leder \& Holmes, 2008). Self-esteem refers to the degree to which individuals value, respect and accept themselves, and is widely considered to be one of the critical elements that affect future behavioural choice and action (Leary et al., 2000; Lee et al., 2018). Hamilton et al. (2017) concluded that students with low self-esteem are drinking because they lack the self-resources to deal with unmet needs of belonging. These findings suggest that low implicit self-esteem may be a risk factor for student drinking.

Similarly, Bartsch et al. (2017) found that youths with low self-esteem have more risk with respect alcohol consumption and $\mathrm{BD}$, confirming the protective role of high levels of self-esteem against substance use for adolescents (Lee et al., 2018). Despite this, other studies did not find links between reported self-esteem and substance abuse (Henderson, Dakof, Schwartz \& Liddle, 2006; McKay et al., 2012), which may be due to different target populations, settings, covariates and measures of substance use.

Regarding the cognitive factors, we found there is little knowledge about BD in both adolescents and mothers, as in the study by Jander et al. (2013), binge drinkers indicated that the amount of alcohol that was defined as BD was low, depending on the "tolerance" of each person. The need to provide health communication messages to prevent misconceptions is thus clearly demonstrated. Moreover, although many adolescents knew that prolonged consumption could cause long-term health problems, the short-term consequences, such as losing control and falling, hangovers, etc., were considered superfluous. Previous studies indicated that this could be due to low risk perception in adolescence (Patrick et al., 2013). In this sense, we also found a difference between both genders, since boys mention more advantages of BD with a lower risk perception than girls (Romo-Avilés, Marcos-Marcos Gil-García Marquina-Márquez \& Tarragona-Camacho, 2015). Instead, the girls referred to dangers, such as an alcoholinduced coma, family damage, fights, traffic accidents, injuries, etc., as short-term consequences of BD.

Similarly, some mothers did not perceive any risk of alcohol consumption in their children, as they believed that they had not started drinking or binge drinking. In summary, our data reveal quite alarming low-risk perceptions concerning alcohol in both adolescents and parents (Graham et al., 2006; Espada et al., 2008). In contrast, Rolando et al. (2014b) claimed that adolescents were active actors whose drinking, like adults', is based on a conscious and rational choice, and they even believe that adolescents are more aware of this risk than adults.

According to the National Drug Plan (ESTUDES, 2018), BD is tolerated by Spanish society, and even approved of. In this sense, adolescent BD could be perceived 
as an inevitable and standardised process. In addition, although non-binge drinkers did not find advantages in engaging in BD, binge drinkers did. Hence, from a public health perspective, we should be concerned about the positive cultural aspects that adolescents associated with BD, and consider encouraging awareness and stigmatising alcohol drinking/BD. This fact highlights the importance of changing attitudes, especially in those who have a greater disposition towards drinking, emphasising the disadvantages.

Regarding social influences, similarly to previous studies, alcohol drinking and BD are influenced by both family behaviour (Espada et al., 2008; Song, Smiler, Wagoner \& Wolfson, 2012) and peer-group behaviour (Jander et al., 2013; Song et al., 2012; Katainen et al., 2015). Furthermore, it seems that there is a relationship between the size of the peer group and BD (Jander et al., 2013; Golpe et al., 2017). The pressure of the group can affect not only the amount of alcohol, but the type of alcoholic drinks consumed as well (Donath et al., 2011). In contrast, sometimes peer influence can prevent youths from drinking/BD, such as the case of the best friends of non-binge drinkers, who may tend to worry more about the drinker's health (Ali \& Nikaj, 2014).

Furthermore, students identified "Botellón" events or parties such as fairs, Holy Week or Christmas as the most difficult times to avoid drinking, showing low selfefficacy in these situations (Ehret et al., 2013). Thus, health communication messages should focus on strategies and alternatives to cope with these difficult situations, as well as on reducing the influence of friends or family members, strengthening self-efficacy and providing them with action plans for managing risk situations satisfactorily.

Parental consumption, absence of parental control and communication, were found as family factors associated with BD in adolescents (Pedersen et al., 2013). In our study, alcohol drinking often takes place in a family context, being a more typical behaviour of families in southern Europe than their northern coevals (Rolando et al., 2014a). Adolescents and mothers reported the availability of alcohol at home, and many students answered that their family had offered them alcohol. The mothers' attitude was one of rejection of $\mathrm{BD}$, while there was greater permissiveness with respect to moderate alcohol consumption. In this sense, in Spain, $48.3 \%$ of parents allowed minors to drink alcohol (ESTUDES, 2018). Furthermore, as in the study of Jander et al. (2013), some mothers do not have clear rules and say they cannot control their children regarding drinking. Moreover, many mothers lack the self-efficacy required to control their children; they even think that forbidding them from going to the "Botellón" or not drinking is harmful, because it is a way of encouraging them to do the opposite. In addition, we found that binge drinkers stated that their parents were not too strict, whereas non-binge drinkers claimed that their parents were stricter with them. Furthermore, some differences between genders were found, since boys stated that their parents allowed them to consume alcohol with them, and that they even offered them alcohol. However, the girls reported that they had never been offered alcohol by their family. In this sense, girls reported more parental control than boys. Previous studies have found association between high levels of parental control and lower alcohol drinking in adolescents (Calafat, García, Juan, Becoña \& Fernández-Hermida, 2014; Mejia et al., 2016). However, Rolando et al. (2014b), state that the traditional alcohol-raising practices, based on applying strict rules, are currently being called into question. In their findings, it was shown that parents are more and more convinced that it is better to socialise their children to alcohol at home (Østergaard, 2009; Rolando et al., 2014b), which could help children to learn to "master intoxication" by controlling the amount and type of alcohol that they consume (Østergaard, 2009). In addition, despite the low level of knowledge observed 
about BD, both adolescents and parents stated that they talk about alcohol and its consequences at home (Ryan et al., 2010). Despite the importance of family communication, a precondition should be to increase parents' awareness about the problem of alcohol drinking and BD in their children, as well as of their influence on this behaviour in order to offer a reliable model.

Regarding abilities and action plans, participants identified different alternatives and strategies to avoid BD in various stressful situations. Non-binge drinkers proposed increased self-confidence, self-esteem, and support from friends to avoid BD. Quality social interactions with peers are a key contributor to positive self-esteem, a pivotal building block to healthy development (Rodríguez et al., 2012). Hence, health communication messages that address self-esteem, the quality of relationships and social support to avoid BD are recommended (Bartsch et al., 2017). Moreover, social support could improve perceived self-efficacy, which is the adolescent's ability to resist consumption, and to initiate behavioural change (McKay et al., 2012; Ehret et al., 2013).

Finally, regarding the intention stage, most adolescents were in the precontemplation phase. According to the I-Change Model, pre-motivational factors (awareness factors such as knowledge, cues to action and risk perception) need to be addressed first, to make adolescents sufficiently aware of the seriousness of the problem (de Vries et al., 2003). Thus, future health programmes aimed at reducing BD should include pre-motivational factors.

\section{Limitations and Strengths}

Limitations: (1) Group pressure may restrict some participants and limit confidentiality. Therefore, it was explained that the data was going to be treated confidentially, and the researchers intervened only to launch the discussion. Moreover, the adolescents were recruited in the same class, so them knowing each other could condition their speech. One threat in group discussions is that some members may dominate discussions. Yet, as the researcher who chaired the discussion invited all members to freely mention all their opinions, we believe that we minimised this threat. Furthermore, as slightly more girls than boys participated in discussions, a slight overrepresentation of themes mentioned by girls could have occurred. However, the sample was still sufficiently diverse, and the setting allowed males to express their opinions as well. (2) Given that the participants and the researchers were not blinded, this fact could influence the way in which the data is presented. (3) Due to the characteristics of the sample, it was difficult to form a homogeneous group. However, it was possible to form groups according to gender and whether they had engaged in BD previously, as well as according to their academic years. The number of participating parents in groups was slightly lower than recommended, which could potentially reduce the level of interactivity. Despite this, the interactions between parents were very lively. As with other research among parents (Jander et al., 2013; Seay, Iachini, DeHart, Browne \& Clone, 2017; Pruner, Jirikowic, Yorkston \& Olson, 2020), most participants were women, and thus it reflects the mothers' points of view. (4) Some FGs were performed after holiday periods (Holy Week), which would increase the number of adolescents who reported BD, but we tried to increase the number of groups in other periods, to cushion this effect.

One of the strengths of this study is that both parents and adolescents' perceptions on alcohol consumption and BD were collected, making it possible to know the views of both groups about the determinants. Additionally, our study used a comprehensive theoretical model, as the Spanish context may lead to differences in (the importance of) 
certain determinants. For instance, this was also shown by the importance of fairs or the permissiveness of their parents.

\section{Conclusions}

This study reports the perceptions of adolescents and mothers about determinants of BD in Spanish adolescents, based on the I-Change Model, and how families manage their children's drinking behaviour. The findings can help Nurse Practitioners and healthcare professionals who work in Primary Care and School Health, by developing health communication programmes to reduce BD. Our findings highlight that both adolescents and parents reported on gender differences, since the awareness factors, the social influence of the family and the people around them, attitude towards consumption and self-efficacy between others could vary according to gender. For example, boys list more advantages of $\mathrm{BD}$, did not perceive any danger in $\mathrm{BD}$, recognise fewer short-term consequences of $\mathrm{BD}$, and reported less parental control than girls, among other features. In addition, the role of self-esteem and self-efficacy was highlighted, as was the importance of increasing the risk perception. This could be achieved, for example, by showing situations where adolescents feel identified, which could attract their attention, improve their awareness and favour the pre-motivational and motivational components of adolescents to decrease BD. Furthermore, our findings highlight the importance of increasing parents' awareness factors, communication skills, adequate family influence, parental supervision and control of adolescents, and thus reduce BD. In summary, we believe that these results could help to design health communication advice. 


\section{Chapter 4}

\section{Cultural adaptation and feasibility assessment of}

a web-based computer-tailoring programme for alcohol consumption and binge drinking prevention in Spanish adolescents: Delphi panel and pilot study.

\section{Based on:}

Martínez-Montilla, J.M., Mercken, L., Lima-Rodríguez, J.S., de Vries, H., Lima-Serrano, M. (submitted). Cultural adaptation and feasibility assessment of Alerta Alcohol, a web-based programme to reduce alcohol consumption and binge drinking in Spanish adolescents. 


\section{Chapter 5}

Effectiveness of a Web-based computer-tailored intervention to reduce alcohol consumption and binge drinking among Spanish adolescents: a cluster randomized controlled trial.

Based on:

Martínez-Montilla, J.M., Mercken, L., de Vries, H., Candel, M., Lima-Rodríguez, J.S., LimaSerrano, M. (2020). Effectiveness of a Web-based computer-tailored intervention to reduce alcohol consumption and binge drinking among Spanish adolescents: a cluster randomized controlled trial. Journal of Medical Internet Research. Jan; 22(1): e15438. https://doi:10.2196/15438 


\begin{abstract}
Background: Alcohol consumption, including binge drinking (BD) and heavy episodic drinking (HED), is one of the leading risk factors among Spanish adolescents leading to significant social, health, and economic consequences. Reduction of BD and HED in adolescents can be achieved using Web-based, computer-tailored (CT) interventions, providing highly personalized feedback that is adapted to a person's individual characteristics and needs. Randomized controlled trials assessing the effects of tailored BD reduction programs among Spanish adolescents are scarce.
\end{abstract}

Objective: The aim of this study was to test the effectiveness of the Web-based, CT intervention Alerta Alcohol, aimed at the prevention of BD in Spanish adolescents. As a secondary outcome, effects on HED, weekly consumption, and any consumption were also assessed. The adherence and process evaluation were assessed.

Methods: A cluster randomized controlled trial conducted among 15 Spanish schools was developed. Each school was randomized into either an experimental condition (EC) $(\mathrm{N}=742)$ or a control condition (CC) $(\mathrm{N}=505)$. Finally, 351 participants for the EC and 261 for the $\mathrm{CC}$ were included in the analysis $(\mathrm{N}=612)$. Baseline assessment took place in January and February 2017. Demographic variables and alcohol use were assessed at baseline. Follow-up assessment of alcohol use took place 4 months later in May and June 2017. Participants were compared according to their randomization group (EC versus CC). After the baseline assessment, participants in the EC started the intervention, which consisted of short stories about BD, in which CT feedback was based on the I-Change Model for behavior change. Participants in the $\mathrm{CC}$ group only received the baseline questionnaire. Effects of the intervention were assessed using a three-level mixed logistic regression analysis for $\mathrm{BD}, \mathrm{HED}$, and any consumption, and a three-level mixed linear regression analysis for weekly consumption.

Results: In total, 1247 adolescents participated in the baseline assessment and 612 participated in the follow-up assessment; the attrition rate was $50.92 \%$. The intervention was effective in reducing HED among adolescents; the odds of HED in the CC was nine times that in the experimental condition $(P=.04)$. No effects were found for $\mathrm{BD}$, weekly consumption, and any consumption. Process evaluations revealed that the adolescents were satisfied with the program $(68.8 \%)$, would use the program again $(52.9 \%)$, and would recommend it to someone else $(62.8 \%)$. Females and non-binge drinkers showed better responses in the process evaluation.

Conclusions: Our intervention was effective regarding HED but not regarding BD, weekly consumption, and any consumption. It may be that limiting alcohol consumption to prevent HED was easier in the Spanish context than it was to carry out further steps, such as reducing other patterns of alcohol consumption. Hence, additional actions are needed to accomplish these latter goals, including community approaches and policy actions aimed at denormalizing alcohol consumption among Spanish adolescents.

Trial Registration: ClinicalTrials.gov NCT03288896; https://clinicaltrials.gov/ct2/show/NCT03288896

International Registered Report Identifier (IRRID): RR2-10.1186/s12889-018-5346-4

Keywords: adolescents; alcohol consumption; binge drinking; cluster randomized controlled trial; computer tailoring 


\section{Introduction}

Alcohol consumption is one of the leading risk factors for mortality and disease worldwide (Chestnov, 2014; WHO, 2018), with significant social, health, and economic consequences (Falcón et al., 2018), and is the leading risk factor globally for both death and disability-adjusted life years (GBD, 2018). In addition, the most common risky drinking behavior among adolescents is binge drinking (BD), which consists of alcohol consumption that results in a blood alcohol concentration of $0.08 \mathrm{~g} / \mathrm{dL}$ or more, within a period 2 hours (NIAAA, 2016; Golpe et al., 2017). In men, blood alcohol concentrations of more than $0.08 \mathrm{~g} / \mathrm{dL}$ typically occur after consuming five or more standard drink units (SDUs), or standard glasses of alcohol, in about 2 hours; in women, this occurs after consuming four or more SDUs in about 2 hours (NIAAA, 2016; Chung et al., 2018). In other words, BD occurs with the consumption of four or more and five or more SDUs of alcohol by women and men, respectively, in a short space of time or during a single occasion (NIAAA, 2016; Golpe et al., 2017; Chung et al., 2018; ESTUDES, 2018). The lack of consensus as to what is considered an SDU could be the result of cross-country variability of criteria regarding the amount of alcohol consumption per episode (Parada et al., 2011; Mongan et al., 2015; Golpe et al., 2017). However, the above definition, which is used in our study, is consistent with the Spanish epidemiological data from the survey Encuesta Sobre Uso de Drogas en Estudiantes de Enseñanzas Secundarias (ESTUDES) (ESTUDES, 2018). The fact is that BD is associated with detrimental longand short-term consequences, since it affects neurocognitive development and leads to physical, psychological, and social alterations. In addition, BD has been associated with traffic accidents, violence, homicide, suicide, early sexual contact, school failure, mental illnesses, and delinquency, among other issues (Kaul \& Coupey, 2002; Anderson, 2007; Martínez-Hernáez et al., 2012; Hunter et al., 2013; Jander et al., 2013; Falcón et al., 2018).

Moreover, heavy episodic drinking (HED) has been defined as the consumption of 10 or more glasses of alcohol on at least one occasion in the previous week (Best et al., 2006; Jander et al., 2016). This pattern of alcohol consumption is believed to be a serious problem in Western society, with major psychological, social, and economic consequences (Best et al., 2006; Cox et al., 2015). Similarly, HED has been linked to several problematic behaviors, such as an increased risk of unplanned sexual activity; increased risk of injury (Wechsler, Dowdall, Maenner, Gledhill-Hoyt \& Lee, 1998); being more likely to engage in delinquent acts, including fighting, truancy from school, stealing, or driving while intoxicated (Best et al., 2006); as well as later alcohol abuse and dependence or illegal drug use (O'Malley, Johnston, \& Bachman, 1998).

The 2018 national Spanish survey ESTUDES showed that $75.6 \%$ of adolescents between 14 and 18 years of age drank alcohol in the last 12 months (ESTUDES, 2018), a slightly lower number compared to that reported in the 2015 European School Survey Project on Alcohol and Other Drugs (ESPAD) (ESPAD, 2016). Furthermore, in Europe, $35 \%$ of 15-16-year-old adolescents reported BD (ESPAD, 2016), while in Spain, the percentage stood at $32.2 \%$ of students between 14 and 18 years of age (ESTUDES, 2018). The national Spanish survey showed that the prevalence of BD at the age of 16 was $37.0 \%$, which was twice that of 14 -year-olds $(13.2 \%)$, and BD reached $47.5 \%$ at the age of 17 (ESTUDES, 2018). Not one of the previous reports shows data on HED; however, Best et al. (2006) found a prevalence of 32\% of HED among 14-16-year-old adolescents in the United Kingdom. These figures highlight the importance of preventing these different patterns of alcohol consumption in adolescents. 
In the prevention area, computer- and Internet-based interventions are increasingly used as platforms for health promotion, including interventions aimed at reducing alcohol consumption (Newton, Andrews, Teeson \& Vogl, 2009; Krebs et al., 2010; Velicer et al., 2013; Drost et al., 2016; Jander et al., 2016; Brick et al., 2017). Thus, the reduction of alcohol use and BD in adolescents could be achieved with the help of Web-based, computer-tailored (CT) interventions (Schulz et al., 2013; Jander et al., 2016); these could provide highly personalized feedback to individuals whose behaviors and opinions would be previously assessed on the basis of their answers to questionnaires, using data-driven decision rules that produce personalized feedback automatically from a database (de Vries et al., 1999). Some studies have shown that tailored advice helps to effectively change health behaviors and their determinants (Krebs et al., 2010; Walton et al., 2010; Lustria et al., 2013; Schulz et al., 2013; Velicer et al., 2013; Jander et al., 2016; Haug et al., 2017), even showing it to be cost-effective (de Bourdeaudhuij et al., 2010), although their effect sizes were generally small to medium (Schuckit et al., 2015; Jander et al., 2016). However, Web-based, CT interventions usually have low adherence and high attrition rates (de Vries et al., 2012; Elfeddali et al., 2012; Jander et al., 2016), including over 50\% (Elfeddali et al., 2012; Kelders, Kok, Ossebaard \& Van GemertPijnen, 2012; Schulz et al., 2013; Jander et al., 2016), causing significant negative consequences, such as a reduced ability to reveal intervention effects (Eysenbach, 2005).

The Alerta Alcohol program is the first Spanish program to be implemented that consists of a dynamic, Web-based, CT intervention in a school environment aimed at the prevention of alcohol consumption and BD in Spanish adolescents. This is a cultural adaptation of the Dutch program carried out by Jander et al. (2014; 2016); however, in the Spanish context, no similar study has targeted these issues to date, and using CT technology at the high school level is still very rare (Lima-Serrano et al., 2018). Moreover, Alerta Alcohol tries to improve program adherence and minimize dropout in an attempt to overcome the limitations of previous studies. This program uses different strategies to accomplish this, such as developing a dynamic intervention with stories adapted to gender and age (Krebs et al., 2010; Pearson et al., 2015; Lima-Serrano et al., 2018), based on the feedback from focus groups with adolescents (Martínez-Montilla et al., 2020), or by carrying out the majority of the study at schools as part of the health promotion curriculum.

The aim of this study was to test the effectiveness of the Web-based, CT intervention Alerta Alcohol. We assessed the effects of the intervention on BD, HED, weekly consumption, and any consumption.

\section{Methods}

\section{Ethics Committee Approval}

The intervention was carried out according to bioethical guidelines; the students needed to answer the questionnaires themselves and confidentiality was guaranteed. Active informed consent was used. The project was approved the Bioethical Committee of Andalusia, Spain, and was registered on August 4, 2015 (registration number: PI-00312014). In addition, this trial was retrospectively registered at ClinicalTrials.gov on September 19, 2017 (NCT03288896). The intervention was not registered prospectively because our organization did not require it. However, the intervention was not modified with respect to the study protocol. 


\section{Study Design}

We conducted a cluster randomized controlled trial, with one experimental condition (EC) and one waiting-list control condition (CC); high schools were randomized into these two groups. Participants completed a baseline (ie, pretest) evaluation and a final (ie, posttest) evaluation performed 4 months after the intervention.

Participants were compared based on their randomization groups: EC versus CC. The EC group received the online intervention that contained CT feedback. The CC group only filled in the online baseline questionnaire. Both groups were given an online followup assessment after 4 months; they completed the same questionnaire that was used in the baseline assessment. The study took place in Spain between January and June 2017. The Consolidated Standards of Reporting Trials (CONSORT) guidelines were followed (Moher et al., 2001).

\section{Participants and Procedure}

Participants were randomly selected from the group of students belonging to the public school system; this group included students in their fourth year of compulsory secondary education (CSE), those in the first year of their baccalaureate program, and those in the first year of continuing education or vocational training (VT), which is equivalent to 10th, 11th, and 12th grades in the United States, respectively. The randomization process was undertaken by two researchers from the team (JMMM and MLS) using a computer software randomization device to avoid contamination. First, we randomly selected at least two schools from each of the eight provinces in Andalusia in Southern Spain. If schools agreed to participate, the inclusion criteria were checked. If they did not agree to participate, we randomized other schools in the same province until at least two schools in each province were included; in total, we contacted 37 Andalusian schools.

The schools were informed of the objective of the study and the sessions of the intervention. Participation by each school was confirmed by email, telephone, or, when necessary, by a visit. A formal letter and an information folder were sent to teachers and coordinators at each school, where they were provided with contact details and the study website address (http://institucional.us.es/alertalcohol/), as well as a manual with frequently asked questions that may occur during the program.

Finally, after 16 high schools, two from each province in Andalusia, accepted, they were randomly assigned to either the EC group or the CC group, taking care that the intervention groups (ie, EC groups) were matched with a province. Within each school, all classes that met the inclusion criteria were invited to participate in the study.

The CC schools were on a waiting list and received the intervention voluntarily once the study was completed. The selected schools were not blinded to their groups, since the EC group needed to schedule a total of four sessions during school hours. The adolescents were recruited from schools through their teachers and counselors. Adolescent participants and their parents had to sign and return the informed consent form to agree to take part in this scientific study. When starting the intervention, participants were asked to visit the study website and create an account. Within their account, they selected their school and were assigned to one of the conditions: CC or EC. Before starting with the baseline questionnaire, students gave informed consent by checking the acceptance box on the first page of the website. If he or she did not wish to participate, or refused to provide informed consent, he or she could select the option I do not wish to 
participate in this study. In this case, he or she was thanked and could leave the website. Participants could, however, also access the website at another time if they wanted to (see Figure 5.1). All students enrolled gave consent through active informed consent for the use of their data for scientific research and publication. Those who were underage were asked that their parents complete an informed consent form.

Figure 5.1: Screenshot of the informed consent page from the Alerta Alcohol website.

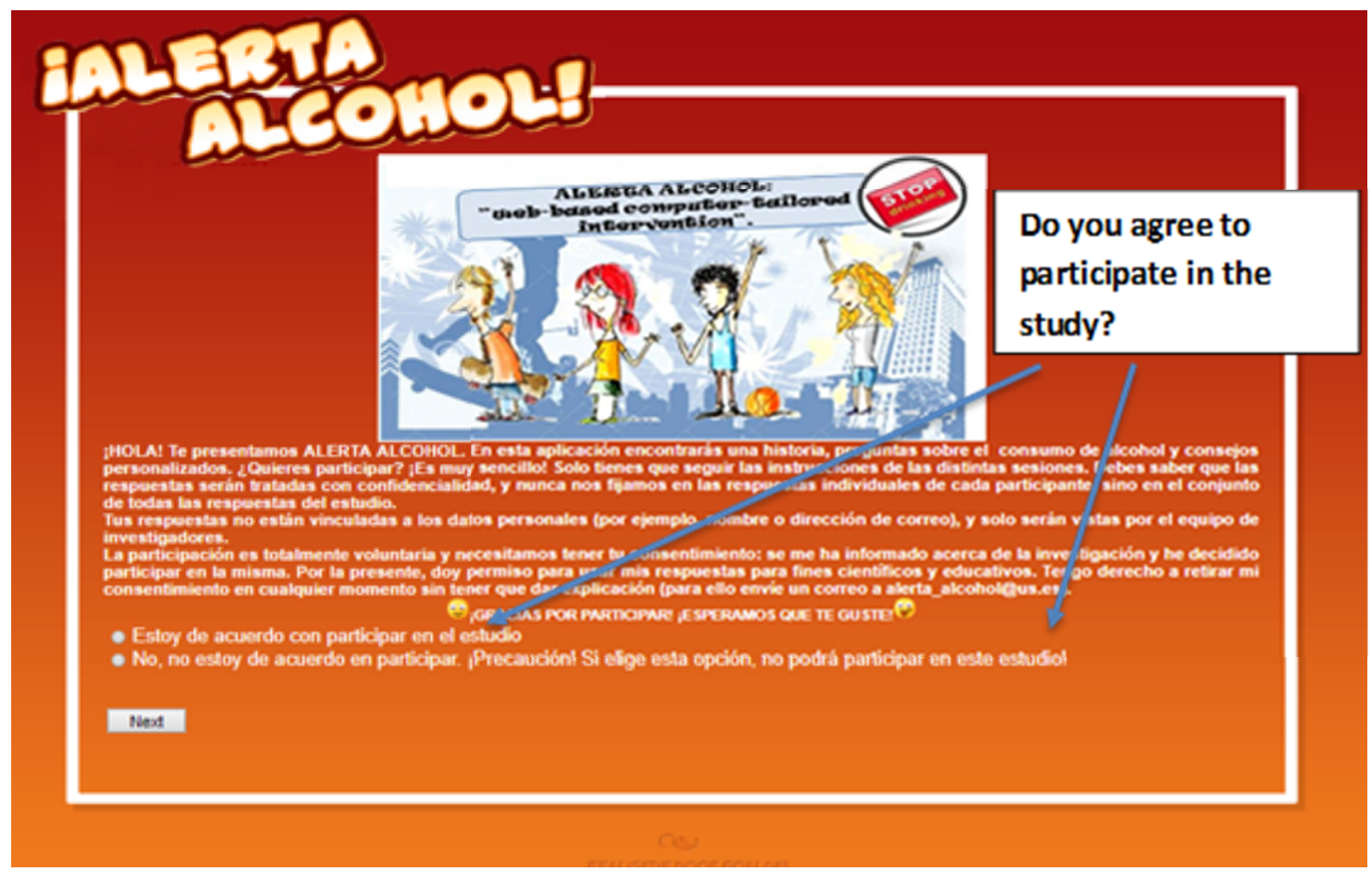

Source: Own elaboration

\section{Inclusion and Exclusion Criteria}

The target group for the Alerta Alcohol program consisted of adolescents aged 1519 years old that were enrolled in fourth-year CSE, first-year baccalaureate programs, or first-year VT. All students enrolled had Internet access at schools and in their homes. Those with language difficulties or those who had previously participated in prevention programs of BD were excluded. To check the inclusion criteria, a researcher was present at the pretest.

In addition, the inclusion criteria for schools were as follows: (1) public secondary schools from Andalusia, (2) schools belonging to provincial capitals, and (3) schools with access to the Internet and an equipped information and communication technology room available for students.

\section{Intervention}

Alerta Alcohol consists of short stories in which the main character binge drank the night before and his or her friends talk with him or her about what happened the night before. The drinking event took place in three scenarios: at home, at a celebration, and in a public place. The stories were designed based on the results of a focus group study (Martínez-Montilla et al., 2020) and were adapted to the gender of the participant. 
Participants could choose an avatar and the names of the characters in the stories (see Figures 5.2 and 5.3).

First, the stories were presented and questions and tailored messages were shown, which were designed to reduce alcohol consumption and BD. Concise, direct, and personalized relevant messages were delivered to promote participation in the intervention (Jander et al., 2014; Pearson et al., 2015; Jander et al., 2016). The messages were customized with the names of the participants; elements such as repetition of the answers were used to show respect and empathy, counter persuasion, introduce social modelling and new beliefs, and reinforce positive behaviors and motivational feedback (Bandura, 1986; de Vries et al., 1999). These messages were based on the I-Change Model, in which the central concepts are attitude, social influences, self-efficacy, and action planning (de Vries et al., 2003; Lima-Serrano et al., 2018). In each scenario, selfefficacy is reinforced and action plans are offered to the adolescent in order to reject alcohol and BD in the specific scenario. In addition, we developed questions and tailored messages aiming to increase self-esteem and awareness of factors such as the acknowledgement of risk perception of alcohol consumption and BD.

Based on a previous focus group study, we concluded that it was necessary to favor premotivational and motivational components associated with BD; modification of beliefs; and risk perception and expectations, or those associated with the effects of alcohol experimentation; as well as to promote healthy self-esteem and self-efficacy. Gender differences were also taken into account (Martínez-Montilla et al., 2020). In addition, a Delphi group study for the cultural adaptation study and the pilot study was developed, which allowed us to shorten and rewrite the feedback messages to make them more appealing to our target group (paper not yet published).

Figure 5.2: Screenshot of the page for choosing an avatar from the Alerta Alcohol website.

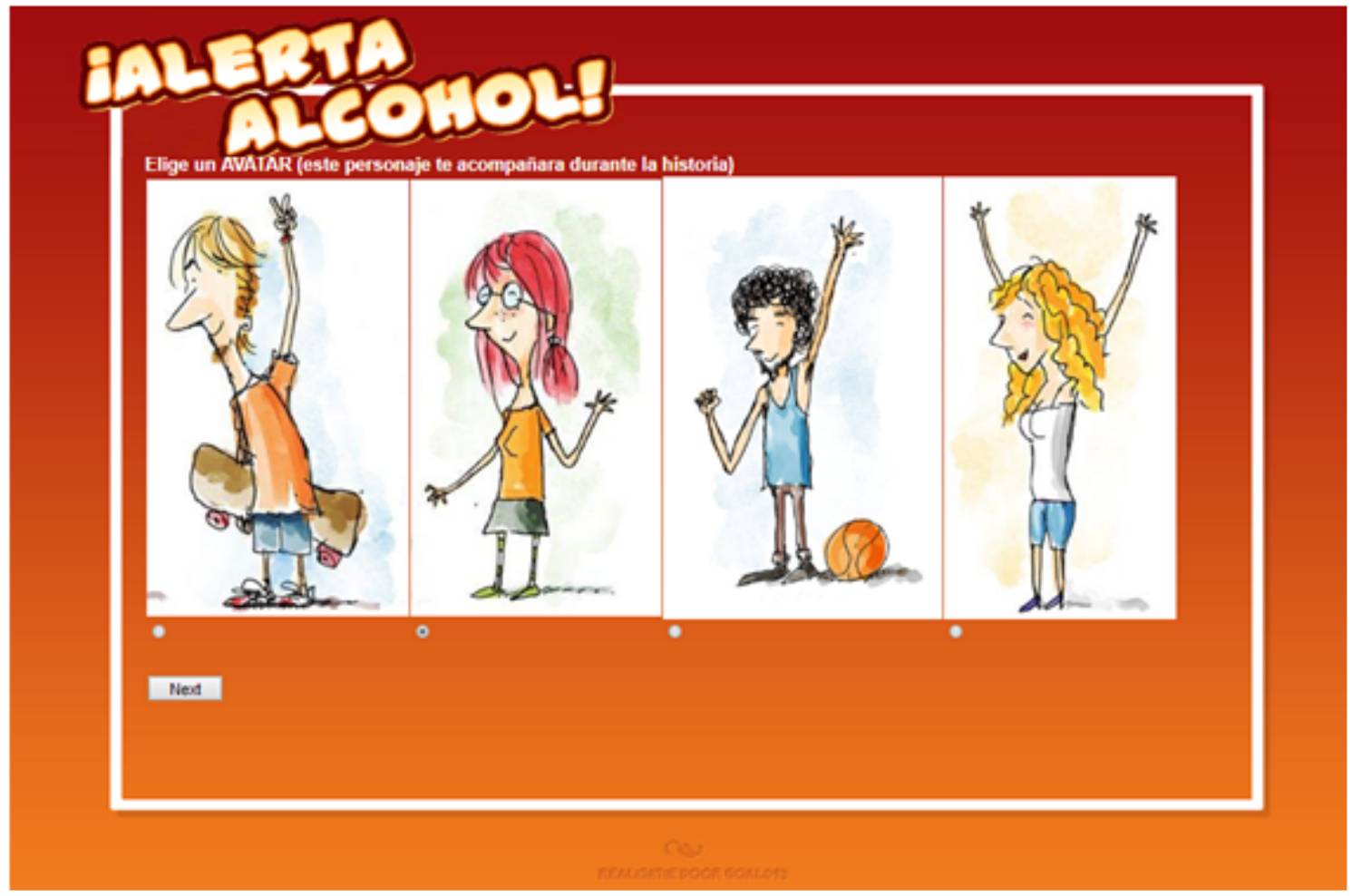

Source: Own elaboration 
Figure 5.3: Screenshot of example stories for a girl from the Alerta Alcohol website.

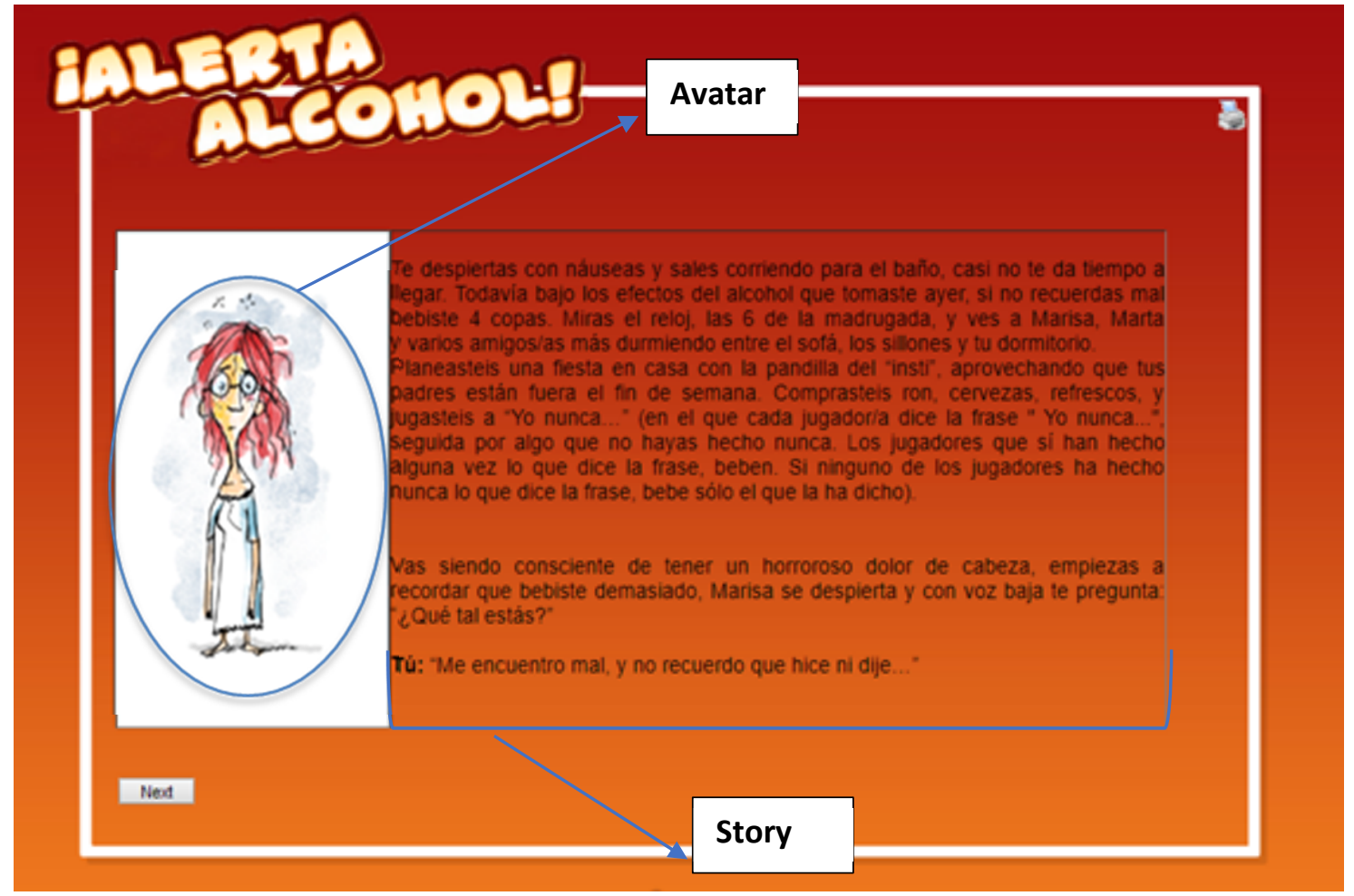

Source: Own elaboration

The intervention was carried out over six sessions. All students had access to a computer in their school's computer room. After registering themselves online, all students had to fill out a baseline questionnaire (ie, pretest), which was supervised by a researcher. The following week, each student from the EC group continued with the intervention by logging in to the website; if needed, they were assisted by their teacher. The EC group members attended a second and third session held at school. There was a 1-2-week period between sessions; when possible, the schedule, which was planned with the researcher, was developed within the school curriculum (ie, class time). Students had two booster sessions at their homes 1 week after the third session. The fourth session was called The Challenge, where adolescents could accept the challenge of not drinking or at least not binge drink at an upcoming drinking event; the program reminded students again of the advice and action plans for this type of event. In the fifth session, 2 days after the drinking event, the program evaluated the challenge to determine whether or not the participants drank or at least whether they engaged in BD during this drinking event. At the end of the study, all students had to complete the sixth session at school (ie, the followup questionnaire), which was carried out throughout May and June 2017 (see Table 5.1). Each session took approximately 1 hour. The CC group only has two sessions: baseline data collection in January and February 2017 and the follow-up questionnaire (ie, posttest) 4 months later. A research technician was present for the pretest and posttest questionnaires at the schools to collaborate with the teachers and to optimize follow-up rates. Moreover, the researcher monitored the intervention by phone call or, if necessary, by visiting the schools in the EC group. Participation reminders were also sent via email when participants had not finished the intervention procedures, so they could complete them outside of school. Because of the nature of study, data were not anonymous. However, confidentiality was ensured through proper data management and security, 
according to the European General Data Protection Regulation (GDPR). This information was enclosed with the consent form. A detailed description of the development and content of the intervention is available in the protocol of this study (Lima-Serrano et al., 2018) and in Appendix 2 (Tabla 1).

Table 5.1: Alerta Alcohol program structure.

\begin{tabular}{|c|c|}
\hline Location and session & Measures \\
\hline \multicolumn{2}{|l|}{ At school } \\
\hline 1 & Initial questionnaire \\
\hline 2 & Scenario 1: at home \\
\hline & - Knowledge and risks \\
\hline & - Attitude: pros and cons \\
\hline & - Self-efficacy and action plans \\
\hline \multicolumn{2}{|r|}{ 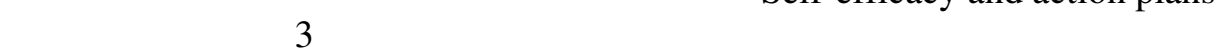 } \\
\hline & Scenario 2: celebrations \\
\hline & - Self-esteem \\
\hline & - Social modelling \\
\hline & - Self-efficacy and action plans \\
\hline & Scenario 3: public places \\
\hline & - Social norms \\
\hline & - Social pressures \\
\hline & - Self-efficacy and action plans \\
\hline \multicolumn{2}{|l|}{ At student's home } \\
\hline 4 & Booster session: The Challenge \\
\hline 5 & Evaluation of The Challenge \\
\hline \multicolumn{2}{|l|}{ At school } \\
\hline 6 & Final questionnaire \\
\hline
\end{tabular}

\section{Measures}

\section{Overview}

Multiple guidelines for how drinking should be measured in surveys have been proposed; however, whether they are consistent in their recommendations has not been considered to date (Nugawela, Langley, Szatkowski \& Lewis, 2016). In this study, a Spanish validated version of the self-administered online questionnaire was used (LimaSerrano et al., 2017), which was adapted from a previous study carried out on Dutch adolescents (Jander et al., 2014). A better description of the concepts and variables can be found in the study protocol (Lima-Serrano et al., 2018) and in Appendix 2 (Tabla 2).

\section{Demographics}

Social demographic variables were assessed at baseline, which consisted of gender ( $1=$ male and $2=$ female), age (in years), educational level ( $1=\mathrm{CSE}$, $2=$ baccalaureate, and $3=\mathrm{VT}$ ), religion (1=Catholic, $2=$ Protestant/Evangelical, $3=$ Muslim/Islamic, $4=$ other religion, and $5=$ no religion), and ethnicity ( $1=$ Spanish and $2=$ other).

In addition, we used the Family Affluence Scale (FAS) to measure social status. The FAS consists of four different questions: "Does your family have a car or a van?" "Do you have your own room at home?" "During the last 12 months, how many times have you gone on holiday with your family?" and "How many computers does your 
family have?" (Currie et al., 2008). The FAS was transformed into three categories, where students could belong to the low level (0-2 points), middle level (3-5 points), or high level (6-9 points).

The Family Apgar Test was used to measure self-perception on familiar functional status (alpha=.778). It consists of five questions answered on a 3-point Likert scale $(0=$ almost never, $1=$ sometimes, and $2=$ almost always); the resulting score was dichotomized into dysfunctional family status (score 0-6) and functional family status (score 7-10) (Smilkstein, Ashworth \& Montano, 1982).

\section{Binge Drinking, Heavy Episodic Drinking, Weekly Consumption, and Any Consumption}

BD was assessed using an open-ended question on how many BD occasions they participated in during the previous 30 days (eg, for girls, "How often did you drink 4 or more standard glasses of alcohol on one occasion in the previous 30 days?"; for boys, the number of drinks was 5 or more). A figure showing different standard drinks was shown to make the concept more comprehensible (Jander et al., 2016). This variable was then dichotomized $(0=$ reported no BD and $1=$ reported $\mathrm{BD})$.

For HED, participants were dichotomized into two groups: those who consumed 10 or more glasses of alcohol on at least one occasion in the previous week (1=HED) and those who did not ( $0=$ no HED) (Best et al., 2006; Jander et al., 2016).

For weekly consumption, we assessed how many glasses of alcohol students drank each day during the last week. Based on this information, we calculated the total number of glasses consumed in the past week (Jander et al., 2016).

Any consumption was calculated using the question "On which days of the past week did you drink alcohol?" Possible answers were as follows: "Monday to Sunday"; "I haven't drunk in the past week"; and "I have never drunk alcohol." This variable was dichotomized into two groups $(0=$ no and $1=y e s)$.

\section{Process Evaluation and Adherence}

To assess adherence, the number of intervention sessions attended by the participants at schools was registered. Furthermore, after completing each session, we asked respondents whether they have been reading the advice, whether the intervention was useful, whether the content was credible and appropriate, and whether the advice was interesting, understandable, too long or short, and personally relevant; responses were based on a 5-point Likert scale (eg, 1=totally disagree and 5=totally agree). We also assessed whether the advice increased their knowledge, changed their risk perception, changed their attitude, or improved their skills to prevent BD. For the analysis of these questions, answers were converted into three categories: 1=totally disagree/partially disagree, $2=$ neither agree nor disagree, and $3=$ totally agree/partially agree.

Finally, we also assessed general satisfaction with the program using a 5-point Likert scale. This question was converted into three categories: $1=$ very dissatisfied/dissatisfied, 2=neither satisfied nor dissatisfied, and 3=very satisfied/satisfied. Using a 5-point Likert scale, we also assessed whether, given the opportunity, they would use the program again and whether they would recommend the program to others (eg, 1=totally disagree and 5=totally agree) (Bannink et al., 2014). 


\section{Power Analyses}

The primary outcome was the difference in binge-drinking occasions in the previous 30 days in the EC group compared with the CC group. According to the 2016 national Spanish survey ESTUDES (2016), the prevalence of adolescent BD within a previous 30 -day timeframe was $32.2 \%$. It is estimated that the intervention reduces consumption to $22 \%$. Requiring a statistical power of .80 for a two-sided test with a type I error rate of alpha $=.05,309$ subjects were required for the $\mathrm{CC}$ group and 309 were required for the EC group (ie, 618 participants in total); $G^{*}$ Power, version 3.1.9.2 (Heinrich-Heine-Universität Düsseldorf), was used for the statistical power analyses (Faul, Erdfeller, Lang \& Buchner, 2007). Following the study by Jander et al. (2014), a dropout rate of about $50 \%$ was anticipated; therefore, 1236 total subjects needed to be recruited.

\section{Statistical Analyses}

Descriptive analyses were performed to describe the characteristics of the participants at baseline. Differences between the conditions in the baseline sample, as well as between consumers and nonconsumers, BD, HED, weekly consumption, and any consumption were assessed via a t test for continuous variables and a chi-square test for categorical variables. Also, when the dependent variable was not normally distributed, the Mann-Whitney $U$ test was used.

Since pupils were nested within classes in the study, and classes were nested within schools, in order to examine predictors of dropout versus nondropout, a three-level mixed logistic regression analysis was conducted. To test the effectiveness of the program, we also performed three-level mixed logistic regression analyses for the outcomes $B D$, any consumption, and $H E D$, and a three-level mixed linear regression for the outcome weekly consumption. When variances of the random intercept at the school level and class level turned out to be zero, a standard logistic or linear regression was carried out. This turned out to be the case for the binary outcomes any consumption, BD, and $H E D$.

To evaluate the effect, the intention-to-treat principle was followed. The independent variable of interest was included in the $\mathrm{EC}$ versus $\mathrm{CC}$, and covariates were the outcome at baseline as well as several sociodemographic variables: gender, age, educational level, religion, ethnicity, Apgar score, and affluence level. Also, the interaction effects between intervention condition and all sociodemographic variables were entered as covariates into the analyses. To build the refined model, we first examined whether the covariance model of random effects could be simplified. In the second phase, the variables with the least statistical significance, provided their significance was above .10 (for interaction terms) or .05 (for main effect terms), were eliminated one by one from the model. However, the variable of central interest, EC versus $\mathrm{CC}$, always remained in the model. To quantify the predictive power of the logistic regression models, Nagelkerke's R2 was reported. Due to the high attrition rate $(>50 \%)$ in the majority of variables in the follow-up questionnaire, thus hampering the validity of multiple imputation techniques, we decided not to use multiple imputation and we performed the analysis with pairwise deletion (White \& Carlin, 2010; White, Royston, \& Wood, 2011).

To study predictors of adherence, we also analyzed the associations between potential participant characteristics (ie, gender, age, educational level, religion, ethnicity, 
Apgar score, family affluence, and alcohol use at baseline) on the one hand and participation in the intervention (ie, adherent or not) on the other.

Finally, for the process evaluation a descriptive analysis was performed using chisquare tests to examine differences between males and females and between binge drinkers and non-binge drinkers. We used SPSS Statistics for Windows, version 21.0 (IBM Corp), for these analyses. The level of significance used for the main effects was alpha $=.05$ and for the interaction effects was alpha $=.10$. Also, effect sizes (odds ratios [ORs]) and 95\% CIs were calculated.

\section{Results}

\section{Participation and Attrition Rate}

After contacting several schools, 16 accepted our invitation. Reasons for nonacceptance were as follows: the program was too time-consuming, the schools were involved in another drug-related program, or there were logistical problems, such as not having a computer room. Other schools did not respond to our phone calls and emails.

In total, 16 schools were randomly assigned to either the EC or CC. However, one of the schools from the $\mathrm{CC}$ did not begin the baseline assessment and withdrew their participation due to logistical problems. In total, 1431 adolescents from 15 schools, $8 \mathrm{EC}$ and $7 \mathrm{CC}$, were requested to fill in the baseline questionnaire. Subsequently, 75 adolescents from the EC group and 38 from the $\mathrm{CC}$ group were removed because they were over 19 years of age, 48 students were removed from the EC group and 13 from the $\mathrm{CC}$ group because they did not fill in the questionnaire, and an additional 6 students from EC group and 4 from the CC group were removed because they provided unrealistic answers. In total, 1247 interviews were used at the baseline assessment, 742 from the EC and 505 from the CC. Figure 5.4 shows the flowchart of participants at the participating schools.

All 15 schools participated in the completion of the 4-month follow-up questionnaire, with only 612 participants: 351 from the EC group and 261 from the CC group. There was a clear decrease in participation between the baseline assessment $(\mathrm{N}=742)$ and the follow-up assessment $(\mathrm{N}=351)$ in the EC group, resulting in an attrition rate of 50.92\% (612/1247). Most schools had problems with their Wi-Fi or reported trouble finding a suitable date, due to final exams. Also, groups participating in VT were beginning their placements in companies around this time, so this was also a cause of dropout. 
Figure 5.4. Flowchart of participant recruitment and dropouts in the Alerta Alcohol program.

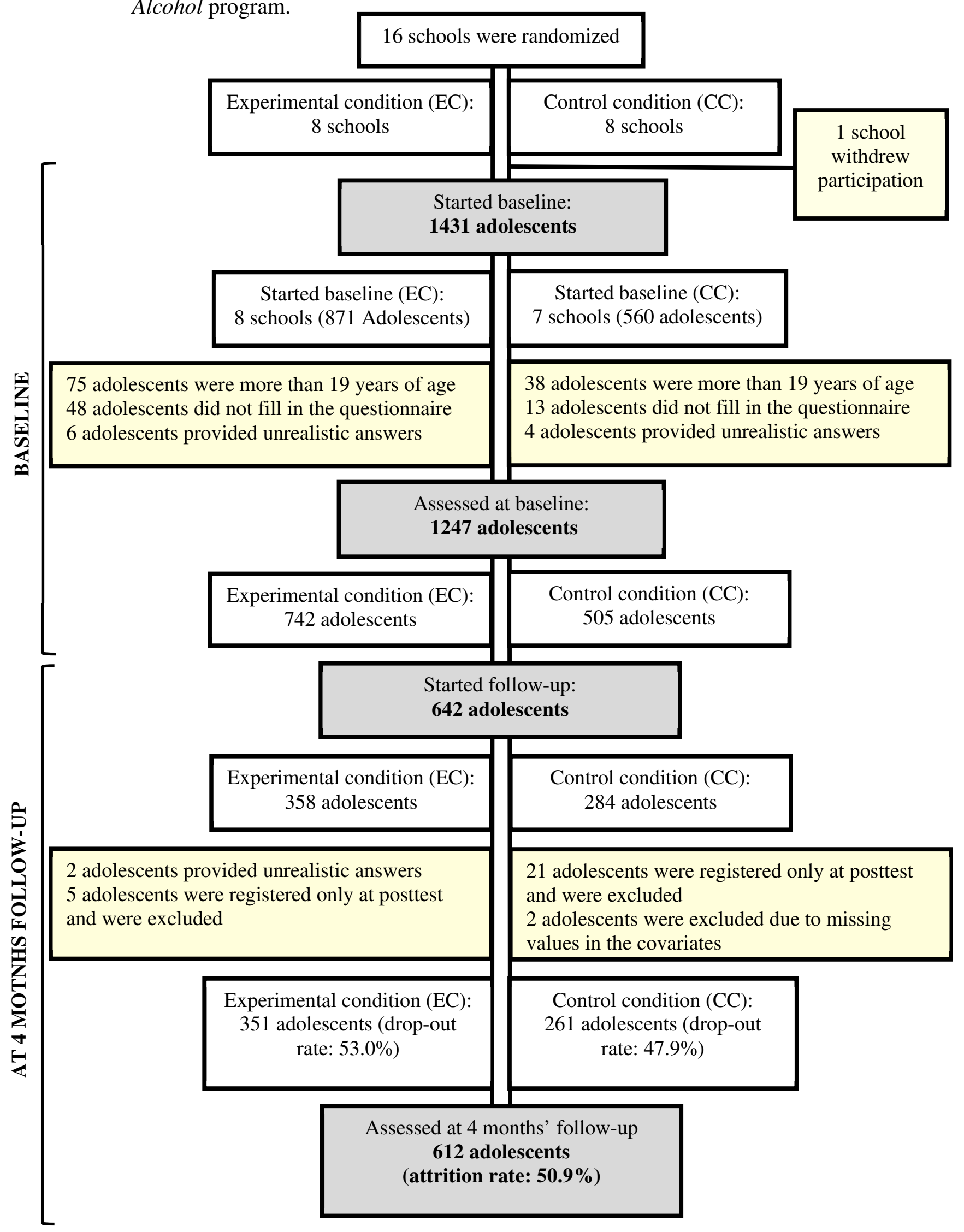

Source: Own elaboration 
The dropout analyses showed that adolescents returning the follow-up questionnaires were significantly younger $(P<.001)$ and had lower educational levels $(P<.001)$. The adolescents that returned the questionnaires were less likely to be binge drinkers $(P=.02)$ and had a lower weekly consumption $(P=.01)$ (see Table 5.2). When a multilevel analysis was carried out, the older participants (OR 1.319, 95\% CI 1.101$1.581, P=.003$ ) and those who reported a higher weekly consumption (OR 1.045, 95\% CI 1.004-1.087, $P=.03$ ) were more likely to drop out of the intervention.

Table 5.2: Differences in baseline characteristics between participants that returned and those that dropped out at the 4-month follow-up.

\begin{tabular}{|c|c|c|c|c|c|}
\hline $\begin{array}{c}\text { Variable (number of missing } \\
\text { values) }\end{array}$ & $\begin{array}{c}\text { Total } \\
(\mathrm{N}=1247)\end{array}$ & $\begin{array}{c}\text { Returned } \\
(\mathrm{N}=612)\end{array}$ & $\begin{array}{c}\text { Dropped } \\
\text { out } \\
(\mathbf{N}=635)\end{array}$ & Test statistic & $\begin{array}{c}P \\
\text { value }\end{array}$ \\
\hline $\begin{array}{l}\text { Age (15-19-year-olds) }(0) \text {, } \\
\text { mean (SD) }\end{array}$ & $16.32(1.07)$ & $\begin{array}{l}16.11 \\
(0.99)\end{array}$ & $16.53(1.10)$ & $\begin{array}{l}\mathrm{U}^{\mathrm{a}}=236280.5 \\
t_{1237.926}=-7.090\end{array}$ & $\begin{array}{l}<.001 \\
<.001\end{array}$ \\
\hline $\begin{array}{l}\text { Gender }(\mathbf{0}), \mathbf{n}(\mathbf{\%}) \\
\quad \text { Male } \\
\text { Female }\end{array}$ & $\begin{array}{l}586(46.99) \\
661(53.01)\end{array}$ & $\begin{array}{l}282(46.1) \\
330(53.9)\end{array}$ & $\begin{array}{l}304(47.9) \\
331(52.1)\end{array}$ & $\chi^{2}{ }_{1}=0.5$ & .49 \\
\hline $\begin{array}{l}\text { Educational level }(\mathbf{0}), \mathbf{n}(\%) \\
\text { Compulsory secondary } \\
\text { education } \\
\text { Baccalaureate program }\end{array}$ & $\begin{array}{l}545(43.70) \\
515(41.30)\end{array}$ & $313(51.1)$ & $\begin{array}{l}232(36.5) \\
263(41.4)\end{array}$ & $\chi^{2}=58.8$ & $<.001$ \\
\hline Vocational training & $187(15.00)$ & $47(7.7)$ & $140(22.1)$ & & \\
\hline $\begin{array}{l}\text { Religion }(\mathbf{3}), \mathbf{n}(\%) \\
\text { Catholic } \\
\text { Protestant or Evangelical } \\
\text { Muslim or Islamic } \\
\text { Other } \\
\text { No religion }\end{array}$ & $\begin{array}{l}767(61.65) \\
26(2.09) \\
18(1.45) \\
28(2.25) \\
405(32.56)\end{array}$ & $\begin{array}{l}385(62.9) \\
11(1.8) \\
9(1.5) \\
10(1.6) \\
196(32.1)\end{array}$ & $\begin{array}{l}382(60.4) \\
15(2.4) \\
9(1.4) \\
18(2.8) \\
209(32.9)\end{array}$ & $\chi^{2}{ }_{4}=2.9$ & .57 \\
\hline $\begin{array}{l}\text { Ethnicity (3), n (\%) } \\
\quad \text { Spanish } \\
\text { Non-Spanish }\end{array}$ & $\begin{array}{l}1178(94.69) \\
66(5.31)\end{array}$ & $\begin{array}{l}583(95.4) \\
28(4.6)\end{array}$ & $\begin{array}{l}595(94.0) \\
38(6.0)\end{array}$ & $\chi^{2}{ }_{1}=1.2$ & .26 \\
\hline $\begin{array}{l}\text { Apgar test (55), n (\%) } \\
\text { Functional family } \\
\text { Dysfunctional family }\end{array}$ & $\begin{array}{l}886(74.33) \\
306(25.67)\end{array}$ & $\begin{array}{l}446(75.7) \\
143(24.3)\end{array}$ & $\begin{array}{l}440(73.0) \\
163(27.0)\end{array}$ & $\chi^{2}{ }_{1}=1.2$ & .28 \\
\hline $\begin{array}{l}\text { Family affluence (49), n (\%) } \\
\text { Low } \\
\text { Medium } \\
\text { High }\end{array}$ & $\begin{array}{l}33(2.76) \\
387(32.30) \\
778(64.94)\end{array}$ & $\begin{array}{l}16(2.7) \\
183(31.0) \\
391(66.3)\end{array}$ & $\begin{array}{l}17(2.8) \\
204(33.5) \\
387(63.7)\end{array}$ & $\chi^{2}{ }_{2}=0.9$ & .63 \\
\hline \multicolumn{6}{|l|}{ Alcohol use (0) } \\
\hline $\begin{array}{l}\text { Binge drinking, } \mathrm{n}(\%) \\
\text { Heavy episodic drinking, } \mathrm{n} \\
(\%)\end{array}$ & $\begin{array}{l}487(39.05) \\
16(1.28)\end{array}$ & $\begin{array}{l}219(35.8) \\
8(1.3)\end{array}$ & $\begin{array}{l}268(42.2) \\
8(1.3)\end{array}$ & $\begin{array}{l}\chi_{1}^{2}=5.6 \\
\chi_{1}^{2}=0.005\end{array}$ & $\begin{array}{l}.02 \\
.95\end{array}$ \\
\hline $\begin{array}{l}\text { Weekly consumption, mean } \\
\text { (SD) }\end{array}$ & $1.45(4.30)$ & $1.22(3.33)$ & $1.68(5.06)$ & $\begin{array}{l}\mathrm{U}=206367 \\
t_{1098.665}=-1.929\end{array}$ & $\begin{array}{l}.01 \\
.054\end{array}$ \\
\hline Any consumption, n (\%) & $832(66.72)$ & $404(66.0)$ & $428(67.4)$ & $\chi^{2}{ }_{1}=0.4$ & .55 \\
\hline
\end{tabular}

\section{Sample Characteristics}

Baseline characteristics are shown in Table 5.3. We found that the adolescents in the EC group were older than those in the CC group $(P<.001)$. We also found that the educational level of adolescents was higher in the CC group compared to the EC group $(P=.002)$. 
Table 5.3: Baseline characteristics of participants by condition.

\begin{tabular}{|c|c|c|c|c|c|}
\hline $\begin{array}{c}\text { Variable (number of missing } \\
\text { values) }\end{array}$ & $\begin{array}{c}\text { Total } \\
(\mathrm{N}=1247)\end{array}$ & $\begin{array}{c}\text { Experimental } \\
\text { group } \\
(\mathrm{N}=742) \\
\end{array}$ & $\begin{array}{l}\text { Control } \\
\text { group } \\
(\mathbf{N}=\mathbf{5 0 5})\end{array}$ & $\begin{array}{c}\text { Test } \\
\text { statistic }\end{array}$ & $\begin{array}{c}P \\
\text { value }\end{array}$ \\
\hline Schools, $\mathrm{n}$ & 15 & 8 & 7 & $\mathrm{~N} / \mathrm{A}^{\mathrm{a}}$ & N/A \\
\hline Classrooms per school, $\mathrm{n}$ & 62 & 38 & 24 & N/A & N/A \\
\hline $\begin{array}{l}\text { Students per classroom, mean } \\
\text { (SD), range }\end{array}$ & $\mathrm{N} / \mathrm{A}$ & $\begin{array}{l}19.53(6.90) \\
25\end{array}$ & $\begin{array}{l}21.04(5.87), \\
26\end{array}$ & N/A & N/A \\
\hline $\begin{array}{l}\text { Age (15-19-year-olds) }(0) \\
\text { mean (SD) }\end{array}$ & $\begin{array}{l}16.32 \\
(1.07)\end{array}$ & $16.40(1.06)$ & $16.21(1.06)$ & $\begin{array}{l}\mathrm{U}^{\mathrm{b}}=208553 \\
t_{1245}=-3.150\end{array}$ & $\begin{array}{l}<.001 \\
.002\end{array}$ \\
\hline $\begin{array}{l}\text { Gender }(\mathbf{0}), \mathbf{n}(\%) \\
\text { Male } \\
\text { Female }\end{array}$ & $\begin{array}{l}586(46.99) \\
661(53.01)\end{array}$ & $\begin{array}{l}345(46.5) \\
397(53.5)\end{array}$ & $\begin{array}{l}241(47.7) \\
264(52.3)\end{array}$ & $\chi^{2}{ }_{1}=0.2$ & .67 \\
\hline $\begin{array}{l}\text { Educational level }(\mathbf{0}), \mathbf{n}(\mathbf{\%}) \\
\text { Compulsory secondary } \\
\text { education }\end{array}$ & $545(43.70)$ & $321(43.3)$ & $224(44.4)$ & $\chi_{2}^{2}=12.1$ & .002 \\
\hline $\begin{array}{l}\text { Baccalaureate program } \\
\text { Vocational training }\end{array}$ & $\begin{array}{l}515(41.30) \\
187(15.00)\end{array}$ & $\begin{array}{l}289(38.9) \\
132(17.8)\end{array}$ & $\begin{array}{l}226(44.8) \\
55(10.9)\end{array}$ & & \\
\hline $\begin{array}{l}\text { Religion }(\mathbf{3}), \mathbf{n}(\mathbf{\%}) \\
\text { Catholic } \\
\text { Protestant or Evangelical } \\
\text { Muslim or Islamic } \\
\text { Other } \\
\text { No religion }\end{array}$ & $\begin{array}{l}767(61.65) \\
26(2.09) \\
18(1.45) \\
28(2.25) \\
405(32.56)\end{array}$ & $\begin{array}{l}462(62.3) \\
19(2.6) \\
10(1.4) \\
15(2.0) \\
235(31.7)\end{array}$ & $\begin{array}{l}305(60.6) \\
7(1.4) \\
8(1.6) \\
13(2.6) \\
170(33.8)\end{array}$ & $\chi^{2}{ }_{4}=3.1$ & .55 \\
\hline $\begin{array}{l}\text { Ethnicity (3), n (\%) } \\
\text { Spanish }\end{array}$ & $\begin{array}{l}1178 \\
(94.69)\end{array}$ & $707(95.4)$ & $471(93.6)$ & $\chi^{2}{ }_{1}=1.9$ & .17 \\
\hline Non-Spanish & $66(5.31)$ & $34(4.6)$ & $32(6.4)$ & & \\
\hline $\begin{array}{l}\text { Apgar test }(\mathbf{5 5}), \mathbf{n}(\mathbf{\%}) \\
\text { Functional family } \\
\text { Dysfunctional family }\end{array}$ & $\begin{array}{l}886(74.33) \\
306(25.67)\end{array}$ & $\begin{array}{l}516(72.8) \\
193(27.2)\end{array}$ & $\begin{array}{l}370(76.6) \\
113(23.4)\end{array}$ & $\chi^{2}{ }_{1}=2.2$ & .14 \\
\hline $\begin{array}{l}\text { Family affluence (49) } \\
\text { Low } \\
\text { Medium } \\
\text { High }\end{array}$ & $\begin{array}{l}33(2.76) \\
387(32.30) \\
778(64.94)\end{array}$ & $\begin{array}{l}17(2.4) \\
244(34.2) \\
452(63.4)\end{array}$ & $\begin{array}{l}16(3.3) \\
143(29.5) \\
326(67.2)\end{array}$ & $\chi_{2}^{2}=3.5$ & .17 \\
\hline \multicolumn{6}{|l|}{ Alcohol use (0) } \\
\hline $\begin{array}{l}\text { Binge drinking, } \mathrm{n}(\%) \\
\text { Heavy episodic drinking, } \\
\mathrm{n}(\%)\end{array}$ & $\begin{array}{l}487(39.1) \\
16(1.30)\end{array}$ & $\begin{array}{l}298(40.2) \\
8(1.1)\end{array}$ & $\begin{array}{l}189(37.4) \\
8(1.6)\end{array}$ & $\begin{array}{l}\chi^{2}{ }_{1}=0.9 \\
\chi^{2}{ }_{1}=0.6\end{array}$ & $\begin{array}{l}.33 \\
.44\end{array}$ \\
\hline $\begin{array}{l}\text { Weekly consumption, } \\
\text { mean (SD) }\end{array}$ & $1.45(4.30)$ & $1.47(3.78)$ & $1.42(4.96)$ & $\begin{array}{l}\mathrm{U}=190393.5 \\
t_{1245}=-0.2\end{array}$ & $\begin{array}{l}.52 \\
.84\end{array}$ \\
\hline Any consumption, n (\%) & $832(66.70)$ & $486(65.5)$ & $346(68.5)$ & $\chi_{1}^{2}=1.2$ & .27 \\
\hline
\end{tabular}

${ }^{\mathrm{a} N} / \mathrm{A}$ : not applicable; ${ }^{\mathrm{b}}$ Mann-Whitney $U$ test.

\section{Binge Drinking}

At baseline, 40.2\% (298/742) of adolescents in the EC group and 37.4\% (189/505) in the $\mathrm{CC}$ group reported $\mathrm{BD}$ in the previous 30 days. At the follow-up session, $32.2 \%$ $(113 / 351)$ of adolescents in the EC group and 33.0\% (86/261) in the CC group reported $\mathrm{BD}$. There was a reduction in $\mathrm{BD}$ in both conditions, but this reduction was only significant in the EC group: BD was reduced by $8.0 \%$ (OR $0.716,95 \%$ CI $0.547-0.937$, $P=.02$ ) in the EC group versus a reduction of $4.4 \%$ (OR $0.821,95 \%$ CI $0.600-1.126$, $P=.22)$ in the CC group. However, in the logistic regression analysis, the intervention did not show a significant effect; although, in the $\mathrm{CC}$ group, the odds of BD were 1.1 times the odds of BD in the EC group. In addition, the analysis revealed that family affluence was marginally significant $(P=.08)$; people who had medium family affluence (OR 3.365, 
95\% CI 1.058-10.704, $P=.04$ ) had a higher risk of BD than people who had high family affluence (see Tables 5.4 and 5.5).

Table 5.4: Effects of the Alerta Alcohol program on binge drinking, heavy episodic drinking, weekly consumption, and any consumption in the complete model.

\begin{tabular}{|c|c|c|c|c|c|c|c|c|c|}
\hline \multirow[t]{2}{*}{ Variable } & \multicolumn{2}{|c|}{$\begin{array}{l}\text { Binge drinking }^{\mathrm{a}} \\
(\mathrm{N}=586)\end{array}$} & \multicolumn{2}{|c|}{$\begin{array}{c}\text { Heavy episodic } \\
\text { drinking }^{\mathrm{a}} \\
(\mathrm{N}=612) \\
\end{array}$} & \multicolumn{3}{|c|}{$\begin{array}{l}\text { Weekly consumption } \\
\qquad(\mathrm{N}=\mathbf{5 8 9})\end{array}$} & \multicolumn{2}{|c|}{$\begin{array}{c}\text { Any consumption } \\
(\mathrm{N}=589)\end{array}$} \\
\hline & $\begin{array}{c}\text { OR }^{\mathbf{c}}(95 \% \\
\text { CI })\end{array}$ & $\begin{array}{c}P \\
\text { value }\end{array}$ & $\begin{array}{c}\text { OR }(95 \% \\
\text { CI })\end{array}$ & $\begin{array}{c}P \\
\text { value }\end{array}$ & B (SE) & $\begin{array}{c}P \\
\text { value }\end{array}$ & $95 \% \mathrm{CI}$ & $\begin{array}{c}\text { OR }(95 \% \\
\text { CI })\end{array}$ & $\begin{array}{c}P \\
\text { value }\end{array}$ \\
\hline $\begin{array}{l}\text { Condition } \\
\text { (control vs } \\
\text { experimental) }\end{array}$ & $\begin{array}{l}1.106 \\
(0.730- \\
1.674)\end{array}$ & .63 & $\begin{array}{l}9.129 \\
(1.107- \\
75.259)\end{array}$ & .04 & $\begin{array}{l}-0.244 \\
(0.385)\end{array}$ & .53 & $\begin{array}{l}-1.000- \\
0.511\end{array}$ & $\begin{array}{l}0.866(0.506- \\
1.484)\end{array}$ & .60 \\
\hline $\begin{array}{l}\text { Gender (male } \\
\text { vs female) }\end{array}$ & $\mathrm{N} / \mathrm{A}^{\mathrm{d}}$ & N/A & $\begin{array}{l}3.394 \\
(0.669- \\
17.223)\end{array}$ & .14 & N/A & N/A & N/A & N/A & N/A \\
\hline \multicolumn{10}{|l|}{$\begin{array}{l}\text { Family } \\
\text { affluence }\end{array}$} \\
\hline $\begin{array}{l}\text { Low versus } \\
\text { high }\end{array}$ & $\begin{array}{l}3.365 \\
(1.058- \\
10.704)\end{array}$ & .04 & N/A & N/A & $\begin{array}{l}-1.503 \\
(0.921)\end{array}$ & .10 & $\begin{array}{l}-3.313- \\
0.306\end{array}$ & $\begin{array}{l}3.401(0.710- \\
16.129)\end{array}$ & .13 \\
\hline $\begin{array}{l}\text { Medium } \\
\text { versus high }\end{array}$ & $\begin{array}{l}1.309 \\
(0.841- \\
2.036)\end{array}$ & .23 & N/A & N/A & $\begin{array}{l}0.410 \\
(0.325)\end{array}$ & .21 & $\begin{array}{l}-0.228- \\
1.048\end{array}$ & $\begin{array}{l}1.801(0.987- \\
3.289)\end{array}$ & .06 \\
\hline $\begin{array}{l}\text { Consumption } \\
\text { behavior } \\
\text { pretest }^{\mathrm{e}} \\
\end{array}$ & $\begin{array}{l}11.986 \\
(7.951- \\
18.069) \\
\end{array}$ & $<.001$ & $\begin{array}{l}8.360 \\
(0.820- \\
85.239) \\
\end{array}$ & .07 & $\begin{array}{l}0.502 \\
(0.044)\end{array}$ & $<.001$ & $\begin{array}{l}0.416- \\
0.589\end{array}$ & $\begin{array}{l}59.518 \\
(34.789- \\
101.823) \\
\end{array}$ & $<.001$ \\
\hline
\end{tabular}

${ }^{\mathrm{a}}$ Logistic regression; ${ }^{\mathrm{b}}$ Linear mixed regression; ${ }^{\mathrm{c}} \mathrm{OR}$ : odds ratio; ${ }^{\mathrm{d}} \mathrm{N} / \mathrm{A}$ : not applicable; ${ }^{\mathrm{e}}$ Consumption behavior refers to binge drinking, heavy episodic drinking, weekly consumption, and any consumption at the pretest evaluation.

Table 5.5: Fixed effects of the Alerta Alcohol program on binge drinking, heavy episodic drinking, weekly consumption, and any consumption in the complete model.

\begin{tabular}{|c|c|c|c|c|c|c|c|c|}
\hline \multirow[t]{2}{*}{ Variable } & \multicolumn{2}{|c|}{$\begin{array}{l}\text { Binge drinking }^{\mathrm{a}} \\
\qquad(\mathrm{N}=586)\end{array}$} & \multicolumn{2}{|c|}{$\begin{array}{c}\text { Heavy episodic } \\
\text { drinking }^{\mathrm{a}}(\mathrm{N}=612)\end{array}$} & \multicolumn{2}{|c|}{$\begin{array}{c}\text { Weekly } \\
\text { consumption }^{b} \\
(\mathrm{~N}=589)\end{array}$} & \multicolumn{2}{|c|}{$\begin{array}{l}\text { Any consumption } \\
(\mathrm{N}=589)\end{array}$} \\
\hline & Statistic & $\begin{array}{c}P \\
\text { value }\end{array}$ & Statistic & $\begin{array}{c}P \\
\text { value }\end{array}$ & Statistic & $\begin{array}{c}P \\
\text { value }\end{array}$ & Statistic & $\begin{array}{c}P \\
\text { value }\end{array}$ \\
\hline Condition & $\mathrm{W}^{\mathrm{c}}=0.225$ & .64 & $\mathrm{~W}=4.222$ & .04 & $\mathrm{~F}^{\mathrm{d}}=0.403$ & .53 & $\mathrm{~W}=0.271$ & .60 \\
\hline & $\mathrm{W}=5.108$ & .08 & $\mathrm{~N} / \mathrm{A}^{\mathrm{e}}$ & N/A & $\mathrm{F}=2.405$ & .09 & $\mathrm{~W}=5.443$ & .07 \\
\hline & $\mathrm{R}^{2 \mathrm{f}}=.349$ & N/A & $\mathrm{R}^{2}=.150$ & N/A & N/A & N/A & $\mathrm{R}^{2}=.638$ & N/A \\
\hline $\begin{array}{l}\text { Intracluster } \\
\text { correlation } \\
\text { (ICC) }\end{array}$ & & & & & & & & \\
\hline School level & N/A & N/A & N/A & N/A & $\mathrm{ICC}=0$ & N/A & N/A & N/A \\
\hline Class level & N/A & N/A & N/A & N/A & $\mathrm{ICC}=.046$ & N/A & N/A & N/A \\
\hline
\end{tabular}




\section{Heavy Episodic Drinking}

At baseline, 1.1\% (8/742) of adolescents in the EC group and 1.6\% (8/505) in the $\mathrm{CC}$ group reported heavy episodic drinking in the previous 30 days. At the follow-up stage, $0.3 \%(1 / 351)$ of adolescents in the EC group and 2.7\% (7/261) in the CC group reported heavy episodic drinking in the previous 30 days. The logistic regression analysis showed that the odds of heavy episodic drinking in the $\mathrm{CC}$ group was nine times the odds of heavy episodic drinking in the EC group (OR 9.129, 95\% CI 1.107-75.259, $P=.04$ ).

\section{Weekly Consumption}

At baseline, adolescents in the EC group and in the CC group drank a mean of 1.47 (SD 3.78) and 1.42 (SD 4.96) standard glasses of alcohol, respectively, in the previous week. At the follow-up stage, the mean was 1.64 (SD 3.66) and 1.39 (SD 4.12) standard glasses of alcohol in the EC group and in the $\mathrm{CC}$ group, respectively. The mixed linear regression analysis did not show any significant effects of the intervention.

\section{Any Consumption}

At baseline, 65.5\% (486/742) of adolescents in the EC group and 68.5\% (346/505) in the $\mathrm{CC}$ group reported that they had never drunk alcohol. At the follow-up stage, $68.9 \%$ (242/351) of adolescents in the EC group and 65.5\% (171/261) in the CC group reported that they had never drunk alcohol. In the logistic regression analysis, the intervention had no effect. Again, family affluence was marginally significant $(P=.07)$, where participants with low family affluence (OR 1.801, 95\% CI 3.289-0.987, $P=.06$ ) had a higher probability of drinking alcohol than those with high family affluence.

\section{Adherence}

After the baseline (ie, first) session, of the 742 adolescents who were randomized into the EC, only 461 (62.1\%) started the second session at school and only $350(47.2 \%)$ returned for the third session at school. Only 23 adolescents out of $742(3.1 \%)$ returned for the fourth session at home and $8(1.1 \%)$ returned for the fifth session at home.

We assessed the predictors of adherence, which were as follows: educational level $(P=.009)$ (with students enrolled in VT showing less adherence than baccalaureate program students: beta $=-0.882, P=.002$ ), ethnicity (Spanish versus other: beta $=1.142$, $P=.04$ ), and not engaging in BD in the previous 30 days at baseline (beta $=-0.546, P=.03$ ) (see Table 5.6). 
Table 5.6: Predictors of adherence where both sessions were completed.

\begin{tabular}{lllll}
\hline \multicolumn{1}{c}{ Variable $^{\mathbf{a}}$} & Beta & SE & Exp(beta) & $\boldsymbol{P}$ value \\
\hline Gender (female) & 0.319 & 0.229 & 1.376 & .16 \\
Age & -0.140 & 0.138 & 0.870 & .31 \\
Educational level (baccalaureate) & & & & $\mathbf{. 0 0 9}$ \\
$\quad$ Vocational training & -0.882 & 0.287 & 0.414 & .002 \\
$\quad$ Compulsory secondary education & -0.201 & 0.340 & 0.818 & .55 \\
Religion (no religion) & & & & .30 \\
$\quad$ Others & 0.005 & 0.256 & 1.005 & .98 \\
$\quad$ Catholic & 0.950 & 0.627 & 2.586 & .13 \\
Ethnicity (others) & 1.142 & 0.566 & 3.132 & .04 \\
Apgar test (family dysfunction) & 0.162 & 0.287 & 1.176 &. $\mathbf{5 7}$ \\
$\quad$ High family affluence & & & & .19 \\
$\quad$ Medium family affluence & 1.313 & 1.091 & 3.717 & .23 \\
$\quad$ Low family affluence & 0.385 & 0.257 & 1.470 & .13 \\
Binge drinking & -0.546 & 0.250 & 0.579 & .03 \\
\hline
\end{tabular}

${ }^{a}$ Reference category of categorical variables is indicated between brackets; ${ }^{b}$ Religion was entered as three categories: no religion, others, and Catholic.

\section{Process Evaluation}

Of the EC group members, 295 participants returned the questionnaire. In total, $50.8 \%(150 / 295)$ of students reported that the sessions were too long. Even though $76.1 \%$ (223/293) of students said the advice content was credible, $72.0 \%(211 / 293)$ stated that it was understandable, 63.1\% (185/293) stated that it was useful, and $60.0 \%(177 / 295)$ stated that the advice was interesting. Furthermore, 68.8\% (203/295) of students were satisfied with the program, $52.9 \%$ (155/293) would use the program again, and $62.8 \%$ (184/293) recommended the program to someone else (see Tables 5.7 and 5.8).

Regarding gender, more females, compared to males, reported that the advice was useful $(d=0.294,95 \%$ CI $0.062-0.527, P=.03)$, understandable $(d=0.316,95 \%$ CI 0.083 $0.548, P=.01)$, improved their knowledge $(d=0.212,95 \%$ CI $0.019-0.443, P=.009)$, changed their risk perception $(d=0.236,95 \%$ CI $0.005-0.468, P=.06)$, and improved their skills $(d=0.229,95 \%$ CI $0.003-0.460, P=.02)$. In general, more females, compared to males, more frequently reported that they would recommend the program to someone else $(d=0.102,95 \%$ CI $0.129-0.333, P=.047)$; this was a mixed result, since males also more often answered totally agree/partially agree for this question, as well as there being more males who answered totally disagree/partially disagree. Therefore, we could say that males are somewhat more extreme regarding their opinion on this question.

Regarding $\mathrm{BD}$, more non-binge drinkers reported the advice to be credible $(d=0.199,95 \%$ CI $0.039-0.437, P=.03)$. On the other hand, more binge drinkers reported the advice to be useful $(d=0.040,95 \%$ CI $0.197-0.277, P=.02)$, to be appropriate for them $(d=0.293,95 \%$ CI $0.054-0.531, P=.01)$, and to improve their knowledge $(d=0.068,95 \%$ CI $0.170-0.305, P=.02)$, as well as that the advice changed their risk perception $(d=0.078$, $95 \%$ CI $0.159-0.315, P=.02)$. 
Table 5.7: Process evaluation of the Alerta Alcohol program: responses from participants in the intervention group by gender.

\begin{tabular}{|c|c|c|c|c|c|}
\hline Variable (number of missing values) & $\begin{array}{c}\text { Total } \\
(\mathrm{N}=\mathbf{3 5 1}), \mathbf{n} \\
(\%)\end{array}$ & $\begin{array}{c}\text { Male } \\
(\mathrm{N}=149), \\
\mathrm{n}(\%)\end{array}$ & $\begin{array}{c}\text { Female } \\
(\mathrm{N}=202) \\
\mathrm{n}(\%)\end{array}$ & $\chi^{2}(2)$ & $\begin{array}{c}P \\
\text { value }\end{array}$ \\
\hline Overall satisfaction (56) & & & & $\mathbf{1 . 0}$ & .61 \\
\hline Very dissatisfied/dissatisfied & 35 (11.9) & $18(14.0)$ & $17(10.2)$ & & \\
\hline Neither satisfied nor dissatisfied & $57(19.3)$ & $25(19.4)$ & $32(19.3)$ & & \\
\hline Very satisfied/satisfied & $203(68.8)$ & $86(66.7)$ & $117(70.5)$ & & \\
\hline Length of session: too long ( 56 ) & & & & 2.4 & .31 \\
\hline Totally disagree/partially disagree & 49 (16.6) & $19(14.7)$ & $30(18.1)$ & & \\
\hline Neither agree nor disagree & $96(32.5)$ & $48(37.2)$ & $48(28.9)$ & & \\
\hline Totally agree/partially agree & $150(50.8)$ & $62(48.1)$ & $88(53.0)$ & & \\
\hline Length of session: too short (56) & & & & 1.0 & .60 \\
\hline Totally disagree/partially disagree & $88(29.8)$ & $38(29.5)$ & $50(30.1)$ & & \\
\hline Neither agree nor disagree & $101(34.2)$ & $48(37.2)$ & $53(31.9)$ & & \\
\hline Totally agree/partially agree & $106(35.9)$ & $43(33.3)$ & $63(38.0)$ & & \\
\hline Interest in advice (56) & & & & 1.0 & .60 \\
\hline Totally disagree/partially disagree & $52(17.6)$ & $26(20.2)$ & $26(15.7)$ & & \\
\hline Neither agree nor disagree & $66(22.4)$ & $28(21.7)$ & $38(22.9)$ & & \\
\hline Totally agree/partially agree & $177(60.0)$ & $75(58.1)$ & $102(61.4)$ & & \\
\hline Content credibility (58) & & & & 4.5 & .10 \\
\hline Totally disagree/partially disagree & $24(8.2)$ & $15(11.7)$ & $9(5.5)$ & & \\
\hline Neither agree nor disagree & $46(15.7)$ & $22(17.2)$ & $24(14.5)$ & & \\
\hline Totally agree/partially agree & $223(76.1)$ & $91(71.1)$ & $132(80.0)$ & & \\
\hline Advice was useful (58) & & & & 6.9 & .03 \\
\hline Totally disagree/partially disagree & $44(15)$ & $27(21.1)$ & $17(10.3)$ & & \\
\hline Neither agree nor disagree & $64(21.8)$ & $28(21.9)$ & $36(21.8)$ & & \\
\hline Totally agree/partially agree & $185(63.1)$ & $73(57.0)$ & $112(67.9)$ & & \\
\hline Advice was understandable (58) & & & & 9.1 & .01 \\
\hline Totally disagree/partially disagree & $25(8.5)$ & $18(14.1)$ & $7(4.2)$ & & \\
\hline Neither agree nor disagree & $57(19.5)$ & $25(19.5)$ & $32(19.4)$ & & \\
\hline Totally agree/partially agree & $211(72.0)$ & $85(66.4)$ & $126(76.4)$ & & \\
\hline Advice was appropriate (m58) & & & & 4.3 & .12 \\
\hline Totally disagree/partially disagree & $49(16.7)$ & $28(21.9)$ & $21(12.7)$ & & \\
\hline Neither agree nor disagree & $73(24.9)$ & $30(23.4)$ & $43(26.1)$ & & \\
\hline Totally agree/partially agree & $171(58.4)$ & $70(54.7)$ & $101(61.2)$ & & \\
\hline Improved knowledge (58) & & & & 9.5 & .009 \\
\hline Totally disagree/partially disagree & $46(15.7)$ & $29(22.7)$ & $17(10.3)$ & & \\
\hline Neither agree nor disagree & $72(24.6)$ & $25(19.5)$ & $47(28.5)$ & & \\
\hline Totally agree/partially agree & $175(59.7)$ & $74(57.8)$ & $101(61.2)$ & & \\
\hline Changed attitude (58) & & & & 4.1 & .13 \\
\hline Totally disagree/partially disagree & $54(18.4)$ & $30(23.4)$ & $24(14.5)$ & & \\
\hline Neither agree nor disagree & $90(30.7)$ & $39(30.5)$ & $51(30.9)$ & & \\
\hline Totally agree/partially agree & $149(50.9)$ & $59(46.1)$ & $90(54.5)$ & & \\
\hline Changed risk perception (58) & & & & 5.7 & .06 \\
\hline Totally disagree/partially disagree & 49 (16.7) & $29(22.7)$ & $20(12.1)$ & & \\
\hline Neither agree nor disagree & $81(27.6)$ & $33(25.8)$ & $48(29.1)$ & & \\
\hline Totally agree/partially agree & $163(55.6)$ & 66 (51.6) & $97(58.8)$ & & \\
\hline $\begin{array}{l}\text { Improved skills to reduce binge } \\
\text { drinking (58) }\end{array}$ & & & & 7.6 & .02 \\
\hline Totally disagree/partially disagree & $45(15.4)$ & $28(21.9)$ & $17(10.3)$ & & \\
\hline Neither agree nor disagree & $86(29.4)$ & $33(25.8)$ & $53(32.1)$ & & \\
\hline Totally agree/partially agree & $162(55.3)$ & $67(52.3)$ & 95 (57.6) & & \\
\hline Would use the program again $(58)$ & & & & 5.2 & .07 \\
\hline Totally disagree/partially disagree & $49(16.7)$ & $28(21.9)$ & $21(12.7)$ & & \\
\hline Neither agree nor disagree & $89(30.4)$ & $33(25.8)$ & $56(33.9)$ & & \\
\hline Totally agree/partially agree & $155(52.9)$ & $67(52.3)$ & $88(53.3)$ & & \\
\hline
\end{tabular}




\begin{tabular}{cllll}
\hline $\begin{array}{l}\text { Would recommend the program to } \\
\text { someone else (58) }\end{array}$ & & & $\mathbf{6 . 1}$ & $\mathbf{. 0 4 7}$ \\
Totally disagree/partially disagree & $37(12.6)$ & $22(17.2)$ & $15(9.1)$ & \\
Neither agree nor disagree & $72(24.6)$ & $25(19.5)$ & $47(28.5)$ & \\
Totally agree/partially agree & $184(62.8)$ & $81(63.3)$ & $103(62.4)$ & \\
\hline
\end{tabular}

Table 5.8: Process evaluation of the Alerta Alcohol program: responses from participants in the intervention group by binge-drinking status.

\begin{tabular}{|c|c|c|c|c|}
\hline Variable (number of missing values) & $\begin{array}{c}\text { No binge } \\
\text { drinking } \\
(\mathrm{N}=198), \mathrm{n} \\
(\%)\end{array}$ & $\begin{array}{c}\text { Binge } \\
\text { drinking } \\
(\mathrm{N}=153), \mathbf{n} \\
(\%)\end{array}$ & $\chi^{2}(2)$ & $\begin{array}{c}P \\
\text { value }\end{array}$ \\
\hline Overall satisfaction (56) & & & 0.7 & .69 \\
\hline Very dissatisfied/dissatisfied & $24(12.9)$ & $11(10.1)$ & & \\
\hline Neither satisfied nor dissatisfied & $34(1.3)$ & $23(21.1)$ & & \\
\hline Very satisfied/satisfied & $128(68.8)$ & $75(68.8)$ & & \\
\hline Length of session: too long (56) & & & 5.9 & .053 \\
\hline Totally disagree/partially disagree & 37 (19.9) & $12(11)$ & & \\
\hline Neither agree nor disagree & $53(28.5)$ & $43(39.4)$ & & \\
\hline Totally agree/partially agree & $96(54.6)$ & $54(49.5)$ & & \\
\hline Length of session: too short (56) & & & 6.0 & .049 \\
\hline Totally disagree/partially disagree & $63(33.9)$ & $25(22.9)$ & & \\
\hline Neither agree nor disagree & $55(29.6)$ & $46(42.2)$ & & \\
\hline Totally agree/partially agree & $68(36.6)$ & $38(34.9)$ & & \\
\hline Interest in advice (56) & & & 1.7 & .43 \\
\hline Totally disagree/partially disagree & $36(19.4)$ & $16(14.7)$ & & \\
\hline Neither agree nor disagree & $38(20.4)$ & $28(25.7)$ & & \\
\hline Totally agree/partially agree & $112(60.2)$ & $65(59.6)$ & & \\
\hline Content credibility (58) & & & 7.3 & .03 \\
\hline Totally disagree/partially disagree & $15(8.1)$ & $9(8.3)$ & & \\
\hline Neither agree nor disagree & $21(11.4)$ & $25(23.1)$ & & \\
\hline Totally agree/partially agree & $149(80.5)$ & $74(68.5)$ & & \\
\hline Advice was useful (58) & & & 7.6 & .02 \\
\hline Totally disagree/partially disagree & $33(17.8)$ & $11(10.2)$ & & \\
\hline Neither agree nor disagree & $32(17.3)$ & $32(29.6)$ & & \\
\hline Totally agree/partially agree & $120(64.9)$ & $65(60.2)$ & & \\
\hline Advice was understandable (58) & & & 2.4 & .30 \\
\hline Totally disagree/partially disagree & $17(9.2)$ & $8(7.4)$ & & \\
\hline Neither agree nor disagree & $31(16.8)$ & $26(24.1)$ & & \\
\hline Totally agree/partially agree & $137(74.1)$ & $74(68.5)$ & & \\
\hline Advice was appropriate (58) & & & 8.7 & .01 \\
\hline Totally disagree/partially disagree & $40(21.6)$ & $9(8.3)$ & & \\
\hline Neither agree nor disagree & $43(23.2)$ & $30(27.8)$ & & \\
\hline Totally agree/partially agree & $102(55.1)$ & $69(63.9)$ & & \\
\hline Improved knowledge $(58)$ & & & 7.7 & .02 \\
\hline Totally disagree/partially disagree & 35 (18.9) & $11(10.2)$ & & \\
\hline Neither agree nor disagree & $37(20.0)$ & $35(32.4)$ & & \\
\hline Totally agree/partially agree & $113(61.1)$ & $62(57.4)$ & & \\
\hline Changed attitude $(58)$ & & & 2.3 & .31 \\
\hline Totally disagree/partially disagree & $38(20.5)$ & $16(14.8)$ & & \\
\hline Neither agree nor disagree & $52(28.1)$ & $38(35.2)$ & & \\
\hline Totally agree/partially agree & $95(51.4)$ & $54(50.0)$ & & \\
\hline Changed risk perception $(58)$ & & & 7.6 & .02 \\
\hline Totally disagree/partially disagree & $34(18.4)$ & $15(13.9)$ & & \\
\hline Neither agree nor disagree & $41(22.2)$ & $40(37)$ & & \\
\hline Totally agree/partially agree & $110(59.5)$ & $53(49.1)$ & & \\
\hline
\end{tabular}




\begin{tabular}{lllll}
\hline $\begin{array}{l}\text { Improved skills to reduce binge drinking (58) } \\
\text { Totally disagree/partially disagree }\end{array}$ & $30(16.2)$ & $15(13.9)$ & & $\mathbf{3 . 8}$ \\
$\quad$ Neither agree nor disagree & $47(25.4)$ & $39(36.1)$ & & \\
$\quad \begin{array}{l}\text { Totally agree/partially agree } \\
\text { Would use the program again (58) }\end{array}$ & $108(58.4)$ & $54(50.0)$ & & \\
$\quad$ Totally disagree/partially disagree & $34(18.4)$ & $15(13.9)$ & & \\
$\quad$ Neither agree nor disagree & $50(27.0)$ & $39(36.1)$ & & \\
$\quad$ Totally agree/partially agree & $101(54.6)$ & $54(50.0)$ & & \\
Would recommend the program to someone & & & $\mathbf{4 . 2}$ & $\mathbf{. 1 2}$ \\
else (58) & $27(14.6)$ & $10(9.3)$ & & \\
$\quad$ Totally disagree/partially disagree & $39(21.1)$ & $33(30.6)$ & & \\
$\quad$ Neither agree nor disagree & $119(64.3)$ & $65(60.2)$ & & \\
$\quad$ Totally agree/partially agree & &
\end{tabular}

\section{Discussion}

\section{Principal Findings}

In this paper, the effectiveness of the first Web-based, CT intervention to reduce BD in Spanish adolescents was tested through a cluster randomized controlled trial. An overall effect of the intervention on BD was not found at 4 months, but there was an effect on reducing HED. In addition, no effects were found on weekly consumption or on any consumption.

In a similar previous study, Jander et al. (2016) found a significant link between condition and age, where their intervention turned out to be effective in reducing BD in adolescents between 15 and 16 years or age. In our study, although there was a trend in $\mathrm{BD}$ reduction in both conditions, effects of the intervention on BD behavior was not found. Nevertheless, the intervention was effective in reducing HED, in contrast to Jander et al. (2016), where this pattern of alcohol consumption showed a lower prevalence than in previous studies (Measham, 2009; Jander et al., 2016). One explanation for our results may be that alcohol consumption is accepted in the Spanish context, including BD, whereas the more extreme type of drinking is less accepted and, thus, easier to change. As alcohol use is quite normative among Spanish adolescents (Romo-Avilés et al., 2016b; Golpe et al., 2017; ESTUDES, 2018), mostly in the context of parties or celebrations, it could be that the adolescents had no incentive to change their behaviors at these events (Kuntsche et al., 2005; Jander et al., 2016). In fact, in a previous qualitative study, many adolescents reported that they usually drink when they are at parties or during special occasions, such as fairs, Holy Week, or Christmas, showing a low-risk perception of BD (Martínez-Montilla et al., 2020).

Moreover, in Spain, the alcohol drinking phenomenon called Botellón is one of the main sources of entertainment among young people, especially during nonschool periods, and it is normal for youths to binge drink at this kind of event (Donath et al., 2011; Romo-Avilés et al., 2016b). Because of this, our study may have reduced the number of glasses of alcohol in the EC to be effective on HED, but it was not reduced enough to be effective on BD. Hence, future research needs to look at how to change norms regarding $\mathrm{BD}$ and how to prevent $\mathrm{BD}$ using more comprehensive campaigns and addressing cultural norms on BD. In addition, due to a lack of consensus as to what is considered an SDU (Parada et al., 2011; Mongan et al., 2015; Golpe et al., 2017), there may be varied results between countries, so these results may not be applicable to other populations. 
Another possible explanation is that the follow-up in the EC, with respect to the $\mathrm{CC}$, was closer to holiday periods, such as Holy Week or fairs, when adolescents usually go out to drink. Thus, this might be another reason related to the lack of effect on BD. Moreover, the intervention was only assessed in the fourth month; it would be advisable to carry out long-term assessments (ie, 12 or 24 months or an even longer time period) because several authors state that it requires a longer time period to see a real behavioral change (Velicer et al., 2013; Jander et al., 2016).

Previous studies on CT interventions found high attrition rates (Elfeddali et al., 2012; Kelders et al., 2012; Jander et al., 2016), often caused by a lack of face-to-face contact and a high degree of anonymity (Eysenbach, 2005; de Ruijter, Smit, de Vries \& Hoving, 2016). A 50\% attrition rate was taken into account in our power calculation, as with another study with a similar purpose to ours (Lima-Serrano et al., 2018), and our study reported a lower attrition rate than that in other studies, such as Jander et al. (2016), Elfeddali et al. (2012), and Stanczyk, de Vries, Candel, Muris \& Bolman (2016), whose dropout rates were $68.9 \%, 62.9 \%$, and $52.60 \%$, respectively. Hence, strategies such as carrying out most of the sessions within the schools as part of the health promotion curriculum, collaborating with teachers at the pre- and posttest sessions by phone call, or, if necessary, assisting teachers at the schools, could be useful to minimize the dropout rate. That is why we believe that future studies should continue to carry out the intervention within the school curriculum to reduce dropout rates. Furthermore, older adolescents and those who were enrolled in higher educational-level programs dropped out more often. Moreover, those who dropped out were more likely to engage in BD and reported a higher weekly consumption. These characteristics are consistent with other studies (Elfeddali et al., 2012; Schulz et al., 2013; Schulz et al., 2014a; Jander et al., 2016).

The recommendations by Jander et al. (2016) on how to approach the intervention were taken into account in the Alerta Alcohol program in trying to improve the adherence to the intervention, which seems to show slightly better results in our study. We focused on premotivational determinants, such as knowledge and risk perception (de Vries et al., 2003; de Vries et al., 2008), since, in a previous qualitative study, we found that the majority of adolescents were in the precontemplation phase, they had no intention of changing their health behavior (Martínez-Montilla et al., 2020). According to the Transtheoretical Model, an increase of consciousness is an important first step leading toward behavior change (Prochaska et al., 2008). We also developed a dynamic intervention, with different stories adapted to gender and age (Krebs et al., 2010; LimaSerrano et al., 2018). Moreover, we followed up on the intervention at the schools (eg, by phone call or, if necessary, in-person visit). It is possible that these actions could slightly improve the adherence to the Alerta Alcohol program.

Although two booster sessions were introduced at home, there was little participation; a possible solution to increase participation may be to incorporate these booster sessions within the school. Most of the participants stated that the reminder emails arrived in their spam folders, making the emails ineffective, which explains the low participation in these sessions. Some authors highlight the importance of the content and the schedule of the reminders (Cremers et al., 2012; Schneider, de Vries, Candel, van de Kar \& van Osch, 2013a), as well as sending notifications by other means, such as by text message and WhatsApp, among others, so these aspects could be improved in future studies. 
To improve adherence in future interventions, it is necessary to be familiar with the predictors of adherence. In our study, adolescents belonging to VT and CSE groups showed less adherence. In this sense, it should be emphasized that the adolescents who belonged to the VT group could have had a higher dropout rate because they finished the academic year before the posttest, and at the time of the posttest they were out of school. This should be taken into account for upcoming interventions. Furthermore, we found that being Spanish also appears to be a predictor of adherence. Also, the analyses of adherence indicated that non-binge drinkers adhered better to the intervention, this last finding being typical in health promotion. This is because, as a rule, people who adhere better to a health program tend to have better lifestyle habits (Schulz et al., 2012). However, other studies, such as that conducted by Schneider, van Osch, Schulz, Kremers $\&$ de Vries (2012), found that people with an unhealthy lifestyle usually visit their health intervention website more frequently; although, it is true that people with a healthier lifestyle were more likely to complete the health intervention. The problem is that health promotion programs should focus, particularly, on improving the health and lifestyle of people who lack a healthy lifestyle, even though the people who already lead a healthy lifestyle will strengthen their own. That is why we believe that more research is needed to know how to improve the adherence of people engaging in BD.

Finally, in the process evaluation, we found that adolescents in the EC group, in general, were very satisfied with the program. Regarding BD, binge drinkers were more satisfied with the program and showed a better response. Regarding gender, we can verify that females reported better a response to the program, which could be positive, since girls reported a higher rate of $\mathrm{BD}$, and the intention of the health program is to focus on those who have an unhealthy lifestyle (Schneider et al., 2012). Moreover, it could be that boys are more reluctant to change their behavior or participate in programs to improve their health.

\section{Strength and Limitations}

The main strength of this study is that it was based on the I-Change Model for predicting healthy behavior acquisition and was preceded by quantitative (Lima-Serrano et al., 2017) and qualitative research (Lima-Serrano et al., 2018). Furthermore, the Alerta Alcohol program was an adaptation of a previous intervention developed in the Netherlands based on extensive research that showed cost-effectiveness and effectiveness on BD among 15-16-year-olds (Jander et al., 2014; Drost et al., 2016; Jander et al., 2016). Although several interventions exist regarding alcohol, few address BD, and even fewer interventions use CT technology in this target group at the school level. In addition, this study builds on earlier work done in the Netherlands, which was adapted to the Spanish context. As both replication and implementation are important for science, we are convinced that this intervention is highly relevant and innovative. Moreover, for the Spanish context, there is no similar study targeting alcohol consumption and BD prevention using a Web-based, CT intervention in adolescents. Moreover, our sample was randomized into EC and CC groups, and there were hardly any differences at baseline between these groups.

One of the limitations of this study was that only short-term outcomes of the intervention were assessed. It would be advisable to add more long-term assessments to evaluate the effects in the long run. In addition, the follow-up evaluation coincided with periods after holidays, which may have increased the probability of $\mathrm{BD}$, as well as with periods in which adolescents belonging to the VT group were out of school, so this population was underrepresented. Further, many adolescents reported that some advice 
messages were long, therefore, they may have found them tiresome to read. In addition, it should be noted that Jander et al. (2016) developed their intervention in the context of a serious tailored game, which was not possible in our case, even though our program was a tailored dynamic intervention. Instead of a serious game, we used stories based on real facts identified in the previous focus group study.

Another limitation is that the sample size was determined for logistic regression, not taking clustering due to schools and classes into account. However, although we allowed for clustering in the analyses, for all binary outcomes the variances of the random effects turned out to be zero, which actually reduced the analysis to a logistic regression. Furthermore, it must be noted that we were rather close to complying with the required number of people, 612 versus 618 .

Moreover, compliance with the intervention protocol was relatively high for the initial classroom sessions, but this tailed off toward the end of the experimental period. However, this study improved the attrition rate through an adaptation of recommendations from the previous intervention developed in the Netherlands, resulting in a lower attrition rate, $50.9 \%$ vs $68.9 \%$ (Jander et al., 2016); high attrition rates are common in Web-based, CT interventions (Kohl et al., 2013).

The large volume of missing data $(>50 \%)$ was mainly due to missing values on the outcome variables, with less than $4 \%$ being due to missing values on covariates. In the case of missing values on outcomes, it is known that complete case analysis and multiple imputation yield the same results (White et al., 2010). Since the fraction of missing cases due to covariates is very small, the added value of multiple imputation of these covariates is considered to be minor. It is also worth noting that, although multiple imputation might be of added value, there is also the risk of choosing an incorrect imputation model, which could lead to biased results (White et al., 2011).

Finally, one should be cautious when interpreting these results on the effectiveness of the program for the variable HED, since only 16 subjects were classified as heavy drinkers at the pretest stage.

\section{Conclusions}

We observed that the rate of $\mathrm{BD}$ decreased more in the EC group than in the $\mathrm{CC}$ group, and the overall effect on BD was not significant. However, we did find that there was an effect on HED. We believe that using the CT intervention at schools could be a good option for reducing some alcohol patterns such as HED among adolescents. However, we must be cautious when interpreting the results due to the low number of subjects in the HED group, which could affect the generalization of the study. Further research with long-term measurements is needed, as well as improvements in adherence to eHealth interventions, which will increase effectiveness and public health impact. In this sense, as one of the strategies for improving the program was to shorten the messages, perhaps future programs could benefit from the use of more pictures and avatars. Another option is to compare written messages with video or audio messages, so that the adherence to, and effectiveness of, the program can be improved. 


\section{Chapter 6}

General Discussion 


\section{Aim of this dissertation}

The purpose of this dissertation was to design and develop the cultural adaptation of the Alerta Alcohol programme, the first web-based computer-tailored intervention to reduce alcohol consumption and binge drinking in Spanish adolescents, as well as to assess its effectiveness,. Alerta Alcohol was culturally adapted from the Alcohol Alert programme developed for the same objective for Dutch adolescents, an evidence-based intervention that has proven effective among Dutch adolescents (Jander et al., 2016), as well as being cost-effective (Drost et al., 2016), which suggests it may have potential for dissemination to European adolescents internationally. We are convinced that the cultural adaptation of an evidence-based programme to a completely different setting may be highly relevant and innovative (Cuijpers et al., 2005; Holtrop et al., 2018).

The discussion section was divided into five parts. In the first part, the main findings and the implications of the formative research, i.e., cultural adaptation and pilot study of the Alerta Alcohol programme, are described. For this, the main results of a previous study of focus group interviews to know the determinants that influence alcohol consumption and BD in Spanish adolescents are discussed. These results were used for the development of the computer-tailored intervention, the content of which was assessed through a two-round Delphi panel; and the assessment of adaptability, feasibility and satisfaction of the cultural adaptation of Alerta Alcohol programme was conducted through a pilot study before its implementation in schools. Subsequently, in the second part, the main findings and implications of the effect study, i.e., effectiveness evaluation of the intervention itself, as well as the effect of adherence, attrition rates and the development of the process evaluation, will be discussed. The third part consists of the discussion of the main methodological considerations encountered during the study evaluation. In the fourth part, suggestions for future research and practice are provided. The fifth and final part consists of the dissertation's general conclusion.

\section{PART I - FORMATIVE RESEARCH. CULTURAL ADAPTATION AND PILOT STUDY}

The cultural adaptation of the Alerta Alcohol programme was carried out through formative research in several studies, such as the qualitative research through focus groups of adolescents and parents, as well as the critical analysis of the cultural adaptation through a Delphi panel, and the feasibility assessment of the programme through a pilot study. A detailed description of the design and development process, and the content of the intervention, can be found in Chapter 2 (study protocol).

According to the focus group study (Chapter 3), one of the main findings was that Spanish students are often involved in BD in open-air public spaces, such as parks, squares, etc., probably due to the good weather, during weekends and with their group of friends. This phenomenon is called a Botellón (Donath et al., 2011; Romo-Avilés et al., 2016b). The Botellón is the most prevalent drinking event attended by the Spanish adolescent population and consists of drinking alcohol excessively in public places (Donath et al., 2011; Romo-Avilés et al., 2016b). In Spain, around 70\% of adolescents between 16 and 18 years old have participated in a Botellón in the last 12 months (ESTUDES, 2019). This situation differs from the pattern of consumption in Dutch adolescents, since they indicated that drinking mostly happened at a party, a bar or at home, with family or friends (Jander et al., 2014, Jander et al, 2016). Therefore, our intervention focused on the three most important drinking situations identified in the qualitative research, which were drinking in public spaces, celebrations such as parties, 
and at home, and the three were added as scenarios for the short stories (Lima-Serrano et al., 2018).

Regarding parents' perceptions, mothers reported that alcohol consumption and BD have become institutionalised in Spanish culture. They also report perceiving that the industry has an economic interest in encouraging adolescents to drink alcohol (ESTUDES, 2019). A study carried out by Hawkins, Holden, Eckhardt \& Lee (2018) assessed the global tobacco and alcohol regulation policies, showing that the sale, use and marketing of tobacco products are subject to extensive regulation and formal measures, which through policymaking have been adopted into the Framework Convention on Tobacco Control (FCTC), such as bans on smoking in public places or the regulation of industry sponsorships in sporting and cultural events, with the Spanish progress in tobacco control deemed to be considerable (ESTUDES, 2019). However, alcohol is subject to weak and less stringent forms of regulation, so the alcohol industry continues to play a central role in policymaking in many countries and at the global level (Anderson et al., 2012; Hawkins et al., 2018). In addition, alcohol advertising on the internet is among the least regulated domains (Anderson et al., 2012). Furthermore, at the global level, there is no equivalent of the FCTC for alcohol policy, and there are few signs of political will to negotiate such an agreement (Hawkins et al., 2018). The parents' reports thus voice the result of such a lack of clear preventive policies.

Although currently in Spain you can only buy it and consume it legally from the age of 18, alcohol remains a very easily accessible drug for adolescents (Anderson et al., 2012; Montes, 2012; Romo-Avilés et al., 2016b), with supermarkets being the place where the highest percentage of underage youths obtain alcohol (54\%) (ESTUDES, 2019). A recent study shows that many young Spaniards consume alcohol in public places (a phenomenon known as Botellón) before visiting pubs, bars and nightclubs, with a general trend towards BD and even intoxication (Donath et al., 2011; Anderson et al., 2012; Romo-Avilés et al., 2016a). One of the main reasons was the cheaper price of alcohol in off-premise locations particularly in supermarkets, as it is three times lower than in a bar or pub (Rabinovich et al., 2009). In addition, the companies lobby strongly to defend their right to sell cheap alcohol (Anderson et al., 2012; Hawkins et al., 2018), which has a significant impact on public health (Howell et al., 2013; Golpe et al., 2017; ESTUDES, 2019). Fairman et al. (2019) identified that a lower overall strength in alcohol policy was associated with increased risk of BD. Besides, higher beer excise taxes were associated with reduced risk of $\mathrm{BD}$, although the number of liquor stores was not significantly associated with any BD trajectory. In 2006, the antibotellón law was enacted, which also saw the installation of the "Botellodromo" (legal site to engage in a "Botellón") as a palliative to reduce the noise and pollution caused by young drinkers (Amezcua et al., 2015). Consequently, not only should the development of alternatives for leisure activities and free time for adolescents be addressed, but the legislation, sociopolitical and environmental factors should also be tackled (Romo-Avilés et al., 2016a). Health policies, accessibility to alcohol, organisation of spaces and leisure time was considered one of the key explanatory elements within the contextual factors that facilitate the behaviour of this consumption (Romo-Avilés et al., 2016a). It is important to highlight that this dissertation does not seek to explain the emergence and maintenance of different policy regimes applied to alcohol industries, since this would require a fuller engagement with the myriad of factors that determine policy outcomes and is beyond the scope of this paper. 
An important conclusion that can be drawn based on the studies described in this dissertation is that parents' permissiveness is a significant problem in the Spanish environment and it must be addressed. Several studies have shown that parental consumption, absence of parental control, lack of family ties and communication have been found to be robust risk factors associated with BD in adolescents (Martínez-Hernáez et al., 2012; Pedersen et al., 2013; Gersh et al., 2017). In our study, alcohol drinking often takes place at celebrations, or at home in a family context, being a more typical behaviour of families in southern Europe than their northern coevals (Rolando et al., 2014b). Adolescents and mothers reported the availability of alcohol at home, and many students claimed that their family had offered them alcohol, these findings being in line with previous studies (Jander et al., 2013; ESTUDES, 2018). In this sense, in Spain, 93.2\% of alcohol users were minors and $48.3 \%$ of their parents allowed them to drink alcohol (ESTUDES, 2018). Authors such as Mejia et al. (2016) confirmed the positive association between proper levels of restriction and parental demands and consumption as a protective factor. Clak et al. (2012) stated that high levels of parental control decrease alcohol consumption and alcohol intoxication. However, as in the study of Jander et al. (2013), many parents are not fully aware of the negative consequences of alcohol use, and they lack self-efficacy to control and reduce alcohol intake in their children. Some parents even think that forbidding them to go to a Botellón or to drink is harmful because it is a way of encouraging them to do so. This is in line with some qualitative research which claimed that letting children drink at home with their family can be protective against $\mathrm{BD}$, claiming that traditional alcohol-raising practices appear to be ambiguous and are being called into question (Østergaard, 2009; Rolando et al., 2014a). Therefore, as well as the intervention carried out by Jander et al. (2016), in future programmes it would be ideal to develop an intervention focused on both adolescents and their parents as a target group. Despite this, our advice on parental influence was adapted to our context.

Another important factor that can be drawn upon based on our qualitative study was that the adolescents highlighted low self-esteem as an important factor that influences BD, since they used alcohol to socialise, to try to "fit in" as well as lose fear and shame. Some authors suggest that self-esteem and the need to belong to a group may both be related to student drinking (Hamilton et al., 2017). Much of human behaviour is motivated by a desire to satisfy belongingness needs. Therefore, there is a fundamental need to feel accepted and fit in with those around them (Baumeister et al., 1995; Hamilton et al., 2017). Furthermore, self-esteem may influence how individuals satisfy their connectedness goals within specific relationships (Murray et al., 2008). Self-esteem refers to the degree to which individuals value, like, respect, and accept themselves, and it is widely considered to be one of the critical elements that affect future behavioural choice and action (Leary et al., 2000; Lee et al., 2018). Hamilton et al. (2017) concluded that students with low self-esteem drink because they lack the self-resources to deal with unmet belongingness needs. Similarly, Bartsch et al. (2017) found that youths with low self-esteem are at a higher risk of drinking and engaging in $\mathrm{BD}$, confirming the protective role of high levels of self-esteem against substance use for adolescents (Lee et al., 2018). Despite this, other studies did not find associations between reported self-esteem and substance abuse (Henderson et al., 2006; McKay et al., 2012), which may be due to different target populations, settings, covariates, and measures of substance use. In addition, it should be noted that several authors claimed that programmes that emphasise only affective goals, such as self-esteem, are less effective than those that focus on promoting attitudes, behaviours and life skills (Sambrano et al., 2005; Vázquez et al., 2018). However, in our study, in addition to advice for promoting attitudes and 
behaviours for life skills, such as action plans, we included specific tips to improve adolescents' self-esteem. However, due to the length of the evaluation questionnaire, it was not possible to assess effects on perceived self-esteem in our target group.

In addition, gender was also considered as a predisposing factor for BD in the focus group study. Several studies show that boys tend to drink alcohol more heavily than girls (Montes, 2012; Golpe et al., 2017). However, recent evidence suggests a diminishing gender gap in the prevalence of drinking, with equal levels between boys and girls (Keyes et al., 2011; Romo-Avilés et al., 2016b; Jang et al., 2017; ESTUDES, 2019). Despite this, in our study, girls stated to have more gender stereotypes and a stigmatised negative social image of drinking, with higher risk of being exposed to non-consensual sex. In addition, girls and mothers reported greater parental control over girls than boys, as well as more punishments if they got drunk (Romo-Avilés et al., 2016b). In addition, we found some differences between awareness factors, social influence of family and surrounding people, attitude towards consumption, and self-efficacy. For example, boys gave more advantages to $\mathrm{BD}$, did not perceive any danger in $\mathrm{BD}$, recognised less short-term consequences of $\mathrm{BD}$, and reported less parental control than girls, among others. Therefore, an increase in female alcohol consumption, together with the exposed vulnerability and the differences between determinants that influence consumption among boys and girls would make us aware of the need for increased prevention efforts to address drinking problems by gender (Bartsch et al., 2017). Therefore, in the cultural adaptation of the Alerta Alcohol programme for adolescents, gender differences were taken into account in the design of the intervention.

In addition, experts advised us to design short stories and avatars for both genders, for boys and girls, considering gender differences (Chapter 4). Likewise, as several studies showed that personalisation and feedback are effective working mechanisms of CT interventions (Dijkstra, 2005; Schulz, et al 2013; Jander et al., 2015), each participant was given the opportunity to choose the names of the avatars and characters from the story. This attracted much attention from the participants, as they chose names that were familiar to them. Moreover, experts also proposed using emoticons to emphasise the answers, since this practice is very common among adolescents. The opportunity to identify with the avatars may result in more thoughtful information processing via the central route of persuasion, since tailored messages are perceived as being personally relevant (Cacioppo, Petty, Kao \& Rodriguez, 1986). Thus, this strategy aims to make participants feel personally addressed, and to increase their attention and processing of information, encouraging the person to pursue the desired behaviour effectively (Boudreau et al., 2015; van het Schip et al., 2020). In addition, regarding the content of the programme, experts suggested focusing on reducing alcohol consumption in general, and not only on BD. Furthermore, knowledge about the detrimental effects of alcohol and BD on adolescents was further emphasised. Therefore, we developed new advice regarding the perception of damage, the seriousness of health problems related to $\mathrm{BD}$, and the probability of acquiring these problems (e.g., liver problems, alcohol dependence, traffic accidents, etc.). This is in line with previous studies, since it is necessary to focus not only on motivational factors, but to emphasise pre-motivational factors that are relatively easy to manipulate and change (de Vries et al., 2003; de Vries et al., 2008; Jander et al., 2016).

On the other hand, experts also proposed that advice should be more concise, direct and personalised in order to increase rates of subjects' continued participation in the intervention. This is also in line with previous studies (Jander et al., 2015; Pearson et 
al., 2015; Jander et al., 2016). In addition, due to the high drop-out rate in previous studies (de Vries et al., 2012; Elfeddali et al., 2012; Jander et al., 2016), experts proposed that the intervention should be implemented in schools as part of the health promotion curriculum. Hence, they proposed not only to send reminders to the participants but also that the researcher should monitor the intervention development by telephone or, if necessary, by visiting the schools, since often teachers could require help to offer the intervention (Cremers et al., 2012; Lima-Serrano et al., 2018). In this sense, Cremers et al. (2012) said that in-school programmes have several drawbacks, such as limited time and insufficiently trained or unmotivated personnel, which makes monitoring necessary. The fact that some of the researchers had to be present at school during the sessions may have influenced the drop-out decrease.

A well-adapted programme could require some actions such as adding, omitting, or altering programme components or changing implementation processes to respond to the local context, as long as the core original programme components are preserved (McKleroy et al., 2006; Holtrop et al., 2018). Based on this approach, we altered some components to develop the Alerta Alcohol programme. One of the most important and influential changes that had to be made was an adaption in the programme design, since Jander et al. (2016) developed their intervention in the context of a serious tailored game, which was not possible in our case due to time constraints and the high cost of making such a game. Additionally, in the preparatory phase, adolescents indicated that they would prefer an intervention in which they saw examples of real cases of how alcohol affects other adolescents. Therefore, instead of a serious tailored game, and trying to maintain our goal of developing a tailored and dynamic intervention (Krebs et al., 2010), we developed interactions through short stories with avatars, which were based on real situations that were identified in the previous focus group study, maintaining the central dynamics of providing the adapted messages through the I-Change Model (Lima-Serrano et al., 2018).

Lastly, Alerta Alcohol was well received by Spanish secondary school students, who rated the intervention positively. They claimed that they liked the general design of the programme, the avatars and stories, and that the language used was appropriate for them. Furthermore, they said that they were very satisfied with the programme, that they would use it again, and they would recommend the programme to others. This offering is a potential intervention tool that is operational and feasible for use in secondary schools. In addition, the critical analysis of the cultural adaptation and feasibility testing, through a Delphi study and a pilot study, of the evidence-based Alerta Alcohol programme has allowed us to refine this intervention while taking into account the characteristics of Spanish adolescents and the Spanish drinking culture.

\section{PART II - EFFECTIVENESS OF THE ALERTA ALCOHOL PROGRAM}

Through the analysis of the effectiveness of the programme (Chapter 5), we found that, although there was a trend in BD reduction in both conditions, significant effects of the intervention on BD behaviour was not found. Nevertheless, the results of the intervention suggest that it was more effective in adolescents who engaged in heavy episodic drinking (HED), which referred to the consumption of 10 or more glasses of alcohol on at least one occasion in the previous week (Best et al., 2006; Jander et al., 2016). The logistic regression analysis showed that the odds of HED in the CC group was nine times the odds of HED in the EC group. We can highlight that this pattern of alcohol consumption is also a serious problem in Western society, with major psychological, social, and economic consequences (Best et al., 2006; Cox et al., 2015), so this finding 
becomes relevant. Unfortunately, weekly consumption and any consumption were not affected by the intervention, as we found no significant effect in any of those subgroups.

One of the most consistent explanations for our result may be that alcohol consumption, including BD, is accepted in the Spanish context, whereas the more extreme type of drinking is less accepted and, thus, it is easier to change this behaviour. Several studies have already stated that alcohol consumption is quite common and socially accepted among Spanish adolescents (Romo-Avilés et al., 2016b; Golpe et al., 2017; ESTUDES, 2018), mostly in the context of parties or celebrations as well as the Botellon, which is one of the main sources of entertainment among young people today (Donath et al., 2011; Romo-Avilés et al., 2016b). Therefore, our study may have reduced the number of glasses of alcohol in the EC to be effective on HED, but it was not reduced enough to be effective on $\mathrm{BD}$, since adolescents had no incentive to change their behaviours at these events (Kuntsche et al., 2005; Jander et al., 2016). However, we should be cautious when interpreting these results, since only 16 subjects were classified as HED at the pre-test stage, and 8 subjects reported HED at the follow-up stage. In addition, another reason for the lack of effectiveness in BD could be that this was evaluated at short-term (4 months), since several authors stated that it is necessary to add more long-term assessments, i.e. 12 or 24 months, or even more time, to know the true effects in terms of behavioural change (Velicer et al., 2013; Jander et al., 2016). Moreover, the follow-up in the EC with respect to the $\mathrm{CC}$ was closer to holiday periods, such as Holy Week or fairs, when adolescents usually go out to drink, and this can further increase the chances of engaging in BD.

The analysis showed that educational level, ethnicity and not having engaged in $\mathrm{BD}$ in the previous 30 days at baseline were predictors of adherence, which should be considered in future interventions aimed at Spanish adolescents. In addition, Alerta Alcohol showed better adherence with respect to interventions carried out in the Netherlands. After the baseline, $62.1 \%$ started the second session at school and $47.2 \%$ returned for the third session at school. Regarding home sessions, adherence rates were very low, as in the study by Jander et al. (2016), with only 3.1\% returning for the fourth session and $1.1 \%$ returning for the fifth session at home. High drop-out rates are common in web-based CT interventions (Elfeddali et al., 2012; Kelders et al., 2012; Kohl et al., 2013; Schulz et al., 2013; Jander et al., 2016), reducing the ability to reveal intervention effects (Eysenbach, 2005). Despite the high level of attrition recorded from adolescents and schools at the follow-up assessment, we managed to improve the drop-out rate slightly with regard to previous interventions. These limitations and their implications for future research and practice are discussed later on this paper.

Finally, adolescents in the EC group were very satisfied with the programme, they would use the programme again, and would recommend it to others. Furthermore, nonbinge drinkers and females provided positive answers in the process evaluation. This could be because boys and drinkers are more reluctant to change their behaviour or participate in a programme to improve their health (Martínez-Montilla et al., 2020).

\section{PART III - METHODOLOGICAL CONSIDERATIONS}

Based on the studies presented in this dissertation, the results must be interpreted in light of numerous methodological considerations that may have affected internal and external validity. Therefore, this section will provide an overview of the most important methodological concerns regarding the participation and attrition rate, operationalisation of the intervention and study designs, measurements, and statistical analyses. 


\section{Participation and attrition rate}

One of the main limitations shown by previous studies on web-based CT interventions was finding high attrition rates (de Vries et al., 2012; Elfeddali et al., 2012; Kelders et al., 2012; Jander et al., 2016), often caused by a lack of face-to-face contact and a high degree of anonymity (Eysenbach, 2005; de Ruijter et al., 2016). In our study, a $50 \%$ attrition rate was taken into account in our power calculation, based on other studies with a similar purpose to ours (Lima-Serrano et al., 2018). It is known that for an intervention to be effective and have a great impact on public health, it should not differ from how it was supposed to be used in the previously established protocol (Glasgow, Vogt \& Boles, 1999; Eysenbach, 2005). In this sense, compliance with the intervention protocol was relatively high for the initial classroom sessions, but this tailed off towards the end of the experimental period. However, this study improved the attrition rate through an adaptation of recommendations from the previous intervention carried out in the Netherlands, resulting in a lower attrition rate (50.9\% vs. 68.9\%) (Jander et al., 2016); as well as a lower attrition rate than that in other previous studies, such as Elfeddali et al. (2012), and Stanczyk et al. (2016).

Although we improved drop-out rates, approaching the goal we set in the study protocol, a high level of dropouts was recorded from adolescents and schools during the intervention or at the follow-up assessment. Therefore, this could mean that a high number of adolescents did not finish receiving all the intervention contents, or that they did not respond to the follow-up evaluation. These missing data from the intervention could affect the results and effectiveness of the programme. Thus, the adolescent dropout rate could also explain the intervention's lack of effect on BD, due to the analysis' low ability to detect possible effects, as it is very likely that the real effectiveness could not be determined, or that it does not become apparent due to high attrition rates (Eysenbach, 2005).

\section{- School attrition rate}

After contacting 37 Andalusian schools, 16 accepted our invitation, and they were randomly assigned to either the EC or CC. The main reasons why schools did not accept participation were that the programme was too time-consuming, since it spanned several sessions. However, the number of sessions cannot be shortened, since several authors state that it requires a longer time period to see a real behavioural change, going from the pre-contemplation to preparation phase (Prochaska et al., 2008; Velicer et al., 2013; Jander et al., 2016). In addition, other schools stated that they were already involved in another drug-related programme, or stated that there were logistical problems, such as not having a computer room with individual computers for each student or not having a good Wi-Fi connection. Other schools did not respond to our phone calls and emails.

Fortunately, only one of the schools from the $\mathrm{CC}$ withdrew their participation due to logistical problems and did not begin the baseline assessment. In addition, we talked to teachers and coordinators from schools, who had several classes that dropped out, to hear their opinions on the problems. Several issues arose from these conversations, such as poor Wi-Fi connection, something quite common currently in Andalusian schools. They also reported having trouble finding a suitable date, due to final exams and the fact that some groups which participated in VT were beginning their placements or training in companies around this time, which was also a cause of drop-out, as projects such as ours are not a priority during those periods. In some cases, this also meant that more than 
half of the participants of the schools, or even entire schools, dropped out because they had enrolled only in this class.

Likewise, one of the most important problems was the start date of the intervention and the period of contact with the schools. Originally the intervention was planned to be implemented in schools in October 2016 with two follow-up assessments, one in February and the other in June 2017. However, due to the delay in the design and preparation of the programme, in October 2016, a pilot study of the programme was carried out. Finally, the baseline assessment of the intervention took place between January-February 2017, with a follow-up assessment at four months in May-June 2017. Since the intervention was to be implemented in schools as part of the health promotion curriculum, most schools rejected us because they reported that they had already prepared the curriculum, and it would have been difficult for them to modify class schedules. Teachers, coordinators, and directors of schools in Spain usually prepare the academic year during the months of JuneJuly to only make small modifications when they arrive in September after the summer holidays.

Lastly, during the fieldwork we observed that the teachers and coordinators lacked interest in implementing any programmes in their schools, since they were unconvinced of the need to participate in the RCT any longer, or conversely, they were unmotivated to do so. This was in line with Cremers et al. (2012) who said that in-school programmes have several drawbacks such as limited time and insufficiently trained or unmotivated personnel, so monitoring becomes necessary.

\section{- Adolescents attrition rate}

The adolescent attrition rate (50.92\%) during the intervention was as expected, and it was even improved over other studies, as preventing drop-out was one of the major focal points during the adaptation and development process of the intervention. In addition, although two booster sessions were introduced at home, there was little participation. Most of the participants stated that the reminder emails arrived in their spam folders, making the emails ineffective, which also explains the low participation in these sessions. Some authors highlight the importance of the content and the schedule of the reminders (Cremers et al., 2012; Schneider, Schulz, Pouwels, de Vries, \& van Osch, 2013b), as well as sending notifications by other means, such as by text message or WhatsApp.

The drop-out analyses showed that adolescents returning the follow-up questionnaires were significantly younger and had lower educational levels. Moreover, the adolescents that returned the questionnaires were less likely to be binge drinkers and had a lower weekly consumption. When a multilevel analysis was carried out, those who reported a higher weekly consumption were more likely to drop-out of the intervention. This last finding is typical in health promotion programmes. This is because people who continue in a health programme for longer tend to have better lifestyle habits (Schulz et al., 2012). In addition, older participants were also more likely to drop out of the intervention, which makes us think that the programme could be more attractive to younger students. These characteristics are consistent with other previous studies (Elfeddali et al., 2012; Schulz et al., 2013; Schulz et al., 2014a; Jander et al., 2016). On the other hand, we might think that older adolescents are generally more opinionated and reluctant than younger adolescents, and this, together with the fact that the intervention was based on voluntary participation, would make them perhaps more likely to participate more frequently in an intervention. 


\section{Operationalization of intervention and study designs}

One of the limitations of this study was that it has only been assessed at a 4-month follow-up, while some authors recommended using a longer follow-up period in future intervention studies, for example, 12 or 24 months, or an even longer time, in order to make a real change in behaviour (Velicer et al., 2013; Jander et al., 2016). Increasing the follow-up period would ensure that conclusions about causal relationships can be drawn in contrast to much more cross-sectional research (Lindell and Whitney, 2001).

In addition, the schools reported the large number of sessions of the intervention to be the main problem, since they found it difficult to include so many sessions during class time. Limiting the number of sessions could also be a way to reduce schools' dropout rates. According to the meta-analytic review carried out by Moyer, Finney, Swearingen, \& Vergun (2002), brief interventions may be equally effective when compared to longer interventions, and with the advantage that they have higher completion rates. Furthermore, according to our results, we did not find associations between more intervention use and better intervention outcomes. In contrast, other studies showed that more intervention use does lead to better health outcomes and that people need to be exposed to educational content multiple times before effects can be expected to take place (Brug, Glanz, van Assema, Kok, \& van Breukelen, 1998; Dijkstra, de Vries, Roijackers \& van Breukelen, 1998; Couper et al., 2010; Wantland, Portillo Holzemer Slaughter \& McGhee, 2004; Elfeddali et al., 2012; Jander et al., 2016). Therefore, while it is necessary for the intervention in schools to be operational, in order to make a real change in health behaviour we must investigate the dose-response relationship and find a balance.

Despite our study showing that adolescents rated the messages as positive overall, most of them reported that some advice messages were too long. Perhaps they received a lot of information and they became overwhelmed and read the information less carefully. A review showed that, in questionnaire studies, shorter questionnaires had higher response rates than longer questionnaires (Edwards et al., 2009). Therefore, efforts should be made to shorten messages.

\section{Measurements}

Following the recommendations from a previous study by Jander et al. (2016), and by the experts from the Delphi study (Chapter 4), we decided not to focus only on motivational determinants but also on pre-motivational determinants that are relatively easy to manipulate and change (de Vries et al., 2003). Therefore, some questions about knowledge, self-esteem, cues to action and risk perception (i.e. perception of damage, the seriousness of health problems, and the probability of acquiring these problems) were included in the programme in order to provide tailored advice to the participants. Additionally, in the previous qualitative study (Chapter 3), adolescents were in the precontemplation phase, which means they had no intention of changing their health behaviour, since they had not yet suffered from negative short-term consequences of alcohol use. These kinds of interventions are mostly suitable for people who are already motivated to change their behaviour. According to the Transtheoretical Model, an increase of consciousness is an important first step leading towards behavioural change (Prochaska et al., 2008). It is possible that these actions slightly improved the adherence rates and reduced the drop-out rates of the Alerta Alcohol programme.

In addition, non-drinkers reported having difficulty when answering some questions, such as those concerning their attitude, their intention to drink or social norms, 
since they had to answer the questions whilst imagining that they were actually drinking. This was a significant problem, because they felt it was difficult to imagine doing something that they had not done in real life. In this vein, some adolescents found some of the questions very personal, such as their parents', siblings' and friends' alcohol use, and they were reluctant to answer these questions. Despite this, these questions cannot be eliminated, since they are essential to evaluate the theoretical model, although we could analyse how to ask certain questions without adolescents feeling as though the questions are formulated intrusively. We also had problems regarding family questions, since adolescents hesitated to provide information about the composition of their family or about the people with whom they currently lived. Thus, it will be necessary to adapt the introductory text. All this could require a new validation test for these questions.

Lastly, the measurements used in the studies presented in this dissertation are also subject to limitations. All independent and dependent variables were, for example, assessed via self-reported questionnaires. Self-reported data are more likely to be inaccurate than objectively assessed variables, since adolescents could provide unrealistic answers (Nawaz, Chan, Abdulrahman, Larson, \& Katz, 2001). Nevertheless, the conclusions of our studies are still considered to be valid, since many of the studies used in this dissertation have been based on this method (de Vries et al., 2003; Cremers et al., 2012; Jander et al., 2016; Boyle, Earle, McCabe \& LaBrie, 2018). Another limitation in this dissertation is a lack of a longitudinal study on the determinants that influence alcohol consumption and BD in Spanish adolescents, as this could have helped to further analyse the influence of the model's factors.

\section{Statistical analyses}

All statistical analyses have been performed in line with the most recent insights. However, there is an ongoing debate about which statistical approaches are most suitable for dealing with missing values (Chapter 5). The missing data in our study was mainly due to missing values on the outcome variables, with less than $4 \%$ being due to missing values on covariates, so we performed the analysis with pairwise deletion. Therefore, in the end it was not necessary to carry out a data imputation analysis. According to the White et al. (2010) study, it is known that complete case analysis and multiple imputation yield the same results when the missing values are on outcomes. There are many imputation techniques, and each technique has both strengths and limitations; there is the risk of choosing an incorrect imputation model, which can result accordingly in biased estimates (Musil, Warner, Yobas, \& Jones, 2002; Donders, Van der Heijden, Stijnen, \& Moons, 2006; White et al., 2011). Because it is unclear which imputation technique is most suitable, and since, in our case, the fraction of missing cases due to covariates is very small, the added value of multiple imputation of these covariates was considered to be minor. Despite what was previously mentioned, multiple imputation is not the perfect solution to deal with missing values (Blankers, Koeter, \& Schippers, 2010; White et al., 2011), and its use in RCT interventions is very common. Therefore, it is recommended to examine how the application of multiple imputation can be improved or if more optimal imputation techniques exist to deal with missing values.

Additionally, another limitation of our study was that the sample size was determined for logistic regression in the original grant proposal, which did not take clustering due to schools and classes into account. In the protocol study, we calculated 615 subjects for the CC group and 615 for the EC group, for a statistical power of .80 and a two-sided test with a type I error rate of alpha $=.05$, instead of 618 subjects. On the other hand, although we allowed for clustering in the analyses, for all binary outcomes the 
variances of the random effects turned out to be zero, which reduced the analysis to a logistic regression. However, it must be noted that we were rather close to complying with the required number of participants (615 vs. 618).

\section{PART IV - RECOMMENDATIONS FOR PRACTICE AND FUTURE RESEARCH}

The following section will provide recommendations for practice and future research based on the previous studies presented in this dissertation.

\section{Recommendations for practice}

- Although the efficacy of the intervention has been examined at a 4-month follow-up, it is recommended to refer to a longer follow-up period in future intervention studies (for example, 12 or 24 months, or an even longer time) in order to make a real change in behaviour (Velicer et al., 2013; Jander et al., 2016). In addition, this would provide a better indication about whether the web-based computer-tailored intervention is actually able to prevent BD in adolescents.

- One of the most significant problems was the start date of the intervention and the period of contact with the schools. Therefore, for future interventions in schools, we recommend contacting them before the months of June to July, so that teachers and coordinators can incorporate the intervention in the following academic year. This would mean carrying out the baseline assessment at the beginning of the course (September-October), and we could incorporate two follow-up assessments every four months in the same course, avoiding losses between academic years.

- Moreover, one of the possible explanations for the lack of effect on BD was that the follow-up was closer to holiday periods, such as Holy Week or fairs, which can further increase the chances of engaging in BD. It is recommended to consider the holiday periods of each city. Additionally, if the follow-up measurement takes place earlier than the end of the course, it could prevent students from being in their exam periods, or vocational training students having started their company placements.

- Based on the problems reported by schools regarding Wi-Fi connection, a solution would be to carry out an off-line intervention that was previously installed in the school computers. In this way, attrition bias could also be reduced, showing the true effect of the intervention on alcohol use and BD.

- In line with one of the problems reported by schools, it seems better to limit the number of sessions of future web-based computer tailored interventions, since the institutions had a real problem adding so many sessions to class time. In addition, despite the positive rating that adolescents gave to the messages, most of them reported that some advice messages were too long. As mentioned previously, perhaps they received a lot of information and they became overwhelmed, which could make them read the information less carefully. Therefore, for future studies, we might therefore consider reducing the number of topics and shorten the messages, and in this way, decrease the number of sessions. This could also be a way to reduce schools' drop-out rates.

- Self-esteem is a critical factor affecting psychological and social adaptation in adolescents (Rodríguez et al., 2012; Richardson et al., 2013). Low self-esteem is considered a determinant for risky behaviours in adolescents, such as alcohol drinking or BD (Bartsch et al., 2017). Hence, a validated questionnaire should be incorporated to assess adolescents' true self-esteem, as well as provide messages in future interventions with the aim of improving this element. 
- Adolescents claimed that the information must be provided in a realistic context, in which they are confronted with alcohol so that they can recognise the cues in real life (Bartholomew et al., 2011). This could be achieved, for example, by showing situations in which adolescents feel identified, something that could attract their attention, improve their adherence rates and awareness, and favour adolescents' premotivational and motivational components to decrease BD. Interventions that make participants feel more involved and supported (through feelings of relatedness) may be more likely to be used among participants (Walthouwer et al., 2015).

- Although most adolescents gave positive scores to the general design of the programme, the capacity to pay attention and participate in our programme was short, which may imply the need for utilising other communication methods as well. Thus, we recommend using a professional writer to improve the stories and the feedback messages, making them more appealing to our target group (Jander et al., 2013).

- According to our results, prevention strategies should focus on gender differences. Results also suggest the need for gender specific analyses of factors associated with $\mathrm{BD}$, since gender can be considered a predisposing factor for this behaviour. Therefore, we encourage the continued development of interventions (i.e. stories, avatars, etc.) that take into account gender differences.

- Some questions were especially difficult for non-drinkers to answer, since they had to answer the questions whilst imagining that they were actually drinking. Therefore, the programme should reformulate the questions in the third person for non-drinkers, or simply not ask them these questions. Questions about family could be confusing, so it will be necessary to adapt the introductory text. In addition, some questions were found to be very personal. Thus, we could analyse how to ask questions without making adolescents feel that they are formulated in an intrusive manner. The operationalisation of these questions should be critically reviewed in order to reduce difficulty in answering, and this could require a new validation test of said questions.

- Most adolescents in our study did not have the intention to change their behaviour. Therefore, we recommend strengthening the current intervention to better address premotivational factors such as risk perceptions, and motivational factors addressing in more detail the cons of BD.

- As alcohol consumption is embedded in the Spanish culture, research must delve into how to better change social norms related to alcohol consumption and BD. Additional research is also needed regarding the impact of environmental and policy approaches (i.e., legislation, price polices, minimum age of consumption, alcohol advertising through new channels such as the internet, etc.) (Anderson et al., 2012).

- Additionally, we also need a better understanding of how to better reach respondents who are not considering changing their behaviour. Furthermore, to improve adherence rates, it is necessary to be familiar with the factors that promote them. Improving adherence is crucial for future interventions. Several strategies may be relevant, but they should preferably be tested in an experimental design to verify whether they have potential. An example may be the use of avatars or animated videos to increase attention and amusement (Boudreau et al., 2015; van het Schip et al., 2020).

\section{Recommendations for future research}

\section{- Using gamification for future interventions}

One of the main differences of the original Dutch programme was that, due to time and economic constraints, it was not possible to use gamification. Gamification is based on the use of elements of video game design in non-game contexts to make a product, 
service or application that is more fun, attractive and motivating (Ortiz-Colon, Jordán \& Agredal, 2018). In this case, the game would serve purely as a vehicle to transport the classical text-based CT intervention. Carrying out a gamified intervention could increase motivation and involve users in the intervention, without letting adolescents explicitly know that we are trying to change their health behaviour, making them less resistant to participate and less likely to come up with counterarguments (Slater \& Rouner, 2002). Several previous studies on the reduction of alcohol consumption and BD have reported some promising results regarding the effectiveness of gamification in CT interventions (Connolly, Boyle, MacArthur, Hainey \& Boyle, 2012; DeSmet et al., 2014; Carrà et al., 2016; Boyle et al., 2018). On the other hand, the study developed by Jander et al. (2016) showed that the very low adherence rates in this study suggest that the game was not optimal in increasing motivation. Therefore, we recommend testing the effectiveness of gamification by comparing it to a non-gamification intervention group to determine the impact of the effect on motivation and adherence in the intervention.

In addition, a modality within gamification would be using videos as a delivery format, which could potentially improve the effects and attractiveness of these interventions. In this sense, recent studies stated that the delivery of intervention content via videos may improve the effectiveness of web-based computer-tailored interventions (Soetens, Vandelanotte de Vries \& Mummery, 2014; Stanczyk et al., 2014; Walthouwer et al., 2015; Cheung et al., 2017). One of the possible causes of the lack of effectiveness in our study could be that the adolescents received a lot of information, so they became overwhelmed and read the information less carefully. Therefore, video messages could be more appropriate, since some people typically have more difficulties processing large amounts of text (Petty \& Cacioppo, 1986). Videos may work better because they reduce the cognitive effort needed to process information from large amounts of text, which can lead to better comprehension (Petty et al., 1986; Sweller, 1994).

Finally, consideration should be given to studying whether advice is best provided through cartoon videos or through real adolescents, those currently called influencers. The spread of healthy behaviours through the social networks of influencers is a promising way to impact adolescent behaviour (Kim et al., 2015). Previous studies have used lay health influencers to communicate information through the internet about preventing sexually transmitted infections, showing that influencers may be central to information flow, facilitating a healthy behaviour spread within their social network (Wu et al., 2019). Adolescents may distrust outside authorities but find use in advice from known influencers who have credibility (Kelly et al., 2006). Hence, a promising intervention would be to evaluate the effectiveness of the video version, where the messages and advice are given by influential adolescents from social networks.

\section{- Interventions with parents}

One of the important findings that can be drawn from the focus group study (Chapter 3) is the importance of parents in educating their children about alcohol consumption. Parents are one of the most influential and important social factors in preventing and reducing adolescents' alcohol consumption (Jander et al., 2013; Hurley, Dietrich \& Rundle-Thiele, 2019).

In Spain, alcohol consumption often takes place in a family context, and alcohol is even offered to the adolescents by their parents (ESTUDES, 2019). Parental consumption, absence of parental control and communication were found to be family factors associated with alcohol consumption and BD in adolescents (Jander et al., 2013; 
Pedersen et al., 2013; Jander et al., 2016). Furthermore, previous studies have found an association between high levels of parental control with lower alcohol consumption in adolescents (Calafat et al., 2014; Mejia et al., 2016). Therefore, parents are key stakeholders in alcohol prevention strategies for adolescents, and alcohol-specific programmes targeting parents remain an important component of multi-faceted approaches to minimising alcohol-related risks in adolescents (Onrust et al., 2016; Newton et al., 2017; Hurley et al., 2019).

A previous study conducted by Jander et al. (2016) carried out an intervention with parents and adolescents to reduce BD. Although the participation of parents was very low, they stated that when parents participated in the intervention, their participating child reported having engaged in less BD in the previous 30 days. In addition, several systematic reviews have examined the efficacy of parent alcohol programmes on preventing alcohol misuse in adolescents (Foxcroft \& Tsertsvadze, 2011; Newton et al., 2017; Hurley et al., 2019). For instance, Newton et al. (2017) found that nine out of ten combined student and parent alcohol programmes showed effectiveness in delaying or reducing alcohol and drug use in adolescents. However, other studies found mixed results (Anderson et al., 2012). A systematic review of 14 parenting programmes found significant results for reduction in alcohol use in only 6 programmes (Petrie, Bunn \& Byrne, 2007). Likewise, another systematic review developed by Foxcroft et al. (2011) found evidence for an effect in six of the nine trials, although this was not consistent across all outcome measures and time periods. In addition, the review conducted by Hurley et al. (2019) showed that most parent programmes had low methodological quality; one third of the programmes did not report theory use or reported that it was weak, and also that the participation of parents was very low. Furthermore, most of them the reported outcome measures that were based on adolescents' self-reports rather than parental responses directly, since there may be discrepancies between parent and adolescent reports, which could explain the ineffectiveness of some programmes (Hurley et al., 2019).

Hence, it would be relevant to explore possibilities to target families in order to increase parents' awareness of the problem of alcohol consumption and BD in their children, and improve parents' communication skills, supervision and control of adolescents, as well as exert a sufficient family influence to reduce alcohol consumption and BD. For this, the quality of future parental programmes, as well as the joint participation of parents and adolescents, should be improved.

\section{PART V - GENERAL CONCLUSION}

The studies presented in this dissertation showed that the process of cultural adaptation, critical analysis of the cultural adaptation and feasibility testing, through different types of studies such as focus groups, Delphi and pilot studies, have allowed to refine this intervention taking into account the characteristics of the Spanish drinking culture. In addition, Alerta Alcohol was well received by Spanish secondary school students, as it offered a potential intervention tool that was operational and feasible for use in secondary schools. Furthermore, we observed that the rate of BD decreased more in the EC group than in the $\mathrm{CC}$ group, although their overall effect was not significant. However, there are some promising indicators of the effectiveness of the intervention described in this thesis to reduce HED. However, we must be cautious when interpreting the results due to the low number of subjects in the HED group, which could affect the generalisation of the study. In addition, although we improved the drop-out rates 
regarding previous studies, the high drop-out rate and thus, the many missing values in the analyses, could also affect the results and the effectiveness of the programme.

In conclusion, future research is needed to improve the adherence and drop-out rates, and adolescents' attitude towards the CT intervention. Hence, it is advisable to make some changes to the intervention in consideration of the recommendations described above, and to test the intervention again in a randomised controlled trial. 


\section{Valorization Addendum}


The results of the studies presented in this dissertation, about the design, cultural adaptation and effectiveness evaluation of the first web-based computer-tailored intervention designed to prevent alcohol consumption and BD among Spanish adolescents, provides a high content of knowledge that is relevant for researchers, clinicians, associated health professionals, families and patients. This dissertation provides a high societal and economic value, as the results presented can be used for further development, optimization, and dissemination of future web-based computertailored alcohol consumption and BD prevention interventions. This valorization addendum will discuss below the relevance of our study results, the target groups for which the results could be of interest, the health products, the degree of innovativeness of these products, and the planning for implementation.

\section{Relevance}

Alcohol is the most widespread psychoactive drug worldwide and one of the main avoidable causes of premature mortality, disease, and disability (Chestnov, 2014; Pulido et al., 2014). Currently, alcohol drinking has become endemic, and part of the social and cultural life, resulting in a great social permissiveness and a low perception of its risks. Alcoholic beverages are widely available, easily accessible to adolescents and lacks restrictive legislation (Espada et al., 2012; ESTUDES, 2018). The 2019 national Spanish survey ESTUDES showed that $75.8 \%$ of adolescents between 14 and 18 years of age drank alcohol in the last 12 months (ESTUDES, 2019).

In Spain, in the recent years, important changes have occurred concerning the amount of ingested alcohol and the drinking patterns, particularly in the adolescent and the young adult population (Parada et al., 2011). This specific pattern of adolescents consumption called binge drinking (BD), was defined as the consumption of 5 or more standard drinks per occasion for male, or 4 or more standard drinks for female, in about 2 hours (Jander et al., 2016; NIAAA, 2020). According to the 2019 national Spanish survey ESTUDES, 32.3\% of students between 14 and 18 years of age reported BD in the last 30 days (ESTUDES, 2019). BD has become a great public health problem as it is held accountable for multiple long- and short-term adverse consequences, affecting neurocognitive development and leads physical injury and social alterations, with significant social and personal costs per year (Rehm et al., 2009; Falcón et al., 2018). Besides, BD in adolescents has been associated with vehicle accidents, violence, delinquency, homicide, suicide, sexually transmitted diseases, unintended pregnancies, school failure, mental illnesses (Farke et al., 2007; Howell et al., 2013; White \& Hingson, 2013; Dormal et al., 2018; Falcón et al., 2018), as well as the development of an alcohol use disorder in adulthood or the consumption of drugs (Pulido et al., 2014). Therefore, these figures and their consequences highlight the importance of preventing BD among adolescents through effective interventions (Miller et al., 2007; Jander et al., 2014; LimaSerrano et al., 2018).

Web-based computer-tailored interventions are considered to be a cost-effective approach in the prevention of alcohol intake as they can reach many people, have the potential to be effective, and can be distributed on a large scale for relatively low costs (Kelders et al., 2012; Schulz et al., 2013; Drost et al., 2016; Jander et al., 2016). These interventions give the possibility of obtaining highly tailored advice and feedback to the participants via the internet, helping to effectively change various health behaviours and their determinants (Dijkstra, 2005; Krebs et al., 2010; Kohl et al., 2013; Lustria et al., 2013). The effectiveness study showed in this dissertation show some promising indications to reduce the number of glasses of alcohol as heavy episodic drinking (HED) 
(consumption of 10 or more glasses of alcohol on at least one occasion) (Best et al., 2006; Jander et al., 2016). Hence, the implementation of this intervention may contribute to the stabilization as well as reducing the number of glasses of alcohol intake among Spanish adolescents.

\section{Target groups}

The research described in this dissertation was funded by the Ministry of Health of the Regional Government of Andalusia (Junta de Andalucía), Spain. This organization aims to act in public health policies as well as in research and clinical practice of public health system, through the financing of health research, stimulating and promoting use of scientific knowledge to improve healthcare in the Andalucía, south of Spain. Accordingly, the results presented in this dissertation are of interest to the Ministry of Health of the Regional Government of Andalusia among others target groups that are presented below.

First and most important, the results of this dissertation are of value for target population of the intervention: Spanish adolescents, whether they have started drinking or not, as well as those who have engaged in BD or not. We focused on the general adolescent population as our prevention program, to reduce BD among adolescents, has a universal orientation. The implementation of this intervention will offer this group a tool that can help them to manage their alcohol consumption. Furthermore, this intervention could be useful for families since they are directly affected by the consequences of their children's alcohol consumption.

In addition, the Ministry of Education of the regional government of Andalusia, Spain, as well as teachers, counsellors and directors of schools could be interested in the results of this dissertation to increase their schools' investment in health promotion and carrying out this kind of study at schools crosswise as part of the health promotion curriculum.

Another important target group are health professionals, including researchers, physicians and nurse practitioners who work in Primary Care and School Health with adolescents, families, and patients, among others. Our findings can help to these health professionals to become aware of the risk factors and determinants for alcohol consumption and $\mathrm{BD}$ in this target group, as well as the need for using evidence based health promotion methods, including eHealth, for their own health services.

Finally, our results are relevant for policy- and lawmakers belonging to the Ministry of Health, of the government of Spain, as these could be used for developing and implement new policies regarding alcohol consumption and taking preventive measures to reduce alcohol consumption in adolescents. Our results indicate that (tailored) eHealth methods can be used to fight against alcohol problems. The results about the potential of using tailored eHealth methods are also relevant for the National Plan on drugs of the Ministry of Health - a political decision-making body formed by the members of the General State Administration and the Directors responsible for drug addiction policy in the autonomous communities. Their ambition is to foster harm reduction in order to achieve a healthier and safer society, and this thesis illustrates the potential of using eHealth as one strategy. From the point of view of organizational strategy, it is therefore relevant to involve the Spanish Council on Drug Addiction and other Addictions as a body for the participation for the development of such eHealth programs in the process of co-creation concerning the design, implementation and 
evaluation of such programs, since a long-term challenge involves building together an architecture of excellence, quality and good governance in prevention.

\section{Product}

The main product of this dissertation is the cultural adaptation to the Spanish context, the implementation, and the effectiveness evaluation of the Alerta Alcohol program. This program is based on the Dutch program (Alcohol Alert) carried out by Jander et al., with the same objective (Jander et al., 2014; Jander et al., 2016). Therefore, based on the previous Dutch study as well as the literature and extensive formative research like focus group interviews with the target group (Chapter 3), and a Delphi and pilot study (Chapter 4), we culturally adapted it to the Spanish context, and finally we designed, implemented and evaluated the Alerta Alcohol program (Chapter 5).

Alerta Alcohol consists of real short stories adapted to gender in which the main character binge drank the night before and his or her friends talk with him or her about what happened. Participants could choose an avatar and the names of the characters in the stories. The program consisted in six sessions. Each session took approximately 1 hour. At the beginning, a baseline questionnaire (session 1) was shown, followed by two session at school (sessions 2-3), in which the drinking event took place in three scenarios: at home, at a celebration, and in a public place. In session 2 and 3, between the stories, questions and tailored messages were shown, which were designed to reduce alcohol consumption and $\mathrm{BD}$, based on pre-motivational and motivational factors of the I-Change Model (de Vries et al., 2003) for example knowledge and risks about drinking and BD, the pros and cons of drinking, perceived pressure from friends and family to drink, and possible difficult drinking situations. In each scenario, self-efficacy was reinforced, and action plans are offered to the adolescent in order to reject alcohol and BD in the specific scenario. In addition, we developed questions and tailored messages aiming to increase self-esteem and awareness of factors such as the acknowledgement of risk perception of alcohol consumption and BD.

In addition, students had two booster sessions at their homes, one week after the third session at school. The fourth session was called "The Challenge", where adolescents could accept the challenge of not drinking or at least not binge drink at an upcoming drinking event; the program reminded students again of the advice and action plans for this type of event. In the fifth session, two days after this event, the program evaluated the challenge to determine whether or not the participants drank or at least whether they engaged in $\mathrm{BD}$ during this drinking event. When the adolescent manages to achieve this goal, a congratulatory message is given to reinforce the positive behaviour; if he/she did not manage to achieve it, he/she is asked about the reasons, so that he/she can receive feedback and information about external and internal reasons for that behaviour and what to do about it. In this feedback, adolescents are encouraged to continue avoiding/reducing alcohol consumption by using a cue reminder (an object that helps them remember not to consume four/five glasses of alcohol) at the next social event. Finally, adolescents are encouraged to repeat the challenge if they wish to. At the end of the study, all students had to complete the sixth session at school, i.e., the follow-up questionnaire (see Appendix 2 (Table 1).

\section{Innovation}

The Alerta Alcohol program is the first Spanish program to reduce BD among Spanish adolescents in the school environment through Web-based Computer-Tailored intervention. Although several interventions exist to reduce alcohol consumption in the 
Spanish context, few evaluate and address BD. Furthermore, no similar study has targeted these issues using CT technology, nor they are based on the I-Change Model as model to change health behaviour at high school level to date (Lima-Serrano et al., 2018). Therefore, to our knowledge, in the Spanish context, there is no similar study targeting alcohol consumption and $\mathrm{BD}$ prevention using a web-based computer-tailored intervention in adolescents, which makes it very innovative.

Furthermore, the studies presented in this dissertation are one of the first that have addressed and described the process of cultural adaptation of a web-based computertailored program. Design, implementation, and evaluation of health programs are a costly and time-consuming endeavour (Escobar-Chaves et al., 2011). Therefore, a pragmatic vision building upon "what works and was effective" was used instead of creating a new program from scratch, as this would be the most expensive and slow option (Villarruel et al., 2005; Zometa et al., 2007). In this sense, as both replication and implementation are important for science, we are convinced that this intervention is highly relevant and innovative.

It is known that web-based computer-tailored interventions give the possibility of obtaining highly tailored advice to the participants, helping to effectively change various health behaviours and their determinants (Dijkstra, 2005; Krebs et al., 2010; Kohl et al., 2013; Lustria et al., 2013). Nearly all previous web-based computer-tailored interventions have used text-driven messages to deliver intervention content, as in our study. And it is known that, recently, more studies have been developed that use video-based messages (Vandelanotte \& Mummery, 2011; Walthouwer, Oenema, Soetens, Lechner \& de Vries, 2013; Stanczyk et al., 2014), or even serious games (Connolly et al., 2012; DeSmet et al., 2014; Jander et al., 2016) to increase the attractiveness of these interventions. In our case, given that it is the first health web-based computer-tailored intervention carried out in Spain, the use of texts was used as a first step, with later planned improvements.

In addition, since the personalization and feedback are an effective working mechanisms of computer-tailored interventions (Dijkstra, 2005; Schulz, et al 2013; Jander et al., 2015), we added important innovations to the original program by adding the possibility of further personalizing stories, choosing avatars and choosing character names. Another innovation concerned making the program more gender tailored by presenting short stories for boys, and short stories for girls, and we designed gender specific avatars. Besides the delivery format, our intervention is also innovative because of its personalized content. For example, only a few interventions have incorporated messages and advice to improve adolescents' self-esteem, as well as providing action planning for specific situations. Finally, implementation in schools of tailored eHealth programs as part of the health promotion curriculum was innovative as such programs do not exist in Spain.

\section{Planning \& Implementation}

The current product of this dissertation could be an effective, innovative tool to solve this important societal problem which is BD and alcohol consumption in Spanish adolescents. The effects of the Alerta Alcohol program showed that the program can successfully reduce heavy episodic drinking (HED) in Spanish adolescents (Chapter 5). Although, an overall effect of the intervention on BD was not found at 4 months, there was also a trend in $\mathrm{BD}$ reduction in both conditions. These are promising results. Yet, before the Alerta Alcohol program can be implemented on a larger scale (e.g., nationally 
or Andalusia) to benefit both adolescents and schools, some improvements to the program and the intervention should be made, such as those mentioned below.

A high problem with this kind of interventions is attrition rate of adolescents and schools. Therefore, this intervention could be adapted and improved to increase adolescent adherence, and thereby increase the effectiveness to the program. We followed the recommendations from previous study by Jander et al. (2016), and by the experts from the Delphi study (Chapter 4), it was even improved over other studies. Among the recommendations, it was highlighted to carry out almost the entire study at schools crosswise as part of the school health promotion curriculum, even being supervised by researchers, by phone, email or even in person at school. But, the completion rates of the current intervention remain very low to determine the real effectiveness (Chapter 6). To improve adherence in future interventions with Spanish adolescents, it is necessary to be familiar with the predictors of adherence. In our study, educational level and ethnicity were showed as predictors of adherence. Therefore, the focus should be on how to better involve adolescents who belong to different academic years and ethnicity to increase effectiveness. Moreover, the analyses of adherence also indicated that non-binge drinkers adhered better to the intervention. This is because, as a rule, people who adhere better to a health program tend to have better lifestyle habits (Schulz et al., 2012). Our prevention program has a universal orientation, focusing on the general adolescent population, but perhaps a different approach is necessary through selective prevention (Foxcroft, 2014). The intervention could be tailored and personalized to consumers and non-consumers.

In addition, implementation of Alerta Alcohol could occur via social media, since Internet are considered the most visited place and where children and adolescents stay for significant amounts of time. Although, in order to make this program successful on social media, we may need to identify how to best do this and also how to optimize attention and adherence.

These improvements should be made in the presentation of the program to improve adolescent adherence, for example by developing usability studies of gamification-based interventions, such as video or serious games, in addition to improving questions and messages. These possible versions, of course, will have to be evaluated again in terms of effectiveness as well as intervention use. Besides, based on the problem reported by schools regarding to the Wi-Fi connection, a solution would be to carry out the also off-line intervention, previously installed in the school computers. Furthermore, results of the focus group study conducted in this dissertation (Chapter 3) showed that parents are still important and influential people in their children' alcohol consumption. Hence, the effect of an additional parental component should be evaluated, in the future, through a randomized controlled trial, e.g., adding three arms, one with parents' intervention, other without parental component, and control group.

After a successful adaption of the Alerta Alcohol program, we recommend its implementation, first, at the level of the Autonomous Community of Andalusia, southern Spain, through the "Forma Joven Program" belonging to the Andalusian Health System (SAS). The Regional Ministry of Health and Family of the Junta de Andalucía provides schools a diverse range of schools health interventions targeted at various health behaviours of children and adolescents, in the following lines of intervention: Emotional education; Healthy Lifestyles; Sexuality and Equal Relations; Positive use of ICT; Prevention of the Consumption of Alcohol, Tobacco, Cannabis and other Drugs. Our eHealth program thus would fit well in this context. 
Next, the program is also relevant to be implemented by the Regional Ministry of Education and Sports of the Junta de Andalucía, given that health promotion in a transversal way in schools. A significant problem is that the implementation of health promotion programs is dependent on the voluntariness of schools and teachers, which causes low participation of schools in interventions that take time from school hours. In this way, teachers, counsellors and directors of schools could simply choose an intervention that they consider necessary and feasible to implement in their school, within established hours for the promotion of health.

In addition, the Seville City Council, as well as that of other cities, could implement the Alcohol Alert program in its "Health Promotion with Young People" program, which is aimed at young people from associations, socio-educational groups, summer schools, etc. ., from the city of Seville, as they serve as an important access point to reach large parts of the Sevillians and Spanish population. Besides, it could also be implemented through collaboration with healthcare organizations, eHealth organizations, or other regional or national socio-health care centres, as well as the "Andalusian Foundation for Drug Addiction Care" in Andalusia, "Proyecto Hombre", "Al-Anon" (Help for family and friends of alcoholics), or the national association of "Alcoholics Anonymous" (AA), between others.

The benefits of this program for the adolescent, the schools and the society could be perfectly perceptible, independently of the way that the adolescents get in contact with the program. It could have a large public health impact for relatively low costs. The only costs associated with the implementation of the intervention will be the hosting costs of the tailoring software package (TailorBuilder) and the website, which are not very high. It should be into account that whether the program is implemented in a future through gamification this could further increase the cost, so it could be risk associated with the large-scale implementation of the intervention. However, the implementing organization (e.g. the Regional Ministry of Education and Sports or Regional Ministry of Health of the Junta de Andalucía) should take responsibility for bearing these costs, otherwise the intervention cannot be used in practice. Nevertheless, this program could decrease adolescents' alcohol consumption and others will not start drinking. decreasing the possibility of acquiring short and long-term health problems. In addition, society and the health system will benefit, since this will be highlighted in the decrease in costs associated with alcohol consumption. 


\section{References}


Abraham, C., Kok, G., Schaalma, H. P., \& Luszczynska, A. (2011). Health promotion. In Martin, P. R., Cheung, F. M., Knowles, M. C., Kyrios, M., Littlefield, L., Overmier J. B., \& Prieto, J. M. (Eds.), Handbook of applied psychology (pp. 83111). Chichester, UK: Wiley-Blackwell.

Ajzen, I. (1991). The theory of planned behavior. Organizational Behavior and Human Decision Processes, 50(2), 179-211.

Alcohol Research: Current Reviews Editorial Staff. (2018). Drinking Patterns and Their Definitions. Alcohol Research: Current Reviews, 39(1),17-18.

Ali, M. M. \& Nikaj, A. A. S. (2014). Alcohol consumption and social network ties among adolescents: Evidence from Add Health. Addictive Behaviors, 39(5), 918-922. https://doi:10.1016/j.addbeh.2013.11.030

Amezcua, M., Hernández-Zambrano, S. M., Rodríguez-Rodríguez, M. A. \& QuesadaGarcía, E. (2015). Riesgo ante el consumo colectivo de alcohol entre los jóvenes: Percepciones desde el entorno educativo. Index de Enfermería, 24(1-2), 25-30. http://dx.doi.org/10.4321/S1132-12962015000100006

Anderson P. (2007). Binge drinking and Europe. London, UK: Institute of Alcohol Studies. http://www.drugsandalcohol.ie/6353/1/3836-4088.pdf

Anderson, P., Gual, A., \& Colon, J. (2008). Alcohol y atención primaria de la salud: informaciones clínicas básicas para la identificación y el manejo de riesgos y problemas. Pan American Health Organization (PAHO). N.W. Washington, D.C 20037,

EE.UU. https://www.who.int/substance_abuse/publications/alcohol_atencion_primaria.p df

Anderson, P., Møller, L., \& Galea, G. (2012). Alcohol in the European Union. Consumption, harm and policy approaches. WHO Regional Office for Europe. Copenhagen $\varnothing$, Denmark. https://www.euro.who.int/_data/assets/pdf_file/0003/160680/e96457.pdf?ua=1

Araújo-Soares, V., McIntyre, T., \& Sniehotta, F. F. (2009). Predicting changes in physical activity among adolescents: the role of self-efficacy, intention, action planning and coping planning. Health Education Research, 24(1), 128-139. https://doi:10.1093/her/cyn005

Arden, M. A., \& Armitage, C. J. (2012). A Volitional Help Sheet to Reduce Binge Drinking in Students: A Randomized Exploratory Trial. Alcohol and Alcoholism, 47(2), 156-159. https://doi:10.1093/alcalc/agr164

Armitage, C. J. (2009). Effectiveness of experimenter-provided and self-generated implementation intentions to reduce alcohol consumption in a sample of the general population: A randomized exploratory trial. Health Psychology, 28(5), 545-553. https://doi.org/10.1037/a0015984

Babor, T. F., \& Higgins-Biddle, J. C. (2001). Brief Intervention For Hazardous and Harmful Drinking. A Manual for Use in Primary Care, Ginebra, Organización Mundial de la Salud.

Bandura, A. (1986). Social foundations of thought and action: a social cognitive theory. Englewood Cliffs, NJ: Prentice-Hall. 
Bandura, A., Cioffi, D., Taylor, C. B., \& Brouillard, M. E. (1988). Perceived self-efficacy in coping with cognitive stressors and opioid activation. Journal of Personality and Social Psychology, 55(3), 479-488. https://doi:10.1037//0022-3514.55.3.479

Bannink, R., Broere, S., Joosten-Van Zwanenburg, E., van As, E., van de Looij-Jansen, P., \& Raat, H. (2014). Effectiveness of a web-based tailored intervention (Ehealth4Uth) and consultation to promote adolescents' health. Journal of Medical Internet Research, 16(5), e143. https://doi:10.2196/jmir.3163

Bannink, R., Joosten-van Zwanenburg, E., van de Looij-Jansen, P., van As, E., \& Raat, H. (2012). Evaluation of computer-tailored health education ('E-health4Uth') combined with personal counselling ('E-health4Uth + counselling') on adolescents' behaviours and mental health status: design of a three-armed cluster randomised controlled trial. BMC Public Health, 17(12), 1083. https://doi:10.1186/1471-2458-12-1083

Bartholomew, L. K., Parcel, G. S., Kok, G., Gottlieb, N. H., \& Fernandez, M. E. (2011). Planning health promotion programs: An intervention mapping approach (third ed.). San Francisco, CA: Jossey-Bass.

Bartsch, L. A., King, K. A., Vidourek, R. A., \& Merianos, A. L. (2017). Self-Esteem and Alcohol Use Among Youths. Journal of Child \& Adolescent Substance Abuse, 26(5), 414-424. https://doi.org/10.1080/1067828X.2017.1322018

Baumeister, R. F. \& Leary, M. R. (1995). The need to belong: Desire for interpersonal attachments as a fundamental human motivation. Psychological Bulletin, 117(3), 497-529. https://doi.org/10.1037/0033-2909.117.3.497

Best, D., Manning, V., Gossop, M., Gross, S., \& Strang, J. (2006). Excessive drinking and other problem behaviours among 14-16 year old schoolchildren. Addictive Behaviors, 31(8), 1424-1435. https://doi:10.1016/j.addbeh.2005.12.002

Bethlehem, M. S., Kramp, K. H., van Det, M. J., ten Cate Hoedemaker, H. O., Veeger, N. J. G. M., \& Pierie, J. P. E. N. (2014). Development of a Standardized Training Course for Laparoscopic Procedures Using Delphi Methodology. Journal of Surgical Education, $\quad$ Nov-Dec; $\quad 71(6), \quad 810-6$. https://doi:10.1016/j.jsurg.2014.04.009

Bewick, B. M., Trusler, K., Barkham, M., Hill, A. J., Cahill, J., \& Mulhern, B. (2008). The effectiveness of web-based interventions designed to decrease alcohol consumption--A systematic review. Preventive Medicine: An International Journal Devoted to Practice and Theory, 47(1), 17-26. https://doi:10.1016/j.ypmed.2008.01.005

Blankers, M., Koeter, M., \& Schippers, G. (2010). Missing data approaches in eHealth research: simulation study and a tutorial for nonmathematically inclined researchers. Journal of Medical Internet Research, 12(5), e54. https://doi:10.2196/jmir.1448

Blasco, J. E., López, A., \& Mengual, S. (2010). Delphi method validation of a questionnaire to get experience and interest in water activities with special attention to windsurfing. Ágora para la Educación física y el Deporte, 12(1), 7596. 
Boers, E., Zebregs, S., Hendriks, H., \& Van Den Putte, B. (2018). Is It More Feeling or Thinking? The Influence of Affective and Cognitive Attitude on Adolescents' Intention to Engage in Binge Drinking. Journal of Health Communication, 23(5), 430-434. https://doi:10.1080/10810730.2018.1461960

Bosque-Prous, M., Kuipers, M. A. G., Espelt, A., Richter, M., Rimpelä, A., Perelman, J., Federico, B., Brugal, M. T., Lorant, V., \& Kunst, A. E. (2017). Adolescent alcohol use and parental and adolescent socioeconomic position in six European cities. BMC Public Health, 17(1), 646. https://doi:10.1186/s12889-017-4635-7

Botvin, G., Griffin, K., Diaz, T., \& Ifill-Williams, M. (2001). Drug abuse prevention among minority adolescents: posttest and one-year follow up of a school-based preventive intervention. Prevention Science, 2(1), 1-13. https://doi:10.1023/a:1010025311161

Boudreau, F., Walthouwer, M. J. L., de Vries, H., Dagenais, G. R., Turbide, G., Bourlaud, A. S., Moreau, M., Côté, J., \& Poirier, P. (2015). Rationale, design and baseline characteristics of a randomized controlled trial of a webbased computer-tailored physical activity intervention for adults from Quebec City. BMC Public Health, 15, 1038. https://doi:10.1186/s12889-015-2364-3

Boyle, S. C., Earle, A. M., McCabe, N., \& LaBrie, J. W. (2018). Increasing ChanceBased Uncertainty Reduces Heavy Drinkers' Cognitive Reactance to Web Based Personalized Normative Feedback. Journal of Studies on Alcohol and Drugs, 79(4), 601-610. https://doi:10.15288/jsad.2018.79.601

Brick, L. A., Redding, C. A., Paiva, A. L., \& Velicer, W. F. (2017). Intervention Effects on Stage Transitions for Adolescent Smoking and Alcohol Use Acquisition. Psychology of Addictive Behaviors, 31(5), 614-24. https://doi:10.1037/adb0000302

Brug, J., Glanz, K., van Assema, P., Kok, G., \& van Breukelen, G. (1998). The impact of computer-tailored feedback and iterative feedback on fat, fruit, and vegetable intake. Health Education \& Behavior, 25(4), 517-531. https://doi:10.1177/109019819802500409

Burkhart, G. (2011). Prevención ambiental de drogas en la Unión Europea. ¿Por qué es tan impopular este tipo de prevención? Adicciones, 23(2), 87-100. https://doi.org/10.20882/adicciones.151

Cacioppo, J. T., Petty, R. E., Kao, C. F., \& Rodriguez, R. (1986). Central and peripheral routes to persuasion: an individual difference perspective. Journal of Personality and Social Psychology, 51(5), 1032-1043. https://doi.org/10.1037/00223514.51.5.1032

Calafat A. (2007). El abuso de alcohol de los jóvenes en España. Adicciones, 19(3):21723. https://doi.org/10.20882/adicciones.302

Calafat, A., García, F., Juan, M., Becoña, E., \& Fernández-Hermida, J.R. (2014). Which parenting style is more protective against adolescent substance use? Evidence within the European context. Drug and Alcohol Dependence, 138, 185-192. https://doi:10.1016/j.drugalcdep.2014.02.705 
Cameron, L. D., Durazo, A., Ramírez, A. S., Corona, R., Ultreras, M., \& Piva, S. (2017). Cultural and Linguistic Adaptation of a Healthy Diet Text Message Intervention for Hispanic Adults Living in the United States. Journal of health communication, 22(3), 262-273. https://doi:10.1080/10810730.2016.1276985.

Card, J. J., Solomon, J., \& Cunningham, S. D. (2011). How to adapt effective programs for use in new contexts. Health Promotion Practice, 12, 25-35. https://doi:10.1177/1524839909348592

Carrà, G., Crocamo, C., Bartoli, F., Carretta, D., Schivalocchi, A., Bebbington, P. E., \& Clerici, M. (2016). Impact of a Mobile E-Health Intervention on Binge Drinking in Young People: The Digitale Alcohol Risk Alertness Notifying Network for Adolescents and Young Adults Project. Journal of Adolescent Health, 58(5), 520e526. https://doi:10.1016/j.jadohealth.2016.01.008

Chestnov, O. (2014) Foreword. In: World Health Organization, editors. Global status report on alcohol and health. Geneva, Switzerland: Editorial World Health Organization, (p. VII-VIII).

Cheung, K. L., Schwabe, I., Walthouwer, M. J. L., Oenema, A., Lechner, L., \& de Vries, H. (2017). Effectiveness of a Video-Versus Text-Based Computer-Tailored Intervention for Obesity Prevention after One Year: A Randomized Controlled Trial. International journal of environmental research and public health, 14(10), 1275. https://doi:10.3390/ijerph14101275

Chung, T., Creswell, K. G., Bachrach, R., Clark, D. B., Martin, C. S. (2018). Adolescent Binge Drinking. Alcohol research: current reviews, 39(1), 5-15.

Clapp, J. D., \& Shillington, A. M. (2001). Environmental predictors of heavy episodic drinking. The American Journal of Drug and Alcohol Abuse, 27(2), 301-313.

Clark, H. K., Shamblen, S. R., Ringwalt, C. L., \& Hanley, S. (2012). Predicting high risk adolescents' substance use over time: the role of parental monitoring. The journal of primary prevention, 33(2-3), 67-77. https://doi:10.1007/s10935-012-0266-z

Connolly, T. M., Boyle, E. A., MacArthur, E., Hainey, T., \& Boyle, J. M. (2012). A systematic literature review of empirical evidence on computer games and serious games. Computers \& Education, 59(2), 661-686. https://doi.org/10.1016/j.compedu.2012.03.004

Cortese, J., Lustria, M. L. A. (2012). Can Tailoring Increase Elaboration of Health Messages Delivered via an Adaptive Educational Site on Adolescent Sexual Health and Decision Making? Journal of the American Society for Information Science and Technology, 63(8), 1567-1580. https://doi.org/10.1002/asi.22700

Couper, M., Alexander, G., Zhang, N., Little, R., Maddy, N., Nowak, M. A., . . Stopponi, M., \& Johnson, C. C. (2010). Engagement and retention: measuring breadth and depth of participant use of an online intervention. Journal of Medical Internet Research, 12(4), e52. https://doi:10.2196/jmir.1430

Cox, W. M., Fadardi, J. S., Hosier, S. G., \& Pothos, E. M. (2015). Differential effects and temporal course of attentional and motivational training on excessive drinking. Experimental and clinical psychopharmacology, 23(6), 445-454. https://doi:10.1037/pha0000038 
Cremers, H. P., Mercken, L., Oenema, A., \& de Vries, H. (2012). A web-bsed computertailored smoking prevention programme for primary school children: intervention design and study protocol. BMC Public Health, 12, 277. https://doi:10.1186/14712458-12-277

Cuijpers, P., de Graaf, I., \& Bohlmeijer, E. (2005). Adapting and disseminating effective public health interventions in another country: towards a systematic approach. European Journal of Public Health, 15(2), 166-169. https://doi.org/10.1093/eurpub/cki124

Currie, C., Molcho, M., Boyce, W., Holstein, B., Torsheim, T., \& Richter, M. (2008). Researching health inequalities in adolescent: The development of the Health Behavior in School-aged children (HBSC) Family Affluence Scale. Social $\begin{array}{llll}\text { Science } \quad \text { Medicine, } & \text { 66(6), }\end{array}$ https://doi:10.1016/j.socscimed.2007.11.024

Dawson, D. A., \& Archer, L. (1992). Gender differences in alcohol consumption: effects of measurement. British Journal of Addiction, 87(1), 119-123. https://doi:10.1111/j.1360-0443.1992.tb01909.x

De Bourdeaudhuij, I., Maes, L., De Henauw, S., De Vriendt, T., et al.; HELENA Study Group. (2010). Evaluation of a computer-tailored physical activity intervention in adolescents in six European countries. The Journal of Adolescent Health, 46(5):458-466. https://doi:10.1016/j.jadohealth.2009.10.006

De Josselin de Jong, S., Candel, M., Segaar, D., Cremers, H. P., \& de Vries, H. (2014). Efficacy of a web-based computer-tailored smoking prevention intervention for Dutch adolescents: randomized controlled trial. Journal of Medical Internet Research, 16(3), e82. https://doi:10.2196/jmir.2469

De la Villa, M., Rodríguez, F. J., \& Ovejero, A. (2010). Correlatos psicosociales del consumo de sustancias psicoactivas en adolescentes españoles. Revista Salud Pública de México, 52(5), 406-415.

De la Villa, M., Rodriguez, F. J., Ovejero, A., \& Sirvent, C. (2009). Attitudinal changes and reduction of alcohol use in adolescents following a psychosocial intervention program. Adicciones, 21(3), 207-220.

De Nooijer, J., Veling, M.L., Ton, A., de Vries, H., \& de Vries, N. K. (2008). Electronic monitoring and health promotion: an evaluation of the E-MOVO Web site by adolescents. Health Education Research, 23(3), 382-391. https://doi:10.1093/her/cym086

De Ruijter, D., Smit, E., de Vries, H., \& Hoving, C. (2016). Web-based computertailoring for practice nurses aimed to improve smoking cessation guideline adherence: A study protocol for a randomized controlled effectiveness trial. Contemporary Clinical Trials, 48, 125-132. https://doi:10.1016/j.cct.2016.04.007

De Vries, H. (2017). An Integrated Approach for Understanding Health Behavior; The IChange Model as an Example. Psychology and Behavioral Science International Journal, 2(2), 555585. https://doi:10.19080/PBSIJ.2017.02.555585 
De Vries, H., \& Brug, J. (1999). Computer-tailored interventions motivating people to adopt health promoting behaviours: Introduction to a new approach. Patient education and counseling, 36(2), 99-105. https://doi:10.1016/s07383991(98)00127-x

De Vries, H., \& Mudde, A. N. (1998). Predicting stage transitions for smoking cessation applying the attitude-social influence-efficacy model. Psychology \& Health, 13(2), 369-385. https://doi.org/10.1080/08870449808406757

De Vries, H., Dijkstra, M., \& Kuhlman, P. (1988). Self-efficacy: the third factor besides attitudes and subjective norm as a predictor of behavioural intentions. Health Education Research, 3(3), 273-282. https://doi.org/10.1093/her/3.3.273

De Vries, H., Eggers, S. M. \& Bolman, C. (2013). The role of action planning and plan enactment for smoking cessation. BMC Public Health, 13, 393. https://doi:10.1186/1471-2458-13-393

De Vries, H., Kremers, S. P. J., Smeets, T., Brug, J., \& Eijmael, K. (2008). The effectiveness of tailored feedback and action plans in an intervention addressing multiple health behaviors. American Journal of Health Promotion, 22(6), 417425. https://doi:10.4278/ajhp.22.6.417

De Vries, H., Lezwijn, J., Hol, M., \& Honing, C. (2005b). Skin cancer prevention: behavior and motives of Dutch adolescents. European journal of cancer prevention, 14(1), 39-50. https://doi:10.1097/00008469-200502000-00006

De Vries, H., Logister, M., Krekels, G., Klaasse, F., Servranckx, V., \& van Osch, L. (2012). Internet-Based Computer Tailored Feedback on Sunscreen Use. Journal of Medical Internet Research, 14(2), e48. https://doi:10.2196/jmir.1902

De Vries, H., Mesters, I., Van de Steeg, H., \& Honing, C. (2005a). The general public's information needs and perceptions regarding hereditary cancer: an application of the Integrated Change Model. Patient Education and Counseling, 56(2), 154-165. https://doi:10.1016/j.pec.2004.01.002

De Vries, H., Mudde, A., Leijs, I., Charlton, A., Vartiainen, E., Buijs, G., .. \& K Kremers, S. (2003). The European Smoking Prevention Framework Approach (ESFA): An Example of Integral Prevention. Health Education Research, 18(5), 611-626. https://doi:10.1093/her/cyg031

DeSmet, A., Van Ryckeghem, D., Compernolle, S., Baranowski, T., Thompson, D., Crombez, G., Poels, K., Van Lippevelde, W., Bastiaensens, S., Van Cleemput, K., Vandebosch, H., \& De Bourdeaudhuij, I. (2014). A meta-analysis of serious digital games for healthy lifestyle promotion. Preventive Medicine, 69(0), 95-107. https://doi:10.1016/j.ypmed.2014.08.026

Dijkstra, A. (2005). Working mechanisms of computer-tailored health education: evidence from smoking cessation. Health Education Research, 20(5), 527-539. https://doi:10.1093/her/cyh014

Dijkstra, A., de Vries, H., Roijackers, J., \& van Breukelen, G. (1998). Tailoring information to enhance quitting in smokers with low motivation to quit: three basic efficacy questions. Health Psychology, 17(6), 513-9. https://doi:10.1037//0278-6133.17.6.513 
Donath, C., Gräßel, E., Baier, D., Pfeiffer, C., Karagülle, D., Bleich, S., \& Hillemacher, T. (2011). Alcohol consumption and binge drinking in adolescents: comparison of different migration backgrounds and rural vs. urban residence-a representative study. BMC Public Health, 11(84). https://doi:10.1186/1471-2458-11-84

Donders, A., Van der Heijden, G., Stijnen, T., \& Moons, K. (2006). Review: A gentle introduction to imputation of missing values. Journal of Clinical Epidemiology, 59(10), 1087-1091. https://doi:10.1016/j.jclinepi.2006.01.014

Donovan, J. E. (2009). Estimated blood alcohol concentrations for child and adolescent drinking and their implications for screening instruments. Pediatrics, 123(6), e975-e981. https://doi:10.1542/peds.2008-0027

Dormal, V., Bremhorst, V., Lannoy, S., Lorant, V., Luquiens, A., \& Maurage, P. (2018). Binge drinking is associated with reduced quality of life in young students: a panEuropean study. Drug and Alcohol Dependence, 193, 48-54. https://doi:10.1016/j.drugalcdep.2018.08.033

Drost, R. M., Paulus, A. T., Jander, A. F., Mercken, L., de Vries, H., Ruwaard, D., \& Evers, S. M. A. A. (2016). A Web-Based Computer-Tailored Alcohol Prevention Program for Adolescents: Cost-Effectiveness and Intersectoral Costs and Benefits. Journal of Medical Internet Research, 18(4), e93. https://doi:10.2196/jmir.5223

Duffield, C. (1993). The Delphi technique: a comparison of results obtained using two expert panels. International Journal of Nursing Studies, 30(3), 227-237. https://doi:10.1016/0020-7489(93)90033-q

Durlak, J. A., \& DuPre, E. P. (2008). Implementation matters: a review of research on the influence of implementation on program outcomes and the factors affecting implementation. American Journal of Community Psychology, 41(3-4), 327-350. https://doi:10.1007/s10464-008-9165-0

Dusenbury, L., Brannigan, R., Hansen, W. B., Walsh, J., \& Falco, M. (2005). Quality of implementation: developing measures crucial to understanding the diffusion of preventive interventions. Health Education Research, 20(3), 308-313. https://doi:10.1093/her/cyg134

Edwards, P., Roberts, I., Clarke, M., DiGuiseppi, C., Ewntz, R., Kwan, I., Cooper, R., Felix, L., \& Pratap, S. (2009). Methods to increase response to postal and electronic questionnaires. Cochrane Database of Systematic Reviews, (3), MR000008. https://doi:10.1002/14651858.MR000008.pub4

Eggers, S. M., Mathews, C., Aarø, L. E., McClinton-Appollis, T., Bos, A. E. R., \& de Vries, H. (2017). Predicting Primary and Secondary Abstinence Among Adolescent Boys and Girls in the Western Cape, South Africa. AIDS and Behavior, 21(5), 1417-1428. https://doi:10.1007/s10461-016-1438-2

Ehret, P. J., Ghaidarov, T. M., \& LaBrie, J. W. (2013). Can you say no? Examining the relationship between drinking refusal self-efficacy and protective behavioral strategy use on alcohol outcomes. Addictive Behaviors, 38(4), 1898-1904. https://doi:10.1016/j.addbeh.2012.12.022 
Elfeddali, I., Bolman, C., Candel, M. J., Wiers, R. W., \& De Vries, H. (2012). Preventing smoking relapse via Web-based computer tailored feedback in the SQ4U-study: a randomized controlled trial. Journal of Medical Internet Research, 14(4), e109. https://doi:10.2196/jmir.2057

Elisaus, P., Williams, G., Bourke, M., Clough, G., Harrison, A., \& Verma, A. (2018). Factors associated with the prevalence of adolescent binge drinking in the urban areas of Greater Manchester. European Journal of Public Health, 28(1), 49-54. https://doi:10.1093/eurpub/ckv115

Ennett, S. T., Bauman, K. E., Foshee, V. A., Pemberton, M., \& Hicks, K. A. (2001). Parent-child Communication about Adolescent Tobacco and Alcohol Use: What Do Parents Say and Does It Affect Youth Behavior? Journal of Marriage and Family, 63(1), 48-62. https://doi.org/10.1111/j.1741-3737.2001.00048.x

Escobar-Chaves, S. L., Shegog, R., Moscoso-Alvarez, M. R., Markham, C., TortoleroLuna, G., Peskin, M., \& Tortolero, S. (2011). Cultural tailoring and feasibility assessment of a sexual health middle school curriculum: a pilot test in Puerto Rico. Journal of School Health, 81(8), 477-484. https://doi:10.1111/j.17461561.2011.00617.x

Espada, J. P., Griffin, K. W., Pereira, J. R., Orgilés, M., \& García-Fernández, J. M. (2012). Component analysis of a school-based substance use prevention program in Spain: contributions of problem solving and social skills training content. Prevention Science, 13(1), 86-95. https://doi:10.1007/s11121-011-0249-y

Espada, J. P., Méndez, F. X., Botvin, G. J., Griffin, K. W., Orgilés, M., \& Rosa, A. I. (2002). Success or failure of school-based drug prevention? a meta-analysis of the programs in Spain. Psicología Conductual, 10, 581-602.

Espada, J. P., Pereira, J. R., \& García-Fernández, J. M. (2008). Influencia de los modelos sociales en el consumo de alcohol de los adolescentes. Psicothema, 20(4), 531537.

Eysenbach, G. (2005). The law of attrition. Journal of Medical Internet Research, 7(1), e11. https://doi:10.2196/jmir.7.1.e11

Ezendam, N. P., Noordegraaf, V. S., Kroeze, W., Brug, J., \& Oenema, A. (2013). Process evaluation of FATaintPHAT, a computer-tailored intervention to prevent excessive weight gain among Dutch adolescents. Health Promotion International, 28(1), 26-35. https://doi:10.1093/heapro/das021

Faggiano, F., Vigna-Taglianti, F. D., Versino, E., Zambon, A., Borraccino, A., \& Lemma, P. (2008). Schoolbased prevention for illicit drugs use: A systematic review. Preventive Medicine, 46(5), 385-396. https://doi:10.1016/j.ypmed.2007.11.012

Fairman, B. J., Simons-Morton, B. G., Haynie, D. L., Liu, D., Goldstein, R. B., Hingson, R. W., \& Gilman, S. E. (2019). State Alcohol Policies, Taxes, and Availability as Predictors of Adolescent Binge Drinking Trajectories Into Early Adulthood. Addiction, 114(7), 1173-1182. https://doi:10.1111/add.14600 
Falcón, M., Navarro-Zaragoza, J., García-Rodríguez, R. M., Nova-López, D., GonzálezNavarro, M. D., Mercadal, M., ... \& Ruiz-Cabello, A. L. (2018). Perceived barriers to implementing screening and brief intervention for alcohol consumption by adolescents in hospital emergency department in Spain. Adicciones, 30(3), 189-196. https://doi:10.20882/adicciones.896

Farke, W., \& Anderson, P. (2007). Binge Drinking in Europe. Adicciones, 19(4): 333339.

Faul, F., Erdfeller, E., Lang, A. G., \& Buchner, A. (2007). G*Power3: A flexible statistical power analysis program for the social, behavioral and biomedical sciences. Behavior Research Methods, 39(2), 175-191. https://doi:10.3758/bf03193146

Fishbein, M. (1979). A theory of reasoned action: Some applications and implications. Nebraska Symposium on Motivation, 27, 65-116.

Foxcroft, D. R. (2014). Can prevention classification be improved by considering the function of prevention? Prevention Science, 15(6), 818-822. https://doi:10.1007/s11121-013-0435-1

Foxcroft, D. R., \& Tsertsvadze, A. (2011). Universal family-based prevention programs for alcohol misuse in young people. Cochrane Database of Systematic Reviews, (9), CD009308. https://doi:10.1002/14651858.CD009308

French, D. P., \& Cooke, R. (2012). Using the theory of planned behaviour to understand binge drinking: The importance of beliefs for developing interventions. British Journal of Health Psychology, 17(1), 1-17. https://doi:10.1111/j.20448287.2010.02010.x

Fromme, K., Katz, E. C., \& Rivet, K. (1997). Outcome expectancies and risk-taking behavior. Cognitive Therapy and Research, 21(4), 421-442. https://doi.org/10.1023/A:1021932326716

Gallet, C. A. (2007). The demand for alcohol: a meta-analysis of elasticities. Australian Journal of Agricultural and Resource Economics, 51(2), 121-135.

GBD 2016 Alcohol Collaborators. (2018). Alcohol use and burden for 195 countries and territories, 1990-2016: a systematic analysis for the Global Burden of Disease Study 2016. The Lancet, 392(10152), 1015-1035. https://doi:10.1016/S01406736(18)31310-2

Gersh, E., Richardson, L. P., Katzman, K., Spielvogle, H., Arghira, A., Zhou, C., \& McCarty, C. (2017). Adolescent health-risk behaviors: Parental concern and concordance between parent and adolescent reports. Academic Pediatrics, 18(1), 66-72. https://doi:10.1016/j.acap.2017.08.012

Gil, E., González, J. R., \& Meneses, C. (2010). Percepción del riesgo y dinámicas promotoras de salud en adolescentes: una mirada de género. Revista Española de Drogodependencias, 35(3), 297-308.

Gilles, D. M., Turk, C. L., \& Fresco, D. M. (2006). Social Anxiety, Alcohol Expectancies, and Self Efficacy as Predictors of Heavy Drinking in College Students. Addictive Behaviors, 31(3), 388-398. https://doi:10.1016/j.addbeh.2005.05.020 
Glasgow, R., Vogt, T., \& Boles, S. (1999). Evaluating the public health impact of health promotion interventions: the RE-AIM framework. American Journal of Public Health, 89(9), 1322-1327. https://doi:10.2105/ajph.89.9.1322.

Gmel, G., Rehm, J., \& Kuntsche, E. N. (2003). Binge drinking in Europe: definitions, epidemiology, trends, and consequences. Sucht: Zeitschrift für Wissenschaft und Praxis, 49(2):105-116. https://doi.org/10.1024/suc.2003.49.2.105

Golpe, S., Isorna, M., Barreiro, C., Braña, T., \& Rial, A. (2017). Binge Drinking among Adolescents: Prevalence, Risk Practices and Related Variables. Adicciones, 29(4), 256-267. https://doi:10.20882/adicciones.932

Gómez, R. A., Luque, L. E., Cortés, M. T., Espejo, B., \& Giménez, J. A. (2012). Estudio preliminar de los determinantes cognitivos que influyen en los jóvenes argentinos para realizar un consumo intensivo de alcohol, o binge drinking. Revista Colombiana de Psiquiatría, 41(2), 309-327. https://doi.org/10.1016/S00347450(14)60007-X

Graham, M. L., Ward, B., Munro, G., Snow, P., \& Ellis, J. (2006). Rural parents, teenagers and alcohol: what are parents thinking? Rural and Remote Health, 6(1), 383.

Green, L. W., \& Kreuter, M. W. (2005). Health program planning: An educational and ecological approach (4th ed.). New York, NY: McGraw-Hill.

Guise, J. M., \& Gill, J. S. (2007). 'Binge drinking? It's good, it's harmless fun': a discourse analysis of accounts of female undergraduate drinking in Scotland. Health Education Research, 22(6), 895-906. https://doi:10.1093/her/cym034

Hagger, M. S., Lonsdale, A., Koka, A., Hein, V., Pasi, H., Lintunen, T., \& Chatzisarantis, N. L. D. (2012). An intervention to reduce alcohol consumption in undergraduate students using implementation intentions and mental simulations: A crossnational study. International Journal of Behavioral Medicine, 19, 82-96. https://doi:10.1007/s12529-011-9163-8

Hagger, M., \& Luszczynska, A. (2014). Implementation Intention and Action Planning Interventions in Health Contexts: State of the Research and Proposals for the Way Forward. Applied Psychology Health and Well-Being, 6(1), 1-47. https://DOI:10.1111/aphw.12017

Hamilton, H. R., \& DeHart, T. (2017). Drinking to belong: The effect of a friendship threat and self-esteem on college student drinking. Self and Identity, 16(1), 1-15. https://doi:10.1080/15298868.2016.1210539

Hampson, S. E., Severson, H. H., Burns, W. J., Slovic, P., \& Fishere, K. J. (2001). Risk perception, personality factors and alcohol use among adolescents. Personality and Individual Differences, 30(1), 167-181. https://doi.org/10.1016/S01918869(00)00025-8

Haug, S., Paz, R., Kowatsch, T., Filler, A., Dey, M., \& Schaub, M. P. (2017). Efficacy of a Web- and Text Messaging-Based Intervention to Reduce Problem Drinking in Adolescents: Results of a Cluster-Randomized Controlled Trial. Journal of Consulting and Clinical Psychology, 85(2), 147-159. https://doi:10.1037/ccp0000138 
Hawkins, B., Holden, C., Eckhardt, J., \& Lee, K. (2018). Reassessing policy paradigms: A comparison of the global tobacco and alcohol industries. Global Public Health, 13(1), 1-19. https://doi:10.1080/17441692.2016.1161815

Henderson, C. E., Dakof, G. A., Schwartz, S. J., \& Liddle, H. A. (2006). Family functioning, self-concept, and severity of adolescent externalizing problems. Journal of Child and Family Studies, 15(6), 721-731. https://doi.org/10.1007/s10826-006-9045-X

Henkel, D., \& Zemlin, U. (2016). Social Inequality and Substance Use and Problematic Gambling Among Adolescents and Young Adults: A Review of Epidemiological Surveys in Germany. Current Drug Abuse Reviews, 9(1), 26-48. https://doi:10.2174/1874473709666151209114023

Hingson, R. W., \& Zha, W. (2018). Binge Drinking Above and Below Twice the Adolescent Thresholds and Health-Risk Behaviors. Alcoholism, Clinical and Experimental Research, 42(5), 904-913. https://doi.org/10.1111/acer.13627

Holtrop, K., \& Holcomb, J. E. (2018). Adapting and Pilot Testing a Parenting Intervention for Homeless Families in Transitional Housing. Family Process, 57(4), 884-900. https://doi:10.1111/famp.12341

Howell, N. A., Worbe, Y., Lange, I., Tait, R., Irvine, M., Banca, P., Harrison, N. A., Bullmore, E. T., Hutchison, W. D., \& Voon, V. (2013). Increased Ventral Striatal Volume in College-Aged Binge Drinkers. PLoS One, 8(9), e74164. https://doi:10.1371/journal.pone.0074164

Hunter, Z., \& Francescutti, L. H. (2013). Facing the consequences of binge drinking. Canadian Family Physician Médecin de famille canadien, 59(10), 1041-1042.

Hurley, E., Dietrich, T., \& Rundle-Thiele, S. (2019). A systematic review of parent based programs to prevent or reduce alcohol consumption in adolescents. BMC Public Health, 19, 1451. https://doi:10.1186/s12889-019-7733-x

Jander, A. F. (2016). Alcohol Alert. The development and evaluation of a Web-based computer-tailored game to reduce binge drinking among adolescents. [Thesis]. Maastricht (The Netherlands): Maastricht University.

Jander, A., Crutzen, R., Mercken, L., \& de Vries, H. (2014). Web-based computertailored game to reduce binge drinking among 16 to 18 year old Dutch adolescents: development and study protocol. BMC Public Health, 14, 1054. https://doi:10.1186/1471-2458-14-1054

Jander, A., Crutzen, R., Mercken, L., \& De Vries, H. (2015). Web-based interventions to decrease alcohol use in adolescents: a Delphi study about increasing effectiveness and reducing drop-out. BMC Public Health, 15(1), 340. https://doi:10.1186/s12889-015-1639-z

Jander, A., Crutzen, R., Mercken, L., Candel, M., \& de Vries, H. (2016). Effects of a Web-based computer-tailored game to reduce binge drinking among Dutch adolescents: a cluster randomized controlled trial. Journal of Medical Internet Research, 18(2), e29. https://doi:10.2196/jmir.4708 
Jander, A., Mercken, L., Crutzen, R., \& de Vries, H. (2013). Determinants of binge drinking in a permissive environment: focus group interviews with Dutch adolescents and parents. BMC Public Health, 13, 882-895. https://doi:10.1186/1471-2458-13-882

Jang, J. B., Patrick, M. E., Keyes, K. M., Hamilton, A. D., \& Schulenberg, J. E. (2017). Frequent Binge Drinking Among US Adolescents, 1991 to 2015. Pediatrics, 139(6), e20164023. https://doi.org/10.1542/peds.2016-4023

Janz, N. K., \& Becker, M. H. (1984). The health belief model: A decade later. Health Education Quarterly, 11(1), 1-47. https://doi:10.1177/109019818401100101

Johnson, H. L., Albery, I. P., Frings, D., \& Moss, A. C. (2018). STI-protective selfefficacy and binge drinking in a sample of university students in the United Kingdom. Sexual \& Reproductive Healthcare, 17, 19-25. https://doi:10.1016/j.srhc.2018.05.004

Kasten, S., van Osch, L., Candel, M., \& de Vries, H. (2019). The influence of pre motivational factors on behavior via motivational factors: a test of the I-Change model. BMC Psychology, 7(1), 7. https://doi:10.1186/s40359-019-0283-2

Katainen, A., \& Rolando, S. (2015) Adolescents' understandings of binge drinking in Southern and Northern European contexts - cultural variations of 'controlled loss of control'. Journal of Youth Studies, 18(2), 151-166. https://doi.org/10.1080/13676261.2014.933200

Kaul, P., \& Coupey, S. M. (2002). Clinical evaluation of substance abuse. Pediatrics in Review, 23, 85-94. https://doi:10.1542/pir.23-3-85

Keeney, S., Hasson, F., \& McKenna, H. P. (2001). A critical review of the Delphi technique as a research methodology for nursing. International Journal of Nursing Studies, 38(2), 195-200. https://doi.org/10.1016/S0020-7489(00)00044-4

Kelders, S. M., Kok, R. N., Ossebaard, H. C., \& Van Gemert-Pijnen, J. E. (2012). Persuasive system design does matter: A systematic review of adherence to Webbased interventions. Journal of Medical Internet Research, 14(6), e152. https://doi:10.2196/jmir.2104

Kelly, J. A., Amirkhanian, Y. A., Kabakchieva, E., Vassileva, S., Vassilev, B., McAuliffe, T. L., ... \& Dimitrov, B. (2006). Prevention of HIV and sexually transmitted diseases in high risk social networks of young Roma (Gypsy) men in Bulgaria: randomised controlled trial. British Medical Journal, 333(7578), 1098. https://doi:10.1136/bmj.38992.478299.55

Keyes, K.M., Li, G., \& Hasin, D. S. (2011). Birth cohort effects and gender differences in alcohol epidemiology: a review and synthesis. Alcoholism, Clinical and Experimental Research, 35(12), 2101-2112. https://doi:10.1111/j.15300277.2011.01562.x

Kim, D. A., Hwong, A. R., Stafford, D., Hughes, D. A., O'Malley, A. J., Fowler, J. H., \& Christakis, N. A. (2015). Social network targeting to maximise population behaviour change: a cluster randomised controlled trial. The Lancet, 386(9989), 145-153. https://doi:10.1016/S0140-6736(15)60095-2 
Kleinjan, M., Strick, M., Lemmers, L., \& Engels, R. C. (2012). The effectiveness of a cue-reminder intervention to reduce adolescents' alcohol use in social contexts. Alcohol and Alcoholism, 47(4), 451-457. https://doi:10.1093/alcalc/ags038

Kohl, L. F. M., Crutzen, R., \& Vries, N. K. d. (2013). Online prevention aimed at lifestyle behaviors: A systematic review of reviews. Journal of Medical Internet Research, 15(7), e146. https://doi:10.2196/jmir.2665

Krebs, P., Prochaska, J. O., \& Rossi, J. S. (2010). A meta-analysis of computer-tailored interventions for health behavior change. Preventive Medicine, 51(3-4), 214-221. https://doi:10.1016/j.ypmed.2010.06.004

Kulick, D., \& Rosenberg, H. (2000). Assessment of university students' coping strategies and reasons for driving in high-risk drinking-driving situations. Accident Analysis \& Prevention, 32(1), 85-94. https://doi:10.1016/s0001-4575(99)00060-3

Kuntsche, E., Knibbe, R., Gmel, G., \& Engels, R. (2005). Why do young people drink? A review of drinking motives. Clinical Psychology Review, 25(7), 841-861. https://doi:10.1016/j.cpr.2005.06.002

Lac, A., \& Donaldson, C. D. (2016). Alcohol attitudes, motives, norms, and personality traits longitudinally classify nondrinkers, moderate drinkers, and binge drinkers using discriminant function analysis. Addictive Behaviors, 61, 91-98. https://doi:10.1016/j.addbeh.2016.05.006

Leary, M. R., \& Baumeister, R. F. (2000). The nature and function of self-esteem: Sociometer theory. Advance in Experimental Social Psychology, 32, 1-62. https://doi.org/10.1016/S0065-2601(00)80003-9

Lee, C.G., Seo, D. C., Torabi, M. R., Lohrmann, D. K., Song, T. M. (2018). Longitudinal Trajectory of the Relationship Between Self-Esteem and Substance Use From Adolescence to Young Adulthood. Journal of School Health, 88(1), 9-14. https://doi:10.1111/josh.12574

Lima-Serrano, M., \& Lima-Rodríguez, J. S. (2014). Impact of school-based health promotion interventions aimed at different behavioral domains: a systematic review. Gaceta Sanitaria, 25(5), 411-7. https://doi:10.1016/j.gaceta.2014.05.003

Lima-Serrano, M., Martínez-Montilla, J. M., Guerra-Martín, M. D., Vargas-Martínez, A. M., \& Lima-Rodríguez, J. S. (2016). Quality-of-life-related factors in adolescents. Gaceta Sanitaria, 32(1), 68-71. https://doi:10.1016/j.gaceta.2016.06.016

Lima-Serrano, M., Martínez-Montilla, J. M., Lima-Rodríguez, J. S., Mercken, L., \& de Vries, H. (2018). Design, implementation and evaluation of a web-based computer-tailored intervention to prevent binge drinking in adolescents: study protocol. BMC Public Health, 18(449). https://doi:10.1186/s12889-018-5346-4

Lima-Serrano, M., Vargas-Martínez, A. M., Gil, E., Martínez-Montilla, J. M., LimaRodríguez, J. S., \& de Vries, H. (2017). Adaptation and validation of five scales to measure determinants of binge drinking in adolescents. Anales del Sistema Sanitario de Navarra, 40(2), 221-236. https://doi:10.23938/ASSN.0028

Lindell, M. K., \& Whitney, D. J. (2001). Accounting for common method variance in cross-sectional research designs. Journal of Applied Psychology, 86(1), 114-121. https://doi.org/10.1037/0021-9010.86.1.114 
Linstone, H. A., \& Turoff, M. (1975). The Delphi method: techniques and applications. MA: Addison-Wesley: Reading.

Löfmark, A., \& Thorell-Ekstrand, I. (2004). An assessment form for clinical nursing education: a Delphi study. Journal of Advanced Nursing, 48(3), 291-298. https://doi:10.1111/j.1365-2648.2004.03198.x

López-Caneda, E., Cadaveira, F., Crego, A., Doallo, S., Corral, M., Gómez-Suárez, A., Rodríguez S. (2013). Effects of a persistent binge drinking pattern of alcohol consumption in young people: a follow-up study using event-related potentials. Alcohol and Alcoholism, 48(4), 464-471. https://doi:10.1093/alcalc/agt046

Luquiens, A., Falissard, B., \& Aubin, H. J. (2016). Students worry about the impact of alcohol on quality of life: Roles of frequency of binge drinking and drinker selfconcept. Drug and Alcohol Dependence, 167, 42-48. https://doi:10.1016/j.drugalcdep.2016.07.031

Lustria, M. L., Noar, S. M., Cortese, J., Van Stee, S. K., Glueckauf, R. L., \& Lee, J. (2013). A meta-analysis of Web-delivered tailored health behavior change interventions. Journal of Health Communication, 18(9), 1039-1069. https://doi:10.1080/10810730.2013.768727

Lustria, M., Cortese, J., Noar, S., \& Glueckauf, R. (2009). Computer-tailored health interventions delivered over the Web: review and analysis of key components. Patient Education and Counseling, 74(2), 156-173. https://doi:10.1016/j.pec.2008.08.023

Marcoux, B. C., \& Shope, J. T. (1997). Application of the Theory of Planned Behavior to adolescent use and misuse of alcohol. Health Education Research, 12(3), 323331. https://doi.org/10.1093/her/12.3.323

Martínez-Hernáez, A., Marí-Klose, M., Julià, A., Escapa, S., \& Marí-Klose, P. (2012). Consumo episódico excesivo de alcohol en adolescentes: su asociación con los estados de ánimo negativos y los factores familiares. Revista Española de Salud Pública, 86(1), 101-114.

Martínez-Montilla, J. M., Mercken, L., Lima-Serrano, L., de Vries, H., \& LimaRodríguez, J. S. (2020). Why are Spanish Adolescents Binge Drinkers? Focus Group with Adolescents and Parents. International Journal of Environmental Research and Public Health, 17(10), 3551. https://doi:10.3390/ijerph17103551

McKay, M. T., Sumnall, H. R., Cole, J. C., \& Percy, A. (2012). Self-esteem and selfefficacy: Associations with alcohol consumption in a sample of adolescents in Northern Ireland. Drugs: Education, Prevention \& Policy, 19(1), 72-80. https://doi.org/10.3109/09687637.2011.579585

McKay, M., Summall, H., McBride, N., \& Harvey, S. (2014). The differential impact of a classroom-based, alcohol harm reduction intervention, on adolescents with different alcohol use experiences: a multi-level growth modelling analysis. Journal of Adolescence, 37(7), 1057-1067. https://doi:10.1016/j.adolescence.2014.07.014 
McKleroy, V. S., Galbraith, J. S., Cummings, B., \& Jones, P. (2006). Adapting evidencebased behavioral interventions for new settings and target populations. AIDS Education and Prevention, 18(4), 59-73. https://doi:10.1521/aeap.2006.18.supp.59

McNaughton, D. B., Cowell, J. M., \& Fogg, L. (2014). Adaptation and feasibility of a communication intervention for Mexican immigrant mothers and children in a school setting. The Journal of School Nursing, 30(2), 103-113. https://doi:10.1177/1059840513487217

Measham, F. (2009). The 'Big Bang' approach to sessional drinking: Changing patterns of alcohol consumption amongst young people in North West England. Addiction $\begin{array}{llll}\text { Research } \quad \text { Theory, 283-299. } & \end{array}$ https://doi.org/10.3109/16066359609005573

Mejia, R., Pérez, A., Peña, L., Morello, P., Kollath-Cattano, C., Braun, S., Thrashe, J. F., \& Sargent, J. D. (2016). Parental Restriction of Mature-rated Media and Its Association With Substance Use Among Argentinean Adolescents. Academic Pediatrics, 16(3), 282-289. https://doi:10.1016/j.acap.2015.11.004

Meneses, C., Romo, N., Uroz, J., Gil, E., Markez, I., Giménez, S., \& Vega, A. (2009). Adolescencia, consumo de drogas y comportamiento de riesgo: diferencias por sexo, etnicidad y áreas geográficas en España. Trastornos Adictivos, 11(1), 51-63. https://DOI:10.1016/S1575-0973(09)71380-7

Mercken, L., Steglich, C., Knibbe, R., \& de Vries, H. (2012). Dynamics of friendship networks and alcohol use in early and mid-adolescence. Journal of Studies on Alcohol and Drugs, 73(1), 99-110. https://doi:10.15288/jsad.2012.73.99

Miller, J. W., Naimi, T. S., Brewer, R. D. \& Jones, S. E. (2007). Binge drinking and associated health risk behaviors among high school students. Pediatrics, 119(1), 76-85. https://doi:10.1542/peds.2006-1517

Ministry of Health, Consumption and Social Welfare, Secretary of State for Social Services. (2018). Survey on alcohol and drugs in Spain EDADES 2017/2018. Government Delegation for the National Plan on Drugs. Spanish Observatory on Drugs and Addictions 2018. Retrieved 20 October, 2018, from: http://www.pnsd.mscbs.gob.es/profesionales/sistemasInformacion/sistemaInfor macion/encuestas_EDADES.htm

Moher, D., Schulz, K. F., \& Altman, D.G. (2001). The CONSORT statement: revised recommendations for improving the quality of reports of parallel group randomized trials. BMC Medical Research Methodology, 1, 2. https://doi:10.1186/1471-2288-1-2

Mongan, D., \& Long, J. (2015). Standard drink measures throughout Europe; people's understanding of standard drinks and their use in drinking guidelines, alcohol survey and labelling. Dublín, Irlanda: Reducing Alcohol Related Harm (RARHA). $\quad$ Retrieved 20 October, 2018, from: https://www.drugsandalcohol.ie/30419/1/Background\%20paper $\% 20$ Standard $\% 2$ 0drink\%20measures\%20HRB.pdf 
Montes, M. P. (2012). La venta de bebidas alcohólicas a menores en el Derecho español. Revista Española de Drogodependencia, 37(2), 205-217.

Moyer, A., Finney, J. W., Swearingen, C. E., \& Vergun, P. (2002). Brief interventions for alcohol problems: A meta-analytic review of controlled investigations in treatment-seeking and non-treatment-seeking populations. Addiction, 97(3), 279292. https://doi:10.1046/j.1360-0443.2002.00018.x

Mravčík, V., Chomynová, P., Nechanská, B., Černíková, T., Csémy, L. (2019). Alcohol use and its consequences in the Czech Republic. Central European Journal of Public Health, 27(27 Suppl), S15-S28. https://doi:10.21101/cejph.a5728

Mullen, P. (2003). Delphi: myths and reality. Journal of Health Organization and Management, 17(1), 37-52. https://doi:10.1108/14777260310469319.

Murray, S. L., Derrick, J. L., Leder, S., \& Holmes, J. G. (2008). Balancing connectedness and self-protection goals in close relationships: A levels-of-processing perspective on risk regulation. Journal of Personality and Social Psychology, 94(3), 429-459. https://doi:10.1037/0022-3514.94.3.429

Musil, C., Warner, C., Yobas, P., \& Jones, S. (2002). A comparison of imputation techniques for handling missing data. Western Journal of Nursing Research, 24(7), 815-829. https://doi:10.1177/019394502762477004

Nation, M., Crusto, C., Wandersman, A., Kumpfer, K. L., Seybolt, D., Morrissey-Kane, E., \& Davino, K. (2003). What works in prevention. Principles of effective prevention programs. The American Psychologist, 58(6-7), 449-456. https://doi:10.1037/0003-066x.58.6-7.449

National Drug Plan. (2016). Survey on Drug Use among Secondary School Students. ESTUDES 1994-2014. Madrid, Spain: Ministry of Health, Social Services and Equality. $\quad$ Retrieved 10 May, 2017, from: https://pnsd.sanidad.gob.es/profesionales/sistemasInformacion/sistemaInformaci on/pdf/2016_Informe_ESTUDES.pdf

National Drug Plan. (2018). Survey on Drug Use among Secondary School Students. ESTUDES (2016-2017). Madrid, Spain: Ministry of Health, Social Services and Equality. $\quad$ Retrieved 15 June, 2018, from: http://www.pnsd.msssi.gob.es/profesionales/sistemasInformacion/sistemaInform acion/pdf/2016_2017_ESTUDES.pdf

National Drug Plan. (2019). Survey on Drug Use among Secondary School Students. ESTUDES 2018-2019. Madrid, Spain: Ministry of Health, Social Services and Equality. Retrieved 20 October, 2018, from: http://www.pnsd.mscbs.gob.es/profesionales/sistemasInformacion/sistemaInfor macion/pdf/ESTUDES_2018-19_Informe.pdf

National Institute on Drug Abuse (NIDA). (2004). Preventing Drug Use Among Children and Adolescents: A Research-Based Guide for Parents, Educators, and Community Leaders. 2nd ed. Bethesda, Maryland: NIDA; 2004. Retrieved 10 May, 2017, from: https://www.drugabuse.gov/sites/default/files/preventingdruguse_2.pdf 
Nawaz, H., Chan, W., Abdulrahman, M., Larson, D., \& Katz, D. (2001). Self-reported weight and height: Implications for obesity research. American Journal of Preventive Medicine, 20(4), 294-298. https://doi:10.1016/s0749-3797(01)002938

Newton, N. C., Andrews, G., Teeson, M., \& Vogl, L. E. (2009). Delivering prevention for alcohol and cannabis using the internet: A cluster randomised controlled trial. Preventive Medicine, 48(6), 579-584. https://doi:10.1016/j.ypmed.2009.04.009

Newton, N. C., Champion, K. E., Slade, T., Chapman, C., Stapinski, L., Koning, I., Tonks, Z., \& Teesson, M. (2017). A systematic review of combined student-and parentbased programs to prevent alcohol and other drug use among adolescents. Drug and Alcohol Review, 36(3), 337-351. https://doi:10.1111/dar.12497

Niaaa.nih.gov. (2016). Alcohol Facts and Statistics | National Institute on Alcohol Abuse and Alcoholism (NIAAA). Retrieved 15 June, 2016, from: https://pubs.niaaa.nih.gov/publications/alcoholfacts\&stats/AlcoholFacts\&Stats.p df. Accessed 14 May 2016

Niaaa.nih.gov. (2020). Alcohol Facts and Statistics | National Institute on Alcohol Abuse and Alcoholism (NIAAA). Retrieved 10 May, 2020, from: https://www.niaaa.nih.gov/sites/default/files/AlcoholFactsAndStats.pdf

Norman, P. (2011). The theory of planned behavior and binge drinking among undergraduate students: Assessing the impact of habit strength. Addictive Behaviors, 36(5), 502-507. https://doi.org/10.1016/j.addbeh.2011.01.025

Norman, P., \& Conner, M. (2006). The theory of planned behaviour and binge drinking: Assessing the moderating role of past behaviour within the theory of planned behaviour. British Journal of Health Psychology, 11(1), 55-70. https://doi:10.1348/135910705X43741.

Nugawela, M. D., Langley, T., Szatkowski, L., \& Lewis, S. (2016). Measuring Alcohol Consumption in Population Surveys: A Review of International Guidelines and Comparison with Surveys in England. Alcohol and Alcoholism, 51(1), 84-92. https://doi.org/10.1093/alcalc/agv073

O’Malley, P., Johnston, L., \& Bachman, J. (1998). Alcohol use among adolescents. Alcohol Health and Research World, 22(2), 85-93.

Onrust, S. A., Otten, R., Lammers, J., \& Smit, F. (2016). School-based programmes to reduce and prevent substance use in different age groups: What works for whom? Systematic review and meta-regression analysis. Clinical Psychology Review, 44, 45-59. https://doi:10.1016/j.cpr.2015.11.002

Ortiz-Colon, A. M., Jordán, J., \& Agredal, M. (2018) Gamificación en educación: una panorámica sobre el estado de la cuestión. Educação e Pesquisa, 44, e173773. http://dx.doi.org/10.1590/S1678-4634201844173773

Østergaard, J. (2009). Learning to become an alcohol user: Adolescents taking risks and parents living with uncertainty. Addiction Research \& Theory, 17(1), 30-53. https://doi.org/10.1080/16066350802161196 
Palfai, T. P., Winter, M., Lu, J., Rosenbloom, D., \& Saitz, R. (2014). Personalized Feedback as a Universal Prevention Approach for College Drinking: A Randomized Trial of an e-Mail Linked Universal Web-Based Alcohol Intervention. The Journal of Primary Prevention, 35(2), 75-84. https://doi:10.1007/s10935-013-0337-9

Pape, H., Rossow, I., \& Brunborg, G. S. (2018). Adolescents drink less: How, who and why? A review of the recent research literature. Drug and Alcohol Review, 37(Suppl. 1), S98-S114. https://doi:10.1111/dar.12695.

Parada, M., Corral, M., Caamaño-Isorna, F., Mota, N., Crego, A., Rodríguez, S., \& Cadaveira, F. (2011). Definition of adolescent binge drinking. Adicciones, 23(1), 53-63.

Pasqualini, D., \& Llorens, A. (2010). Salud y Bienestar de Adolescentes y Jóvenes: Una Mirada Integral. Buenos Aires, Argentina: Edited by Organización Panamericana de la Salud (OPS).

Patrick, M. E., Schulenberg, J. E., Martz, M. E., Maggs, J. L., O’Malley, P. M., \& Johnston, L. (2013). Extreme Binge Drinking among 12th-Grade Students in the U.S.: Prevalence and Predictors. JAMA Pediatrics, 167(11),1-14. https://doi:10.1001/jamapediatrics.2013.2392

Pearson, M., Chilton, R., Wyatt, K., Abraham, C., Ford, T., Woods, H. B., \& Anderson, R. (2015). Implementing health promotion programmes in schools: a realist systematic review of research and experience in the United Kingdom. Implement Science, 10, 149. https://doi:10.1186/s13012-015-0338-6

Pedersen, W., \& von Soest, T. (2013). Socialization to binge drinking: a population based, longitudinal study with emphasis on parental influences. Drug and Alcohol Dependence, 133(2), 587-592. https://doi:10.1016/j.drugalcdep.2013.07.028

Pedrosa, I., Suárez-Álvarez, J., \& García-Cueto, E. (2014). Content Validity Evidences: Theoretical Advances and Estimation Methods. Acción Psicológica, 10(2), 3-20. https://doi.org/10.5944/ap.10.2.11820

Petrie, J., Bunn, F., \& Byrne, G. (2007). Parenting programmes for preventing tobacco, alcohol and drug misuse in children $<18$ years: a systematic review. Health Education Research, 22(2), 177-191. https://doi.org/10.1093/her/cyl061

Petty, R., \& Cacioppo, J. (1986). The Elaboration Likelihood Model of persuasion. Advances in Experimental Social Psychology, 19, 123-205. https://doi.org/10.1016/S0065-2601(08)60214-2

Pineda, S., \& Aliño, M. (2002). El concepto de la adolescencia. In: Márquez, R., Colás, E. F., (Ed.). Manual de Prácticas Clínicas para la intención integral a la Salud en la Adolescencia. (pp. 15-23). Ciudad de la Habana. Cuba: MINSAP.

Prochaska, J. O., \& DiClemente, C. C. (1983). Stages and processes of self-change of smoking: toward an integrative model of change. Journal of consulting and clinical psychology, 51(3), 390-395. https://doi:10.1037//0022-006x.51.3.390

Prochaska, J. O., \& Velicer, W. F. (1997). The Transtheoretical Model of Health Behavior Change. American Journal of Health Promotion, 12(1), 38-48. https://doi:10.4278/0890-1171-12.1.38 
Prochaska, J. O., Redding, C. A., \& Evers, K. E. (2008). The Transtheoretical Model and stages of change. In: Glanz, K., Rimer, B. K., Viswanath, K., editors. Health Behavior and Health Education: Theory, Research, and Practice. (Vol. 4th edition, pp. 97-121). San Francisco, CA: Jossey-Bass.

Pruner, M., Jirikowic, T., Yorkston, K. M., \& Olson, H. C. (2020). The best possible start: A qualitative study on the experiences of parents of young children with or at risk for fetal alcohol spectrum disorders. Research in Developmental Disabilities, 97, 103558. https://doi:10.1016/j.ridd.2019.103558

Pulido, J., Indave-Ruiz, B. I., Colell-Ortega, E., Ruiz-García, M., Bartroli, M., \& Barrio, G. (2014). Population-Based Studies on Alcohol-Related Harm in Spain. Revista Española de Salud Pública, 88(4), 493-513. https://doi:10.4321/S113557272014000400005

Rabinovich, L., Brutscher, P. B., de Vries, H., Tiessen, J., Clift J., \& Reding, A. (2009). The affordability of alcohol beverages in the European Union: understanding the link between alcohol affordability, consumption and harms. Cambridge, RAND Europe.

Rehm, J., Mathers, C., Popova, S., Thavorncharoensap, M., Teerawattananon, Y., \& Patra, J. (2009). Global burden of disease and injury and economic cost attributable to alcohol use and alcohol-use disorders. The Lancet, 373(9682), 2223-2233. https://doi:10.1016/S0140-6736(09)60746-7

Richardson, C. G., Kwon, J. Y., \& Ratner, P. A. (2013). Self-esteem and the initiation of substance use among adolescents. Canadian Journal of Public Health, 104(1), e60-3. https://doi:10.1007/BF03405656

Richter, M., Leppin, A., \& Gabhainn, S. N. (2006). The relationship between parental socio-economic status and episodes of drunkenness among adolescents: findings from a cross-national survey. BMC Public Health, 6, 289. https://doi:10.1186/1471-2458-6-289

Rodríguez, C., \& Caño, A. (2012). Self-esteem in adolescence: analysis and intervention strategies. International Journal of Psychology and Psychological Therapy, 12(3), 389-403.

Rolando, S., \& Katainen, A. (2014a). Images of alcoholism among adolescents in individualistic and collectivistic geographies. Nordic Studies on Alcohol and Drugs, 31(2), 189-205. https://doi:10.2478/nsad-2014-0015

Rolando, S., Beccaria, F., Petrilli, E., \& Prina, F. (2014b). Adults' views of young people's drinking in Italy: An explorative qualitative research. Drugs: Education, Prevention and Policy, 388-397. https://doi.org/10.3109/09687637.2014.899993

Romo-Avilés, N., Marcos-Marcos, J., Gil-García, E., Marquina-Márquez, A., \& Tarragona-Camacho, A. (2015). Bebiendo como chicos: Consumo compartido de alcohol y rupturas de género en poblaciones adolescentes. Revista Española de Drogodependencia, 40, 13-28.

Romo-Avilés, N., Marcos-Marcos, J., Marquina-Márquez, A., \& Gil-García, E. (2016b). Intensive alcohol consumption by adolescents in Southern Spain: The importance 
of friendship. International Journal of Drug Policy, 31, 138-146. https://doi.org/10.1016/j.drugpo.2016.01.014

Romo-Avilés, N., Marcos-Marcos, J., Marquina-Márquez, A., Tarragona-Camacho, A., \& Gil-García, E. (2016a). "I like to be different from how I normally am": Heavy alcohol consumption among female Spanish adolescents and the unsettling of traditional gender norms. Drugs: Education, Prevention and Policy, 25(3),262272. https://doi.org/10.1080/09687637.2016.1259390

Ryan, S. M., Jorm, A. F., \& Lubman, D. I. (2010). Parenting factors associated with reduced adolescent alcohol use: a systematic review of longitudinal studies. Australian and New Zealand Journal of Psychiatry, 44(9), 774-783. https://doi:10.1080/00048674.2010.501759

Sá, C., Rocha, V., Machado, J. C., \& Precioso, J. (2018). Preventing alcohol use among adolescents: assessment of the "alcohol-free" programme. Health and Addictions, $18(2), 133-141$.

Saffer, H., \& Dave, D. (2006). Alcohol advertising and alcohol consumption by adolescents. Health Economics, 15(6), 617-637. https://doi:10.1002/hec.1091

Sambrano, S., Springer, J., Sale, E., Kasim, R., \& Hermann, J. (2005). Understanding prevention effectiveness in real-world settings: the National Cross-Site Evaluation of high risk youth programs. The American Journal of Drug and Alcohol Abuse, 31(3), 491-513. https://doi:10.1081/ada-200068089.

Schneider, F., de Vries, H., Candel, M., van de Kar, A., \& van Osch, L. (2013a). Periodic email prompts to re-use an internet-delivered computer-tailored lifestyle program: Influence of prompt content and timing. Journal of Medical Internet Research, 15(1), e23. http://doi:10.2196/jmir.2151

Schneider, F., Schulz, D., Pouwels, L., de Vries, H., \& van Osch, L. (2013b). The use of a proactive dissemination strategy to optimize reach of an internet-delivered computer tailored lifestyle intervention. BMC Public Health, 13(1), 721. http://doi:10.1186/1471-2458-13-721

Schneider, F., van Osch, L., Schulz, D., Kremers, S., \& de Vries, H. (2012). The influence of user characteristics and a periodic email prompt on exposure to an internet delivered computer-tailored lifestyle program. Journal of Medical Internet Research, 14(2), e40. http://doi:10.2196/jmir.1939

Schuckit, M. A., Smith, T. L., Kalmijn, J., Skidmore, J., Clausen, P., Shafir, A., Saunders, G., ... \& Fromme, K. (2015). The impact of focusing a program to prevent heavier drinking on a pre-existing phenotype, the low level of response to alcohol. Alcoholism, Clinical and Experimental Research, 39(2), 308-316. https://doi:10.1111/acer.12620

Schulz, D. N., Smit, E. S., Stanczyk, N. E., Kremers, S. P., de Vries, H., \& Evers, S. M. (2014b) Economic evaluation of a web-based tailored lifestyle intervention for adults: findings regarding cost-effectiveness and cost-utility from a randomized controlled trial. Journal of Medical Internet Research, 16(3), e91. https://doi:10.2196/jmir.3159 
Schulz, D., Candel, M. J., Kremers, S. J., Reinwand, D. A., Jander, A., De Vries, H. (2013). Effects of a Web-based tailored intervention to reduce alcohol consumption in adults: Randomized controlled trial. Journal of Medical Internet Research, 15(9), e206. https://doi:10.2196/jmir.2568

Schulz, D., Kremers, S. P., Vandelanotte, C., van Adrichem, M. J., Schneider, F., Candel, M. J., \& de Vries, H. (2014a). Effects of a web-based tailored multiple-lifestyle intervention for adults: a two-year randomized controlled trial comparing sequential and simultaneous delivery modes. Journal of Medical Internet Research, 16(1), e26. https://doi:10.2196/jmir.3094

Schulz, D., Schneider, F., de Vries, H., van Osch, L., van Nierop, P., \& Kremers, S. (2012). Program completion of a web-based tailored lifestyle intervention for adults: differences between a sequential and a simultaneous approach. Journal of Medical Internet Research, 14(2), e26. https://doi:10.2196/jmir.1968

Seay, K. D., Iachini, A. L., DeHart, D. D., Browne, T., \& Clone, S. (2017). Substance abuse treatment engagement among mothers: Perceptions of the parenting role and agency-related motivators and inhibitors. Journal of Family Social Work, 20(3), 196-212. https://doi:10.1080/10522158.2017.1300113

Sheeran P. (2002). Intention-behavior relations: A conceptual and empirical review. European review of social psychology, 12(1), 1-36. https://doi:10.1080/14792772143000003

Slater, M. D., \& Rouner, D. (2002). Entertainment-education and elaboration likelihood: Understanding the processing of narrative persuasion. Communication Theory, 12(2), 173-191. https://doi:10.1093/ct/12.2.173

Smeets, T., Brug, J., \& de Vries, H. (2008). Effects of tailoring health messages on physical activity. Health Education Research, 23(3), 402-413. https://doi:10.1093/her/cyl101

Smilkstein, G., Ashworth, C., \& Montano, D. (1982). Validity and reliability of the Family APGAR as a test of family function. The Journal of Family Practice, 15(2), 303-311.

Smit, E. S., de Vries, H., \& Hoving, C. (2012). Effectiveness of a Web-based multiple tailored smoking cessation program: A randomized controlled trial among dutch adult smokers. Journal of Medical Internet Research, 14(3), e82. https://doi:10.2196/jmir.1812

Soetens, K., Vandelanotte, C., de Vries, H., \& Mummery, K. (2014). Using online computer tailoring to promote physical activity: A randomized trial of text, video, and combined intervention delivery modes. Journal of Health Communication, 19(12), 1377-1392. https://doi:10.1080/10810730.2014.894597

Song, E., Smiler, A. P., Wagoner, K. G., \& Wolfson, M. (2012). Everyone says it's ok: Adolescents' perceptions of peer, parent, and community alcohol norms, alcohol consumption, and alcohol-related consequences. Substance Use \& Misuse, 47(1), 86-98. https://doi.org/10.3109/10826084.2011.629704 
Stanczyk, N., Bolman, C., Adrichem, M. v., Candel, M., Muris, J., \& de Vries, H. (2014). Comparison of text and video computer-tailored interventions for smoking cessation: Randomized controlled trial. Journal of Medical Internet Research, 16(3), e69. https://doi:10.2196/jmir.3016

Stanczyk, N., de Vries, H., Candel, M., Muris, J., \& Bolman, C. A. (2016). Effectiveness of video- versus text-based computer-tailored smoking cessation interventions among smokers after one year. Preventive Medicine, 82, 42-50 https://doi:10.1016/j.ypmed.2015.11.002

Suárez, C., Del Moral, G., Musitu, G., \& Villarreal-González, M. (2013). Media and alcohol consumption in adolescents: what do the experts say? Health and Addictions, 13(2), 99-108.

Sussman, S., Arriaza, B., \& Grigsby, T. J. (2014). Alcohol, Tobacco, and Other Drug Misuse Prevention and Cessation Programming for Alternative High School Youth: A Review. Journal of School Health, 84(11):748-758. https://doi:10.1111/josh.12200

Sweller, J. (1994). Cognitive load theory, learning difficulty, and instructional design. Learning and Instruction, 4(4), 295-312. https://doi.org/10.1016/09594752(94)90003-5

Tebb, K. P., Erenrich, R. K., Jasik, C. B., Berna, M. S., Lester, J. C., \& Ozer, E. M. (2016). Use of theory in computer-based interventions to reduce alcohol use among adolescents and young adults: a systematic review. BMC Public Health, 16, 517. https://doi:10.1186/s12889-016-3183-x

The ESPAD Group. (2016). ESPAD Report 2015. Results from the European School Survey Project on Alcohol and Other Drugs. Luxembourg: Publications Office of the European Union, 2016. Retrieved 10 May, 2017, from: http://www.espad.org/sites/espad.org/files/ESPAD_report_2015.pdf

Tong, A., Sainsbury, P., \& Craig, J. (2007). Consolidated criteria for reporting qualitative research (COREQ): A 32-item checklist for interviews and focus groups. International Journal for Quality in Health Care, 19(6), 349-357. https://doi.org/10.1093/intqhe/mzm042

Tortolero, S. R., Markham, C. M., Parcel, G. S, Peters, R. J., Escobar-Chaves, S. L., Basen-Engquist, K., \& Lewis, H. L. (2005). Using intervention mapping to adapt an effective HIV, sexually transmitted disease, and pregnancy prevention program for high-risk minority youth. Health Promotion Practice, 6(3), 286-298. https://doi:10.1177/1524839904266472

Van der Wulp, N. Y., Hoving, C., Eijmael, K., Candel, M. J., van Dalen, W., \& De Vries, H. (2014). Reducing Alcohol Use During Pregnancy Via Health Counseling by Midwives and Internet-Based Computer-Tailored Feedback: A Cluster Randomized Trial. Journal of Medical Internet Research, 16(12), e274. https://doi:10.2196/jmir.3493

Van der Wulp, N.Y., Hoving, C., \& de Vries, H. (2013). A qualitative investigation of alcohol use advice during pregnancy: experiences of Dutch midwives, pregnant women and their partners. Midwifery, 29(11), e89-98. https://doi:10.1016/j.midw.2012.11.014 
Van het Schip, C., Cheung, K.L., Vluggen, S., Hoving, C., Schaper, N.C., \& de Vries, H. (2020). Spoken Animated Self-Management Video Messages Aimed at Improving Physical Activity in People With Type 2 Diabetes: Development and Interview Study. Journal of Medical Internet Research, 22(4), e15397. https://doi:10.2196/15397

Van Keulen, H., Mesters, I., Ausems, M., Van Breukelen, G., Campbell, M., Resnicow, K., Brug, J., \& De Vries, H. (2011). Tailored print communication and telephone motivational interviewing are equally successful in improving multiple lifestyle behaviors in a randomized controlled trial. Annals of Behavioral Medicine, 41(1), 104-118. https://doi:10.1007/s12160-010-9231-3

Van Lettow, B., de Vries, H., Burdorf, A., Boon, B., \& van Empelen, P. (2015). Drinker Prototype Alteration and Cue Reminders as Strategies in a Tailored Web-Based Intervention Reducing Adults' Alcohol Consumption: Randomized Controlled Trial. Journal of Medical Internet Research, 17(2), e35. https://doi:10.2196/jmir.3551

Vandelanotte, C., \& Mummery, W. (2011). Qualitative and quantitative research into the development and feasibility of a video-tailored physical activity intervention. International Journal of Behavioral Nutrition and Physical Activity, 8(1), 70. https://doi:10.1186/1479-5868-8-70

Vázquez, N., Muñoz, L., Juárez, O., \& Ariza, C. (2018). What works in selective prevention of alcohol and cannabis use among vulnerable young people? Revista Española de Salud Pública, 92, e201810070.

Velicer, W. F., Redding, C. A., Paiva, A. L., Mauriello, L. M., Blissmer, B., Oatley, K., Meier, K. S., ... \& Fernandez, A. C. (2013). Multiple behavior interventions to prevent substance abuse and increase energy balance behaviors in middle school students. Translational Behavioral Medicine, 3(1), 82-93. https://doi:10.1007/s13142-013-0197-0

Villarruel, A. M., Jemmott, L. S., \& Jemmott, J. B. III. (2005). Designing a culturally based intervention to reduce HIV sexual risk for Latino adolescents. Journal of the Association of Nurses in AIDS Care, 16(2), 23-31. https://doi:10.1016/j.jana.2005.01.001

Walthouwer, M. J. L., Oenema, A., Candel, M., Lechner, L., \& de Vries, H. (2015). Eating in moderation and the essential role of awareness. A dutch longitudinal study identifying psychosocial predictors. Appetite, 87, 152-159. https://doi:10.1016/j.appet.2014.12.214

Walthouwer, M., Oenema, A., Soetens, K., Lechner, L., \& de Vries, H. (2013). Systematic development of a text-driven and a video-driven web-based computertailored obesity prevention intervention. BMC Public Health, 13(1), 978. https://doi:10.1186/1471-2458-13-978

Walton, M. A., Chermack, S. T., Shope, J. T., Bingham, C. R., Zimmerman, M. A., Blow, F. C., \& Cunningham, R. M. (2010). Effects of a Brief Intervention for Reducing Violence and Alcohol Misuse Among Adolescents A Randomized Controlled Trial. JAMA, 304(5), 527-535. https://doi:10.1001/jama.2010.1066 
Wantland, D., Portillo, C., Holzemer, W., Slaughter, R., \& McGhee, E. (2004). The effectiveness of web-based vs. non-web-based interventions: a meta-analysis of behavioral change outcomes. Journal of Medical Internet Research, 6(4), e40. https://doi:10.2196/jmir.6.4.e40

Wechsler, H., Dowdall, G. W., Maenner, G., Gledhill-Hoyt, J., \& Lee, H. (1998). Changes in binge drinking and related problems among American college students between 1993 and 1997: Results of the Harvard School of Public Health College Alcohol Study. Journal of American college health, 47(2), 57-68. https://doi:10.1080/07448489809595621

Wechsler, H., Kuo, M., Lee, H., \& Dowdall, G.W. Environmental Correlates of Underage Alcohol Use and Related Problems of College Students. American Journal of Preventive Medicine, 19(1), 24-29. https://doi:10.1016/s0749-3797(00)00163-x

Weinstein, N. D. (1988). The precaution adoption process. Health Psychology, 7(4), 355386. https://doi:10.1037//0278-6133.7.4.355

West, B., Abatemarco, D., Ohman-Strickland, P.A., Zec, V., Russo, A. \& Milic, R. (2008). Project Northland in Croatia: Results and lessons learned. Journal of Drug Education, 38(1), 55-70. https://doi:10.2190/DE.38.1.e

White, A., \& Hingson, R. (2013). The burden of alcohol use excessive alcohol consumption and related consequences among college students. Alcohol Research Current Reviews, 35(2), 201-218.

White, I., \& Carlin, J. (2010). Bias and efficiency of multiple imputation compared with complete-case analysis for missing covariate values. Statistics in Medicine, 29(28), 2920-2931. https://doi:10.1002/sim.3944

White, I., Royston, P., \& Wood, A. (2011). Multiple imputation using chained equations: issues and guidance for practice. Statistics in Medicine, 30(4), 377-399. https://doi:10.1002/sim.4067

World Health Organization (WHO). (2011). Global status report on alcohol and health. Geneva, Switzerland: WHO Library Cataloguing-in-Publication Data. Retrieved $10 \quad$ May, 2017, from: https://apps.who.int/iris/bitstream/handle/10665/44499/9789241564151_eng.pdf ;jsessionid=B21838034D9F693FDCD0A51B3DEAACFD? sequence=1

World Health Organization (WHO). (2018). Global status report on alcohol and health. Geneva, Switzerland: WHO. Retrieved 10 May, 2017, from: http://apps.who.int/iris/bitstream/handle/10665/274603/9789241565639eng.pdf?ua $=1$

World Health Organization (WHO). (2019). Maternal, newborn, child and adolescent health. $\quad 06$ October, 2019, from: https://www.who.int/maternal_child_adolescent/adolescence/universal-healthcoverage/en/

World Health Organization. (2014). Global status report on alcohol and health. Geneva, Switzerland: WHO. Retrieved 10 May, 2017, from: https://apps.who.int/iris/bitstream/handle/10665/112736/9789240692763_eng.pd $\mathrm{f} ;$ jsessionid=8B5CD1634DA508C7DA19478234BB57FB? sequence $=1$ 
Wu, D., Tang, W., Lu, H., Zhang, T. P., Cao, B., Ong, J. J., Lee, A., Liu, C., .. \& \& Tucker, J. D. (2019). Leading by Example: Web-Based Sexual Health Influencers Among Men Who Have Sex With Men Have Higher HIV and Syphilis Testing Rates in China. Journal of Medical Internet Research, 21(1), e10171. https://doi:10.2196/10171

Zimmermann, F., Kohlmann, K., Monter, A., \& Ameis, N. (2017). The social image of drinking - mass media campaigns may inadvertently increase binge drinking. Psychology, Health \& Medicine, 22(9), 1032-1044. https://doi:10.1080/13548506.2016.1259481

Zometa, C. S., Dedrick, R., Knox, M. D., Westhoff, W., Siri, R. S., Debaldo, A. (2007). Translation, cross-cultural adaptation and validation of an HIV/AIDS knowledge and attitudinal instrument. AIDS Education and Prevention, 19(3), 231-244. https://doi:10.1521/aeap.2007.19.3.231 
Appendices 


\section{Appendix 1}

Tabla 1: Alerta Alcohol programme evaluation questionnaire for adolescents.

\begin{tabular}{|c|c|c|}
\hline Construct & Questions & Answer options \\
\hline \multirow[b]{2}{*}{ Overall evaluation } & $\begin{array}{l}\text { Do you like the design of the programme } \\
\text { (images, text, sequences, phases)? } \\
\text { - Do you like the design of the characters } \\
\text { (Avatars)? } \\
\text { - Do you like the different stories presented? }\end{array}$ & $\begin{array}{l}\text { A five-point Likert } \\
\text { scale: } \\
\text { 1. "Dislike a lot" } \\
\text { 2. "Dislike" } \\
\text { 3. "Not sure" } \\
\text { 4. "Like" } \\
\text { 5. "Like a lot" }\end{array}$ \\
\hline & $\begin{array}{l}\text { - Is the language used in the Alerta Alcohol } \\
\text { programme appropriate for you? }\end{array}$ & $\begin{array}{l}\text { A five-point Likert } \\
\text { scale: } \\
\text { 1. "Totally disagree" } \\
\text { 2. "Partially disagree" } \\
\text { 3. "Neither agree nor } \\
\text { disagree" } \\
\text { 4. "Partially agree" } \\
\text { 5. "Totally agree" }\end{array}$ \\
\hline $\begin{array}{l}\text { Overall perceived } \\
\text { satisfaction }\end{array}$ & $\begin{array}{l}\text { - What is the overall degree of satisfaction } \\
\text { perceived with the Alerta Alcohol } \\
\text { programme? }\end{array}$ & $\begin{array}{l}\text { A five-point Likert } \\
\text { scale: } \\
\text { 1. "Very dissatisfied" } \\
\text { 2. "Dissatisfied" } \\
\text { 3. "Neither satisfied } \\
\text { nor dissatisfied" } \\
\text { 4. "Satisfied" } \\
\text { 5. "Very satisfied" }\end{array}$ \\
\hline $\begin{array}{l}\text { Contents of the } \\
\text { programme: Credibility }\end{array}$ & $\begin{array}{l}\text { - Do you consider the content of the sessions } \\
\text { credible? }\end{array}$ & \multirow{7}{*}{$\begin{array}{l}\text { A five-point Likert } \\
\text { scale: } \\
\text { 1. "Totally disagree" } \\
\text { 2. "Partially disagree" } \\
\text { 3. "Neither agree nor } \\
\text { disagree" } \\
\text { 4. "Partially agree" } \\
\text { 5. "Totally agree" }\end{array}$} \\
\hline $\begin{array}{c}\text { Contents of the } \\
\text { programme: } \\
\text { Comprehensibility } \\
\end{array}$ & $\begin{array}{l}\text { - Are the advices understandable? } \\
\text { - Is the information organized clearly? }\end{array}$ & \\
\hline $\begin{array}{l}\text { Contents of the } \\
\text { programme: Motivation }\end{array}$ & $\begin{array}{l}\text { - Would you use the Alerta Alcohol } \\
\text { programme again? } \\
\text { - Would you recommend the programme to } \\
\text { someone? }\end{array}$ & \\
\hline $\begin{array}{l}\text { Contents of the } \\
\text { programme: Ease of use }\end{array}$ & $\begin{array}{l}\text { - Is the Alerta Alcohol programme easy to } \\
\text { use? } \\
\text { - Have you found the development of the } \\
\text { programme difficult? } \\
\text { - Have you needed help (from the teacher or } \\
\text { researcher) to complete the sessions? }\end{array}$ & \\
\hline $\begin{array}{c}\text { Contents of the } \\
\text { programme: Perceived } \\
\text { impact }\end{array}$ & $\begin{array}{l}\text { - Have you changed your attitude towards } \\
\text { alcohol consumption or binge-drinking? } \\
\text { - Have you changed your perception of } \\
\text { damage? } \\
\text { - Improve skills for to avoid binge-drinking } \\
\text { - Have you improved your knowledge of } \\
\text { alcohol consumption and binge drinking? }\end{array}$ & \\
\hline $\begin{array}{c}\text { Contents of the } \\
\text { programme: Perceived } \\
\text { interest }\end{array}$ & $\begin{array}{l}\text { - Do you consider the intervention to be } \\
\text { useful? } \\
\text { - Have you found the different } \\
\text { messages/advices interesting? }\end{array}$ & \\
\hline $\begin{array}{c}\text { Contents of the } \\
\text { programme: } \\
\text { Acceptability and length } \\
\text { of the sessions }\end{array}$ & $\begin{array}{l}\text { - Are the sessions too long? } \\
\text { - Are the sessions too short? } \\
\text { - What do you think about how the Alerta } \\
\text { Alcohol programme is divided? }\end{array}$ & \\
\hline
\end{tabular}




\section{Appendix 1}

Tabla 2: Estimated items for the Alerta Alcohol programme in the Delphi group.

\begin{tabular}{|c|c|c|c|c|c|c|c|c|c|c|}
\hline & \multicolumn{5}{|c|}{ 1st ROUND (N=11) } & \multicolumn{5}{|c|}{ 2nd ROUND (N=12) } \\
\hline Items & Mean & Median & SD** & $\begin{array}{c}\% \\
(4-5)\end{array}$ & CVI* & Mean & Median & SD** & $\begin{array}{c}\% \\
(4-5)\end{array}$ & CVI* \\
\hline \multicolumn{11}{|c|}{ DESIGN OF THE INTERVENTION: General aspects. } \\
\hline $\begin{array}{l}\text { What do you think about the design of the } \\
\text { intervention in general? }\end{array}$ & 4.27 & 5 & .905 & 72.7 & .33 & N/A & N/A & N/A & N/A & N/A \\
\hline $\begin{array}{l}\text { What do you think about the division of } \\
\text { the different sessions? }\end{array}$ & 4.18 & 4 & .751 & 81.9 & .50 & N/A & N/A & N/A & N/A & N/A \\
\hline $\begin{array}{l}\text { Do you think the mechanics of the } \\
\text { intervention are simple? }\end{array}$ & 4.18 & 5 & 1.168 & 69.3 & .50 & 4.58 & 5 & .515 & 85.7 & 1 \\
\hline $\begin{array}{c}\text { Is the organization of the information } \\
\text { clear? }\end{array}$ & 3.73 & 4 & 1.348 & 53.9 & .16 & 4.67 & 5 & .492 & 85.7 & 1 \\
\hline $\begin{array}{c}\text { Do you think it's easy to find the } \\
\text { information? }\end{array}$ & 4.09 & 4 & 1.044 & 61.6 & .33 & 4.67 & 5 & .492 & 85.7 & 1 \\
\hline $\begin{array}{l}\text { Is the information provided easy to } \\
\text { understand? }\end{array}$ & 4 & 5 & 1.342 & 53.9 & .16 & 4.67 & 5 & .651 & 78.6 & .83 \\
\hline $\begin{array}{c}\text { Do you think the design is suitable for } \\
\text { adolescents? }\end{array}$ & 3.82 & 4 & 1.168 & 53.9 & .16 & 4.50 & 5 & .905 & 78.5 & .83 \\
\hline $\begin{array}{l}\text { Is the vocabulary used suitable for } \\
\text { adolescents? }\end{array}$ & 3.55 & 3 & 1.128 & 38.5 & -.16 & 4.17 & 5 & 1.267 & 64.3 & .50 \\
\hline Is the length adequate? & 3.36 & 4 & 1.433 & 46.2 & 0 & 4.25 & 5 & 1.215 & 71.4 & .66 \\
\hline $\begin{array}{l}\text { What do you think of the different } \\
\text { scenarios? }\end{array}$ & 4 & 4 & 1.183 & 61.6 & .33 & 4.58 & 5 & .900 & 78.6 & .83 \\
\hline Is the story suitable for adolescents? & 4.27 & 5 & .905 & 61.6 & .33 & $\mathrm{~N} / \mathrm{A}$ & N/A & $\mathrm{N} / \mathrm{A}$ & $\mathrm{N} / \mathrm{A}$ & N/A \\
\hline \multicolumn{11}{|c|}{ SCENARIO 1: At home. } \\
\hline Relevance of the s & 4.36 & 5 & .809 & 69.3 & .50 & N/A & N/A & N/A & N/A & N/A \\
\hline $\begin{array}{l}\text { RELEVANCE. Question 1.1: Knowledge } \\
\text { and risks of alcohol. }\end{array}$ & 4.27 & 4 & .786 & 69.3 & .50 & N/A & N/A & N/A & N/A & N/A \\
\hline $\begin{array}{l}\text { RELEVANCE. Question 1.2: Knowledge } \\
\text { and risks of BD. }\end{array}$ & 4.36 & 5 & .809 & 69.3 & .50 & N/A & N/A & N/A & N/A & N/A \\
\hline $\begin{array}{l}\text { RELEVANCE. Question 2.1: Pros and } \\
\text { Cons. }\end{array}$ & 4.18 & 5 & 1.250 & 69.3 & .50 & 4.58 & 5 & .515 & 85.7 & 1 \\
\hline $\begin{array}{l}\text { RELEVANCE. Question 3.1: Self- } \\
\text { efficacy. }\end{array}$ & 4.27 & 5 & 1.191 & 69.2 & .50 & 4.58 & 5 & .515 & 85.7 & 1 \\
\hline $\begin{array}{l}\text { Do you think the message information for } \\
\text { adolescents is adequate? Question 1.1: } \\
\text { Knowledge and risks of alcohol. }\end{array}$ & 4 & 4 & 1.095 & 53.9 & .16 & 4.75 & 5 & .452 & 85.7 & 1 \\
\hline $\begin{array}{l}\text { Do you think the message information for } \\
\text { adolescents is adequate? Question 1.2: } \\
\text { Knowledge and risks of BD. }\end{array}$ & 4 & 4 & 1.095 & 53.9 & .16 & 4.75 & 5 & .622 & 78.5 & .83 \\
\hline $\begin{array}{c}\text { Do you think the message information for } \\
\text { adolescents is adequate? Question 2.1: } \\
\text { Pros and Cons. }\end{array}$ & 3.55 & 4 & 1.440 & 46.2 & 0 & 4.25 & 5 & 1.215 & 64.2 & .50 \\
\hline $\begin{array}{c}\text { Do you think the message information for } \\
\text { adolescents is adequate? Question 3.1: } \\
\text { Self-efficacy. }\end{array}$ & 3.91 & 4 & 1.300 & 61.6 & .33 & 4.58 & 5 & .669 & 78.5 & .83 \\
\hline $\begin{array}{c}\text { Do you think the length of the messages is } \\
\text { adequate? Question 1.1: Knowledge and } \\
\text { risks of alcohol. }\end{array}$ & 3.82 & 4 & 1.168 & 53.9 & .16 & 4.50 & 5 & .798 & 71.4 & .66 \\
\hline $\begin{array}{c}\text { Do you think the length of the messages is } \\
\text { adequate? Question 1.2: Knowledge and } \\
\text { risks of BD. }\end{array}$ & 3.64 & 4 & 1.286 & 46.2 & 0 & 4.50 & 5 & .905 & 64.3 & .50 \\
\hline $\begin{array}{l}\text { Do you think the length of the messages is } \\
\text { adequate? Question 2.1: Pros and Cons. }\end{array}$ & 3.36 & 3 & 1.502 & 38.5 & -.16 & 4.42 & 5 & .996 & 71.4 & .66 \\
\hline $\begin{array}{l}\text { Do you think the length of the messages is } \\
\text { adequate? Question 3.1: Self-efficacy. }\end{array}$ & 3.64 & 4 & 1.433 & 46.2 & 0 & 4.42 & 5 & .996 & 71.4 & .66 \\
\hline $\begin{array}{l}\text { Do you think that the language used for } \\
\text { adolescents is adequate? Question 1.1: } \\
\text { Knowledge and risks of alcohol. }\end{array}$ & 4.09 & 5 & 1.300 & 53.8 & .16 & 4.25 & 5 & 1.055 & 64.3 & .50 \\
\hline $\begin{array}{l}\text { Do you think that the language used for } \\
\text { adolescents is adequate? Question 1.2: } \\
\text { Knowledge and risks of BD. }\end{array}$ & 3.91 & 5 & 1.375 & 53.9 & .16 & 4.33 & 5 & .888 & 64.3 & .50 \\
\hline
\end{tabular}


Do you think that the language used for adolescents is adequate? Question 2.1: Pros and Cons.

Do you think that the language used for adolescents is adequate? Question 3.1: Self-efficacy.

\begin{tabular}{|c|c|c|c|c|c|c|c|c|c|c|}
\hline \multicolumn{11}{|c|}{ SCENARIO 2: Celebrations. } \\
\hline Relevance of the scenario (general) & 3.91 & 5 & 1.578 & 61.6 & .33 & 4.42 & 5 & 1.240 & 71.4 & .66 \\
\hline RELEVANCE. Question 1.1: Self-esteem. & 4.36 & 5 & 1.027 & 69.2 & .50 & 4.58 & 5 & .515 & 85.7 & 1 \\
\hline $\begin{array}{l}\text { RELEVANCE. Question 2.1: Social } \\
\text { Influence: Social Modelling. }\end{array}$ & 4.27 & 5 & 1.272 & 69.2 & .50 & 4.58 & 5 & .515 & 85.7 & 1 \\
\hline $\begin{array}{l}\text { Influence: Social Modelling (Influence of } \\
\text { parents). }\end{array}$ & 4.27 & 5 & 1.272 & 69.2 & .50 & 4.58 & 5 & .515 & 85.7 & 1 \\
\hline $\begin{array}{l}\text { RELEVANCE. Question 3.1: Self- } \\
\text { efficacy. }\end{array}$ & 4.27 & 5 & 1.272 & 69.2 & .50 & 4.58 & 5 & .515 & 85.7 & 1 \\
\hline $\begin{array}{l}\text { Do you think the message information for } \\
\text { adolescents is adequate? Question 1.1: } \\
\text { Self-esteem. }\end{array}$ & 3.91 & 4 & 1.136 & 61.6 & .33 & 4.67 & 5 & .651 & 78.6 & .83 \\
\hline $\begin{array}{l}\text { Do you think the message information for } \\
\text { adolescents is adequate? Question 2.1: } \\
\text { Social Influence: Social Modelling. }\end{array}$ & 3.73 & 4 & 1.489 & 53.9 & .16 & 4.50 & 5 & 1.000 & 71.4 & .66 \\
\hline $\begin{array}{l}\text { Do you think the message information for } \\
\text { adolescents is adequate? Question 2.2: } \\
\text { Social Influence: Social Modelling } \\
\text { (Influence of parents). }\end{array}$ & 3.82 & 5 & 1.537 & 53.9 & .16 & 4.50 & 5 & 1.000 & 71.4 & .66 \\
\hline $\begin{array}{c}\text { Do you think the message information for } \\
\text { adolescents is adequate? Question 3.1: } \\
\text { Self-efficacy. }\end{array}$ & 3.82 & 5 & 1.537 & 53.9 & .16 & 4.42 & 5 & 1.165 & 78.5 & .83 \\
\hline $\begin{array}{l}\text { Do you think the length of the messages is } \\
\text { adequate? Question 1.1: Self-esteem. }\end{array}$ & 3.73 & 4 & 1.272 & 53.9 & .16 & 4.50 & 5 & 1.000 & 71.4 & .66 \\
\hline $\begin{array}{c}\text { Do you think the length of the messages is } \\
\text { adequate? Question 2.1: Social Influence: } \\
\text { Social Modelling. }\end{array}$ & 3.55 & 4 & 1.572 & 46.2 & 0 & 4.25 & 5 & 1.055 & 64.3 & .50 \\
\hline $\begin{array}{l}\text { Do you think the length of the messages is } \\
\text { adequate? Question 2.2: Social Influence: } \\
\text { Social Modelling (Influence of parents). }\end{array}$ & 3.36 & 3 & 1.502 & 38.5 & -.16 & 4.33 & 5 & 1.073 & 64.2 & .50 \\
\hline $\begin{array}{l}\text { Do you think the length of the messages is } \\
\text { adequate? Question 3.1: Self-efficacy. }\end{array}$ & 3.55 & 4 & 1.572 & 46.2 & 0 & 4.50 & 5 & 1.000 & 71.4 & .66 \\
\hline $\begin{array}{l}\text { Do you think that the language used for } \\
\text { adolescents is adequate? Question 1.1: } \\
\text { Self-esteem. }\end{array}$ & 4 & 5 & 1.414 & 53.8 & .16 & 4.33 & 5 & .985 & 71.4 & .66 \\
\hline $\begin{array}{l}\text { Do you think that the language used for } \\
\text { adolescents is adequate? Question 2.1: } \\
\text { Social Influence: Social Modelling. }\end{array}$ & 3.55 & 4 & 1.572 & 46.2 & 0 & 4.42 & 5 & .996 & 71.4 & .66 \\
\hline $\begin{array}{l}\text { Do you think that the language used for } \\
\text { adolescents is adequate? Question 2.2: } \\
\text { Social Influence: Social Modelling } \\
\text { (Influence of parents). }\end{array}$ & 3.64 & 4 & 1.567 & 53.9 & .16 & 4.42 & 5 & .996 & 71.4 & .66 \\
\hline $\begin{array}{l}\text { Do you think that the language used for } \\
\text { adolescents is adequate? Question 3.1: }\end{array}$ & 3.73 & 5 & 1.618 & 53.9 & .16 & 4.42 & 5 & .996 & 71.4 & .66 \\
\hline
\end{tabular}
Self-efficacy.

Relevance of the scenario (general).

SCENARIO 3: Public space.

RELEVANCE. Question 1.1: Social Influence: Social Norms.

RELEVANCE. Question 2.1: Social Influence: Social Pressure.

RELEVANCE. Question 3.1: Selfefficacy.

$\begin{array}{llllllllll}3.64 & 4 & 1.502 & 46.2 & 0 & 4.33 & 5 & 1.073 & 64.2 & .50\end{array}$

$\begin{array}{lllllllllll}3.91 & 5 & 1.514 & 53.8 & .16 & 4.33 & 5 & .985 & 71.4 & .66\end{array}$

SCENARIO 2: Celebrations.

$\begin{array}{lllll}\text { Relevance of the scenario (general) } & 3.91 & 5 & 1.578 & 61.6\end{array}$ 
Do you think the message information for adolescents is adequate? Question 3.1: Self-efficacy.

Do you think the length of the messages is adequate? Question 1.1: Social Influence: Social Norms.

Do you think the length of the messages is adequate? Question 2.1: Social Influence: Social Pressure.

Do you think the length of the messages is adequate? Question 3.1: Self-efficacy.

Do you think that the language used for adolescents is adequate? Question 1.1: Social Influence: Social Norms.

Do you think that the language used for adolescents is adequate? Question 2.1: Social Influence: Social Pressure.

Do you think that the language used for adolescents is adequate? Question 3.1:

\begin{tabular}{|c|c|c|c|c|c|c|c|c|c|c|}
\hline & & & & & & & & & & \\
\hline $\begin{array}{c}\text { adolescents is adequate? Question 3.1: } \\
\text { Self-efficacy. }\end{array}$ & 4.18 & 5 & 1.250 & 61.5 & .33 & 4.64 & 5 & .674 & 71.4 & .66 \\
\hline $\begin{array}{l}\text { Do you think the length of the messages is } \\
\text { adequate? Question 1.1: Social Influence: } \\
\text { Social Norms. }\end{array}$ & 4 & 5 & 1.265 & 53.9 & .16 & 4.55 & 5 & .820 & 64.2 & .50 \\
\hline $\begin{array}{l}\text { Do you think the length of the messages is } \\
\text { adequate? Question 2.1: Social Influence: } \\
\text { Social Pressure. }\end{array}$ & 3.73 & 4 & 1.272 & 53.9 & .16 & 4.50 & 5 & 1.000 & 71.4 & 66 \\
\hline $\begin{array}{l}\text { Do you think the length of the messages is } \\
\text { adequate? Question 3.1: Self-efficacy. }\end{array}$ & 4 & 5 & 1.265 & 53.9 & .16 & 4.45 & 5 & .820 & 64.3 & .50 \\
\hline $\begin{array}{l}\text { Do you think that the language used for } \\
\text { adolescents is adequate? Question 1.1: } \\
\text { Social Influence: Social Norms. }\end{array}$ & 3.82 & 4 & 1.328 & 53.9 & .16 & 4.64 & 5 & .674 & 71.4 & .66 \\
\hline $\begin{array}{l}\text { Do you think that the language used for } \\
\text { adolescents is adequate? Question 2.1: } \\
\text { Social Influence: Social Pressure. }\end{array}$ & 3.73 & 5 & 1.489 & 46.2 & 0 & 4.33 & 5 & .985 & 71.4 & .66 \\
\hline $\begin{array}{l}\text { Do you think that the language used for } \\
\text { adolescents is adequate? Question 3.1: } \\
\text { Self-efficacy. }\end{array}$ & 3.82 & 4 & 1.328 & 53.9 & .16 & 4.55 & 5 & .688 & 71.4 & .66 \\
\hline & essior & & The cha & llenge & & & & & & \\
\hline Relevance of the scenario (general). & 4 & 4 & 1.095 & 53.9 & .16 & 4.67 & 5 & .651 & 78.6 & .83 \\
\hline $\begin{array}{l}\text { Do you think the message information for } \\
\text { adolescents is adequate? }\end{array}$ & 3.73 & 4 & 1.348 & 46.2 & 0 & 4.58 & 5 & .669 & 78.5 & .83 \\
\hline $\begin{array}{l}\text { Do you think the length of the messages is } \\
\text { adequate? }\end{array}$ & 3.91 & 4 & 1.221 & 53.9 & .16 & 4.58 & 5 & .669 & 78.5 & .83 \\
\hline $\begin{array}{c}\text { Do you think that the language used for } \\
\text { adolescents is adequate? }\end{array}$ & 3.73 & 4 & 1.348 & 46.2 & 0 & 4.58 & 5 & .669 & 78.5 & .83 \\
\hline
\end{tabular}
Self-efficacy.

*CVI: Content Validity Index; **SD: Standard deviation 


\section{Appendix 2}

Table 1: Alerta Alcohol Program structure.

\begin{tabular}{|c|c|c|c|c|c|}
\hline Location & Sessions & \multicolumn{4}{|c|}{ Measures } \\
\hline \multirow{4}{*}{ At School } & Session 1 & \multicolumn{4}{|l|}{ Initial questionnaire } \\
\hline & Session 2 & Scenario 1: At home & Knowledge and risk & Attitude: Pros and cons & $\begin{array}{l}\text { Self-efficacy and action } \\
\text { plans }\end{array}$ \\
\hline & Session 3 & Scenario 2: Celebrations & Self-esteem & Social Modelling & $\begin{array}{l}\text { Self-efficacy and action } \\
\text { plans }\end{array}$ \\
\hline & & Scenario 3: Public places & Social Norm & Social Pressure & $\begin{array}{l}\text { Self-efficacy and action } \\
\text { plans }\end{array}$ \\
\hline At student's & Session 4 & \multicolumn{4}{|c|}{ Booster Session: The Challenge } \\
\hline home & Session 5 & \multicolumn{4}{|l|}{ Evaluation of the Challenge } \\
\hline At School & Session 6 & \multicolumn{4}{|l|}{ Final questionnaire } \\
\hline
\end{tabular}




\section{Appendix 2}

Table 2: Alerta Alcohol: Measurement variables.

\begin{tabular}{|c|c|c|}
\hline Questions & Answers & Variable type \\
\hline \multicolumn{3}{|c|}{ Sociodemographic } \\
\hline Gender & $1=$ Male; $2=$ Female & Nominal binary \\
\hline Age & It was extracted from the period between the pre-test date and the date of birth of the participant & Quantitative \\
\hline Course & $1=4$ th ${ }^{\mathrm{a}} \mathrm{CSE} ; 2=1$ st Baccalaureate; $3={ }^{\mathrm{b}} \mathrm{VT}$ & Ordinal \\
\hline $\begin{array}{l}\text { Religion: What is your } \\
\text { religion? }\end{array}$ & 1 = Catholics; 2 = Protestant/Evangelical; 3 = Muslim/Islam; 4= Other; 5 = No religion; & Nominal \\
\hline $\begin{array}{l}\text { Nationality: What is your } \\
\text { nationality? }\end{array}$ & 1 = Spanish; 2 = Other & Nominal binary \\
\hline $\begin{array}{l}{ }^{\mathrm{c}} \text { Family Affluence } \\
\text { Scale }\end{array}$ & $\begin{array}{l}\text { It was a sum-up of the following questions: Does your family own a car or van? }(1=\text { No; } 2=\text { Yes, one; } 3= \\
\text { Two or more); How many times did you go on vacation with your family during the last } 12 \text { months? }(1= \\
\text { Never; } 2=\text { Once; } 3=\text { Twice; } 4=\text { More than twice); How many computers does your family have? }(1= \\
\text { Nothing; } 2=\text { One; } 3=\text { Two; } 4=\text { More than two); Do you have your own bedroom? }(1=\text { No; } 2=\text { Yes })\end{array}$ & Scale \\
\hline $\begin{array}{l}\text { 'Family Apgar Test: } \\
\text { Satisfaction level with the } \\
\text { help that he/she receives } \\
\text { from his/her family when } \\
\text { he/she has any problem. }\end{array}$ & $\begin{array}{l}1=\text { Almost never } \\
2=\text { Sometimes } \\
3=\text { Almost always }\end{array}$ & Nominal \\
\hline $\begin{array}{l}\text { Family Apgar Test: } \\
\text { Frequency with which } \\
\text { they talk between them } \\
\text { about the problems that } \\
\text { they have at home. }\end{array}$ & $\begin{array}{l}1=\text { Almost never } \\
2=\text { Sometimes } \\
3=\text { Almost always }\end{array}$ & Nominal \\
\hline $\begin{array}{l}\text { Family Apgar Test: } \\
\text { Frequency with which the } \\
\text { important decisions are } \\
\text { taken together at home. }\end{array}$ & $\begin{array}{l}1=\text { Almost never } \\
2=\text { Sometimes } \\
3=\text { Almost always }\end{array}$ & Nominal \\
\hline
\end{tabular}




\begin{tabular}{|c|c|c|}
\hline $\begin{array}{l}\text { Family Apgar Test: } \\
\text { Satisfaction level with the } \\
\text { time that he/she is } \\
\text { together with his/her } \\
\text { family. }\end{array}$ & $\begin{array}{l}1=\text { Almost never } \\
2=\text { Sometimes } \\
3=\text { Almost always }\end{array}$ & Nominal \\
\hline $\begin{array}{l}\text { Family Apgar Test: } \\
\text { Feelings about whether } \\
\text { his/her family loves you. }\end{array}$ & $\begin{array}{l}1=\text { Almost never } \\
2=\text { Sometimes } \\
3=\text { Almost always }\end{array}$ & Nominal \\
\hline \multicolumn{3}{|c|}{ Alcohol use } \\
\hline $\begin{array}{l}\text { Days of last week he/she } \\
\text { drank alcohol. }\end{array}$ & $\begin{array}{l}1=\text { Monday; } 2=\text { Tuesday; } 3=\text { Wednesday; } 4=\text { Thursday; } 5=\text { Friday; } 6=\text { Saturday; } 7=\text { Sunday; } 8=I \\
\text { didn't drink alcohol last week; } 9=\text { I never drink alcohol }\end{array}$ & Nominal \\
\hline $\begin{array}{l}{ }^{\mathrm{e}} \text { How many standard } \\
\text { glasses of alcohol did you } \\
\text { drink last week? }\end{array}$ & Monday; Tuesday; Wednesday; Thursday; Friday; Saturday; Sunday & Quantitative \\
\hline $\begin{array}{l}\text { Number of times he/she } \\
\text { drank } 4 / 5 \text { standard glasses } \\
\text { or more of alcohol in one } \\
\text { single occasion in the last } \\
30 \text { days. }\end{array}$ & $\begin{array}{l}\text { In the last } 30 \text { days, how many times have you consumed } 4 \text { or more standard glasses (if you are a girl) or } 5 \\
\text { standard glasses or more (if you are a boy) of alcohol on one occasion (for example at a party or at night)? } \\
\text { Answer with a number (eg } 0,1,2 \text { etc.) }\end{array}$ & Quantitative \\
\hline
\end{tabular}


Summary 
The consumption of alcoholic beverages is a great public healthcare problem worldwide. The toxicity associated with excessive alcohol ingestion, called binge drinking (BD) (i.e., drinking 4/5 or more standard glasses of alcohol on one occasion for a girl/boy) as well as its enormous addictive power, makes alcohol one of the most consumed and dangerous drugs, causing death and disability worldwide. In Spain, in recent years, important changes have occurred in terms of the amount of ingested alcohol and drinking patterns, particularly among the adolescent and young adult population. In Spain, BD is associated with the Botellón, which consists of drinking alcohol excessively in public places with friends during weekend nights and is used as a synonym for intoxication-oriented drinking. Both BD and Botellón are held accountable for multiple long- and short-term adverse consequences, effects on neurocognitive development, and physical injury and social disorders in adolescents. Furthermore, this behaviour in adolescents has been associated with traffic accidents, violence, delinquency, sexually transmitted diseases, unintended pregnancies, school failure, mental illnesses, various kinds of cancer, cardiovascular diseases, liver damage, and addiction.

In this dissertation, the design, development, and cultural adaptation of the first web-based computer-tailored intervention to reduce BD in Spanish adolescents were described (Chapter 2). First, due to the identification of certain cultural differences between the Dutch and Spanish adolescent population, a cultural adaptation of the intervention was required. For that, a study was conducted to explore the determinants of alcohol consumption and binge drinking in Spanish adolescents (Chapter 3). Then, a critical analysis and feasibility assessment of the cultural adaptation of the Alerta Alcohol programme were developed through a Delphi panel and pilot study, prior to implementation in schools (Chapter 4). Finally, the implementation and evaluation of the effectiveness of the Alerta Alcohol programme was described, as well as the predictors of adherence according to the sessions completed and the process evaluation of the programme (Chapter 5).

Chapter 1 provides an overall introduction to alcohol consumption and BD as a risky behaviour highly prevalent in Spanish adolescents, as well as a presentation of the magnitude of the problem and its significant short-term and long-term consequences. In addition, we explore why adolescents are binge drinkers. For this, we describe the determinants of alcohol consumption and BD in adolescents. Then, web-based computertailored (CT) interventions to prevent BD in adolescents were presented as a very promising intervention method. These kinds of interventions are often based on the IChange Model as the theoretical model for predicting healthy behaviour acquisition. Lastly, the importance of programme evaluation, such as study effectiveness and how it is conducted, process evaluation, and the importance of knowing the predictors of adherence, were addressed.

Chapter 2 describes the study protocol for the design, cultural adaptation, implementation and evaluation of a web-based computer-tailored (CT) intervention to prevent alcohol consumption and BD in Spanish adolescents. The Alerta Alcohol programme is an adaptation to the Spanish context of the original Alcohol Alert programme developed with Dutch adolescents with the same objective, based on extensive research that showed cost-effectiveness and effectiveness on BD among 15-16year-olds. The study protocol establishes the following steps. Firstly, feedback from focus and Delphi groups will be used for cultural adaptation and to obtain further information on the items to be included in the programme, and a pilot study will then be conducted to assess feasibility and to identify strengths and weaknesses. Secondly, a Cluster 
Randomised Controlled Trial will be conducted in 16 secondary schools in Andalusia (southern Spain) to test the effectiveness of Alerta Alcohol on students aged 16 to 18. The Alerta Alcohol programme consists of four sessions at school (baseline questionnaire; two sessions in three scenarios: at home, celebrations, and public places; and a final evaluation). In addition, two booster sessions are given at home to reinforce the previous messages. The intervention provides different stories based on the participant's gender, in which the main character wakes up after an evening in which he/she consumed alcohol excessively and does not remember what happened. The programme provides questions and tailored messages to adolescents. This information is used to provide highly specific feedback regarding their knowledge, risk perception, self-esteem, attitude, social influence, and self-efficacy.

As part of the formative research to develop the cultural adaptation, we focus on qualitative research through focus groups of adolescents and parents. These are described in Chapter 3. The goal of this study was to explore the I-Change Model determinants of BD in Spanish adolescents from the perspective of adolescents and parents, taking into account gender differences and whether they are engaging in BD. Results showed that adolescents were mostly drinking on the weekend, together with friends, either at home, at celebrations or in public places. Adolescents also reported a low level of knowledge and risk perception and limited self-efficacy. Girls reported greater parental control, and stated that when they get drunk, society perceives them worse. Adolescents suggested focus preventive actions to improve self-efficacy and self-esteem, as well as real situations in which alcohol affects other adolescents. Parents reported being lenient about alcohol drinking but rejected BD. However, some of them offered alcohol to their children, mainly during celebrations. The main conclusions from this study were that a permissive family environment, lack of control by parents, adolescents' low-risk perception, low self-esteem and self-efficacy, as well as the increase of BD in girls as part of the reduction of the gender gap, emerge as risk factors for BD in Spanish adolescents.

Taking into consideration the finding of the focus groups' study, the content of the Alerta Alcohol programme was culturally adapted based on a previous intervention for Dutch adolescents. Chapter 4 describes the critical analysis of the cultural adaptation of the programme through a two-round Delphi panel, before its implementation in schools. In addition, the adaptability, feasibility and satisfaction of the cultural adaptation of Alerta Alcohol were assessed through a pilot study. This study has allowed us to refine this intervention, considering the characteristics of Spanish adolescents. In the Delphi panel, the results obtained show that the pieces of advice must be direct and shorter, placing greater emphasis on gender differences, such as story design, advices and avatars. Knowledge, perception of damage, the seriousness of health problems and the probability of acquiring them should be emphasised in the advice. In the pilot study, $76.4 \%$ of students considered the intervention very useful, $75.5 \%$ were very satisfied with the programme, $50.7 \%$ would use it again and $72 \%$ would recommend it. In addition, those non-drinking students considered the intervention more credible $(P=.009)$, and more useful $(P=.046)$, as did non-binge drinking students $(P=.018)$. Students who did not intend to drink stated that the programme had improved their skills $(P=.036)$, perception of damage $(P=.040)$, knowledge $(P=.044)$, and changed their attitude $(P=.033)$.

Subsequently, the effectiveness of the Alerta Alcohol programme through a twoarm Cluster Randomised Controlled Trial (CRCT), as well as the predictors of adherence according to the sessions completed and the process evaluation of the programme, were described in Chapter 5. The trial took place in classes of 15 Andalusian schools (southern 
Spain). Each school was randomised into either an experimental condition (EC) (N=742) or a control condition (CC) $(\mathrm{N}=505)$. Finally, 351 participants for the EC and 261 for the $\mathrm{CC}$ were included in the analysis $(\mathrm{N}=612)$. Effects of the intervention were assessed using a three-level mixed logistic regression analysis for BD, heavy episodic drinking (HED), and any consumption, and a three-level mixed linear regression analysis for weekly consumption. The results of follow-up assessment took place at 4 months, which showed that although there was a trend in BD reduction in both conditions, no significant effects of the intervention on BD behaviour were found. Nevertheless, the results of the intervention suggest that the intervention was more effective in adolescents who engaged in HED (i.e., drinking 10 or more glasses in one day during the previous week). The logistic regression analysis showed that the odds of HED in the $\mathrm{CC}$ group was nine times the odds of HED in the EC group. Unfortunately, further analyses identified no significant subgroup effect. Weekly consumption and any consumption were also not affected by the intervention. In addition, process evaluations revealed that the adolescents were satisfied with the programme $(68.8 \%)$, would use the programme again $(52.9 \%)$, and would recommend it to someone else $(62.8 \%)$. Females and non-binge drinkers showed better responses in the process evaluation. This study improved the attrition rate through an adaptation of recommendations from the previous intervention carried out in the Netherlands, as well as the advice of experts, resulting in a lower attrition rate $(50.9 \%$ vs. $68.9 \%$ ). Yet, no optimal results were obtained for overall adherence in the programme. Analyses of adherence rates revealed that educational level, ethnicity, and being a nonbinge drinker were associated with adherence in the intervention. Specifically, the students enrolled in VT had lower adherence rates than baccalaureate programme students. Moreover, Spanish students had higher adherence rates than students of other ethnicities.

Finally, Chapter 6 provides a general discussion of the main findings and conclusions of all the studies presented in this dissertation (Chapters 2-5), as well as the main methodological considerations encountered during this dissertation, i.e. the participation and attrition rate, operationalisation of the intervention and study designs, measurements, and statistical analyses, as well as recommendations for practice and future research. In conclusion, the studies presented in this dissertation showed that the process of cultural adaptation through different types of studies has allowed to refine this intervention, taking into account the characteristics of Spanish adolescents and the Spanish drinking culture, offering a potential intervention that is operational and feasible for use in secondary schools. In addition, although the overall effect on BD was not significant, some promising indicators of the effectiveness of the intervention to reduce heavy episodic drinking (HED) in Spanish adolescents were shown. Furthermore, although we improved the drop-out rates regarding previous studies, the high drop-out rate could affect the results and the effectiveness of the programme, and thus, these results should be interpreted with caution. Therefore, future research is needed to improve the adherence and drop-out rates, and adolescents' attitude towards the CT intervention. Hence, it is advisable to make some changes to the intervention in consideration of the recommendations described in this dissertation, and to test it again in a randomised controlled trial. 
Resumen 
El consumo de bebidas alcohólicas es un gran problema de salud pública en todo el mundo. La toxicidad asociada con la ingestión excesiva de alcohol como el consumo excesivo de alcohol o binge drinking (BD) (es decir, beber 4/5 o más vasos estándar de alcohol en una ocasión para una chica / chico), así como su enorme poder adictivo hacen que el alcohol sea uno de las drogas más consumidas y peligrosas, que causan la muerte y la discapacidad en todo el mundo. En España, en los últimos años, se han producido cambios importantes con respecto a la cantidad de alcohol ingerido y los patrones de consumo, particularmente en la población de adolescentes y adultos jóvenes. En España, el BD está asociado con el Botellón, que consiste en beber alcohol en exceso en lugares públicos con amigos durante las noches de fin de semana, utilizándolo como sinónimo de bebida orientada a la intoxicación. Tanto el BD como Botellón son responsables de múltiples consecuencias adversas a largo y a corto plazo, que afectan el desarrollo neurocognitivo, provocan lesiones físicas y alteraciones sociales en los adolescentes. Además, este comportamiento en adolescentes se ha asociado con accidentes de tráfico, violencia, delincuencia, enfermedades de transmisión sexual, embarazos no deseados, fracaso escolar, enfermedades mentales, diversos tipos de cáncer, enfermedades cardiovasculares, daño hepático y adicción.

En esta disertación, se describió el diseño, el desarrollo y la adaptación cultural de la primera intervención basada en la web y adaptada al ordenador para reducir el BD en adolescentes españoles (Capítulo 2). Primero, debido a la identificación de ciertas diferencias culturales entre la población adolescente holandesa y española, se requirió una adaptación cultural de la intervención. Para ello, se realizó un estudio para explorar los determinantes del consumo de alcohol y el consumo excesivo de alcohol (binge drinking) en adolescentes españoles (Capítulo 3). Luego, se desarrolló un análisis crítico y una evaluación de viabilidad de la adaptación cultural del programa Alerta Alcohol, a través de un panel de Delphi y un estudio piloto, antes de la implementación en las escuelas (Capítulo 4). Finalmente, se describió la implementación y evaluación de la efectividad del programa Alerta Alcohol, así como los predictores de adherencia según las sesiones completadas y la evaluación del proceso del programa (Capítulo 5).

El Capítulo 1 proporciona una introducción general al consumo de alcohol y BD como un comportamiento de riesgo altamente prevalente en adolescentes españoles, así como la magnitud del problema y sus altas consecuencias a corto y largo plazo. Además, exploramos por qué los adolescentes beben en exceso. Para esto, describimos los determinantes del consumo de alcohol y BD en adolescentes. Luego, las intervenciones basadas en el ordenador y en la web para prevenir la BD en adolescentes se presentaron como un método de intervención muy prometedor. Además, este tipo de intervenciones a menudo se basan en el Modelo I-Change como modelo teórico para predecir la adquisición de un comportamiento saludable. Finalmente, se abordó la importancia de la evaluación del programa, como la efectividad del estudio y cómo se realiza, la evaluación del proceso y la importancia de conocer los predictores de adherencia.

El Capítulo 2 describe el protocolo de estudio para el diseño, la adaptación cultural, la implementación y la evaluación de la intervención basada en el ordenador y basada en la web para prevenir el consumo de alcohol y BD en adolescentes españoles. El programa Alerta Alcohol es una adaptación al contexto español del programa original Alcohol Alert, desarrollado con adolescentes holandeses con el mismo objetivo, y basado en una extensa investigación que demostró la rentabilidad y efectividad en BD entre los adolescentes de 15-16 años de edad. El protocolo de estudio establece los siguientes pasos: Primero, la retroalimentación de los grupos focales y Delphi se utilizará para la 
adaptación cultural y para obtener más información sobre los elementos que se incluirán en el programa, y luego se realizará un estudio piloto para evaluar la viabilidad e identificar fortalezas y debilidades. En segundo lugar, se realizará un ensayo controlado aleatorizado por grupos en 16 escuelas secundarias de Andalucía (sur de España) para evaluar la eficacia del programa Alerta Alcohol en estudiantes de 16 a 18 años. El programa Alerta Alcohol consta de cuatro sesiones en la escuela (cuestionario de referencia, dos sesiones en tres escenarios: en el hogar, celebraciones y lugares públicos, y una evaluación final). Además, se imparten dos sesiones de refuerzo en casa para reforzar los mensajes anteriores. La intervención proporciona diferentes historias basadas en el género del participante, en la que el personaje principal se despierta después de una noche en la que consumió alcohol en exceso y no recuerda lo que sucedió. El programa proporciona preguntas y mensajes a medida para adolescentes. Esta información se utiliza para proporcionar retroalimentación altamente específica con respecto al conocimiento, percepción de riesgo, autoestima, actitud, influencia social y autoeficacia.

Como parte de la investigación formativa para la adaptación cultural, nos enfocamos en la investigación cualitativa a través de grupos focales de adolescentes y padres. Estos se describen en el Capítulo 3. El objetivo de este estudio fue explorar los determinantes del BD, en base al Modelo I-Change, en adolescentes españoles, desde la perspectiva de adolescentes y padres, teniendo en cuenta las diferencias de género y si están participando en BD. Los resultados mostraron que los adolescentes bebían principalmente el fin de semana, junto con amigos, ya sea en casa, en celebraciones o en lugares públicos. Los adolescentes también informaron un bajo nivel de conocimiento y percepción de riesgo y una autoeficacia limitada. Las niñas informaron más control parental, y cuando se emborrachan, la sociedad las percibe peor. Los adolescentes sugirieron enfocar acciones preventivas para mejorar la autoeficacia y la autoestima, así como situaciones reales de cómo el alcohol afecta a otros adolescentes. Los padres informaron ser permisivos sobre el consumo de alcohol, pero rechazaron el BD. Aunque algunos de ellos ofrecieron alcohol a sus hijos, principalmente durante las celebraciones. Las principales conclusiones de este estudio fueron que un ambiente familiar permisivo, la falta de control por parte de los padres, la percepción de bajo riesgo de los adolescentes, la baja autoestima y la autoeficacia, así como el aumento de BD en las niñas como parte de la desaparición de la brecha de género, emerge como factores de riesgo de $\mathrm{BD}$ en adolescentes españoles.

Teniendo en cuenta los hallazgos del estudio de los grupos focales, el contenido del programa Alerta Alcohol fue adaptado culturalmente en base a una intervención previa para adolescentes holandeses. El Capítulo 4 describe el análisis crítico de la adaptación cultural del programa a través del panel de Delphi de dos rondas, antes de la implementación en las escuelas. Además, se evaluó la adaptabilidad, la viabilidad y la satisfacción de la adaptación cultural del programa Alerta Alcohol a través de un estudio piloto. Este estudio nos ha permitido refinar esta intervención teniendo en cuenta las características de los adolescentes españoles. En el panel de Delphi, los resultados obtenidos muestran que los consejos deben ser directos y más cortos, poniendo mayor énfasis en las diferencias de género, en el diseño de las historias, consejos y avatares. El conocimiento, la percepción del daño, la gravedad de los problemas de salud y la probabilidad de adquirirlos deben enfatizarse en los consejos. En el estudio piloto, el $76.4 \%$ de los estudiantes consideró que la intervención era muy útil, el $75.5 \%$ estaba muy satisfecho con el programa, el $50.7 \%$ lo usaría nuevamente y el $72 \%$ lo recomendaría. Además, los estudiantes no bebedores consideraron la intervención más creíble $(P=.009)$ y más útil $(P=.046)$, así como los estudiantes que no realizaron $\mathrm{BD}(P=.018)$. Los 
estudiantes que no tenían la intención de beber declararon que el programa había mejorado sus habilidades $(P=.036)$, la percepción del daño $(P=.040)$, el conocimiento $(P=.044)$, y cambiaron su actitud $(P=.033)$.

Posteriormente, la efectividad del programa Alerta Alcohol, a través de un ensayo controlado aleatorizado por conglomerados (CRCT) de dos brazos, así como los predictores de adherencia según las sesiones completadas y la evaluación del proceso del programa se describieron en el Capítulo 5. El ensayo tuvo lugar en clases de 15 escuelas andaluzas (sur de España). Cada escuela se asignó al azar a una condición experimental (CE) $(\mathrm{N}=742)$ o una condición de control $(\mathrm{CC})(\mathrm{N}=505)$. Finalmente, 351 participantes para la CE y 261 para la $\mathrm{CC}$ se incluyeron en el análisis $(\mathrm{N}=612)$. Los efectos de la intervención se evaluaron mediante un análisis de regresión logística mixta de tres niveles para BD, consumo excesivo episódico de alcohol (HED) y cualquier consumo, y un análisis de regresión lineal mixta de tres niveles para el consumo semanal. Los resultados de la evaluación de seguimiento tuvieron lugar a los 4 meses, lo que mostró que, aunque había una tendencia en la reducción del BD en ambas condiciones, no se encontraron efectos significativos de la intervención sobre el comportamiento del BD. Sin embargo, los resultados de la intervención sugieren que la intervención fue más efectiva en adolescentes que participaron en HED (es decir, tomar 10 o más vasos en un día durante la semana anterior). El análisis de regresión logística mostró que las probabilidades de $\mathrm{HED}$ en el grupo $\mathrm{CC}$ eran nueve veces mayores que las probabilidades de HED en el grupo CE. Desafortunadamente, los análisis posteriores no identificaron ningún efecto de subgrupo significativo. El consumo semanal y cualquier consumo tampoco se vieron afectados por la intervención. Además, las evaluaciones del proceso revelaron que los adolescentes estaban satisfechos con el programa (68.8\%), usarían el programa nuevamente $(52.9 \%)$ y lo recomendarían a otra persona $(62.8 \%)$. Las mujeres y los bebedores no compulsivos (No BD) mostraron mejores respuestas en la evaluación del proceso. Este estudio mejoró la tasa de deserción a través de una adaptación de las recomendaciones de la intervención anterior desarrollada en los Países Bajos, así como los consejos de expertos, lo que resultó en una tasa de deserción más baja $(50.9 \%$ vs $68.9 \%$ ). Sin embargo, no se obtuvieron resultados óptimos para el cumplimiento general del programa. Los análisis de adherencia revelaron que el nivel educativo, el origen étnico y ser un bebedor no compulsivo (No BD) se asociaron con la adhesión a la intervención. Específicamente, los estudiantes inscritos en formación profesional (FP) mostraron menos adherencia que los estudiantes del programa de bachillerato. Además, ser español mostró una mayor adherencia que otra etnia.

Finalmente, el capítulo 6 proporciona una discusión general de los principales hallazgos y conclusiones de todos los estudios presentados en esta disertación (Capítulos 2-5), así como las principales consideraciones metodológicas encontradas durante esta disertación, es decir, la tasa de participación y deserción, operacionalización de diseños de intervención y estudio, mediciones y análisis estadísticos, así como recomendaciones para la práctica y futuras investigaciones. En conclusión, los estudios presentados en esta disertación mostraron que el proceso de adaptación cultural a través de diferentes tipos de estudios ha permitido refinar esta intervención teniendo en cuenta las características de los adolescentes españoles y la cultura española de consumo, ofreciendo una intervención potencial, operativa y factible, para uso en escuelas de secundaria. Además, aunque el efecto general sobre BD no fue significativo, se mostraron algunas indicaciones prometedoras de la efectividad de la intervención para reducir el consumo excesivo episódico de alcohol (HED) en adolescentes españoles. Además, aunque mejoramos las tasas de abandono con respecto a estudios anteriores, la alta tasa de abandono podría 
afectar los resultados y la efectividad del programa, por lo que estos resultados deben interpretarse con precaución. Por lo tanto, se necesita investigación futura para mejorar la adherencia, el abandono y la motivación de los adolescentes en las intervenciones basadas en el ordenador y en la web. Por lo tanto, es aconsejable realizar algunos cambios en la intervención teniendo en cuenta las recomendaciones descritas en esta disertación, y probar nuevamente la intervención en un ensayo controlado aleatorizado. 


\section{Acknowledgments}


Despite the fact that this thesis is signed in my name, there are many people who have contributed or helped directly and indirectly during the realization of this project. For this reason, I would like to thank all those who have made this thesis possible, of whom I would like to mention some of them in particular.

First of all, I would like to thank Marta Lima for the trust placed in me and the opportunity you gave me to work with you on this great project. Thank you for your knowledge, listening and great advice that helped me make important decisions that guided me to obtain a doctor's degree. I would also like to thank Joaquín Lima for her knowledge and critical vision, as well as her great support throughout the most difficult process, the fieldwork. He has always been when I have needed him.

Furthermore, I would like to thank Hein and Liesbeth for the opportunity you gave me to obtain a doctorate degree from Maastricht University. Thank you very much for your commitment and time invested in my learning. Thank you very much Hein, for your experience, your great scientific knowledge and ideas that have been very valuable to me. Without a doubt, your great enthusiasm about my learning has inspired me. To Liesbeth, for your unconditional support and your practical approach to problems. Your doors were always open, and it didn't matter if I was in Maastricht or Seville, you always helped me quickly with problems, and always with comforting words.

I would like to thank Math Candel for his time and enormous help with the statistical analysis of this thesis. Thank you also for the great effort and the important support and help from the secretariat of the Department of Health Promotion of Maastricht University, especially Kim, Patricia, and Daisy. Also, to Leon for helping me with the computer problems. Patricia and Leon, thank you for being my paranimf!

Thanks also to all my colleagues from the Department of Nursing of the University of Seville, especially Carmen, Pablo, Curro, Marisa, María, Ana Magdalena, Isabel and Nícia, for your support and affection. To $\mathrm{M}^{\mathrm{a}}$ Dolores Guerra for introducing me to the world of research and transmitting her passion for this field.

Thanks also to all my colleagues from the Virgen del Rocío Hospital in Seville and to all my colleagues from the Red Cross Nursing School of Seville, for your support in recent years. I do not name you because there are many of you and I am sure someone forgets me.

To all the schools and young people who participated in the program, as well as all the people who have contributed to the design and configuration of this project. Thank you!

Of course, thank you very much to the "Old Guard", José Carlos, Jesús and Helena. Also, to Dani and Erin. For all those good moments lived, trips, concerts and even your visits when I was on my doctoral stay. "Years go by and inside us the flame burns as it started, feeling, passion, strength and freedom. We are the old guard!"

To my family, for enduring my professional and personal ups and downs, but they have always been there to give me their unconditional support. To my parents Ramón and Isabel, and my brothers Ramón and Daniel, to my sisters-in-law María Ángeles and Clemencia. And to my nieces who brighten my day when I see them, Marta, Claudia, and Cristina, I love you all very much. 
Of course, thank Bárbara, the best traveling companion I can have. To whom she has shown me all her unconditional support at all moments of my life, she has endured me in all my ups and downs and has always been by my side when I needed her, with comforting words. I love you very much, you know very well that without you all this effort would not make sense, since as you well know "My objective is to collect years with you".

\title{
To all, THANK YOU
}

\author{
José Manuel
}

That we don't want to be so much.

We want to live in our land

cracked from crystal clear springs,

walk a little further than the borders

for the sublime longing for the return.
That we don't want to be so much.

We want to be a little of sun and a little of night, we want to be wind and calm,

storm, rain and smell of wet earth.

(Manolillo Chinato) 
Agradecimientos 
A pesar de que esta tesis está firmada a mi nombre, son muchas las personas que han contribuido o ayudado directa e indirectamente durante la realización de este proyecto. Por ello, me gustaría agradecer a todas aquellas personas que han hecho posible esta tesis, de los cuales me gustaría mencionar a algunos de ellos en particular.

En primer lugar, me gustaría agradecer a Marta Lima la confianza depositada en mí y la oportunidad que me distes para trabajar contigo en este gran proyecto. Gracias por tus conocimientos, escucha y grandes consejos que me ayudaron a tomar decisiones importantes que me guiaron hasta la obtención del título de doctor. También me gustaría agradecer a Joaquín Lima por sus conocimientos y visión crítica, así como su gran apoyo durante todo el proceso más duro, el trajo de campo. Siempre ha estado cuando lo he necesitado.

Además, me gustaría agradecer a Hein y Liesbeth por la oportunidad que me disteis de obtener el título de doctor en la Universidad de Maastricht. Muchas gracias por vuestro compromiso y tiempo invertido en mi aprendizaje. Muchas gracias Hein, por tu experiencia, tus grandes conocimientos científico e ideas que han sido muy valiosas para mí. Sin duda, tu gran entusiasmo sobre mi aprendizaje me ha inspirado. A Liesbeth, por tu apoyo incondicional y tu enfoque practico de los problemas. Tus puertas siempre estaban abiertas, y daba igual que estuviese en Maastricht o en Sevilla, siempre me ayudaste rápidamente con los problemas, y siempre con palabras reconfortantes.

Me gustaría agradecer a Math Candel por su tiempo invertido y enorme ayuda con los análisis estadísticos de esta tesis. Gracias también por el gran esfuerzo y el importante apoyo y ayuda por parte de la secretaría del Departamento de Promoción de la Salud de la Universidad de Maastricht, en especial a Kim, Patricia y Daisy. También a Leon por ayudarme con los problemas informáticos. Patricia y Leon, gracias por ser mi paranimf!

Gracias también a todos/as mis compañeros/as del Departamento de Enfermería de la Universidad de Sevilla, en especial a Carmen, Pablo, Curro, Marisa, María, Ana Magdalena, Isabel y Nícia, por vuestro apoyo y afecto. A $\mathrm{M}^{\mathrm{a}}$ Dolores Guerra por introducirme en el mundo de la investigación y transmitirme su pasión por este campo.

Gracias también a todos/as mis compañeros/as del hospital Virgen del Rocío de Sevilla y a todos/as mis compañeros/as de la Escuela de Enfermería de Cruz Roja de Sevilla, por vuestro apoyo en estos últimos años. No os nombro porque sois muchos y seguro que alguno se me olvida.

A todas las escuelas y jóvenes que participaron en el programa, así como a todas las personas que han contribuido al diseño y configuración de este proyecto. ¡Gracias!

Por supuesto muchas gracias a la "Vieja Guardia", José Carlos, Jesús y Helena. También a Dani y Erin. Por todos esos buenos momentos vividos, viajes, conciertos e incluso vuestras visitas cuando estaba de estancia doctoral. "Pasan los años y en nuestro interior arde la llama tal como empezó, sentimiento, pasión, fuerza y libertad. ¡Somos la vieja guardia!"

A mi familia, por aguantar mis altibajos profesional y personal, pero siempre han estado ahí para darme su apoyo incondicional. A mis padres Ramón e Isabel, y mis hermanos Ramón y Daniel, a mis cuñadas María Ángeles y Clemencia. Y a mis sobrinas que me alegran el día cuando las veo, Marta, Claudia y Cristina, os quiero mucho a todos/as. 
Por supuesto, agradecer a Bárbara, la mejor compañera de viaje que puedo tener. A la que me ha mostrado todo su apoyo incondicional en todos los momentos de mi vida, me ha aguantado en todos mis altibajos, y siempre ha estado a mi lado cuando la he necesitado, con palabras reconfortantes. Te quiero mucho, sabes de sobra que sin ti todo este esfuerzo no tendría sentido, ya que como bien sabes "Mi objetivo es coleccionar años contigo".

\section{A todos/as, GRACIAS}

José Manuel

Que no queremos ser tanto.

Queremos vivir en nuestra tierra

agrietada de manantiales cristalinos,

andar un poco más lejos que las fronteras

por la sublime añoranza del regreso.
Que no queremos ser tanto.

Queremos ser un poco de sol y un poco de noche, queremos ser viento y calma, tormenta, lluvia y olor de tierra mojada.

(Manolillo Chinato) 


\section{Curriculum Vitae}


José Manuel Martínez Montilla was born on March 23, 1988 in Seville, Spain. After completing secondary school (Baccalaureate in Natural Sciences and Health) in 2006 at the Institute of Secondary Education (ISE) Albert Einstein (Seville), he started pursuing a bachelor's degree in Nursing in 2009, at the Faculty of Nursing, Physiotherapy and Podiatry of the University of Seville (2009-2013). After finishing his degree, he obtained a master's degree in New Healthcare Trends in Health Sciences at the Faculty of Nursing, Physiotherapy and Podiatry of the University of Seville in 2015. At the same time, he obtained a master's degree in Pharmacotherapeutic Care for Nursing in Primary Care at the Department of Nursing and Podiatry of the University of Valencia. While pursuing his master's degree, he was granted a collaboration scholarship by the Ministry of Education, Culture and Sport for the 2014-15 academic year, in Spain, conducting a collaborative research programme carried out by Dr. Marta Lima Serrano and her team at the Faculty of Nursing, Physiotherapy and Podiatry of the University of Seville. Immediately after, he started working on his $\mathrm{PhD}$ project, which is presented in this dissertation, at the Department of Health Promotion at Maastricht University (Netherlands) and at the Department of Nursing in the Faculty of Nursing, Physiotherapy and Podiatry of the University of Seville (Spain), through an agreement between both universities. In his first year as a PhD student, he completed the course "Health Communication \& Health Promotion: Theory and Practice" in 2016, at the Department of Health Education \& Promotion at Maastricht University (Netherlands). Moreover, during the first two years of his $\mathrm{PhD}$ project, José Manuel worked at FISEVI as a research assistant for this same project. He has presented his research at different national and international conferences.

In addition, José Manuel collaborated as Honorary Assistant to the Department of Nursing (Faculty of Nursing, Physiotherapy and Podiatry of the University of Seville) from 2015 to 2018. José Manuel belongs to the Research Group CTS 969 "Innovation in Healthcare and Social Determinants of Health". Furthermore, since he finished his nursing degree, he has been working as a nurse in two hospitals in the city of Seville, Virgen Macarena University Hospital and Virgen del Rocío University Hospital, the latter being the institution in which he continues to provide care in the Emergency Room (ER). Moreover, José Manuel has been working as a teacher in the Nursing degree at the University School of the Red Cross in Seville, belonging to the University of Seville, from the 2017/2018 academic year to the present time. 


\section{Publications}




\section{Publications presented in this dissertation}

Lima-Serrano, M., Martínez-Montilla, J.M., Lima-Rodríguez, J.S., Mercken, L., de Vries, H. (2018). Design, implementation and evaluation of a web-based computertailored intervention to prevent binge drinking in adolescents: study protocol. BMC Public Health, 18(449). https://doi.org/10.1186/s12889-018-5346-4

Martínez-Montilla, J.M., Mercken, L., Lima-Serrano, M., de Vries, H., Lima-Rodríguez, J.S. (2020). Why are Spanish adolescents binge-drinkers? Focus group with adolescents and parents. International Journal Environmental Research and Public Health. 17(10), 3551. https://doi.org/10.3390/ijerph17103551.

Martínez-Montilla, J.M., Mercken, L., Lima-Rodríguez, J.S., de Vries, H., Lima-Serrano, M. (under review). Cultural adaptation and feasibility assessment of Alerta Alcohol: a web-based intervention to reduce binge drinking in Spanish adolescents.

Martínez-Montilla, J.M., Mercken, L., de Vries, H., Candel, M., Lima-Rodríguez, J.S., Lima-Serrano, M. (2020). Effectiveness of a Web-based computer-tailored intervention to reduce alcohol consumption and binge drinking among Spanish adolescents: a cluster randomized controlled trial. Journal of Medical Internet Research. Jan; 22(1): e15438. https://doi:10.2196/15438

\section{In progress}

Martínez-Montilla, J.M., Lima-Serrano, M., Candel, M., de Vries, H., Lima-Rodríguez, J.S., Mercken, L. A longitudinal study on determinants of binge-drinking among boys and girls of high and low socioeconomic status.

\section{Publications in the same line of research.}

Lima-Serrano, M., Vargas-Martínez, A.M., Gil-García, E., Martínez-Montilla, J.M., Lima-Rodríguez, J.S., De Vries, H. (2017). Adaptation and validation of five scales to measure determinants of binge drinking in adolescents. Anales del Sistema Sanitario de Navarra. 2017 Aug 31;40(2):221-236. https://doi:10.23938/ASSN.0028.

Lima-Serrano, M., Martínez-Montilla, J.M., Guerra-Martín, M.D., Vargas-Martínez, A.M., Lima-Rodríguez, J.S. (2018). Quality-of-life-related factors in adolescents. Gaceta Sanitaria. Jan-Feb;32(1):68-71. https://doi:10.1016/j.gaceta.2016.06.016.

Lima-Serrano M, Martínez-Montilla JM, Vargas-Martínez AM, Zafra-Agea JA, LimaRodríguez JS. (2019). Characteristics present in secondary school students who do not smoke and who have no intention to smoke. Gaceta Sanitaria. MayJun;33(3):259-262. https://doi:10.1016/j.gaceta.2017.11.013.

Pabón-Carrasco, M., Ramirez-Baena, L., Jiménez-Picón, N., Ponce Blandón, J.A., Martínez-Montilla, J.M., Martos-García, R. (2020). Influence of Personality Traits and Its Interaction with the Phenomenon of Bullying: Multi-Centre Descriptive Study. International Journal Environmental Research and Public Health. Jan; 17(1): 172. Published online 2019 Dec 25. https://doi:10.3390/ijerph17010172 


\section{Other publications}

Guerra-Martín, M.D., Amador-Marín, B., Martínez-Montilla, J.M. (2015) Health problems of family caregivers of people over 65 suffering from chronic renal failure: a systematic review. Anales del Sistema Sanitario de Navarra. SepDec;38(3):425-38. https://doi:10.23938/ASSN.0283.

Amador-Marín, B., Mártinez-Montilla, J.M. (2016). The buttonhole method like puncture technical of arteriovenous fistula in hemodialysis. A literature review. Enfermería Global. Oct;15(44): 341-353. Retrieved on May 29, 2020, from http://scielo.isciii.es/scielo.php?script=sci_arttext\&pid=S1695$61412016000400014 \& \operatorname{lng}=$ es\&tlng=es.

Guerra-Martín, M.D., Martínez-Montilla, J.M., Amador-Marín, B. (2016). Need of cardiopulmonary resuscitation training in the sport of soccer. Enfermería Clínica. May-Jun;26(3):165-73. https://doi:10.1016/j.enfcli.2015.05.004.

Amador-Marín, B., Mártinez-Montilla, J.M. (2017). Therapeutic hypnosis in nursing. Review of the literature. Hygia de Enfermería. 95 (XXXI): 27-32. Retrieved on May 29, 2020, from http://www.colegioenfermeriasevilla.es/wpcontent/uploads/Hygia95.pdf

Mártinez-Montilla, J.M., Amador-Marín, B., Guerra-Martín, M.D. (2017). Family coping strategies and impacts on family health: A literature review. Enfermería Global. Jul;16(3): 592-604. Retrieved on May 29, 2020, from http://dx.doi.org/10.6018/eglobal.16.3.255721 
